\title{
Evolution and Diversity of Ornithomimid Dinosaurs in the Upper Cretaceous Belly River Group of Alberta
}

\author{
by \\ Bradley McFeeters \\ A thesis submitted to the Faculty of Science in partial fulfillment of the requirements for \\ the degree of Master of Science \\ Department of Earth Sciences \\ Carleton University \\ Ottawa, Ontario
}

May, 2015

(C) 2015 Bradley McFeeters 


\begin{abstract}
Ornithomimids (Dinosauria: Theropoda) from the Campanian (Upper Cretaceous) Belly River Group of Alberta have a fossil record that ranges from isolated elements to nearly complete articulated skeletons. The Belly River Group ornithomimids are among the best-known theropods from these deposits, as well as some of the best-known ornithomimids in the world. However, questions remain concerning the identification of the oldest definitive occurrence of these dinosaurs in Alberta, as well as the taxonomic diversity of the articulated material from the Dinosaur Park Formation. These topics have important implications for reconstructing the palaeobiogeographic and phylogenetic history of Ornithomimidae in Laramidia.
\end{abstract}

The literature on all ornithomimosaurs from the Cretaceous of North America is reviewed, with special attention to their taxonomic history and geological context in the Belly River Group. The species Struthiomimus altus has historically contained most of the articulated ornithomimid material from the Belly River Group, but this is not supported by synapomorphic characters in all cases, and the material referred to $S$. altus is morphologically heterogeneous. An articulated partial skeleton from the lower Dinosaur Park Formation near Dinosaur Provincial Park is removed from S. altus and proposed as the holotype of a new taxon, Rativates evadens gen. et sp. nov. $R$. evadens is diagnosed by autapomorphic characters including 1) a short contact on the maxilla for the jugal, 2) reduced neural spines over the transition point of the tail, 3) a fused contact between the right and left ischia, 4) a larger medial than lateral condyle of the proximal tibia, and 5) a uniquely shaped distal end of the third metatarsal that lacks a groove on the flexor surface between the distal condyles. At least three ornithomimid taxa are roughly 
contemporaneous in the lower Dinosaur Park Formation. Unfortunately, the phylogenetic relationships of $R$. evadens to other ornithomimids are difficult to determine, due to missing data in the type specimen. The result of the preliminary phylogenetic analysis is consistent with a single origin of Albertan ornithomimids, as has been previously proposed.

Articulated ornithomimid material with reliable stratigraphic data has been reported exclusively from the Dinosaur Park Formation in the Belly River Group. A reevaluation of isolated elements from Alberta catalogued as Ornithomimidae rejects previous reports of this clade from the Santonian Milk River Formation. Their presence is supported in the lower, regressive phase of the Campanian Belly River Group (Foremost and Oldman formations), and the oldest Albertan material definitively referrable to Ornithomimidae is from the lower Oldman Formation. It is proposed that the clade containing the Albertan ornithomimids migrated into Laramidia during the Campanian. Characters previously considered diagnostic of the Chinese ornithomimid Qiupalong henanensis are reported for the first time in ornithomimid material from the Belly River Group, supporting the previously suggested close relationship between Qiupalong and Albertan ornithomimids, and possibly a more complex palaeobiogeographic history of this clade than was previously hypothesized. 


\section{ACKNOWLEDGEMENTS}

I would like to thank my advisors, Michael Ryan and Claudia Schröder-Adams, for their guidance and support during this project. Steve Cumbaa and Quentin Gall provided helpful reviews of the manuscript. This work has also benefited from discussions with David Evans and Thomas Cullen of the University of Toronto, and the countless others I have discussed ornithomimids with at conferences in the past few years. I thank the members of the Southern Alberta Dinosaur Project for an enjoyable summer 2013 field season, and especially Thomas Cullen, Aaron LeBlanc, and Wendy Sloboda for keeping my project in mind during their prospecting trips that recovered several potential new records of Ornithomimidae from southern Alberta. For assistance during collection visits I thank Carl Mehling and Mark Norell at the American Museum of Natural History; Margaret Currie, Jordan Mallon, and Kieran Shepherd at the Canadian Museum of Nature; David Evans, Brian Iwama, Ian Morrison and Kevin Seymour at the Royal Ontaro Museum; Graeme Housego, Joanna Northover and Brandon Strilisky at the Royal Tyrrell Museum of Palaeontology; Philip Currie, Eva Koppelhus and Ian MacDonald at the University of Alberta Lab for Vertebrate Palaeontology; and Warren Fitch and Anthony Russell at the University of Calgary. Channing Redford at the American Museum of Natural History and Katherine Bramble at the University of Alberta e-mailed me the photographs I forgot to take. Thomas Cullen at the University of Toronto imaged and assisted with the interpretation of the histological section of ROM 1790. The Dinosaur Research Institute provided funding for this research. Ruth Harrison, Kayla McFeeters, Elaine Stafford and Will MacDonald, Joanna Northover and Graeme Housego, and Derek Larson also assisted with travel or accommodation during the 
collections visits. Thanks are also due to Athena Sparks for her tolerance of my unconventional working hours while describing "Pinky." Finally, I thank all of the paleontologists whose work on Albertan ornithomimids before me prepared the foundation and inspiration for the present contribution. 


\section{TABLE OF CONTENTS}

$\begin{array}{ll}\text { Abstract } & 2\end{array}$

$\begin{array}{ll}\text { Acknowledgements } & 4\end{array}$

1. Introduction 12

$\begin{array}{ll}\text { Project Overview } & 12\end{array}$

Taxonomic Review 13

Global Record of Early Ornithomimosaurs $\quad 14$

Ornithomimosaurs in the Lower Cretaceous of North America 19

Ornithomimosaurs in the Upper Cretaceous of North America 22

$\begin{array}{ll}\text { Canada } & 22\end{array}$

United States of America 35

$\begin{array}{ll}\text { Mexico } & 43\end{array}$

$\begin{array}{ll}\text { Regional Geology } & 44\end{array}$

Stratigraphic Distribution in Dinosaur Provincial Park $\quad 45$

Paleoenvironment in Dinosaur Provincial Park 48

$\begin{array}{ll}\text { Materials and Methods } & 49\end{array}$

$\begin{array}{lr}\text { Institutional Abbreviations } & 50\end{array}$

2. Anatomy and Classification of ROM 1790, an Ornithomimid (Dinosauria, Theropoda) from the Late Cretaceous of Alberta 51 
$\begin{array}{ll}\text { Introduction } & 51\end{array}$

$\begin{array}{ll}\text { Description } & 56\end{array}$

$\begin{array}{ll}\text { Skull } & 56\end{array}$

$\begin{array}{ll}\text { Vertebrae } & 78\end{array}$

$\begin{array}{ll}\text { Pelvis } & 83\end{array}$

$\begin{array}{ll}\text { Hindlimb } & 85\end{array}$

$\begin{array}{ll}\text { Discussion } & 100\end{array}$

Taxonomic Status of ROM 1790

Ontogenetic Stage of ROM 1790

$\begin{array}{lr}\text { Conclusion } & 127\end{array}$

$\begin{array}{ll}\text { Systematic Palaeontology } & 128\end{array}$

3. Evaluation of Identified Occurrences of Ornithomimidae in the Upper Cretaceous (Santonian-Campanian) Milk River, Foremost, and Oldman Formations of Alberta

$\begin{array}{lr}\text { Introduction } & 130\end{array}$

Milk River Formation 136

$\begin{array}{lr}\text { Foremost Formation } & 143\end{array}$

$\begin{array}{lr}\text { Oldman Formation } & 148\end{array}$

Lower Unit of Oldman Formation $\quad 150$

Middle Unit of Oldman Formation (Comrey Sandstone) 155

Upper Unit of Oldman Formation (time-equivalent to Dinosaur Park

$\begin{array}{ll}\text { Formation) } & 163\end{array}$ 
$\begin{array}{ll}\text { Introduction } & 171\end{array}$

$\begin{array}{ll}\text { Methods } & 178\end{array}$

$\begin{array}{ll}\text { Results and Discussion } & 180\end{array}$

$\begin{array}{ll}\text { Phylogenetic Position of ROM } 1790 & 182\end{array}$

Relationship of Qiupalong to Albertan Ornithomimids 183

Appendix 1. List of Characters 192

Appendix 2. Data Matrix 205

$\begin{array}{ll}\text { 5. Conclusions } & 208\end{array}$

Diversity of Belly River Group Ornithomimidae 208

Origin of Ornithomimidae in Laramidia 210

Phylogeny and Paleobiogeography of Laramidian Ornithomimids 212

$\begin{array}{ll}\text { Summary } & 216\end{array}$

$\begin{array}{ll}\text { References } & 217\end{array}$ 


\section{LIST OF FIGURES AND TABLES}

Figure 2.1. Locality of ROM 1790.

Figure 2.2. Preserved material of ROM 1790 . 57

Figure 2.3. Skull of ROM 1790.

Figure 2.4. Anterior preserved portion of skull of ROM 1790.

Figure 2.5. Striated texture below the maxilla of ROM 1790.

$\begin{array}{lr}\text { Figure 2.6. Palate of ROM } 1790 . & 69\end{array}$

$\begin{array}{ll}\text { Figure 2.7. Dorsal view of skull of ROM } 1790 . & 71\end{array}$

Figure 2.8. Posterior preserved portion of skull of ROM 1790.

Figure 2.9. Dentaries of ROM $1790 . \quad 75$

Figure 2.10. Unidentified possible skull fragment of ROM 1790.

Figure 2.11. Vertebrae of ROM 1790 . 80

Figure 2.12. Pelvis of ROM $1790 . \quad 84$

Figure 2.13. Femur of ROM 1790 . 87

Figure 2.14. Tibiotarsus and fibula of ROM 1790. 90

Figure 2.15. Detail of tibiotarsus fusion in ROM 1790.

Figure 2.16. Metatarsus of ROM 1790. 93

Figure 2.17. Pedal phalanges of ROM 1790. 96

Figure 2.18. Pedal unguals of ROM 1790. 98

Figure 2.19. Pelvis of Struthiomimus compared to other ornithomimids. 102

Figure 2.20. Metatarsus of Struthiomimus compared to other ornithomimids. 103

Figure 2.21. Variation in the metacarpus of Struthiomimus. 104

Figure 2.22. Holotype and "proxy holotype" of Struthiomimus altus. 105 
Figure 2.23. Pedal phalanx II-2 proportions of ornithomimids compared. 106

Figure 2.24. Proximal articulation of pedal phalanx III-2 compared. 108

Figure 2.25. Proximal articulation of pedal phalanx II-2 compared. 109

Figure 2.26. Autapomorphic maxilla-jugal contact of ROM 1790.

Figure 2.27. Autapomorphic caudal neural spine reduction of ROM $1790 . \quad 118$

Figure 2.28. Autapomorphic fusion of ischia of ROM 1790.

Figure 2.29. Autapomorphic character of tibia of ROM 1790.

Figure 2.30. Autapomorphic character of metatarsal III of ROM 1790.

Figure 2.31. Narial regions of ornithomimosaurs compared. 124

Figure 2.32. Maxilla texture of ornithomimids and tyrannosaurids. 126

Figure 3.1. Caudal vertebra TMP 1991.105.0006 from Milk River Fm. 138

Figure 3.2. Pedal phalanx CMN 8728 with comparison to Elmisaurus. $\quad 139$

Figure 3.3. Pedal phalanx TMP 1994.377.0013 from Milk River Fm. 141

Figure 3.4. Manual phalanx TMP 1994.377.0018 from Milk River Fm. 142

Figure 3.5. Pedal phalanx TMP 1988.086.0020 from Foremost Fm. $\quad 145$

Figure 3.6. Pedal phalanx TMP 2009.037.0065 from Foremost Fm. $\quad 147$

Figure 3.7. Two manual ungual fragments from Oldman Fm. 151

Figure 3.8. Non-ornithomimid metatarsal TMP 2011.053.0007. 152

Figure 3.9. Three ornithomimid phalanges from lower Oldman Fm. 154

Figure 3.10. Possible ornithomimid femora from middle Oldman Fm. 156

Figure 3.11. Non-ornithomimid astragalus UALVP 49009.

Figure 3.12. Pedal phalanx TMP 2002.068.0303 from Oldman Fm. 159

Figure 3.13. Pedal phalanx TMP 2005.012.0271 from Oldman Fm. 160 
Figure 3.14. Two ornithomimid pedal unguals from Oldman Fm.

Figure 3.15. Caudal vertebra TMP 2007.035.0026 from Oldman Fm.

Figure 4.1. Early cladistic hypotheses for ornithomimosaurs.

Figure 4.2. Previous results using Kobayashi \& Lü's dataset.

Figure 4.3. Previous results using Theropod Working Group dataset.

Figure 4.4. Results of the present phylogenetic analysis.

Figure 4.5. Pelvis of Hell Creek ornithomimid, LACM 47520.

Figure 4.6. Pubis of CMN 8902 compared to Qiupalong.

Figure 4.7. Ankle of UALVP 53595 compared to Qiupalong.

Figure 4.8. Tibia of ROM 851 compared to Qiupalong.

Table 1.1. Summary of global record of Ornithomimosauria.

Table 1.2. Regional geology of Albertan ornithomimids.

Table 2.1. Postcranial measurements of ROM 1790.

Table 2.2. Comparative cranial measurements of ROM 1790.

Table 3.1. Occurrences in Milk River Fm. and lower Belly River Grp. 


\section{CHAPTER 1}

\section{INTRODUCTION}

\section{PROJECT OVERVIEW}

The presence of ornithomimid dinosaurs in the Upper Cretaceous Belly River Group of Alberta, Canada has been recognized for over a century (Lambe 1902), but the diversity, evolutionary history, and palaeobiogeography of these dinosaurs are still not completely understood. A full description is provided of ROM 1790, a partial ornithomimid skeleton from the Dinosaur Park Formation near Dinosaur Provincial Park. Despite being collected over 80 years ago, the anatomy of ROM 1790 has never been thoroughly described, and its referral to the species Struthiomimus altus (Russell 1972), though widely accepted, has not been rigorously evaluated. ROM 1790 is one of the oldest articulated ornithomimid specimens from North America preserving an association of cranial, axial, and appendicular elements. It is also among the most complete ornithomimid specimens from the Dinosaur Provincial Park area with a precisely marked quarry and measured stratigraphic position, making it pertinent to discussions of the taxonomic diversity and evolutionary rates of ornithomimids within this formation. Dissociated material referred to Ornithomimidae from the older Milk River, Foremost, and Oldman formations is also reevaluated to establish the oldest definitive occurrence of Ornithomimidae in Alberta. An updated phylogenetic analysis of ornithomimosaurs is presented to test the evolutionary relationships of Albertan ornithomimids, 
including ROM 1790. Some specimens relevant to the distribution of character states in Asian and Albertan ornithomimids are also described in the chapter on phylogeny.

\section{TAXONOMIC REVIEW}

Ornithomimosauria is a clade of small to large-bodied, long-limbed theropods present in many Upper Cretaceous dinosaur assemblages in the northern hemisphere. Unlike most theropods, ornithomimosaurs had relatively small skulls with reduced or absent teeth, and their paleoecological role as carnivores, omnivores, or herbivores has long been debated (Osborn 1917, Barrett 2005). In addition to their body fossil record, ornithomimosaurs may also be represented in the trace fossil record as possible trackmakers of the ichnofamily Ornithomimopodidae (Sternberg 1926, Lockley et al. 2011, Matsukawa et al. 2014). The fossil record of ornithomimosaurs differs from those of most other well-known maniraptoriform theropod clades (Oviraptorosauria, Therizinosauroidea, Alvarezsauridae, Troodontidae, Dromaeosauridae) in the absence of any identified fossil eggshells.

Although ornithomimid remains were first discovered and described in North America (Leidy 1865, Marsh 1890), the distribution and diversity of ornithomimosaurs on this continent during much of the Cretaceous is still poorly understood. Several "Ornithomimus" species named in the early decades of ornithomimid research (Marsh 1890, 1892, Parks 1933) are now known to be nonornithomimosaurian theropods (Russell 1972). Despite ornithomimosaurs having a 
fossil record in North America that potentially spans up to 59 million years of the Cretaceous (base of Aptian to end of Maastrichtian) and includes material from both the Laramidian and Appalachian subcontinents, a recent review of the clade by Makovicky et al. (2004) listed only two valid genera and three valid species of North American ornithomimosaurs, all from the Campanian-Maastrichtian of Laramidia. The fossil record of North American ornithomimosaurs will be reviewed here in more detail, in order to place these fossils in a global context and determine what is known about the evolutionary and biogeographic history of ornithomimosaurs in North America.

\section{Global Record of Early Ornithomimosaurs}

Ornithomimosauria can be defined phylogenetically as a branch-based clade sharing a more recent common ancestor with Ornithomimus velox than with extant birds (Sereno 1998), and is the sister taxon of Maniraptora within the clade Maniraptoriformes (Gauthier 1986, Holtz 1996). Various lineages of Maniraptora are known to have existed by the Oxfordian stage of the Late Jurassic (Xu et al. 2010), indicating that ornithomimosaurs must also have existed by that time, but no definitive ornithomimosaurs are presently recognized in the fossil record below the Cretaceous. Shuvosaurus inexpectatus, initially described by Chatterjee (1993) as a basal ornithomimosaur from the Norian (Upper Triassic) of Texas, is a nondinosaurian archosaur (Nesbitt and Norell 2006). The theropod genus Elaphrosaurus, known from the Kimmeridgian (Upper Jurassic) of Tanzania and Colorado, was for a time considered an early representative or close relative of 
Ornithomimidae (Russell 1972, Galton 1982, Barsbold and Osmólska 1990), but more recent analyses place it in Ceratosauria (Holtz 1994, Rauhut 2003). A partial skeleton from the Upper Jurassic of China, tentatively reported by Clark et al. (2002) as the oldest known ornithomimosaur, was also subsequently identified as belonging to a ceratosaur, Limusaurus (James Clark, pers. comm. 2014). An ungual and a non-ungual phalanx from the Kimmeridgian Kimmeridge Clay in England had been tentatively identified as ornithomimid, but were reevaluated as probably indeterminate within Theropoda in a review by Martill et al. (2006).

Two Lower Cretaceous theropods have been recently reinterpreted as the two oldest known ornithomimosaurs, Nqwebasaurus thwazi from the BerriasianValanginian Kirkwood Formation in South Africa (Choinere et al. 2012) and Valdoraptor oweni from the Valanginian Tunbridge Wells Sand Formation in England (Allain et al. 2014). Incorporating data obtained from new preparation of the N. thwazi holotype, a phylogenetic analysis by Choinere et al. (2012) found the most basal divergence in Ornithomimosauria to be between Nqwebasaurus and other named ornithomimosaurs, though no characters of Nqwebasaurus were recognized exclusively in Ornithomimosauria. The inclusion of Valdoraptor in Ornithomimosauria was proposed by Allain et al. (2014) based on characters shared with an unnamed Early Cretaceous ornithomimosaur from France, but again no characters were identified as exclusively ornithomimosaurian, and Allain et al. (2014) considered Valdoraptor oweni a nomen dubium. 
Definitive ornithomimosaurs were taxonomically diverse and widespread in the northern hemisphere by the end of the Barremian (Table 1.1). Pelecanimimus polyodon from the Calizas de La Huérguina Formation (Los Hoyas locality) in Spain was originally described as deriving from the upper Hauterivian-lower Barremian (Pérez-Moreno et al. 1994), but has been redated to the upper Barremian (PeredaSuberbiola et al. 2012). Allain et al. $(2011,2014)$ reported a bonebed containing an as-yet-unnamed new ornithomimosaur taxon from the Hauterivian-Barremian Angeac-Charente locality in France. Enigmatic theropod bones from the Barremian Wessex Formation in England, including the partial vertebra dubiously named as Thecocoelurus daviesi, were also referred to Ornithomimosauria by Allain et al. (2014), based on comparisons to the Angeac ornithomimosaur. In Asia, Harpymimus okladnikovi from the Shinekhudug Formation in Mongolia may also be HauterivianBarremian in age (Kobayashi and Barsbold 2005b), rather than Aptian-Albian as originally described (Barsbold and Perle 1984). Kinnareemimus khonkaenensis from the imprecisely dated Sao Khua Formation in Thailand is pre-Aptian Cretaceous, possibly Barremian, in age (Buffetaut et al., 2009). An indeterminate ornithomimosaur vertebra has been described from the Barremian Sebayashi Formation in Japan (Hasegawa et al. 1999). Two basal ornithomimosaurs, Shenzhousaurus orientalis and Hexing qingyi, are known from the lower part of the Yixian Formation in Liaoning Province, northeastern China (Ji et al. 2003, Jin et al. 2012). These taxa have both been called the oldest known ornithomimosaurs, with ages initially reported to be between 139 and 128 million years (lower Valanginianlower Barremian), citing Swisher et al. (2002). However, more recent studies 
TABLE 1.1. Summary of global distribution of ornithomimosaur taxa in the Cretaceous, based on references discussed in the text.

\begin{tabular}{|c|c|c|c|}
\hline Age & Europe & Asia & North America \\
\hline $\begin{array}{l}\text { Campanian to } \\
\text { Maastrichtian }\end{array}$ & $\begin{array}{l}\text { Ornithomimosauria } \\
\text { indet.? (Mateus et al. } \\
\text { 2010) }\end{array}$ & $\begin{array}{l}\text { Anserimimus } \\
\text { planinychus, } \\
\text { Archaeornithomimus } \\
\text { asiaticus?, } \\
\text { Deinocheirus } \\
\text { mirificus, } \\
\text { Gallimimus bullatus, } \\
\text { Qiupalong } \\
\text { henanensis }\end{array}$ & $\begin{array}{l}\text { "Ornithomimus" } \\
\text { antiquus, } \\
\text { Ornithomimus } \\
\text { ?brevitertius ( } O . \\
\text { edmontonicus sensu } \\
\text { Makovicky et al. } \\
\text { 2004), } \\
\text { Ornithomimus } \\
\text { ?samueli, } \\
\text { Ornithomimus velox, } \\
\text { Struthiomimus altus, } \\
\text { Struthiomimus? } \\
\text { sedens, } \\
\text { unnamed new taxa }\end{array}$ \\
\hline $\begin{array}{l}\text { Turonian to } \\
\text { Santonian }\end{array}$ & & $\begin{array}{l}\text { Garudimimus } \\
\text { brevipes?, } \\
\text { Sinornithomimus } \\
\text { dongi }\end{array}$ & $\begin{array}{l}\text { Ornithomimidae } \\
\text { indet.? }\end{array}$ \\
\hline Cenomanian & & $\begin{array}{l}\text { Garudimimus } \\
\text { breivpes?, } \\
\text { Ornithomimidae } \\
\text { indet. }\end{array}$ & $\begin{array}{l}\text { Ornithomimidae } \\
\text { indet.? }\end{array}$ \\
\hline $\begin{array}{l}\text { Aptian to } \\
\text { Albian }\end{array}$ & & $\begin{array}{l}\text { Beishanlong grandis, } \\
\text { Harpymimus } \\
\text { okladnikovi?, Hexing } \\
\text { qingyi?, } \\
\text { Shenzhousaurus } \\
\text { orientalis? }\end{array}$ & $\begin{array}{l}\text { "Ornithomimus" } \\
\text { affinis, } \\
\text { "Ornithomimus" sp., } \\
\text { "Arkansaurus" }\end{array}$ \\
\hline $\begin{array}{l}\text { Hauterivian } \\
\text { to Barremian }\end{array}$ & $\begin{array}{l}\text { Pelecanimimus } \\
\text { polyodon, unnamed } \\
\text { French } \\
\text { ornithomimosaur }\end{array}$ & $\begin{array}{l}\text { Harpymimus } \\
\text { okladnikovi?, Hexing } \\
\text { qingyi?, } \\
\text { Kinnareemimus } \\
\text { khonkanensis, } \\
\text { Shenzhousaurus } \\
\text { orientalis? }\end{array}$ & $\begin{array}{l}\text { Ornithomimosauria } \\
\text { indet.? }\end{array}$ \\
\hline
\end{tabular}


suggest that the base of the Yixian Formation could be as young as 125 million years, in the lowermost Aptian (Zhou 2006).

The family name Ornithomimidae is conventionally applied to the clade of ornithomimosaurs characterized by a fully arctometatarsalian pes (Marsh 1896, Kobayashi and Lü 2003). Lee et al. (2014, supplementary information) redefined Ornithomimidae phylogenetically as "Ornithomimus velox and all taxa sharing a more recent common ancestor with it than with Deinocheirus mirificus." Their phylogenetic analysis recovered the Albian ornithomimosaur Beishanlong grandis as more closely related to Deinocheirus than Ornithomimus (Lee et al. 2014: fig. 4b), implying that Ornithomimidae (sensu Lee et al. 2014) also existed by that time. However, fossils pertaining to Ornithomimidae have not been definitively reported from below the Upper Cretaceous. An unnamed, evidently basal ornithomimid possessing an arctometatarsus while retaining the first pedal digit (Lü et al. 2009: fig. 5a) is present in the Ruyang Gigantic Sauropod Dinosaur Fauna of the imprecisely-dated (?Cenomanian) Mangchuan Formation in Henan Province, China (Lü et al. 2009). A more derived unnamed ornithomimid, lacking pedal digit I, has been reported from the lower Upper Cretaceous (Cenomanian-Santonian) Bayanshiree Formation in southeastern Mongolia, where it co-occurs with the nonornithomimid ornithomimosaur Garudimimus brevipes (Barsbold et al. 2007). The oldest definitive named ornithomimid, Sinornithomimus dongi from the Ulansuhai Formation in northern China, was assigned an imprecise "early Late Cretaceous" age in part based on the presence of a plesiomorphic iguanodont at the same locality, but it is not older than 92 million years (Turonian) based on radiometric dating of 
the unconformably underlying basalts (Kobayashi and Lü 2003; contra Makovicky et al. 2004, who erroneously gave its age as Aptian-?Albian).

Averianov (2006) reported a partial coracoid that he referred to Ornithomimidae from the lower Cenomanian Abshir River locality in Kyrgyzstan. Averianov (2006) described this specimen as "phylogenetically intermediate in coracoid structure between Archaeornithomimus ... and Sinornithomimus" in possessing a massive horizontal crest connected to the biceps tubercle, but also resembling Gallimimus, Anserimimus and ornithomimids from the CenomanianTuronian of Uzbekistan in having the infraglenoid buttress of the coracoid offset laterally from the line of the posterior process. This latter character was used by Kobayashi and Lü (2003, character 23) to support an endemic Asian GallimimusAnserimimus clade, which they considered the sister taxon of the endemic North American Ornithomimus-Struthiomimus clade. The Kyrgyzstani ornithomimid, though fragmentary, thus hints that the phylogenetic divergences between the familiar Campanian-Maastrichtian Asian and North American ornithomimids may have already been underway by the very beginning of the Late Cretaceous (or, alternatively, that this character is homoplastic).

\section{Ornithomimosaurs in the Lower Cretaceous of North America}

Compared to those found in Eurasia, Lower Cretaceous ornithomimosaurs from North America are poorly known. The oldest potentially ornithomimosaurian material currently known from North America was reported by Britt et al. (1996) from the Dalton Wells Quarry, at the base of the Yellow Cat Member of the Cedar 
Mountain Formation in Utah. Although formerly thought to be probably Barremian in age, the base of the Yellow Cat Member is now considered basal Aptian (Britt et al. 2009). Material listed by Britt et al. (2009) as "ornithomimid?" includes eight bones representing at least two individuals, which differ in body size. Additional ornithomimid material from Dalton Wells may include an ischium that was originally referred to the large dromaeosaurid Utahraptor (Turner et al. 2012). However, Scheetz et al. (2010) recently reported the discovery of an unnamed, gracile-limbed theropod from the lower Yellow Cat Member that they interpreted as a non-maniraptoriform coelurosaur convergent with ornithomimids, and it is unclear from the literature whether the material previously listed as "ornithomimid?" by Britt et al. (2009) is distinguishable from this taxon. Also present in the Yellow Cat Member is Nedcolbertia justinhofmanni, a small coelurosaur of uncertain affinities (Kirkland et al. 1998). Kirkland et al. (1998) excluded Nedcolbertia from Ornithomimidae, but detailed comparisons between this taxon and Lower Cretaceous ornithomimosaurs have not been published. Gilmore (1920) described a new species of Ornithomimus, O. affinis, based on a collection of fragmentary metatarsals, phalanges and an astragalus from the middle to upper Aptian Arundel Formation in Maryland. It should be noted that Gilmore's $(1920,1933)$ concept of the genus Ornithomimus was more inclusive than that of his contemporaries Osborn (1917) and Parks $(1926,1928,1933)$, essentially encompassing all ornithomimosaurs recognized at the time. Russell (1972) later referred "O." affinis to the ornithomimid genus Archaeornithomimus, known otherwise from the Upper Cretaceous of China. Galton and Smith (1990), reviewing 
Archaeornithomimus, removed the Arundel species from Ornithomimidae, and concluded that all of the material was indeterminate at the level of Theropoda or Coelurosauria. This was recently contested by Buffetaut et al. (2009), who noted that certain features of " $O$." affinis do suggest it to be an ornithomimosaur; a possibility that was echoed by Allain et al. (2014). It was listed (as "Coelosaurus" affinis) as an ornithomimosaur nomen dubium by Barsbold and Osmólska (1990) and Makovicky et al. (2004).

Ostrom (1970) described fragmentary metatarsals and pedal phalanges from unit VII of the Aptian-Albian Cloverly Formation in both southern Montana and northern Wyoming that he tentatively referred to Ornithomimus sp., following Gilmore's broad usage of Ornithomimus. Russell (1972) rediagnosed Ornithomimus in a more restricted sense, and referred to the Cloverly material as Ornithomimidae indet. The identification of Ornithomimidae in the Cloverly Formation was accepted by Zanno and Makovicky (2011), based on characters of the pedal ungual. A nonarctometatarsian theropod pes collected from the Aptian-Albian Trinity Group in southwestern Arkansas, sometimes informally referred to as "Arkansaurus fridayi" (nomen nudum), has also been compared to ornithomimosaurs (Quinn 1973, Hunt 2003). Hunt (2003) figured and described this specimen, but did not reach a definitive conclusion regarding its affinities. Kirkland et al. (1998) suggested that "O." affinis, the Cloverly Fm. "Ornithomimus" sp., and the Arkansas theropod could all represent the same taxon. Theropod footprints from the Aptian Gething Formation in northeastern British Columbia described by Sternberg (1932) as Irenesauripus and Colombosauripus were provisionally included in the ichnofamily 
Ornithomimopodidae by Lockley et al. (2011), whose trackmakers they identified as probably coelurosaurian and "perhaps" ornithomimosaurian.

Weishampel et al. $(1990,2004)$ included "?Ornithomimus sp." in their list of dinosaur taxa from the lower-middle Albian Paluxy Formation in Texas, citing Langston (1974). Langston (1974: 85) discussed a single small theropod manual ungual from this formation and noted its similarity to "a number of coelurosaurian dinosaurs, including Ornithomimus," but he did not suggest that it was referable to that genus, and his figure of the specimen identifies it only as "Coelurosaur of uncertain affinity." However, Farlow (2013) suggested that one morphotype of theropod footprint from the Glen Rose Formation in Texas likely was produced by ornithomimosaurs, being of appropriate size and possessing a relatively long metatarsal print with no impression of a hallux. Ornithomimopodid (sensu Lockley et al. 2011) footprints are the most common theropod traces reported from the middle Albian to lower Cenomanian Ross River Block in Yukon, including Colombosauripus, Irenesauripus, and Ornithomimipus (Gangloff et al. 2004).

\section{Ornithomimosaurs in the Upper Cretaceous of North America}

\section{Canada}

The oldest body fossils tentatively assigned to ornithomimosaurs from Canada consist of isolated, often fragmentary elements from the Deadhorse Coulee Member of the Milk River Formation in southern Alberta (Table 1.2). The age of the Deadhorse Coulee Member is often given as lowermost Campanian (Ryan and 
TABLE 1.2. Geological distribution of Ornithomimidae in southern and central

Alberta, after references discussed in the text.

\begin{tabular}{|c|c|c|c|c|}
\hline Age & \multicolumn{3}{|c|}{ Geological Unit } & $\begin{array}{c}\text { Notable } \\
\text { Ornithomimid } \\
\text { Specimens }\end{array}$ \\
\hline \multirow[t]{6}{*}{ Maastrichtian } & \multirow[t]{10}{*}{$\begin{array}{l}\text { Edmonton } \\
\text { Group }\end{array}$} & \multicolumn{2}{|c|}{ Scollard Formation } & $\begin{array}{l}\text { TMP } \\
1993.104 .0001 \\
\end{array}$ \\
\hline & & \multicolumn{2}{|c|}{ Battle Formation } & \\
\hline & & \multirow{8}{*}{$\begin{array}{l}\text { Horseshoe } \\
\text { Canyon } \\
\text { Formation }\end{array}$} & Whitemud Member & \\
\hline & & & Carbon Member & \\
\hline & & & Tolman Member & $\begin{array}{l}\text { AMNH 5201, CMN } \\
12068, \text { CMN } \\
12069, \text { CMN } \\
12070\end{array}$ \\
\hline & & & Morrin Member & AMNH 5257, CMN \\
\hline \multirow[t]{4}{*}{ Campanian } & & & & $\begin{array}{l}\text { 12228?, ROM } 852 \\
\text { (holotype of } \\
\text { Ornithomimus } \\
\text { ingens) }\end{array}$ \\
\hline & & & Horsethief Member & $\begin{array}{l}\text { CMN } 8632 \\
\text { (holotype of } \\
\text { Ornithomimus } \\
\text { edmontonicus), } \\
\text { CMN 12228?, } \\
\text { ROM 797 } \\
\text { (holotype of } \\
\text { Ornithomimus } \\
\text { brevitertius), ROM } \\
\text { 851 (holotype of } \\
\text { Ornithomimus } \\
\text { currellii), TMP } \\
\text { 2008.070.0001 }\end{array}$ \\
\hline & & & Drumheller Member & $\begin{array}{l}\text { TMP } \\
1990.026 .0001, \\
\text { TMP } \\
2009.110 .0001\end{array}$ \\
\hline & & & Strathmore Member & \\
\hline
\end{tabular}


TABLE 1.2, Continued.

\begin{tabular}{|c|c|c|c|c|}
\hline \multirow[t]{5}{*}{ Campanian } & \multicolumn{3}{|c|}{ Bearpaw Formation (marine) } & \multirow[b]{2}{*}{$\begin{array}{l}\text { Isolated elements } \\
\text { AMNH 5339, CMN } \\
\text { 930? (holotype of } \\
\text { Struthiomimus } \\
\text { altus), ROM } 840 \\
\text { (holotype of } \\
\text { Ornithomimus } \\
\text { samueli), ROM } \\
\text { 1790, TMP } \\
\text { 1995.110.0001, } \\
\text { UCMZ 1980.1 } \\
\end{array}$} \\
\hline & \multirow[t]{3}{*}{$\begin{array}{l}\text { Belly River } \\
\text { Group }\end{array}$} & \multicolumn{2}{|c|}{ Dinosaur Park Formation } & \\
\hline & & \multicolumn{2}{|c|}{ Oldman Formation } & $\begin{array}{l}\text { Isolated } \\
\text { elements? }\end{array}$ \\
\hline & & \multicolumn{2}{|c|}{ Foremost Formation } & $\begin{array}{l}\text { Isolated } \\
\text { elements? }\end{array}$ \\
\hline & \multicolumn{3}{|c|}{ Pakowki Formation (marine) } & \\
\hline Santonian & \multicolumn{2}{|c|}{ Milk River Formation } & $\begin{array}{l}\text { Deadhorse Coulee } \\
\text { Member }\end{array}$ & $\begin{array}{l}\text { Isolated } \\
\text { elements? }\end{array}$ \\
\hline
\end{tabular}


Russell 2001, Weishampel et al. 2004), but it was recently redated to upper Santonian (Evans et al. 2013). Russell (1935) figured a small non-ungual pedal phalanx, CMN 8728, as the first record of Ornithomimidae from the Milk River Formation, and additional unpublished elements are identified as Ornithomimidae indet. in the collections of the Royal Tyrrell Museum of Palaeontology (Ryan and Russell 2001).

The upper Campanian Belly River Group in Alberta consists of the Foremost, Oldman, and Dinosaur Park formations. While the Dinosaur Park Formation is, along with the Edmonton Group, among the most productive sources of Laramidian ornithomimid material, potential ornithomimids from the Foremost and Oldman formations are poorly known. Material from the Foremost Formation catalogued as Ornithomimidae is presently limited to isolated non-ungual phalanges (TMP 1988.086.0020, TMP 2009.037.0065). Material catalogued as ornithomimid that is reliably from the Oldman Formation (in the modern sense excluding the Dinosaur Park Formation, following Eberth and Hamblin 1993) is also limited to isolated elements, primarily phalanges, or small questionable associations of a few fragmentary elements (e.g., TMP 2009.033.0013). An undescribed, isolated caudal vertebra collected from the upper Campanian Cedar District Formation on Denman Island, British Columbia, was mentioned as possibly ornithomimid by Dyke et al. (2011), potentially representing the westernmost discovery of ornithomimosaurs in Canada. An unpublished partial humerus (CMN 40807) from the Kanguk Formation on Bylot Island, Nunavut is catalogued as a possible Arctic ornithomimid. 
Ornithomimids from the Dinosaur Park Formation have a complex taxonomic history, and the number of coexisting species is uncertain. The genus Ornithomimus was originally established by Marsh (1890) for Ornithomimus velox from the upper Maastrichtian of Colorado. Lambe (1902) described a new ornithomimid species, "Ornithomimus" altus, on the basis of a fragmentary postcranial skeleton (CMN 930) from the "Belly River series" along the Red Deer River near present-day Dinosaur Provincial Park. Osborn (1917), upon referring more complete material to Lambe's species, made it the type species of a new genus, Struthiomimus. The fossil quarry that produced CMN 930 has never been reliably relocated, and its noted location "1 mile back of camp" on the west side of the Red Deer River below Berry Creek indicates that it lies outside of the presently accessible limits of Dinosaur Provincial Park (see fig. 14.1 of Sato et al. 2005 for the approximate location of the Berry Creek locality and the Park boundaries). The precise stratigraphic horizons of specimens collected by Lambe at Berry Creek are unknown (Sato et al 2005:259), and consequently there is some confusion in the secondary literature over which formation of the Belly River Group yielded CMN 930. Glut (1997: 856-857) described the locality of the S. altus holotype as "member B of the Belly River Series (now Oldman Formation), at Berry Creek, Red Deer River (probably near what is now Dinosaur Provincial Park)", in contrast to the material referred by Osborn (1917) that was collected "in the Dinosaur Park Formation, basin of Little Sandhill Creek, Dinosaur Provincial Park" (Glut 1997: 859). More recently, Ryan and Russell (2001) and Makovicky et al. (2004: 138) listed S. altus as occurring only in the Dinosaur Park and Horseshoe Canyon formations, and not in the Oldman Formation. 
Currie (2005a, table 1.1) included CMN 930 in a table titled "Holotypes of vertebrate fossils from the Dinosaur Park Formation of the Park and surrounding regions," but this table also includes holotypes with a known Oldman Formation provenance (e.g. CMN 8506, Daspletosaurus torosus).

Osborn (1917) was the first author to divide ornithomimids into two genera, Ornithomimus and Struthiomimus, the latter based on Lambe's "Ornithomimus" altus and including all of the ornithomimid material then known from the Belly River Group. In addition to Ornithomimus being restricted to geologically younger strata, Osborn distinguished the two genera on the basis of the plesiomorphic retention of a fifth metatarsal in Struthiomimus, versus its supposed absence in Ornithomimus. Osborn referred to both genera as stratigraphically segregated evolutionary "stages" of Ornithomimidae, implying that he may have considered Struthiomimus ancestral to Ornithomimus. The majority of articulated and associated ornithomimid skeletons from the Dinosaur Park Formation have been referred to S. altus, and are the subject of the major descriptive papers on this species (Osborn 1917, Russell 1972, Nicholls and Russell 1981, 1985). However, the diagnostic value of the holotype has been questioned (Russell 1972; Chapter 2).

Parks (1928) described the skull and partial skeleton ROM 840 as the holotype of a new species, "Struthiomimus" samueli, which was later included in the genus "Dromiceiomimus" by Russell (1972). The referral of "Struthiomimus" samueli to Struthiomimus was admitted by Parks (1928) as "doubtful" due to the missing metatarsus, but was made on the basis of the stratigraphic horizon and cranial anatomy being close to Struthiomimus altus (the only other ornithomimid known at 
the time with cranial material preserved). The holotypes of S. altus and "S." samueli unfortunately contain no overlapping elements, but the latter can at least be distinguished from the more complete referred specimen of S. altus, AMNH 5339 (Parks 1928).

Recent authors have recognized two (Makovicky et al. 2004, Longrich 2008) or three (Russell 1972, Barsbold \& Osmólska 1990, Ryan \& Russell 2001, Currie 2005, Brown et al. 2013a) named ornithomimid taxa from the Dinosaur Park Formation of Alberta, with an additional unnamed large-bodied taxon possibly represented by rare, dissociated elements (Longrich 2008, Brown et al. 2013a). Ornithomimid remains from the Dinosaur Park Formation in Saskatchewan are generically indeterminate (Weishampel et al. 2004). The number of accepted names varies due to disagreement over whether the specimens described as "Dromiceiomimus" (= Ornithomimus) samueli and Ornithomimus edmontonicus belong to the same species. Russell (1972) considered "D." samueli and $O$. edmontonicus to each be represented in the Belly River Group by single specimens, which have only forelimb elements in common (additional specimens of $O$. edmontonicus, including the holotype, have been described from the younger Horseshoe Canyon Formation). These two specimens reportedly differ in the length of the ulna relative to the humerus (approximately 95\% in ROM 840, after Parks 1928; vs. approximately $80 \%$ in CMN 12441, after Russell 1972), but remeasurement of ROM 840 found that the ulna is considerably shorter than reported by Parks ( $245 \mathrm{~mm}$ vs $280 \mathrm{~mm}$ ), and the ulna-humerus ratio not distinct from Ornithomimus. The use of limb element ratios to distinguish ornithomimid species 
has been considered inconclusive, especially when the sample size is very small (Nicholls \& Russell 1981). Other differences were not observed, but a more rigorous comparison is needed.

A nearly complete Ornithomimus skeleton, TMP 1995.110.0001, was collected from the Dinosaur Park Formation in the 1990s. A full osteological description of TMP 1995.110.0001 has not yet appeared, but several studies have been published on features of its anatomy that are rarely preserved in ornithomimids, such as the nasal respiratory passages (Ruben et al. 1996), rhamphothecae (Norell et al. 2001), cranial pneumatic system (Tahara and Larsson 2011), and traces of feather shafts (Zelenitsky et al. 2012). Zelenitsky et al. (2012, supplementary materials) referred TMP 1995.110 .1 to O. edmontonicus based on the presence of a bifid dorsal ramus of the quadratojugal, an embayment in the caudal border of the quadratojugal, and the absence of a surangular foramen. The former two characters also occur in the holotype of "D." samueli (ROM 840), supporting its close relationship to other Albertan Ornithomimus material, though a tiny posterior surangular foramen is present in this specimen (Parks 1928; pers. obs.). If these forms are accepted as a single species, the name Ornithomimus samueli (Parks 1928) would have priority over Ornithomimus edmontonicus (Sternberg 1933). Resolving the taxonomy of Ornithomimus in the Belly River Group is ultimately beyond the scope of this project, but for the remaining discussion ROM 840 will be referred to as Ornithomimus samueli (combination following Russell 1930: 148) and TMP 1995.110.1 will be referred to as "Ornithomimus sp." (following Kobayashi and Lü 2003). 
Isolated elements referred to Ornithomimidae indet. have been reported from the marine shales of the upper Campanian Bearpaw Formation in Alberta (Ryan and Russell 2001), which overlies the Dinosaur Park Formation and interfingers with the lower members of the nonmarine Horseshoe Canyon Formation. The upper Campanian to lower Maastrichtian Horseshoe Canyon is the lowest formation of the Edmonton Group in central Alberta, and the biostratigraphy of its dinosaur record is now especially well-documented (Eberth and Braman 2012, Eberth et al. 2013). Eberth et al. (2013) listed the stratigraphic horizon of 25 ornithomimid partial skeletons from the Horseshoe Canyon Formation. The stratigraphically lowest Horseshoe Canyon Formation ornithomimid is TMP 1990.026.0001, from the level of the first to second coal seam in the Drumheller Member. It was partially figured by Sereno (2001) as Struthiomimus altus. TMP 2009.110.0001, a feathered young juvenile referred to Ornithomimus edmontonicus by Zelenitsky et al. (2012), was collected towards the top of the Drumheller Member at the level of the fifth to seventh coal seam.

The upper part of the overlying Horsethief Member has yielded three ornithomimid holotypes—ROM 797 ("S." brevitertius, Parks 1926; the type species of the genus Dromiceiomimus, Russell 1972), CMN 8632 (O. edmontonicus, Sternberg 1933), and ROM 851 ("S." currellii, Parks 1933) — as well as TMP 2008.070.0001, a feathered adult referred to O. edmontoncius (Zelenitsky et al. 2012). CMN 12228, a large specimen described as " $D$." brevitertius by Russell (1972), comes from either the top of the Horsethief or lower Morrin Member. The Morrin Member, which in its uppermost portion contains the Campanian-Maastrichtian boundary, has yielded 
the partial skeletons AMNH 5257 (referred to S. altus, Russell 1972) and ROM 852 (holotype of "S." ingens, Parks 1933). The lower Maastrichtian Tolman Member has yielded the partial skeleton AMNH 5201 (referred to "D." brevitertius, Russell 1972) and the bonebed of three ornithomimid individuals described by Cullen et al. (2013). Sternberg (1926) described possible ornithomimosaur footprints from the Horseshoe Canyon Formation as the new ichnotaxon Ornithomimipus angustus. Generically indeterminate ornithomimid elements have been reported from the equivalent-aged Wapiti Formation in northwestern Alberta (Ryan and Russell 2001) and the St. Mary River Formation in southern Alberta (Langston 1975) and stretching into Montana, USA (Weishampel et al. 1990).

Citing Osborn (1917), Parks (1926) placed his new, stratigraphically intermediate species "Struthiomimus" brevitertius in the genus Struthiomimus based on the presence of a fifth metatarsal, but also hinted at the possibility of it representing a third genus. He regarded the metatarsus of "Struthiomimus" brevitertius as not intermediate in form between Struthiomimus altus and Ornithomimus velox, but did not further speculate on the relationships of these three species. Parks' (1933) reasons for referring the new species "Struthiomimus" currellii and "Struthiomimus" ingens to Struthiomimus were never explicitly stated. However, in the same paper, Parks (1933) used the supposed absence of the fifth metatarsal as the only justification for his classification of the new species "Ornithomimus" elegans, later reassigned by Currie (1989) to the oviraptorosaur genus Elmisaurus. In naming "Ornithomimus" elegans from the Belly River Group, Parks partially challenged Osborn's concept of Struthiomimus and Ornithomimus as 
stratigraphically segregated "stages" of Ornithomimidae. Although Parks (1933) ultimately recognized five species of Struthiomimus, all from the Upper Cretaceous of Alberta (two in the Belly River Group, and three in the Edmonton Group), he did not openly speculate about their phylogenetic relationships.

Sternberg (1933) followed Gilmore (1920) in considering the genus Struthiomimus to have been insufficiently distinguished from Ornithomimus, but provisionally retained it for species that had already been assigned to it. Accordingly, while Sternberg (1933) described a new species as Ornithomimus edmontoncius, nothing in his paper suggests that he considered it particularly closely related to Ornithomimus velox, or that he considered Struthiomimus altus and "S." brevitertius (both discussed as species of Struthiomimus in Sternberg's paper) particularly closely related to each other, leaving Struthiomimus in use but without a clear diagnosis at the time ROM 1790 was collected. Sternberg (1934) was also the first to propose the synonymy of two previously named Albertan ornithomimid species, sinking "Struthiomimus" currellii Parks (published in August 1933) as a junior synonym of Ornithomimus edmontonicus Sternberg (published in May 1933). This synonymization has been widely accepted (Russell 1972, Osmólska et al. 1972, Barsbold \& Osmólska 1990, Makovicky et al. 2004), but has never been tested in a phylogenetic analysis.

D. A. Russell (1972) presented the most detailed hypothesis of how the various Albertan ornithomimid specimens are related. He introduced a third genus, "Dromiceiomimus," and considered Ornithomimus, Struthiomimus, and "Dromiceiomimus" to all be monophyletic genera that coexisted in the Late 
Cretaceous of Alberta, though he did not indicate a preferred phylogenetic relationship between the three genera. Russell (1972: 379) made the first attempt to justify the monophyly of Ornithomimus velox and Ornithomimus edmontonicus (including 0 . currellii, following Sternberg) on morphological grounds, noting that these ornithomimids shared a first metacarpal that was longer than the other two. However, the state of this character is not determinable in any of the eight specimens that Russell included in "Dromiceiomimus." The monophyly of "Dromiceiomimus", proposed by Russell to include the species "Dromiceiomimus" brevitertius (Parks 1926) and "Dromiceiomimus" samueli (Parks 1928), was poorly established. None of the characters listed in his formal diagnosis of the genus (Russell 1972: 388) can be confirmed both in his hypodigm for "Dromiceiomimus" brevitertius (for which the scapula and manus are unknown) and the sole specimen of "Dromiceiomimus" samueli (for which the hindlimb and tail are unknown). Russell (1972: 392) wrote that the "detailed resemblance of the preserved cranial bones of NMC 12228 to corresponding elements in ROM 840 provides the basis for referring the latter specimen to Dromiceiomimus," but he did not name any specific characters shared by these specimens that differed from other known ornithomimid skulls (e.g. ROM 851, ROM 1790, or AMNH 5339). His claim that "D. samueli may be distinguished from $D$. brevitertius in that the humerus is approximately five times longer than an anterior dorsal centrum of average proportions, while in the latter species is may be nearly six times longer" (Russell 1972: 392) is also uncertain, because none of the specimens that he referred to "Dromiceiomimus" brevitertius include both a humerus and a dorsal vertebra, and most (including the holotype) 
include neither. Russell (1972: 388) considered "Struthiomimus" ingens (Parks 1933) a junior synonym of "Dromiceiomimus" brevitertius based on proportional similarities, but did not fully discuss the diagnosis of the former species proposed by Parks (1933). Nicholls and A. P. Russell (1981) considered "Dromiceiomimus" a tentatively valid genus distinguishable only by limb proportions, but no comparable limb proportions are known between the material assigned to "D." brevitertius and "D." samueli.

I agree with Eberth et al. (2013: 710) that the taxonomy of ornithomimids from the Edmonton Group is in need of revision. Makovicky et al. (2004) lumped $O$. edmontonicus, "S." brevitertius, "S." currellii, "S." ingens, along with "S." samueli from the Dinosaur Park Formation into a single species, which they called Ornithomimus edmontonicus. This usage of 0 . edmontoncius is incorrect according to the International Commission on Zoological Nomenclature's principle of priority, since the names "S. brevitertius" (Parks 1926) and "S. samueli" (Parks 1928) were published before the name "O. edmontonicus" (Sternberg 1933). If future research upholds the synonymy of the above taxa and their close congeneric relationship to Ornithomimus velox, the combination Ornithomimus brevitertius (Russell 1930) should be used. Longrich (2008: 983) considered the Horseshoe Canyon Formation Struthiomimus a distinct species from S. altus, diagnosed by a relatively longer metacarpus, and referred to it as "Struthiomimus sp."

Upper Maastrichtian ornithomimids have been collected from the Scollard Formation (upper Edmonton Group) in Alberta, and from the Frenchman Formation in Saskatchewan, but little has been published on them (Sternberg 1924, Russell 
1972). Russell (1972: 393) noted the difference between two manual unguals, one from the Scollard Formation more closely resembling Ornithomimus and one from the Frenchman Formation more closely resembling Struthiomimus. Gross (1998: 120) considered Struthiomimus to be "the only [Albertan ornithomimid taxon] for which there is indisputable evidence, from the Scollard Formation, of having survived until the very last stage of the Cretaceous," but Ryan and Russell (2001) considered this occurrence of Struthiomimus, based on unpublished isolated elements, to be problematic and in need of validation. Two partial skeletons from the Scollard Formation are currently being studied by Francois Therrien, and suggest the presence of a taxon distinct from Ornithomimus and Struthiomimus (Eberth et al. 2013: 710). The manus of one of these specimens was previously figured by Rauhut (2003: 99) as "probably Ornithomimus edmontonicus."

\section{United States of America}

The oldest Upper Cretaceous dinosaurs in North America occur in the Mussentuchit Member of the Cedar Mountain Formation in Utah, dated as lower Cenomanian. Kirkland et al. (1998: 87) mentioned the presence of "Ornithomimidae? new genus and species" in a list of dinosaurs from this member. This occurrence is based on undescribed material in the Oklahoma Museum of Natural History, including a femur with an ornithomimid-like medial tuberosity on the distal end (James Kirkland, pers. comm. 2014). The ichnogenus Magnoavipes, based on tridactyl footprints possibly attributable to ornithomimosaurs, occurs in the uppermost Albian to lowermost Cenomanian Sarten Member of the Mojado 
Formation in New Mexico and Texas, the Cenomanian Dakota Group in Colorado, and the Cenomanian Woodbine Formation in Texas (Lockley et al. 2011, Matsukawa et al. 2014).

Ornithomimosaurs have not been reported from Turonian to lower Campanian sediments in the western United States (Weishampel et al. 2004, Zanno et al. 2013). Ornithomimids from the upper Campanian in the United States are poorly known compared to those from Canada, but are geographically widespread. Isolated material assigned to Ornithomimidae indet. has been listed or described from the Judith River and upper Two Medicine formations in Montana (Fiorillo 1991, Varricchio 1995, Trexler 2001), the Kaiparowits Formation in Utah (Zanno et al. 2013), the Fruitland and Kirtland formations in New Mexico (Sullivan 1997, Lucas et al. 2000, Sullivan et al. 2000), and the Aguja Formation in Texas (Sankey 2010). Longrich (2008: 993) noted that an unspecified number of unguals from the Judith River Formation resemble those of the unnamed large ornithomimid from the Dinosaur Park Formation. Lucas et al. (1987) described a relatively straight manual ungual from the Fruitland Formation as similar to Ornithomimus edmontonicus, but larger than the described material from Alberta. A dorsal centrum and two pedal fragments from the Kirtland Formation were described as comparing favorably to Struthiomimus altus (Lucas et al. 1987), but this was based only on their size. Sankey (2010: 531), citing personal communication from Longrich, identified three ornithomimid "morphotypes" from a mixed species bonebed within the Aguja Formation: "(1) a small ornithomimid, (2) a Struthiomimus-sized ornithomimid, and (3) a very large, Ornithomimus-sized ornithomimid." This description is problematic 
because Struthiomimus is usually larger than Ornithomimus (Currie 2005b).

Footprints referred to Ornithomimipus from the Campanian Mesaverde Group in Colorado were described by Lockley et al. (2011).

Few attempts have been made to identify Campanian ornithomimid material from the United States at the species level. DeCouten and Russell (1985) described a partial skeleton from the Kaiparowits Formation in southern Utah as belonging to the type species of Ornithomimus, O. velox (Marsh 1890), but this referral was considered unjustified by Zanno et al. (2013). Although ornithomimids are among the most common theropods recovered from the Kaiparowits Formation, and several potentially diagnostic articulated or associated specimens are now known, their lower level taxonomy in this formation remains undetermined (Zanno et al. 2013). Some of the more recently collected manual and pedal material does share derived characters with the genus Ornithomimus (Neabore et al. 2007, Claessens et al. 2011). Lavender et al. (2010) suggested that an ornithomimid manus from the Kaiparowits Formation could represent an unnamed new species of Ornithomimus, and Claessens et al. (2011) suggested that at least two ornithomimid species are present in the formation, based on differing proportions of the metatarsals.

Sullivan (1997) described an isolated tibia from the De-Na-Zin member of the Kirtland Formation in New Mexico and referred it to the species "Ornithomimus" antiquus (Leidy 1865), which he considered a senior subjective synonym of $O$. velox and O. edmontonicus. Sullivan's proposed revision of the Ornithomimus species has not been adopted by subsequent authors (Makovicky et al. 2004, Brusatte et al. 2012), and is not internally consistent: Sullivan (1997:251) stated that the Kirtland 
tibia was compared to "the holotypes of Ornithomimus antiquus (ANSP 9222), $O$. edmontonicus (ROM 851) and Dromiceiomimus brevitertius (=holotype of Struthiomimus brevitertius) (ROM 797)" and "cannot be referred to either of the two latter species, based on the presence of this distinctive cnemial crest," but on the following page (Sullivan 1997:252) he concluded that "O." antiquus and $O$. edmontonicus are synonymous. Weishampel et al. (2004) listed the Kirtland Formation record of "O." antiquus as Ornithomimosauria indet.

The presence of ornithomimosaurs in the Campanian-Maastrichtian of Alaska is so far based on scant and contentious material. An indeterminate ornithomimid has been listed as a faunal component of the lower Maastrichtian Pachyrhinosaurus perotorum-dominated Kikak-Tegoseak bonebed in the Prince Creek Formation on the North Slope of Alaska (Fiorillo et al. 2010), but awaits verification (Watanabe et al. 2013). A distal fragment of a right metatarsal IV from another locality in the Prince Creek Formation was referred to Ornithomimosauria by Watanabe et al. (2013), despite failure to distinguish it from other taxa such as tyrannosaurids morphologically, because the specimen's histology indicated that it belonged to an adult individual and was therefore presumably too small to be tyrannosaurid. However, this argument can no longer be considered persuasive following the discovery of a surprisingly small adult tyrannosaurine, Nanuqsaurus hoglundi (Fiorillo and Tykoski 2014), in the same formation. The makers of Magnoavipes footprints from the upper Campanian or lower Maastrichtian Cantwell Formation in central Alaska were originally interpreted as avian by Fiorillo et al. (2011), but were 
considered more likely to have been ornithomimosaurian by Matsukawa et al. (2014).

Ornithomimosaurs from Lancian (upper Maastrichtian) assemblages in the western United States have a long history of discovery. Ornithomimus velox, the type species of Ornithomimus, was named by Marsh (1890) on the basis of a fragmentary distal hindlimb and a metacarpus, possibly belonging to the same relatively small individual, from the upper Maastrichtian Denver Formation in Colorado. A few additional elements from this formation, including manual unguals and a distal caudal vertebra, were referred to 0 . velox by Carpenter and Young (2002), but have not been described. $O$. velox has historically proven difficult to diagnose, and has been considered morphologically indistinguishable from the geologically older $O$. edmontonicus from Alberta (Russell 1972, Makovicky et al. 2004). The syntype material of $O$. velox has only recently received additional preparation to reveal new morphological details, which should clarify this issue (Claessens et al., 2011).

Marsh (1892) briefly described an ornithomimid sacrum and pelvis from the Lance Formation in Wyoming as the holotype of another species, Ornithomimus sedens, which was figured and described in more detail by Gilmore (1920). The validity of $O$. sedens is not well established, with Makovicky et al. (2004) listing it as a nomen dubium. Longrich (2008) tentatively referred additional material, noting the need for additional study of the holotype, and placed the species in the genus Struthiomimus. The most complete specimen referred to Struthiomimus sedens by Longrich (2008) is an undescribed, articulated partial skeleton of a large individual (BHM 1266, given the nickname "CLAWS" by the Black Hills Institute), also from the 
Lance Formation in eastern Wyoming. The Lance Formation's ichnofossil assemblage includes unnamed tridactyl dinosaur tracks that Lockley et al. (2003) favorably compared to Ornithomimipus angustus. Two unassociated pedal elements assigned to Ornithomimus sp. from a Puercan (lowermost Paleocene) locality in the Ferris Formation in southern Wyoming are waterworn and probably reworked from the upper Maastrichtian strata of the same formation, which have also uncommonly produced ornithomimid elements (Lillegraven and Eberle, 1999).

Taphonomic studies by White et al. (1998) and Horner et al. (2011) found that ornithomimids account for approximately $5 \%$ of all dinosaur fossils in the upper Maastrichtian Hell Creek Formation in eastern Montana and western North Dakota. Osborn (1917) listed fragmentary Hell Creek ornithomimid material from Montana as "?Ornithomimus velox ?sp.", but Russell (1972) considered this material generically indeterminate. The "undescribed genus" of ornithomimid from the Hell Creek Formation listed by Russell (1984, citing "Long and Russell in prep.") was never described. Triebold (1997), following identifications by Russell, listed three ornithomimid genera from the Sandy Site of the Hell Creek Formation in South Dakota: Ornithomimus, Struthiomimus, and "Orcomimus" (nomen nudum). A later review of the Hell Creek Formation dinosaurs by Russell and Manabe (2002) listed only Ornithomimus sp. and Struthiomimus sp., omitting "Orcomimus." Dale Russell (pers. comm. 2014) does not presently consider the latter name to be adequately supported, and considers this material, as well as the "undescribed genus" of Russell (1984), to merely indicate the presence of multiple ornithomimids in the Hell Creek Formation, not a specific new taxon that warrants a name. Makoto Manabe (pers. 
comm. 2014) presently considers all of the Sandy Site ornithomimid material indeterminate at the generic level. Lyson and Longrich (2011, supplementary data) identified Hell Creek ornithomimid material in the UCMP collections as O. velox and S. sedens.

An undescribed partial postcranial skeleton of a large ornithomimid, LACM 47520, was collected from the Hell Creek Formation near Jordan, Montana in the 1960s, and includes most of the hindlimbs, pelvis, and proximal portion of the tail (Fig X). It is presently on display at the Natural History Museum of Los Angeles County as a specimen of Struthiomimus, but this identification is not definitive (Luis Chiappe, pers. comm. 2014). Another undescribed skeleton informally referred to Struthiomimus, nicknamed "Margie," was privately collected in the late 1990s from the Hell Creek Formation near Glendive, and is the most complete ornithomimid known from Montana, including the complete skull, most of the neck, right fore and hind limb, ribs, and some of the pelvis in articulation (Mike Triebold, pers. comm. 2014). The "Margie" specimen now resides in the National Council for Culture, Arts, and Heritage, Qatar (Carl Mehling, pers. comm. 2014).

Additional undescribed upper Maastrichtian examples of Ornithomimidae indet. in the western United States are reported from the Naashoibito Member of the Ojo Alamo Formation in New Mexico (Sullivan et al. 2000) and the Javelina Formation in Texas (Hunt and Lehman 2008). Longrich (2008) speculated that a relatively small pedal ungual from the Javelina Formation could be from a form related to the unnamed large ornithomimid from the Dinosaur Park Formation. 
Upper Cretaceous dinosaurs from eastern North America (Appalachia) are less common and generally less well known than those from the western side of the continent (Laramidia). Campanian to Maastrichtian ornithomimosaurs from the eastern United States are potentially represented by isolated and often fragmentary elements from the Mount Laurel and Navesink formations in New Jersey, the Merchantville and Marshalltown formations in Delaware, the Severn Formation in Maryland, the Black Creek Formation in North Carolina, the Blufftown Formation in Georgia, and the Mooreville Chalk in Alabama (Baird and Horner 1979, Baird 1986, Schwimmer et al. 1993, King and Jones 1997, Weishampel et al. 2004). A problematic occurrence from the Coniacian-Santonian Eutaw or McShan Formation in Mississippi may instead represent a deinonychosaur (King and Jones 1997). Fix and Darrough (2004) mentioned a phalanx from the Campanian Chronister dinosaur site in southeastern Missouri as another "problematic" record of ornithomimids east of the Western Interior Seaway. King and Jones' (1997) sorting of some of this material into "Ornithomimus"/"Coelosaurus" antiquus versus Ornithomimidae indet. appears to be based solely on stratigraphic age, rather than any morphological characters.

Leidy (1865) named "Coelosaurus" antiquus on the basis of a tibia from the Maastrichtian Navesink Formation in New Jersey. The relationship of this species to other ornithomimids was not recognized until the 20th century, when the coelurosaurs were reviewed by Matthew and Brown (1922). Baird and Horner (1979) pointed out that the name "Coelosaurus" was preoccupied, and referred Leidy's species to the Laramidian genus Ornithomimus. "O." antiquus has widely 
been considered a nomen dubium (Russell 1972, Weishampel et al. 2004), and Weishampel et al. (2004) listed it as Ornithomimosauria indet. However, a rediagnosis of "O." antiquus was recently presented by Brusatte et al. (2012), who considered it a valid taxon of derived ornithomimid distinct from Ornithomimus. A new replacement name for "Coelosaurus" Leidy will appear in a forthcoming paper on this taxon by Brusatte, Choiniere, Benson, and Norell (Stephen Brusatte, pers. comm. 2014).

\section{Mexico}

Ornithomimid remains from the upper Campanian of Mexico have been reported from the El Gallo Formation in Baja California and the Cerro del Pueblo Formation in Coahuila, constituting the southernmost occurrence of this clade (Rivera-Sylva et al. 2006, Rivera-Sylva and Carpenter 2014). The Baja California material is undescribed and has only been mentioned as an indeterminate ornithomimid (Weishampel et al. 2004, Rivera-Sylva et al. 2006). Rivera-Sylva et al. (2006) listed the Coahuila ornithomimid as cf. Ornithomimus in their text and as "Dromiceiomimus" in a table (these two genera are commonly regarded as synonyms, following Makovicky et al. 2004). Rivera-Sylva and Carpenter (2014) figured ornithomimid unguals from the Cerro del Pueblo Formation. Ornithomimid material from the Cerro del Pueblo Formation was described by Anguillon-Martinez (2010) in her unpublished Master's thesis. Material from the La Majada and La Parrita localities, including an adult partial posterior postcranial skeleton and a juvenile partial pes, was determined to represent a new genus and species of 
ornithomimid, known exclusively from this formation. A larger, and more fragmentary partial postcranial skeleton, from the uppermost Cerro del Pueblo Formation at El Pantero locality, was referred to cf. Ornithomimus (AnguillonMartinez 2010). Tracks attributed to ornithomimids are also known from the Cerro del Pueblo Formation, and from the Upper Cretaceous "Aguililla Sandstone" in Michoacán (Rivera-Sylva et al. 2006, Bravo-Cuevas and Rodriguez-de la Rosa 2014).

\section{REGIONAL GEOLOGY}

The articulated ornithomimid material described in this study was collected in or near Dinosaur Provincial Park, Alberta. The exposed part of the Belly River Group (Oldman and Dinosaur Park formations) in Dinosaur Provincial Park spans approximately 2.5 million years of late Campanian time (Eberth 2005: 65), including the upper portion of the middle Oldman Formation (Comrey Sandstone) that is disconformably overlain by the Dinosaur Park Formation. The Dinosaur Park Formation is capped by the Lethbridge coal zone and the marine Bearpaw Formation in the eastern portion of the park that marks the maximum transgression of the Western Interior Seaway. A regional dip in the area results in Oldman and lower Dinosaur Park formations being exposed in the western region of the park, and the older Oldman Formation not being exposed in the eastern region. Dissociated material referred to Ornithomimidae was also observed from the Milk River, Foremost, and Oldman formations of southern Alberta (Chapter 3). In this region, the Oldman Formation has both a lower unit that is older than the Oldman 
Formation in Dinosaur Provincial Park, and an upper unit that is equivalent in age to the lower Dinosaur Park Formation.

\section{Stratigraphic Distribution of specimens in Dinosaur Provincial Park}

Béland and Russell (1978) attempted the first summary of the distribution of articulated dinosaur material in the Dinosaur Provincial Park area. They assigned specimens to three vertical levels, based on the specimen's approximate elevation with respect to the Red Deer River, within a resolution of approximately $15 \mathrm{~m}$.

Although these levels should be roughly correlated with the stratigraphic position of the specimens, and Béland and Russell (1978: 1014) did attempt to correct for the regional dip in the Belly River Group in the west end of the park, their "level I" does not distinguish between the Oldman Formation and the lower Dinosaur Park Formation (Currie \& Russell 2005). Béland and Russell (1972: table 4) reported a single indeterminate ornithomimid from "level II," a single specimen of "Dromiceiomimus" (ROM 840) from "level II," three specimens of Struthiomimus from "level I," three specimens of Struthiomimus from "level II," and two specimens of Struthiomimus from "level III." Nine articulated or associated specimens from the Dinosaur Provincial Park area were referred to Struthiomimus altus by Russell (1972) and were included in the summary of horizontal distribution by Béland and Russell (1978), so it is indicated that Béland and Russell (1978) were able to at least roughly estimate the vertical position of all but one of these specimens. Unfortunately, the data for individual specimens is not tabulated, and it is impossible to derive from clues in the locality data in published sources. For 
example, Russell (1972: 383) gave an identical locality description ("basin of Little Sandhill Creek, Dinosaur Provincial Park") for five specimens that he referred to $S$. altus, but there are not five Struthiomimus skeletons from the same vertical level according to Béland and Russell (1978: table 4).

Currie and Russell (2005) updated the work of Béland and Russell (1978) by redefining the vertical levels with direct reference to the park's stratigraphy, and limiting their assignment of levels only to specimens with precisely marked quarries. No articulated or associated ornithomimid specimens are definitively known from the revised "level I," which corresponds to the Oldman Formation only (Currie \& Russell 2005: table 2). Currie and Russell (2005: table 1) considered only four ornithomimid specimens with precisely marked quarries in the Dinosaur Provincial Park area to be diagnostic at the generic level: ROM 840, ROM 1790, TMP 1995.110.1, and UCMZ 1980.1. All four diagnostic specimens were assigned to "level II" of Russell and Currie (2005), which was defined as the lower $45 \mathrm{~m}$ of the Dinosaur Park Formation and includes part of the former "level I" of Béland and Russell (1978). Currie and Russell (2005: table 2) also indicated the presence of 13 marked quarries (six uncollected at the time of publication) containing articulated or associated specimens of Ornithomimidae indet. from "level II," and a single uncollected occurrence of Ornithomimidae indet. from "level III." This uncatalogued specimen, described as "many phalanges and metatarsal ends" (Currie \& Koppelhus 2005, CD-ROM supplement), occurs at the highest reported elevation of any articulated or associated dinosaur in Dinosaur Provincial Park (Currie \& Russell 2005: table 1). 
The Ornithomimus specimen TMP 1995.110.1 has a measured stratigraphic position $0.5 \mathrm{~m}$ above the base of the Dinosaur Park Formation (Zelenitsky et al. 2012, supplementary materials). The quarry yielding ROM 1790 was measured by Dodson (1971) to be $233 \mathrm{ft}$ (71 m) below the base of the Bearpaw Formation, and indicated by Currie and Russell (2005: table 2) to be in the lower part of the Dinosaur Park Formation. The Dinosaur Park Formation in Dinosaur Provincial Park has a thickness of approximately 70 m (Eberth 2005), so ROM 1790 appears to also be from very close to the base of this formation, assuming Dodson's stratigraphic measurement is accurate. The Struthiomimus specimen UCMZ 1980.1 does not have a stratigraphic position reported in the literature, but is indicated to be from the lower part of the Dinosaur Park Formation (Currie \& Russell 2005: table 2). Reexamination of the quarry site supports a position within the lowest 5-10 m of the Dinosaur Park Formation (Philip Currie, David Eberth, and Eva Koppelhus, pers. comm. February 2015). These three ornithomimids thus occur at approximately the same level in the Dinosaur Park Formation, and were contemporaneous with the ornithischian biostratigraphic zone variously termed the CentrosaurusCorythosaurus faunal zone (Ryan \& Evans 2005), Megaherbivore Assemblage Zone 1a (Mallon et al. 2012), or Dinosaur Park Faunal Zone 1 (Ryan et al. 2012, Evans et al. 2014). The quarry yielding the Ornithomimus samueli holotype ROM 840 was measured by Dodson (1971) to be $118 \mathrm{ft}$. (36 m) below the Bearpaw Formation. This places it in the middle of the Dinosaur Park Formation, assuming a typical thickness of approximately $70 \mathrm{~m}$, and contemporaneous with the ornithischian biostratigraphic zone variously termed the Styracosaurus-Lambeosaurus faunal zone 
(Ryan \& Evans 2005), Megaherbivore Assemblage Zone 2a (Mallon et al. 2012), or Dinosaur Park Faunal Zone 2 (Ryan et al. 2012, Evans et al. 2014). Whether or not this could be interpreted as evidence of species turnover in Ornithomimidae is uncertain, because it has not been resolved whether or not TMP 1995.110.1 and ROM 840 represent the same species (see below). In any case, the sample size of diagnostic ornithomimids with precise stratigraphic data is much too small for species turnover in the Dinosaur Park Formation to be demonstrated statistically.

\section{Paleoenvironment in Dinosaur Provincial Park}

Russell (1977: 96) observed that among the ornithomimid genera recognized in Alberta, Struthiomimus (sensu Russell 1972) is most common in river deposits in the Dinosaur Park Formation, "Dromiceiomimus" (sensu Russell 1972) is most common in the forested coastal plain paleoenvironment of the upper Horseshoe Canyon Formation, and Ornithomimus (sensu Russell 1972) is best known from the deltaic palaeoenvironment of the lower Horseshoe Canyon Formation. This led Russell (1977: 96) to suggest that Struthiomimus "may have preferred more bushy surroundings." Although this idea was originally advanced only to explain the differing relative abundances of Struthiomimus and "Dromiceiomimus" in the Dinosaur Park versus Horseshoe Canyon formations, and not as a suggestion of spatial niche partitioning or habitat exclusivity by ornithomimids within those

formations, it has nevertheless become a recurring meme in popular books to state that Struthiomimus lived in more open habitats along river banks, while 
Ornithomimus in contrast lived in swamps and forests (Lambert 1983: 57, Reid 1990: 82-84, Cox et al. 1999: 109).

The sedimentological context of articulated ornithomimid specimens from the Dinosaur Park Formation has been described by Dodson (1971) for ROM 840 and ROM 1790, Nicholls and Russell (1981) for UCMZ 1980.1, and Zelenitsky et al. (2012, supplementary materials) for TMP 1995.110.1. All four specimens were found in sand-dominated facies that fit the profile of a channel palaeoenvironment (Dodson 1971, Lyson \& Longrich 2011). The fact that all diagnostic ornithomimid specimens from the Dinosaur Park Formation with published sedimentological data are from palaeochannel facies also does not indicate that rivers were the preferred habitat of these taxa. It is a known taphonomic bias in the Dinosaur Park Formation that nearly all articulated dinosaur specimens are found in river channel deposits (Dodson 1971, Eberth \& Currie 2005).

\section{MATERIALS AND METHODS}

All material examined had been previously deposited in museum collections. Fossil material representing the majority of articulated and associated ornithomimid specimens reported from Alberta was examined at the American Museum of Natural History (AMNH 5201, AMNH 5257, AMNH 5339, AMNH 5355, AMNH 5375, AMNH 5385, AMNH 5241), Canadian Museum of Nature (CMN 930, CMN 8632, CMN 8897, CMN 8902, CMN 12068, CMN 19069, CMN 12070, CMN 12228, CMN 12441), Royal Ontario Museum (ROM 797, ROM 840, ROM 851, ROM 852, ROM 1790), Royal Tyrrell Museum of Paleontology (TMP 1995.110.0001), 
University of Calgary (UCMZ 1980.1), and University of Alberta (UALVP 16182).

Numerous dissociated ornithomimid elements were also examined at these

institutions. Measurements were taken using a digital caliper for smaller elements or a measuring tape for larger elements. Geological and locality data for Albertan ornithomimids were obtained from the literature and the museums. Data for nonAlbertan ornithomimosaurs were obtained primarily from the literature, supplemented by casts at the CMN and ROM, and the original fossil material of Archaeornithomimus asiaticus at the AMNH. The matrix for the phylogenetic analysis was constructed in MacClade 4.08a and the analysis was run using TNT 1.0 [18].

\section{INSTITUTIONAL ABBREVIATIONS}

AMNH: American Museum of Natural History, New York; BHM: Black Hills Museum of Natural History, Hill City; CMN: Canadian Museum of Nature, Ottawa; CMNH: Cleveland Museum of Natural History, Cleveland; IGM: Institute of Geology, Mongolian Academy of Sciences, Ulan Bator; LACM: Natural History Museum (formerly Los Angeles County Museum), Los Angeles; ROM: Royal Ontario Museum, Toronto; TMP: Royal Tyrrell Museum of Palaeontology, Drumheller; UALVP: University of Alberta Laboratory for Vertebrate Paleontology, Edmonton; UCMZ: University of Calgary Museum of Zoology, Calgary; YPM: Yale Peabody Museum of Natural History, New Haven. 


\section{CHAPTER 2}

\section{ANATOMY AND CLASSIFICATION OF ROM 1790, AN ORNITHOMIMID (DINOSAURIA, THEROPODA) FROM THE LATE CRETACEOUS OF ALBERTA}

\section{INTRODUCTION}

A partial skeleton of an ornithomimid theropod, ROM 1790, was collected by Levi Sternberg in 1934 along the Red Deer River in Alberta, Canada, near what is now Dinosaur Provincial Park (Fig. 2.1). Sternberg's field notes for this specimen read: "Specimen No. 13, Struthiomimus (part of skull, pelvis, parts of hind legs, two feet of the tail). The rock is poor and this will take a great deal of care in preparation. This seems to be a very small species. Found three miles below Steveville, one mile west of the river, $75 \mathrm{ft}$. above the level of the river" (David Evans, pers. comm. May 2015). The site of this discovery was included on a map of dinosaur quarries by C. M. Sternberg (1950), who listed the specimen as "Struthiomimus, pelvis, hind legs, and feet." However, the genus Struthiomimus lacked an adequate diagnosis at the time, having been named by Osborn (1917: 744) to simply denote an earlier evolutionary "stage" of Ornithomimidae than Ornithomimus, and used in this sense by Parks $(1926,1928,1933)$ to include various ornithomimids that would later be reclassified as "Dromiceiomimus" (Russell 1972) or Ornithomimus (Makovicky et al. 2004). Dodson (1971, table 2) described the stratigraphic and sedimentary context of the ROM 1790 quarry, and interpreted the environment as a channel deposit. The stratigraphic horizon was reported as being 233 feet $(71 \mathrm{~m})$ below the base of the 
FIGURE 2.1. Locality of ROM 1790. A) Map of Dinosaur Provincial Park and surrounding area showing location of the quarry (modified from Farke et al. 2011). B) Photograph of the quarry site in the Dinosaur Park Formation, from Currie \& Koppelhus (2005, CD-ROM supplement).

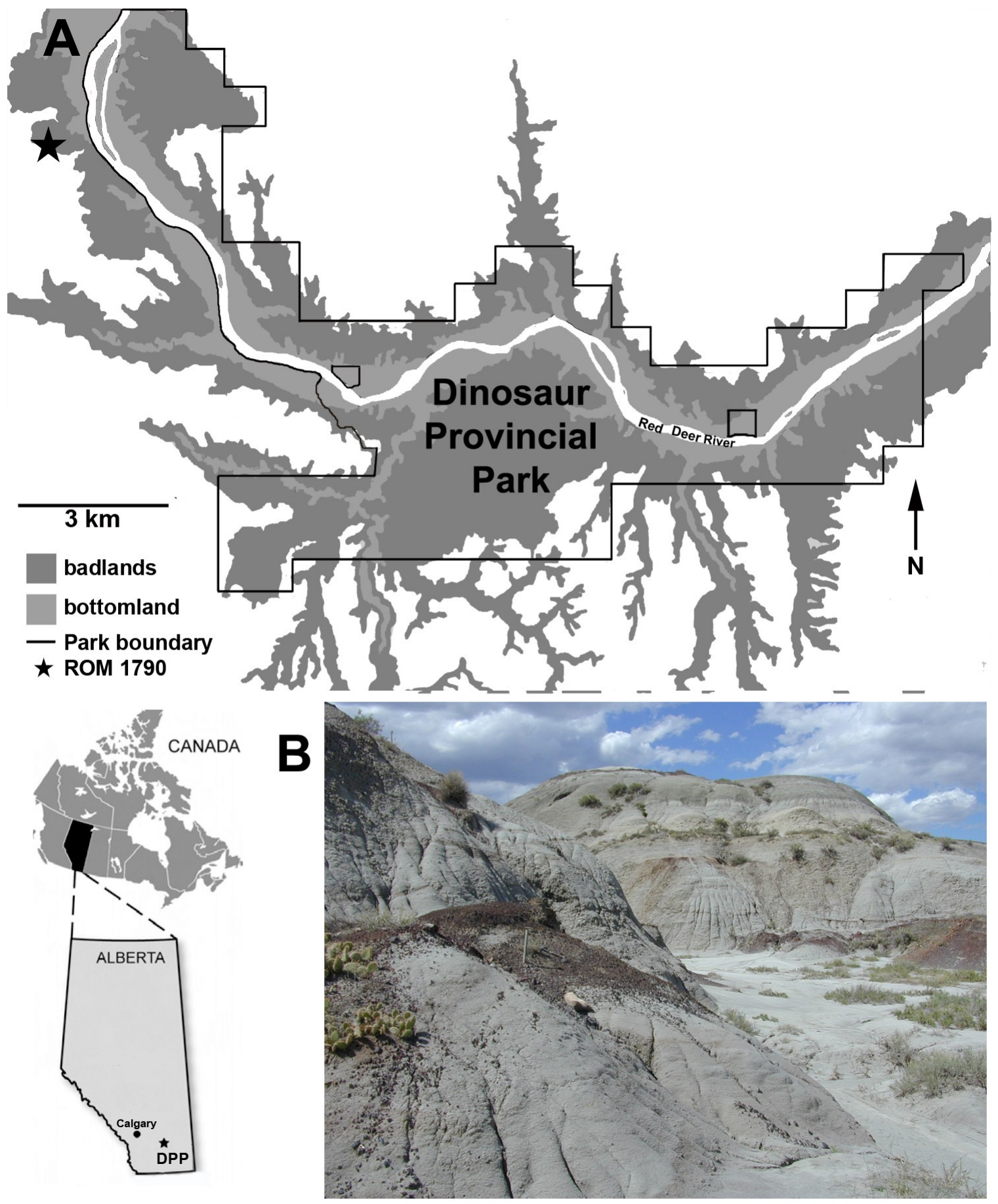


Bearpaw Formation, in what was then considered part of the Oldman Formation. Eberth and Hamblin (1993: 177) defined the base of the newly recognized Dinosaur Park Formation as a regional discontinuity that occurs "approximately $80 \mathrm{~m}$ " below the base of the Bearpaw Formation in the region where ROM 1790 was discovered, suggesting that ROM 1790 is actually from the lower part of the Dinosaur Park Formation. This was confirmed by Currie and Russell (2005, table 2; see also the CDROM supplement) who indicate that ROM 1790 was collected from the lower $45 \mathrm{~m}$ of the Dinosaur Park Formation. The site was not accessible for the present study, because it is located on private land outside the boundaries of Dinosaur Provincial Park.

Russell (1972) provided the first modern diagnosis of Struthiomimus, and restricted the genus to the type species, Struthiomimus altus. Among the specimens that Russell (1972: 383) referred to S. altus was ROM 1790. Russell (1972: 383) was the first to publish on the presence of a partial skull and vertebrae with ROM 1790, and his skull reconstruction of S. altus (Russell 1972, fig. 3) is a composite based on ROM 1790 and AMNH 5339, the most complete referred specimen of $S$. altus described by Osborn (1917). Russell (1972, table 7) also included some measurements of the postcranial skeleton, demonstrating the proportional similarity between ROM 1790 and other specimens referred to S. altus. Measurements of ROM 1790 (Table 2.1) have been used in various other studies (Holtz 1995, Gatesy and Middleton 1997, Currie 2000, Rainforth 2003, Kobayashi and Barsbold 2005a, Cullen et al. 2013), but the anatomy of ROM 1790 remains 
TABLE 2.1. Postcranial measurements of ROM 1790. Measurements of incomplete elements are marked with an asterisk. Complete measurements are also expressed as a percentage of femur length, to facilitate comparisons with previous descriptive literature on Ornithomimidae (Russell 1972, Nicholls \& Russell 1981).

\begin{tabular}{|c|c|c|}
\hline Element & Measurement (mm) & As Percentage of Femur \\
\hline Dorsal centrum 12 & $40^{*}$ & \\
\hline Sacrum & $\sim 360$ & $\sim 90$ \\
\hline Sacral 1 & 61 & 15 \\
\hline Sacral 2 & 65 & 16 \\
\hline Sacral 3 & 55 & 14 \\
\hline Sacral 4 & 54 & 14 \\
\hline Sacral 5 & 66 & 17 \\
\hline Sacral 6 & 62 & 16 \\
\hline \multicolumn{3}{|l|}{ Caudal centra } \\
\hline Caudal 1 & $\sim 55$ & 14 \\
\hline Caudal 2 & $20^{*}$ & \\
\hline Caudal 3? & $\sim 40$ & 10 \\
\hline Caudal 4? & 46 & 12 \\
\hline Caudal 5? & 46 & 12 \\
\hline Caudal 6? & $\sim 45$ & 11 \\
\hline Caudal 7? & $\sim 42$ & 11 \\
\hline Caudal 8? & 42 & 11 \\
\hline Caudal 9? & 40 & 10 \\
\hline Caudal 10? & 42 & 11 \\
\hline Caudal 11? & - & \\
\hline Caudal 12? & 39 & 10 \\
\hline Caudal 13? & 40 & 10 \\
\hline Caudal 14? & 45 & 11 \\
\hline Ilium & 395 (left) & 99 \\
\hline Antilium & $150 \mathrm{e}$ (left) & 38 \\
\hline Height above acetabulum & 102 (left) & 26 \\
\hline Acetabulum width & 66 & 17 \\
\hline Acetabulum height & 70 & 18 \\
\hline Pubic peduncle width & 55 & 14 \\
\hline \multirow{2}{*}{ Ischiac peduncle width } & 21 & 5 \\
\hline & $325^{*}$ (left), 314* (right) & \\
\hline $\begin{array}{l}\text { Pubis (broken piece) } \\
\text { Ischium (broken niece) }\end{array}$ & $260 *$ & \\
\hline \multirow[t]{2}{*}{ Femur } & 397 (left) & 100 \\
\hline & $41 \mathrm{e}$ (left) & 10 \\
\hline Distal width & 43 & 11 \\
\hline
\end{tabular}


TABLE 2.1, Continued.

\begin{tabular}{|c|c|c|c|c|c|c|}
\hline $\begin{array}{l}\text { Proximal width } \\
\text { Distal width }\end{array}$ & $\begin{array}{l}430 \text { (le } \\
63 \text { left } \\
56 \text { lleft }\end{array}$ & $\begin{array}{l}367^{*}( \\
\text { nd right }\end{array}$ & ght) & $\begin{array}{l}108 \\
16 \\
14\end{array}$ & & \\
\hline Fibula & $390 *(\mathrm{lt}$ & & & & & \\
\hline Metatarsus & & & & & & \\
\hline Metatarsal II & 281 (lef & & & 71 & & \\
\hline Metatarsal III & 296 (lef & & & 75 & & \\
\hline Metatarsal IV & 288 lef & & & 73 & & \\
\hline Metatarsal V & 95 (righ & ), $87 *(\mathrm{le}$ & & 24 & & \\
\hline Proximal width & 51 (righ & ), 59 (lef & & 15 & & \\
\hline Pedal phalanges (left) & Length & Height & Width & Length & Height & Width \\
\hline 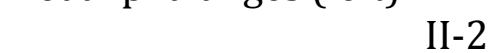 & & 21 & 18 & & & \\
\hline II-3 & $44 \mathrm{e}$ & 17 & 13 & 11 & 4 & 3 \\
\hline III-1 & 65 & 24 & 29 & 16 & 6 & 7 \\
\hline III-2 & 50 & 17 & 23 & 13 & 4 & 6 \\
\hline III-3 & 39 & 15 & 20 & 10 & 4 & 5 \\
\hline III-4 & $49 \mathrm{e}$ & - & - & 12 & & \\
\hline IV-1 & 39 & - & - & 10 & & \\
\hline IV-2 & 31 & 20 & 20 & 8 & 5 & 5 \\
\hline IV-3 & 20 & 19 & 18 & 5 & 5 & 5 \\
\hline IV-4 & 22 & 18 & 17 & 6 & 5 & 4 \\
\hline IV-5 & $39 \mathrm{e}$ & 17 & 13 & 10 & 4 & 3 \\
\hline
\end{tabular}


otherwise undescribed apart from some very brief remarks made on the skull by Russell (1972). The specimen has never been figured outside of Russell's composite skull reconstruction. This paper describes the anatomy of ROM 1790 in greater detail, and compares it to other ornithomimosaurs in order to reevaluate its taxonomic placement.

\section{DESCRIPTION}

ROM 1790 (Fig. 2.2) includes the pre-orbital portion of the skull and mandibles, the proximal caudal vertebrae, and a nearly complete pelvis with both hindlimbs. The external surface of the skull is well preserved in three dimensions, but is damaged around the oral margin. The ilia and the most proximal caudal vertebrae are badly crushed. The extremities of the pelvic and hindlimb elements are also damaged to varying degrees, and the right hindlimb is missing the knee and the digits. The left pes is reasonably well preserved with minor restoration on the unguals.

Skull - The preserved portion of the skull (Fig. 2.3) is approximately $150 \mathrm{~mm}$ long. The skull roof is displaced upwards to the left, and the left maxilla is displaced inwards below the nasal and the maxillary process of the premaxilla. The anterior rim of the left antorbital fenestra is displaced $5 \mathrm{~mm}$ anteriorly relative to that on the right side, where no displacement of the maxilla relative to the nasal or premaxilla is evident. Although the skulls differ somewhat in how they are distorted, the skull of ROM 1790 is estimated to have been approximately $80 \%$ as large as the holotype skull of Ornithomimus samueli (ROM 840), and approximately 90\% as large as the 
FIGURE 2.2. Preserved material and hypothetical body outline of ROM 1790.

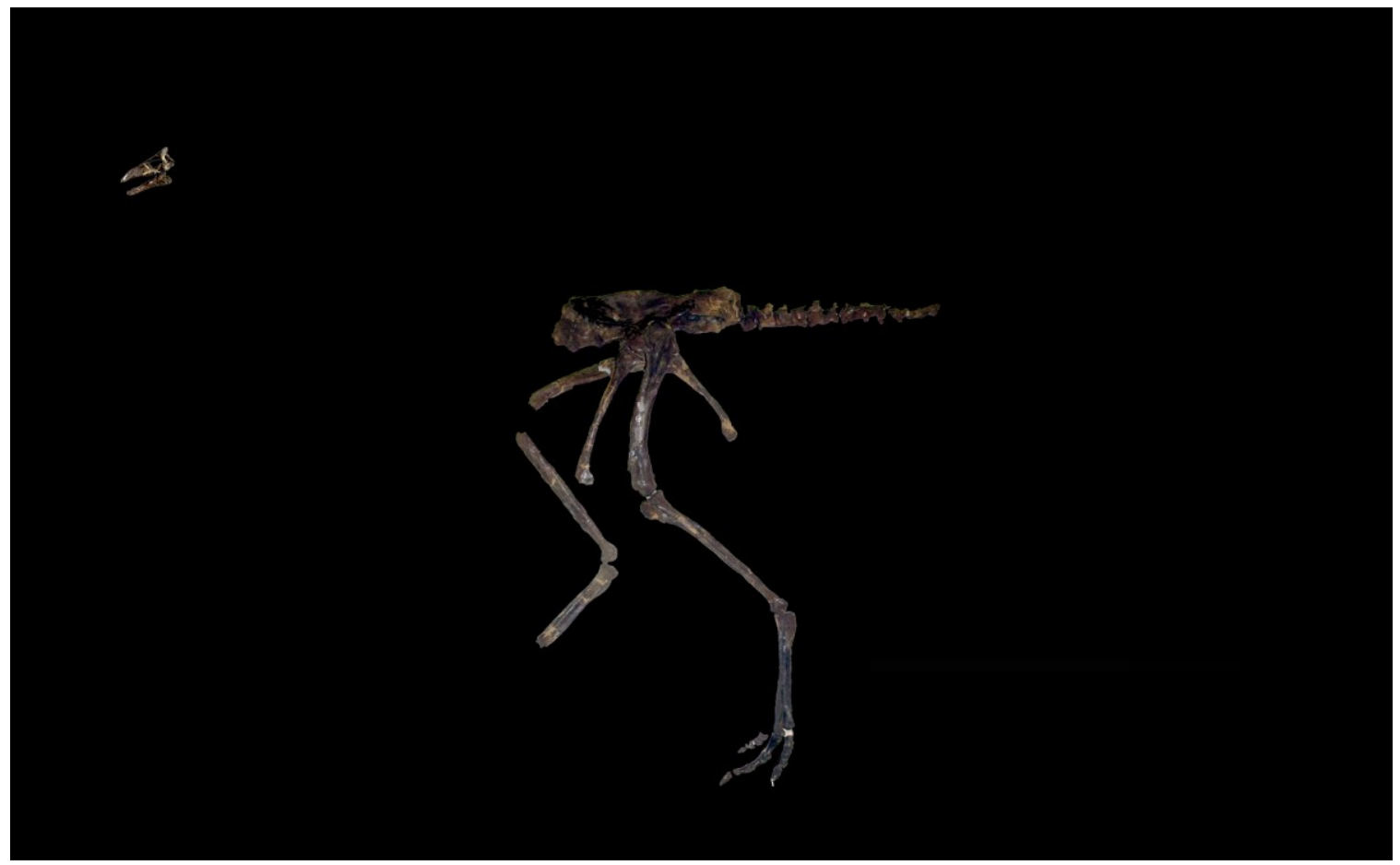


FIGURE 2.3. Partial skull of ROM 1790 in A) right lateral, B) dorsal, C) ventral, D) posterior, E) anterior, and F) left lateral view.

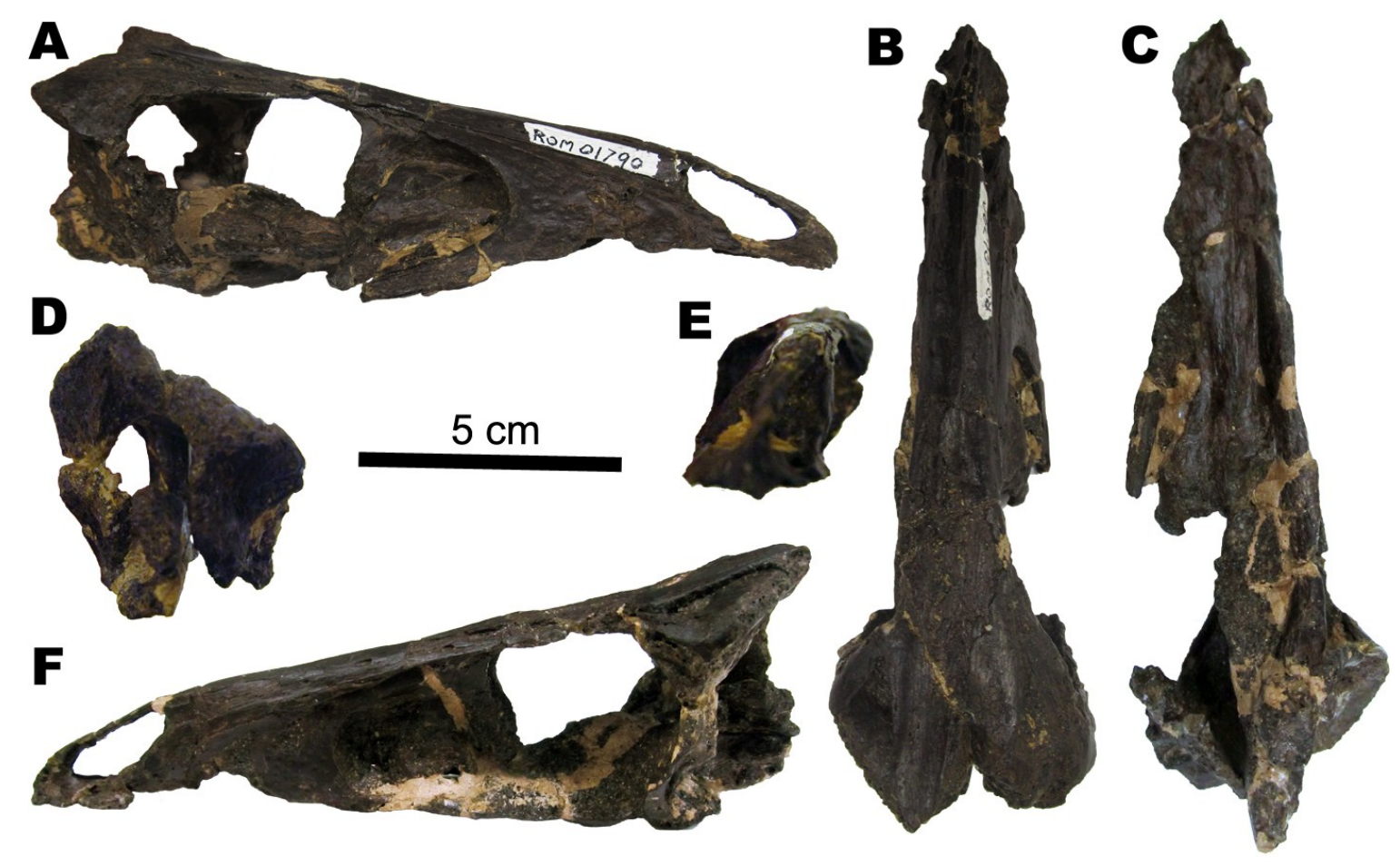


holotype skull of Ornithomimus currellii (ROM 851), based on measurements of a variety of features of the preorbital region (Table 2.2).

The external nares are bordered by the premaxillae and nasals, and the antorbital fenestrae are bordered by the maxillae and lacrimals (Fig. 2.4). The external nares are elongate but do not extend farther posteriorly than the point of the premaxilla-maxilla contact, as in most ornithomimids, but unlike Ornithomimus sp. (TMP 1995.110.1) in which the most posterior point of the nares slightly overlies the preantorbital body of the maxilla. The antorbital fenestra is approximately as tall as it is long.

The premaxillae are edentulous. The premaxillary body is shallow dorsoventrally, but the oral margin is incompletely preserved. Makovicky et al. (2004) described the snout of Struthiomimus (no specimen specified) as "more pointed" than that of Garudimimus or Gallimimus, but the sharply pointed, spadeshaped appearance of the premaxillae in ROM 1790 could be partly or completely attributable to breakage. The dorsal surface of the premaxillary bodies, forming the floor of the narial chamber, is also damaged posteriorly. A pair of laminae descending posteriorly from the nasal rami define a shallow median fossa on the premaxillae between the anteroventral corners of the external nares, below and behind the internarial bar. A similar condition of a lamina-bound median opening has been described in Gallimimus (IGM 100/1133) and in the Xanadu ornithomimosaur (IGM 100/1245), in which it is an open passage connected to the incisive foramen on the palate (Kspeka and Norell 2004: 2). There is no lateral 
TABLE 2.2. Comparative cranial measurements of ROM 1790, ROM 840 (holotype of Ornithomimus samueli), and ROM 851 (holotype of Ornithomimus currellii), in mm.

\begin{tabular}{|l|l|l|l|l|l|l|l|}
\hline \multirow{2}{*}{ Measurement } & \multicolumn{3}{|l|}{ ROM 1790 } & \multicolumn{2}{l|}{ ROM 840 } & \multicolumn{2}{l|}{ ROM 851 } \\
\cline { 2 - 8 } & Right & Left & Right & Left & Right & Left \\
\hline $\begin{array}{l}\text { Length of } \\
\text { premaxillary body }\end{array}$ & 31 & 32 & 41 & 41 & 34 & - \\
\hline $\begin{array}{l}\text { Length of external } \\
\text { nares }\end{array}$ & 25 & 24 & 31 & 31 & 32 & - \\
\hline $\begin{array}{l}\text { Length of nasal } \\
\text { processes of } \\
\text { premaxillae }\end{array}$ & \multicolumn{2}{|c|}{60} & \multicolumn{2}{|c|}{55} & \multicolumn{2}{|c|}{$>50$} \\
\hline $\begin{array}{l}\text { Length of } \\
\text { internasal suture }\end{array}$ & \multicolumn{2}{|c|}{$\sim 70$} & \multicolumn{2}{|c|}{113} & \multicolumn{2}{|c|}{$\sim 84$} \\
\hline $\begin{array}{l}\text { Length of maxilla } \\
\text { from anterior to } \\
\text { antorbital fossa }\end{array}$ & 32 & 30 & 35 & 35 & 35 & 37 \\
\hline $\begin{array}{l}\text { Total length of } \\
\text { maxilla }\end{array}$ & 85 & 85 & 107 & 110 & 100 & 95 \\
\hline $\begin{array}{l}\text { Total length of } \\
\text { antorbital fossa }\end{array}$ & 62 & 60 & 82 & 80 & 63 & 62 \\
\hline $\begin{array}{l}\text { Height of } \\
\text { antorbital fossa }\end{array}$ & 35 & 33 & $35+$ & 35 & 35 & - \\
\hline $\begin{array}{l}\text { Length of skull } \\
\text { from anterior to } \\
\text { lacrimal }\end{array}$ & 120 & 120 & 150 & 150 & 130 & 130 \\
\hline Length of dentary & $129 *$ & $113^{*}$ & - & 170 & - & $?$ \\
\hline Depth of dentary & 25 & 17 & - & 28 & - & 25 \\
\hline
\end{tabular}


FIGURE 2.4. Anterior portion of the skull of ROM 1790 in A) right lateral view, and B) right oblique posterolateral view. Abbreviations: aos, antorbital sinus; asrM, ascending ramus of maxilla; 'cs', 'columnar structures' (Norell et al. 2001); en, external naris; jurM, jugal ramus of maxilla; laofM, lateral antorbital fossa of maxilla; M, maxilla; $\mathbf{m f o}$, median fossa on premaxillary body; $\mathbf{m r P m}$, maxillary ramus of premaxilla; $\mathbf{N}$, nasal; $\mathbf{N f}$, nasal foramina; $\mathbf{n p}$, narial passage; $\mathbf{n r P m}$, nasal ramus of premaxilla; PI, palatine; PIf, palatine foramina; Pm, premaxilla; (p)Mfe, (pro)maxillary fenestra; snf, subnarial foramen; vpPm, ventral process of premaxilla. 


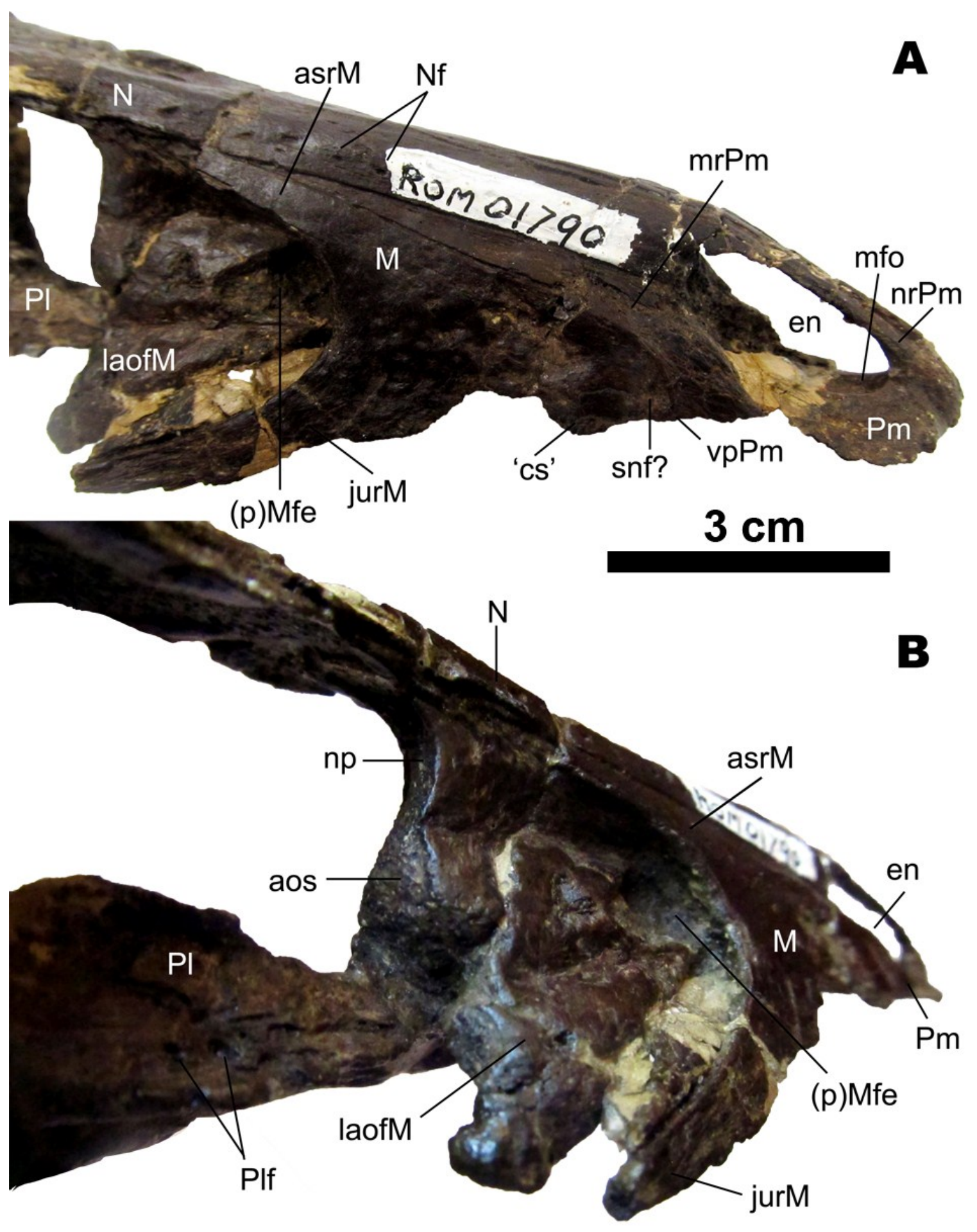


foramen positioned at the base of the nasal process. The presence of a foramen in this position was previously described in Garudimimus as being "as in other ornithomimosaurs" (Kobayashi and Barsbold 2005a: 1506), and it is present in Ornithomimus (ROM 840).

The suture between the right and left premaxillae is visible along the length of the paired nasal rami, which form the majority of the internarial bar. The internarial bar is dorsoventrally flattened as in other ornithomimosaurs (Sereno 2001: 93), but it does not have the T-shaped cross-section reported by Ksepka and Norell (2004: 2) to be present in the Xanadu ornithomimosaur, and regarded as characteristic of ornithomimosaurs in general. Posterior to the external nares, the ends of the nasal rami are exposed dorsally between the nasals and terminate by tapering to a point slightly more anterior than the start of the antorbital fossa. The maxillary rami are wider than the nasal rami and are wedged between the nasal and the maxilla on each side of the skull, excluding the maxillae from the borders of the external nares. The posterior ends of the maxillary rami overlie the antorbital fossae. The maxillary rami do not bear extensive pitting or foramina, unlike the adjacent surfaces of the maxillae and nasals. At least a small ventral process is present on the premaxilla, in that the most anterior point of the maxilla does not correspond to its most ventral point along the premaxilla-maxilla contact, but the incomplete preservation of the oral margin makes the extent of this process indeterminate.

Ventrally, the premaxillae form the anterior portion of the palate. ROM 1790 differs from Garudimimus (Kobayashi and Barsbold 2005a) and the Xanadu 
ornithomimosaur (Kspeka and Norell 2004) in the absence of a midline incisive foramen on the palate, and in the absence of a visible suture between the right and left premaxillae in ventral view. The sutures between the premaxillae and the palatal shelves of the maxillae are also indistinct. The premaxillae have a pair of foramina on the palate that are similar in position to those described for Garudimimus (Kobayashi and Barsbold 2005a: 1506) and the Xanadu ornithomimosaur (Kspeka and Norell 2004: 2), but differ from those of the Xanadu ornithomimosaur in that they are not elongated anteroposteriorly, and they do penetrate the dorsal surface of the premaxillary body to open into the narial chamber. Instead, the internal passages of these foramina appear to be oriented more posteriorly, and contained within the ventral bulge (sensu Ksepka and Norell 2004: 2) of the palate. The absence of an incisive foramen and the presence of small, circular paired foramina resemble ROM 840, the only other North American ornithomimid with the premaxillae fully exposed in ventral view. However, the ventral bulge on the premaxillae in ROM 1790 is broad and triangular, unlike the narrow antero-posterior ridge observed in ROM 840.

Both maxillae are present, but incomplete. The shape of the oral margin is indeterminate, due to breakage. The preantorbital body is characterized by a strongly pitted or dimpled texture, with the largest pits measuring up to $1 \mathrm{~mm}$ across. A pitted texture on the maxilla is also present in Struthiomimus (AMNH 5339) and the Ornithomimus specimen TMP 1995.110.1. It contrasts with the condition in the Ornithomimus specimens ROM 851, and especially ROM 840, in which the preantorbital body is comparatively smooth. These pits number 
approximately 20 per side in ROM 1790 and are concentrated on the core maxillary body only, not extending onto the anterior portion of the maxillary body, lateral antorbital fossa, ascending ramus, or jugal ramus. Russell (1972: fig. 3) reconstructed the snout of "Struthiomimus," largely based on ROM 1790, as lacking the opening in the preantorbital body that Parks (1928) originally described as "antorbital fenestra IV" in ROM 840, and Russell (1972: fig. 5) retained in his composite reconstruction of "Dromiceiomimus." However, the edges of this supposed fenestra in ROM 840 are broken and its form may be exaggerated. A small foramen that occurs in a similar position on the maxillae of the troodontid Byronosaurus and the alvarezsaurid Shuvuuia has been interpreted as the subnarial foramen by Makovicky et al. (2003). The maxilla of ROM 1790 has a pronounced divot in this position, but it is not apparent that this structure perforates the surface of the maxilla.

A small patch on the ventral edge of the right maxilla has a striated texture on its external surface (Fig. 2.5), resembling the fine columnar structures extending sub-perpendicularly from the oral margin in a specimen of Gallimimus (IGM 100/1133). In the latter taxon, these were interpreted as fossilized soft-tissue lamellae by Norell et al. (2001a) and as a natural cast of the internal surface of the rhampotheca by Barrett (2005). The columnar structures have a density of approximately two per mm, as in IGM 100/1133 (Norell et al. 2001a). However, the structures in IGM 100/1133 are entirely ventral to the well-preserved oral margin of the skull, whereas the oral margin in ROM 1790 is estimated to have been lower than the striated area. 
FIGURE 2.5. Right lateral view of striated texture perpendicular to the upper jaw of A) ROM 1790 (indicated by arrow) and B) Gallimimus bullatus IGM 100/1133 (after Norell et al. 2001a).

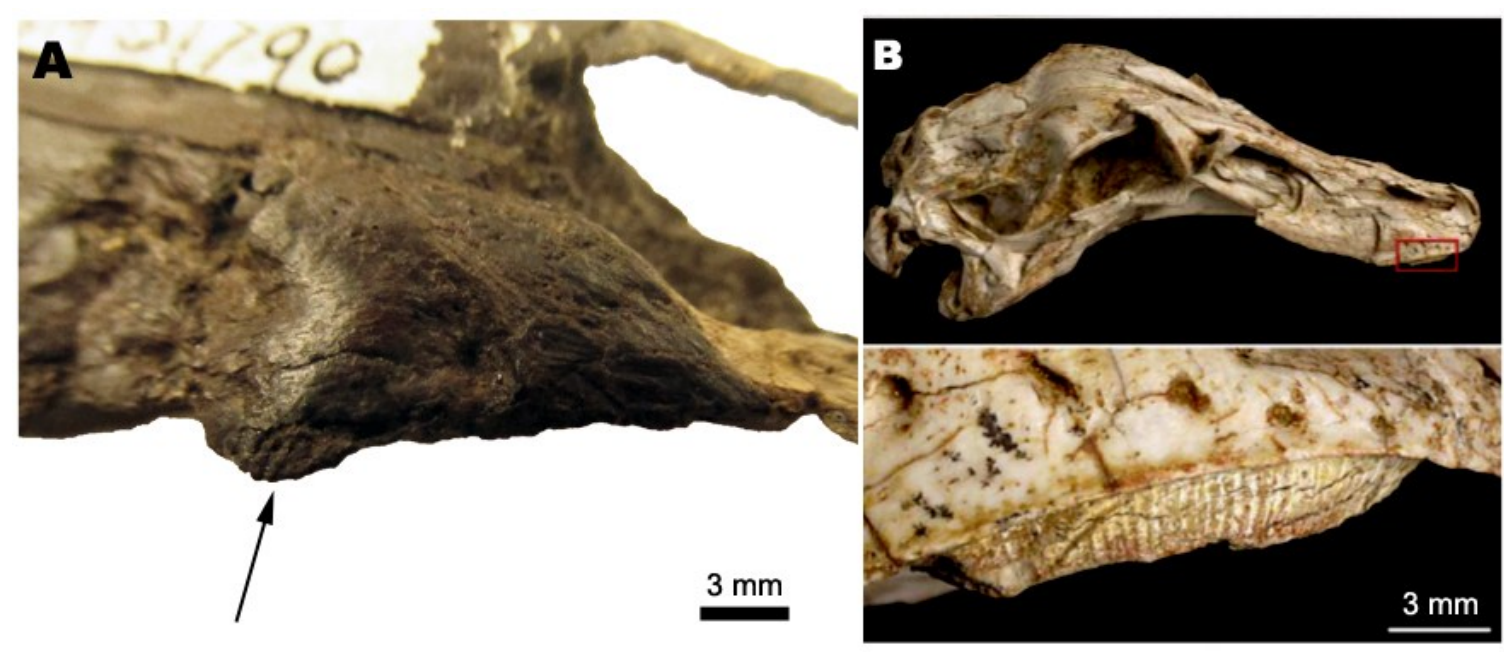


The rim of the lateral antorbital fossa is sharply defined. It follows a broad curve from the ventral edge of the ascending ramus to the dorsal edge of the jugal ramus. The surface within the antorbital fossa is better preserved on the right maxilla than on the left. Russell (1972, fig. 3) reconstructed the snout of "S. altus," based on ROM 1790, with only a single fenestra in the antorbital fossa. However, neither maxilla is well enough preserved to confirm the absence of the lower fenestra (the maxillary fenestra of Kobayashi and Barsbold 2005a, or the promaxillary fenestra of Tahara and Larsson 2011), and it was considered present in this specimen by Witmer (1997: 42). The lateral surface of the antorbital fossa is inflected medially along a horizontal crease dorsal to the upper fenestra that marks the division between the narial passage and the antorbital sinus. Although the walls of the maxillae are pinched in, there is no complete floor of bone separating the narial passage from the antorbital sinus, which is present in Byronosaurus (Makovicky et al. 2003). A second horizontal crease on the exterior surface of the antorbital fossa is positioned immediately below the upper fenestra.

The jugal ramus of the left maxilla is preserved. It contacts the anteroventral tip of the lacrimal. This region of the skull is poorly preserved in most ornithomimids, but these elements do not appear to be in contact in a specimen of Struthiomimus from the Horseshoe Canyon Formation (TMP 1990.26.1; Sereno 2001, fig. 14). The contact for the unpreserved jugal occupies only the posteroventral surface of the jugal ramus, and is distinctive for being short and blunt in comparison to other ornithomimids. In Struthiomimus (Osborn 1917, fig. 5a) and Ornithomimus (ROM 851), the jugal ramus has an elongated ventrolateral 
groove. The Ornithomimus specimen ROM 840 was described by Parks (1928) as having a very long and tapering anterior process of the jugal that contacts a delicate inferior flange on the jugal ramus of the maxilla, but this region of ROM 840 has since been damaged. It is plausible that the groove or flange visible on the maxillae of AMNH 5339 and ROM 851 is the same structure that was described in ROM 840 for receiving a long anterior process of the jugal. A long, tapering anterior process of the jugal that contributes to the posteroventral border of the antorbital fenestra is also present in Pelecanimimus (Pérez-Moreno et al. 1994: 364) and Struthiomimus (TMP 1990.26.1; Sereno 2001, fig. 14). In contrast, a relatively short and blunt maxilla-jugal contact appears to be present in the non-ornithomimid Deinocheirus (Lee et al. 2014, fig. 2), potentially resembling the condition inferred for ROM 1790.

The maxillae also contribute to the palate (fig. 2.6). Russell (1972: 386), correctly noting that the palatal region was "slightly distorted and difficult to interpret," identified "a smooth horizontal sheet of bone, evidently representing the broadened ventral surfaces of the vomers and pterygoids," which he viewed as probably contacting "the anterior part of the maxilla, to which it has been crushed." The boundaries between these elements could not be determined, but an apparent midline suture is visible anteriorly. Posteriorly, the horizontal sheet is continuous with the medial walls of the maxillae, rather than contacting them by a suture, indicating that at least a majority of the preserved area of the palate is formed by the maxillae. The contact of the maxillae along the midline is complete, as reconstructed by Osmólska et al. (1972, fig. 2a) for Gallimimus, and differs from the modified reconstruction of a "generalized ornithomimid" by Tsuihiji et al. (2014, fig. 
FIGURE 2.6. Palate of ROM 1790. Abbreviations: csM, continuous surface on maxilla from medial wall to palatal shelf; if?, fossa in position of the incisive foramen in Asian ornithomimosaurs; jurM, jugal ramus of maxilla; Mps, maxillary palatal shelf; Pm, premaxilla; Pm-M, level of premaxilla-maxilla suture; Pmf, premaxillary foramen; rM-lM, right maxilla-left maxilla suture; V, vomer; vbPm, ventral bulge of premaxillae.

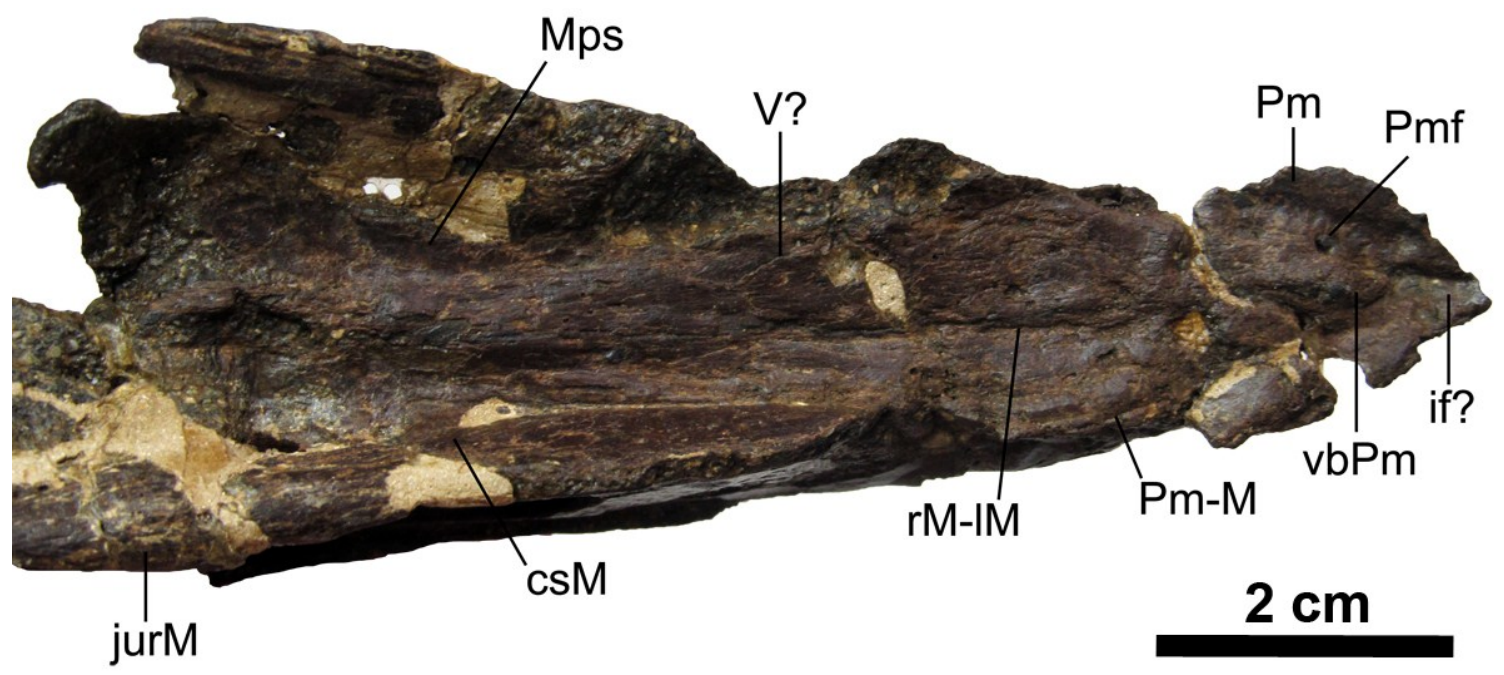


7c) that includes an open gap between the palatal shelves of the maxillae. Makovicky et al. (2004: 139) described the maxillary palatal shelves of Struthiomimus (no specimen specified) as perforated by "small, irregular foramina." ROM 1790 resembles this description, but it cannot be determined whether these irregular perforations are truly foramina, or the result of damage. Comparison to ROM 851 confirms that the choanae would have been beneath the antorbital fenestra, posterior to the preserved part of the palate, as was considered most likely by Russell (1972: 386). The contribution of the pterygoids to the preserved part of the palate is therefore unlikely, because in ornithomimosaurs, and theropods in general (Tsuihiji et al. 2014, fig. 7), the pterygoids are positioned posterior to the choanae, and do not contact the maxillae. A contribution from the vomers is possible, but, if present, their outlines are not as prominently defined as in TMP 1990.26.1 (Knutsen 2007, fig. 9), due to either crushing or fusion to the maxillae. Alternatively, the vomers may be absent or unpreserved on this part of the palate, as in the holotype of Garudimimus brevipes in which the contact of the maxillary palatal shelves is very long, and the questionably identified vomer is preserved only medial to the choanae (Kobayashi and Barsbold 2005a, fig.4e).

The nasals are paired, with a visible suture between the left and right elements. The nasals are straight along the dorsal edge of the skull, and are broadest posteriorly (fig. 2.7). The ventral surfaces of the nasals and a portion of the dorsal surface above the antorbital fenestra are poorly preserved. Each nasal has a single linear array of approximately eight small foramina on the dorsolateral surface, which are partly covered by the painted label on the right side. These foramina are 
FIGURE 2.7. Posterior preserved portion of the skull of ROM 1790 in oblique right dorsolateral view. Abbreviations: IF, left frontal; IN, left nasa; IPf, left prefrontal; M, right maxilla; rL, right lacrimal; rN, right nasal.

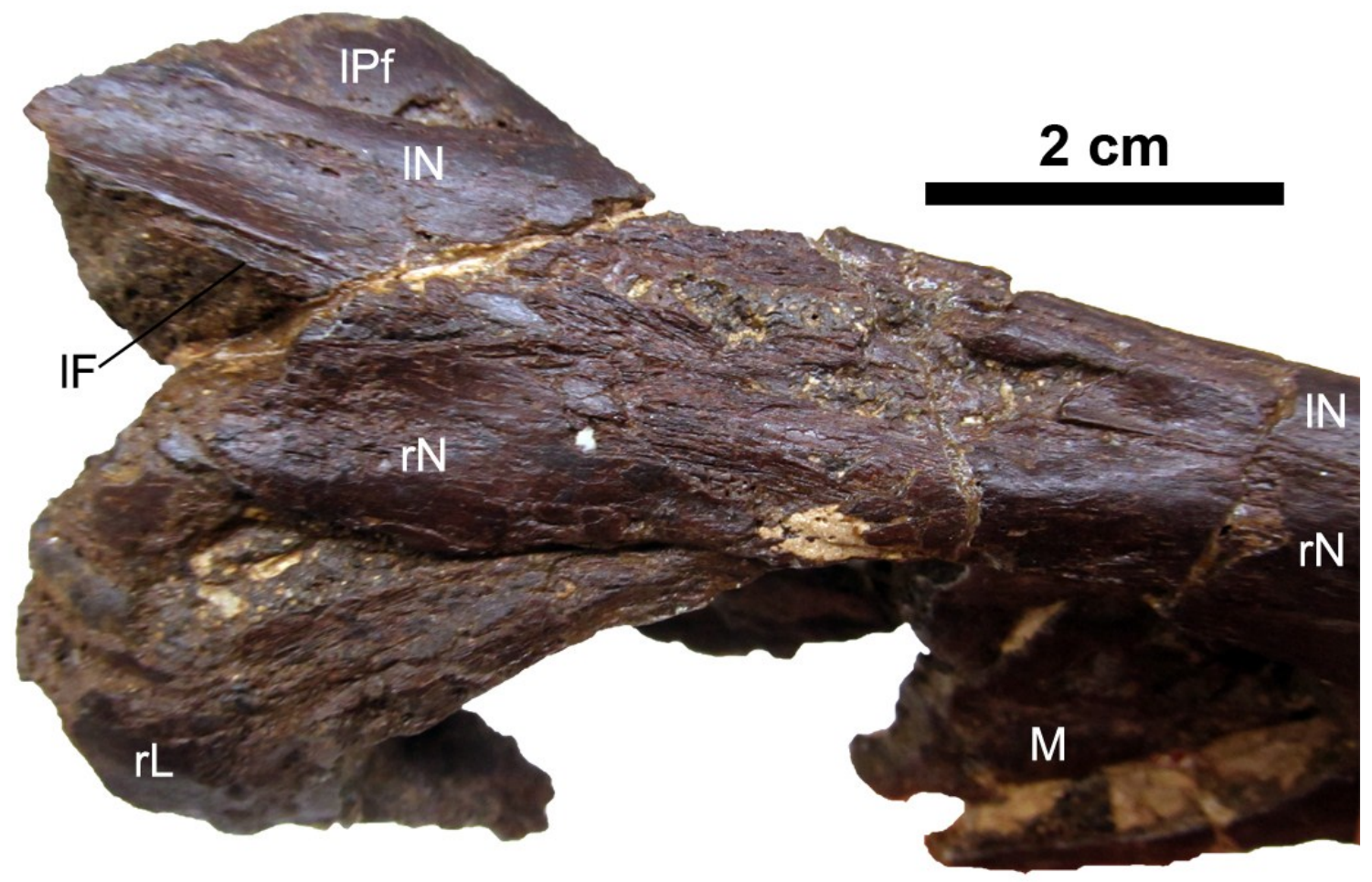


very prominent on the portion of the nasal adjacent to the maxilla, and are not present on the posterior portion of the nasal adjacent to the prefrontal. In Ornithomimus (ROM 840, ROM 851) and Struthiomimus (TMP 1990.26.1; Sereno 2001, fig. 13), these foramina may be more sparsely or irregularly positioned in the region above the maxillae.

Both lacrimals are present, but their surfaces are poorly preserved with a somewhat battered appearance. The left lacrimal is missing most of the anterior process. The main body of the lacrimal is inclined anteroventrally. The posterior surface of the lacrimal body is deeply concave, and the lacrimals are broader in posterior view than in lateral view. The lacrimal foramen indicated by Sereno (2001, fig. 13) in Struthiomimus was not observed. There is no lacrimal horn or crest, unlike Pelecanimimus (Pérez-Moreno et al. 1994: 364).

The prefrontals are poorly preserved, and are represented mostly by the anteromedial portion of the left prefrontal. The space between the right nasal and lacrimal contains only small fragments and sandstone matrix. The left prefrontal overlies the lacrimal, but is positioned more ventrally than the nasal (possibly due to displacement). A small sliver of bone $7 \mathrm{~mm}$ long and $1 \mathrm{~mm}$ wide, probably representing the anterior tip of the left frontal, is preserved adhering to the left nasal. Although the internasal suture is damaged over much of the region directly adjacent to the prefrontal, the prefrontal probably reached farther anteriorly on the dorsal surface of the skull than the frontal, as in Ornithomimus (ROM 851) and Struthiomimus (Knutsen 2007, fig. 8), but unlike Gallimimus as reconstructed by Osmólska et al. (1972, fig. 2b). 
The dorsal process of the palatine is unpreserved or unexposed in most ornithomimids, but it is visible laterally within the antorbital fenestra of several other ornithomimosaurs, including Deinocheirus (Lee et al. 2014), Garudimimus (Kobayashi and Barsbold 2005a), Shenzhousaurus (Ji et al. 2003), and Hexing (Jin et al. 2012). In ROM 1790, a part of this element is visible only from the right side of the skull. The preserved surface is bracket-shaped, with a vertical wall and short dorsal and ventral shelves. A pair of large foramina is present in the wall near the ventral shelf. The top of the palatine is approximately level posteriorly with a pinch in the maxilla that marks the separation of the narial passage from the antorbital sinus, and descends anteriorly. The palatine differs from that of Hexing (Jin et al. 2012), in which the dorsal process is taller and more hook-like. On the left side of the skull, fragmentary palatal elements are visible posteromedial to the lacrimal, in approximately the same plane as the dorsal process of the palatine (fig. 2.8). The more ventral surface is a vertical sheet that becomes more concave posteriorly, forming a cup-shaped concavity overhung by a dorsal shelf. This shelf is in turn overlain by the ventral surface of another shelf, such that the posterior cross-section resembles the character "3", but with the ventral cavity being more deeply incised. Although comparisons are limited by the variances in preservation between different ornithomimid specimens, these surfaces are thought to represent the bulbous capsule or bulla of the parasphenoid, which is present in the same anatomical position in Gallimimus (Osmólska et al. 1972, fig. 3a).

The dentaries are long, delicately constructed, and edentulous, as in other ornithomimids (fig 2.9). Both are crushed, with a thickness of approximately $2 \mathrm{~mm}$. 
FIGURE 2.8. Posterior preserved portion of the skull of ROM 1790 in oblique left ventrolateral view. Abbreviations: dcb, dorsal chamber of bulla; IL, left lacrimal; IM, left maxilla; MJc, area for of maxilla-jugal contact; Psb, parasphenoid bulla; rL, right lacrimal; rM, right maxilla; vcb, ventral chamber of bulla.

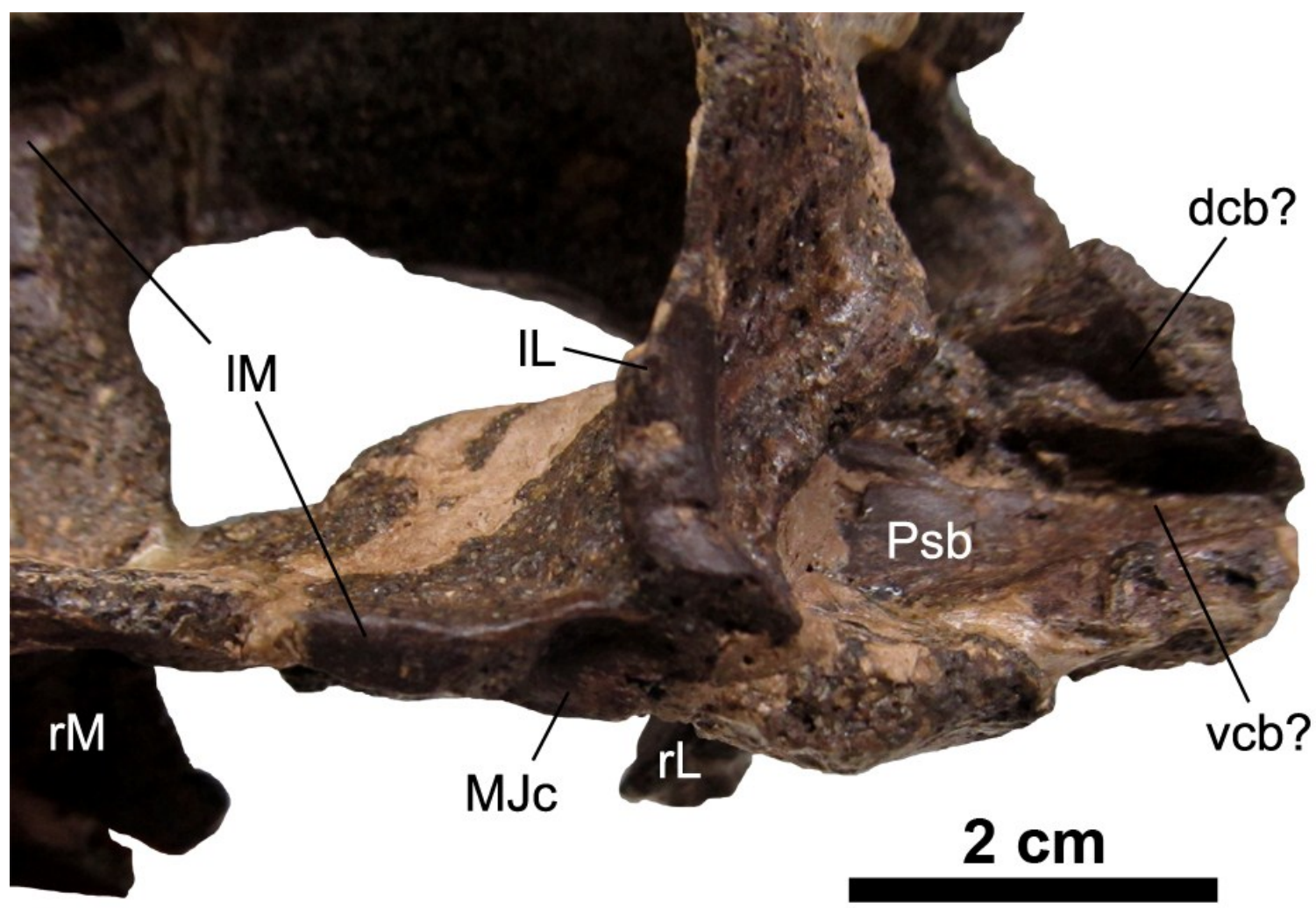


FIGURE 2.9. Dentaries of ROM 1790. A) right dentary in lateral view; B) right dentary in medial view; C) left dentary in lateral view; D) left dentary in medial view.

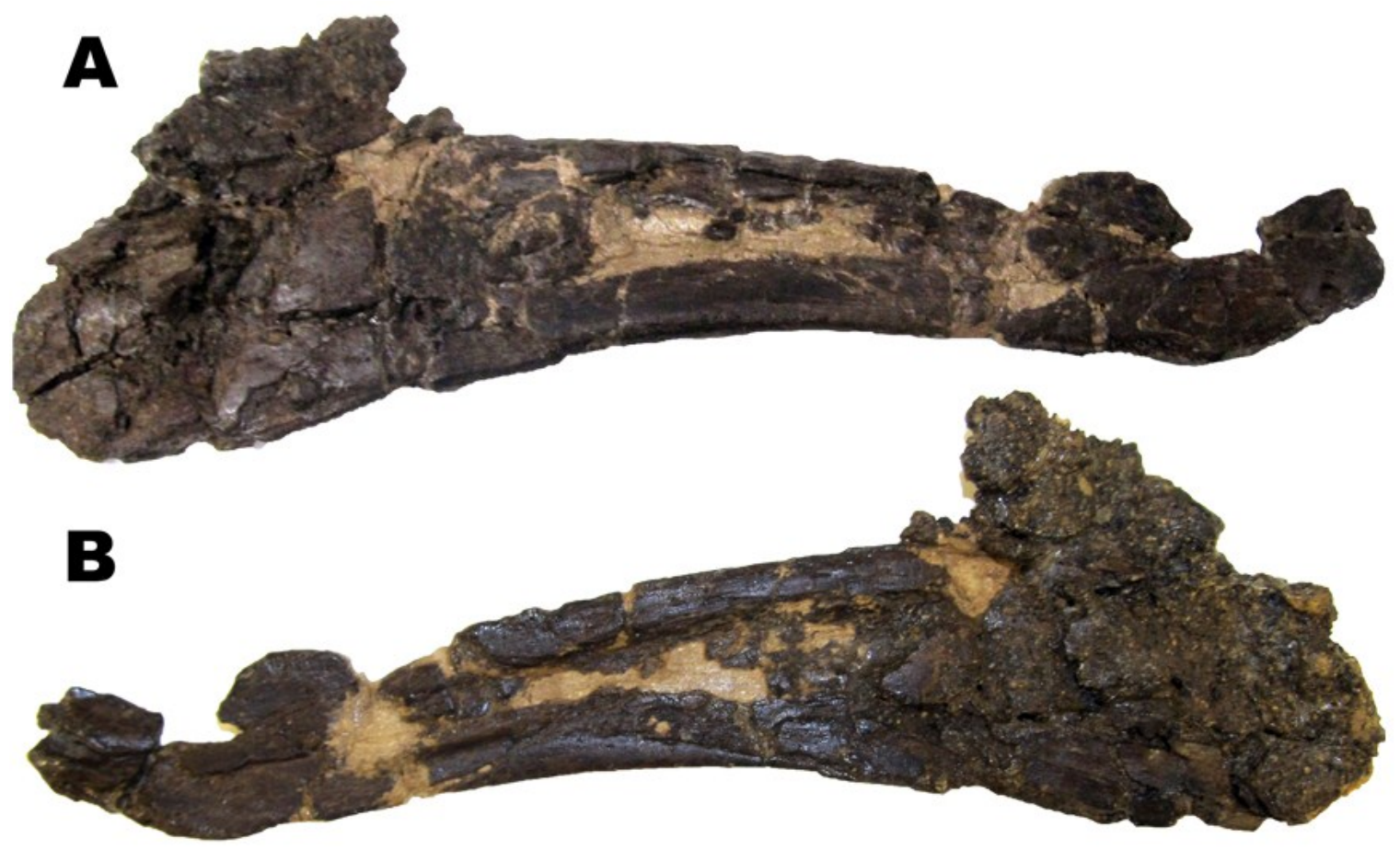

C

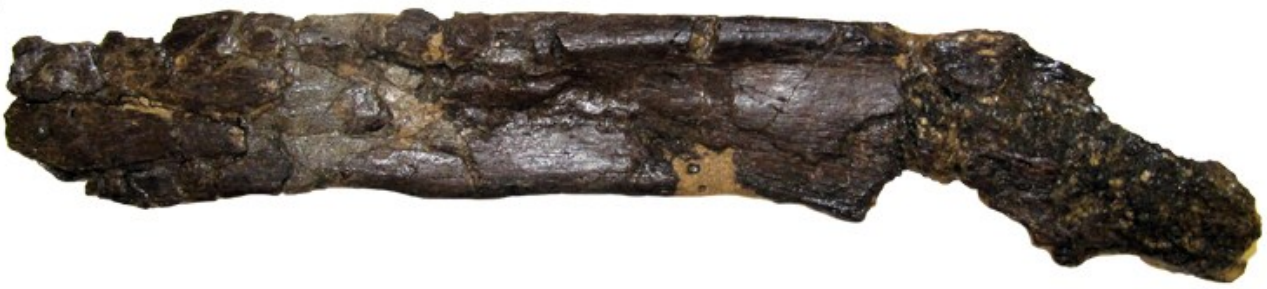

D

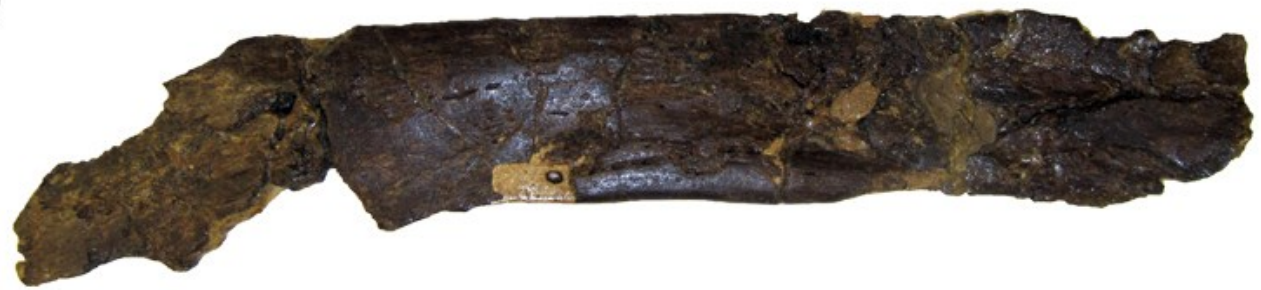

$5 \mathrm{~cm}$ 
The left preserved part of the left dentary has nearly parallel dorsal and ventral margins, while the right dentary deepens posteriorly. However, both elements can be identified and oriented as dentaries because they preserve the Meckelian groove on the medial surface, and the thickened dorsal rim on the lateral surface, as in other ornithomimids. In dorsal view, the dentaries are nearly straight. As preserved on the right dentary, the ventral prominence of the symphysis is relatively weak and rounded, as in the Ornithomimus specimen ROM 840. In some other specimens of Ornithomimus (ROM 851, TMP 1995.110.1) and Struthiomimus (Knutsen 2007, fig. 7), the ventral prominence is more sharply defined and shaped like an inverted dune. The lateral foramina on the dentary are relatively few in number and are restricted to the region that rests below the premaxilla, as in Ornithomimus (ROM 840, TMP 1995.110.1). In specimens referred to Struthiomimus (Osborn 1917, fig. 5a; Knutsen 2007, fig. 7), the foramina continue more posteriorly along the dentary, underlying the anterior part of the maxilla.

An unidentified bone fragment, measuring $43 \mathrm{~mm}$ by $8 \mathrm{~mm}$, is contained in the box with the skull of ROM 1790 (fig 2.10). It is a strap-like element with approximately parallel long edges, and a gentle curvature in the plane with the greatest compression. Its cross-section is triangular, with one long edge relatively thick $(3 \mathrm{~mm})$ and the other thin $(1 \mathrm{~mm})$. The thick edge has a lengthwise groove, possibly for articulation with another element, and the thin edge has a straight, flattened rim on the concave side. This fragment may be tentatively identified as part of a jugal or surangular. 
FIGURE 2.10. An unidentified bone fragment stored with the skull of ROM 1790, in four views.

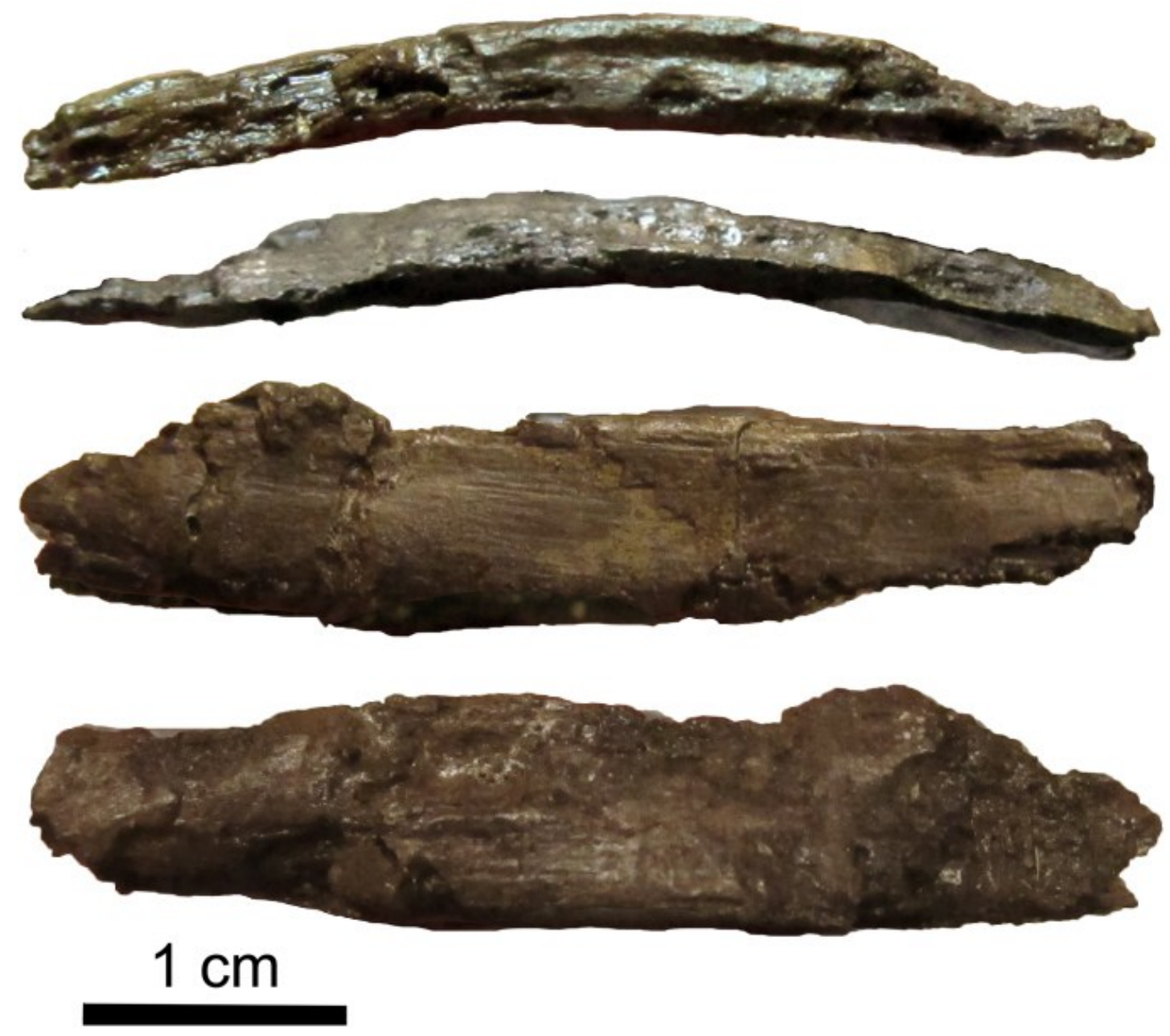


Vertebrae - The posterior part of the last dorsal vertebra is preserved in articulation with the sacrum. The spool-shaped centrum is crushed flat mediolaterally, and the neural arch does not have any features preserved.

There are six sacral vertebrae, as in other ornithomimids (Makovicky et al. 2004: 142). The complete sacrum measures approximately $359 \mathrm{~mm}$ as preserved. The vertebrae are slightly out of alignment, with the fifth centrum being tilted on an angle between the more dorsally elevated, dorsoventrally crushed fourth centrum and the less elevated, mediolaterally crushed sixth centrum. As for the last dorsal, the first sacral is crushed mediolaterally, and little morphology can be distinguished.

The ventral surface of the first sacral centrum is concave in lateral view, and flat on its ventral surface. The transverse processes project dorsolaterally to contact the ilia. The second sacral centrum is deeply excavated laterally and preserves a thick lamina along the ventrolateral border of the centrum, as in other ornithomimids (Makovicky et al. 2004: 142). The ventral surface of the second sacral is flat anteriorly, but develops a shallow, posteriorly broadening midline groove in its posterior half. The badly crushed third and fourth sacrals are only exposed ventrally, and preserve no morphological features. They are medial to the pubic and ischial peduncles, respectively. The fifth sacral is damaged anteriorly and ventrally. Like the second sacral, it has a thick ventrolateral border. A poorly preserved depression dorsal to this border may correspond to a pneumatic fossa, which is well-defined on the fifth sacral vertebra of at least some other ornithomimids, including Struthiomimus (UCMZ 1980.1). The sixth sacral is extremely crushed mediolaterally (only a few millimetres thick), resembling the 
condition of the first sacral, but without a flat ventral surface. There is no indication of a ventrolateral lamina or a well-developed lateral fossa, and the neural arch is very poorly preserved. The neural spine does not contact the ilia or the neural spines of the preceding sacrals, which are hidden between the ilia.

The first caudal vertebra and an anterior fragment of the second are preserved in articulation with the sacrum. These vertebrae are very poorly preserved and crushed mediolaterally. As preserved, the ventral edge of the first caudal is nearly straight in lateral view. The lateral surface does not show any evidence of a fossa. The transverse processes of the first caudal are angled upwards, but do not contact the ilium.

At least fourteen additional caudals are preserved in semi-articulation (Fig. 2.11). However, they cannot be articulated with the first two caudals, and thus their numerical positions cannot be established with certainty.

The three most proximal free caudals are disarticulated, poorly preserved, and mediolaterally crushed (Fig. 2.11 A-C). The centra are weakly spool-shaped, and do not preserve any evidence of lateral fossae or laminae. The neural arches are warped and partially reconstructed, but the orientation of the transverse processes is generally dorsolateral. On the third of these caudals, the right transverse process is oriented strongly dorsolaterally and the left is oriented laterally, as preserved. The neural spine is sheet-like and positioned posteriorly on the arch. At least as far back as the third of these caudals, the postzygapophyses are a pair of small, laterally-directed surfaces at the posteroventral corner of the neural spine. 
FIGURE 2.11. Caudal vertebrae of ROM 1790 in left lateral view. Letters refer to the vertebrae identified in the text.
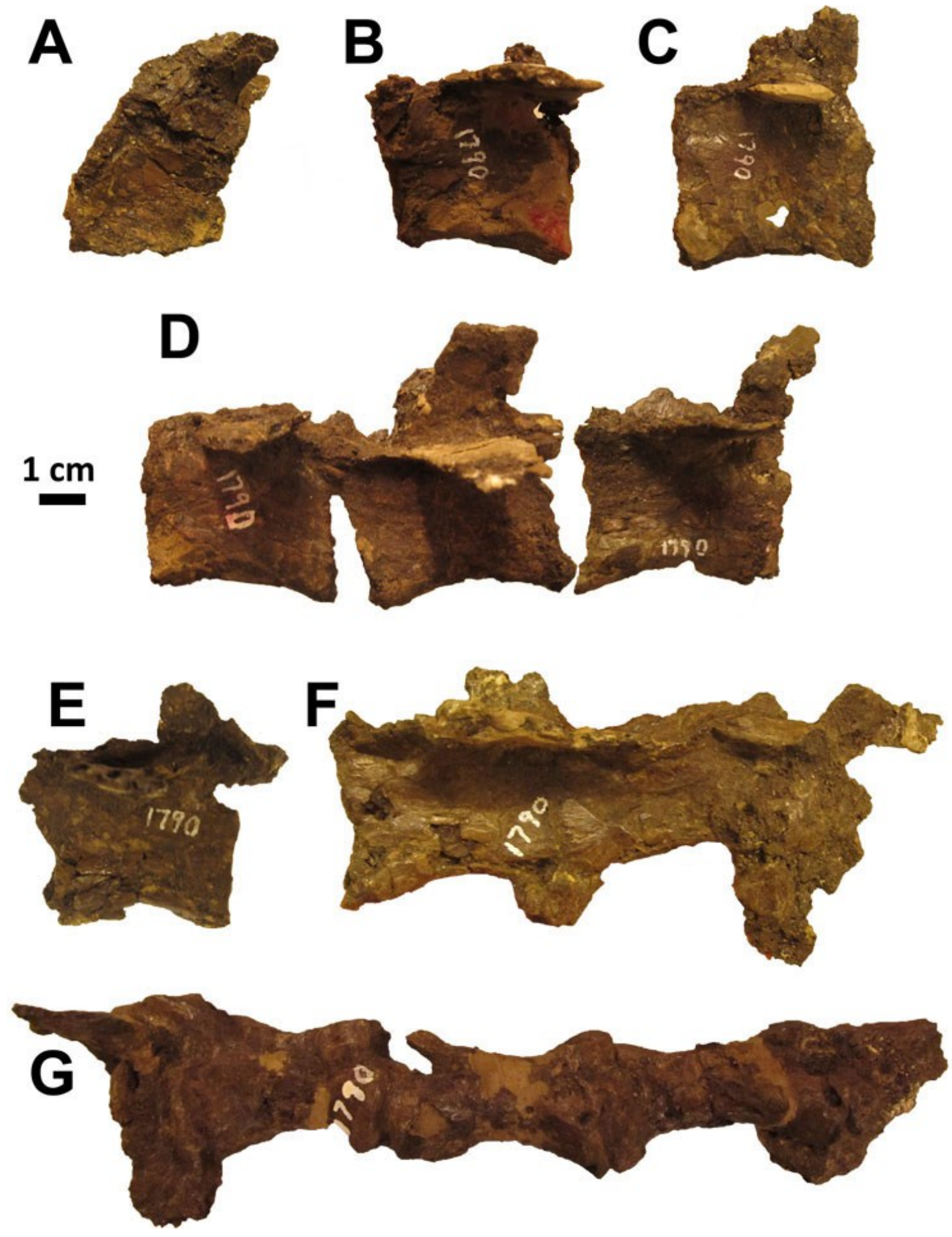
The next three vertebrae form an articulated series (Fig. 2.11 D), followed by an unattached fourth vertebra (Fig. 2.11 E). They all have a similar morphology, with the centra being crushed mediolaterally. The transverse processes have a similar range of elevations and are posteriorly swept. The transverse processes are asymmetrically developed on the fourth vertebra, but it is possible that this is an artifact of preparation. The neural spine is best preserved on the second of these vertebrae, where it is more than half as long as the centrum and inclined posteriorly. On the third and fourth of these vertebrae the neural spine is anteroposteriorly shortened and restricted to the posterior third of the neural arch, but the spine is poorly preserved and its unusual shape (which is not seen in other ornithomimid caudals) may be due to breakage. From at least the second of these vertebrae onwards (the first is poorly preserved), the postzygapophyses are joined into a single block that is wider than tall, and is extended posteriorly of the rest of the neural arch.

The following two crushed vertebrae and an anterior fragment of a third are attached with fragments of the chevrons in place (Fig. 2.11 F). The second centrum is longer and lower than the first. The transverse processes are horizontal and the neurocentral sutures are visible. The neural spine is vertical and subrectangular on the first of these vertebrae, but much lower on the second. On the third of these vertebrae, the prezygapophyses are moderately elongate, overlapping approximately $20 \%$ of the preceding centrum. 
The final section of articulated caudal vertebrae consists of a posterior centrum fragment, three complete vertebrae, and an anterior centrum fragment (Fig. 2.11 G). Proximal chevron fragments are attached in articulation between the first and second, and the fourth and fifth of these vertebrae. The spool-shaped centra are relatively elongate and are not as crushed mediolaterally as the more proximal caudals, though some restoration on the centra is visible. The prezygapophyses are moderately elongate, overlapping approximately $20 \%$ of the preceding centra lengths, except on the third vertebra where they are incompletely preserved. The prezygapophyses have deep bases that arise from the proximal half of each neural arch and contribute to a distinct shelf above the centrum, especially visible on the right side of the second vertebra. The second vertebra also has a small transverse process on the posterior half of its neural arch. The transverse process is absent on the more distal vertebrae, though its absence on the third vertebra is ambiguous due to restoration on the middle of the vertebra, at the approximate location of the final, greatly reduced transverse process in Ornithomimus (CMN 12228, TMP 1995.110.1) and Struthiomimus (AMNH 5339). Neural spines are very low and mound-like, and arise posteriorly on the neural arches. This differs from Ornithomimus (CMN 12228, TMP 1995.110.1) and Struthiomimus (AMNH 5339), in which the neural spines over the transition point, although low, are rectangular and sheet-like, and cover most of the length of the neural arch (excluding the zygapophyses). 
Pelvis - The pelvis is propubic, as in other ornithomimids. All of the pelvic elements are preserved, but incomplete (Fig. 2.12). The pelvic elements are fused around the acetabulum, which has been interpreted as a feature of adult ornithomimids (Makovicky et al. 2004: 144). The acetabulum is slightly taller than wide. The length of the contact between the ischial peduncle and the ischium is very short, approximately $20 \mathrm{~mm}$, compared to approximately $55 \mathrm{~mm}$ for the pubic peduncle and the pubis, and approximately $35-40 \mathrm{~mm}$ for the ischial peduncle in the similar-sized Ornithomimus specimens ROM 797 and ROM 851.

The ilia are very long and low, with the maximum height above the acetabulum being approximately one quarter of the ilium length. The dorsal margins of the ilia are joined along their preacetabular processes and over the acetabulum, concealing the sacral neural spines. The extreme narrowness of the pelvis lateromedially along the fossa iliaca dorsalis is interpreted as an artifact of fossilization. As in other ornithomimids, the brevis fossa is well developed, and hidden by the overhang of the postacetabular process in lateral view. The preacetabuluar process (best preserved on the right) and postacetabular process (best preserved on the left) are subequally developed. Although the standardized measurement of the antilium as defined by Russell (1972: 378) cannot be exactly obtained, because neither ilium preserves the anteroventral corner of the cranial process, it is estimated to be approximately $150 \mathrm{~mm}$. This is proportionately long compared to other Canadian ornithomimids (over $37 \%$ of the femur length) and potentially distinct from Struthiomimus, which generally has a shorter antilium than Ornithomimus (Russell 1972, but see also Nicholls and Russell 1981). 
FIGURE 2.12. Pelvis of ROM 1790. A) Pelvis with articulated vertebrae in left lateral view, B) Pelvis with articulated vertebrae proximal right femur in right lateral view, C) Pelvis in dorsal view, D) Pelvis and sacrum in ventral view, E) Shaft of pubis in left lateral view, F) Pubic apron in anterior view, G) Shaft of ischium in left lateral view.

A

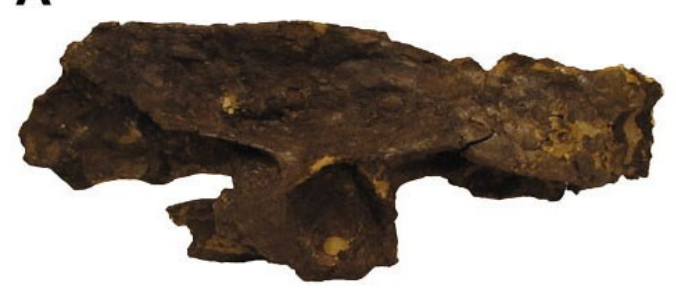

C

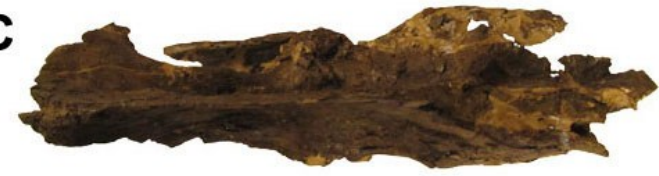

D

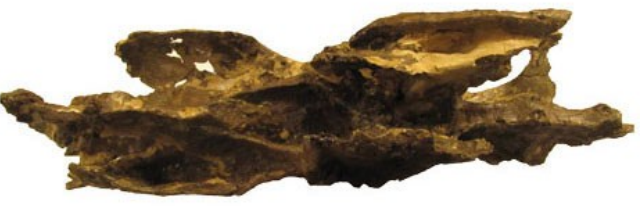

B

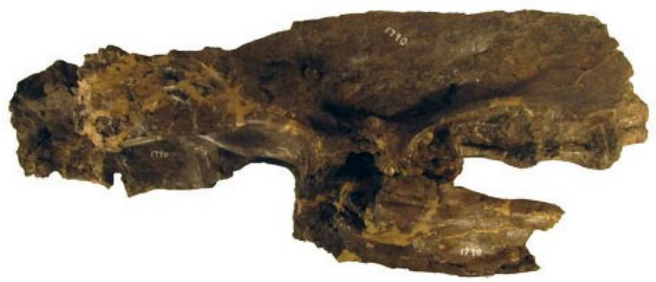

$\mathrm{E}$

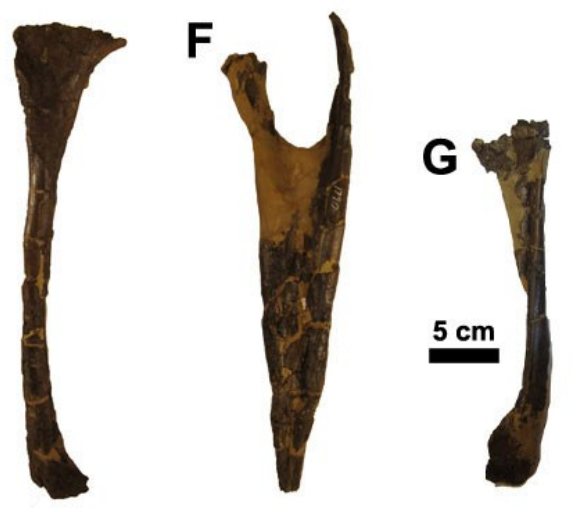


The broken surfaces of the pubic fragments attached to the ilia can be reconnected to the conjoined pubic shafts, indicating that only the distal ends of the pubes are missing. The proximal portion of the right pubic shaft and the pubic apron are poorly preserved and heavily restored, but there does not appear to have been a pubic foramen beneath the apron. The pubic shafts are nearly straight. The rearward distal expansion of the pubic shafts indicates that the distal break occurred near the start of the pubic boot. When the pelvic fragments are assembled, the distal end of the pubic shaft (excluding the expanded boot) projects approximately as far cranially as the anterior end of the right ilium, as in Ornithomimus (CMN 12068, CMN 12228, ROM 851, ROM 852, TMP 1995.110.1), rather than well beyond the ilium, as in Struthiomimus (AMNH 5339, UCMZ 1980.1).

The ischia are similarly represented mainly by their conjoined shafts that can be reconnected to the proximal ischial fragments still attached to the ilia, and the end of the ischial boot is missing. The extensive ischial apron is V-shaped, opening posteriorly, with its apex at the obturator process. The distal contact between the right and left ischium is unusual in being convex and completely fused along the posterodorsal surface. In Ornithomimus (AMNH 5201, ROM 797, ROM 851, ROM 852) and Struthiomimus (CMN 930, UCMZ 1980.1), the ischial shafts are separated by a well-defined cleft along their posterodorsal contact.

Hindlimb - Both femora are preserved. The incomplete right femur is broken in two fragments, the more proximal of which is attached to the pelvis in articulation with the acetabulum. Although these fragments cannot be perfectly 
reattached, the length lost between them is estimated to be minimal. The top of the lesser trochanter is lower than the greater trochanter. The shaft of the right femur is crushed inward from the lateral side, but the medial side of the shaft is better preserved and its cross-section has a distinct, angular corner where the medial surface meets the posterior surface below the fourth trochanter. The distal end of the right femur is missing. The left femur is nearly complete, except for the missing lesser trochanter, but it is crushed mediolaterally (Fig. 2.13). The femur is curved in lateral or medial view. The left femoral head and greater trochanter are poorly preserved. The fourth trochanter is a low but prominent lamina on the medial side of the upper third of the femur that ends in an expanded rugosity. As in other ornithomimids, there is a distinct oval muscle scar on the upper medial side of the femur anterior to the fourth trochanter, which has been interpreted as the insertion of the mm. pubo-ischio-femoralis (Osmólska et al. 1972). There is no indication of the accessory trochanter on the distal posteromedial surface of the femur, but this feature may be obscured because the shaft is crushed inwards from the medial side. Distally, the lateral condyle is larger than the medial one, but their margins are poorly preserved. The intercondylar fossa is deep, as in other ornithomimids. A shallow lengthwise groove is present on the outer surface of the distal femur above the lateral condyle.

The tibiae are represented by an incomplete distal portion of the right tibia, and the nearly complete, but crushed left tibia (Fig. 2.14). The tibia is longer than the femur, and noticeably stouter than tibiae of some Horseshoe Canyon Formation specimens of Ornithomimus, including ROM 797 and ROM 851. Proximally, the 
FIGURE 2.13. Left femur of ROM 1790 in A) lateral, B) medial, C) anterior, D) posterior, E) proximal, and F) distal view.

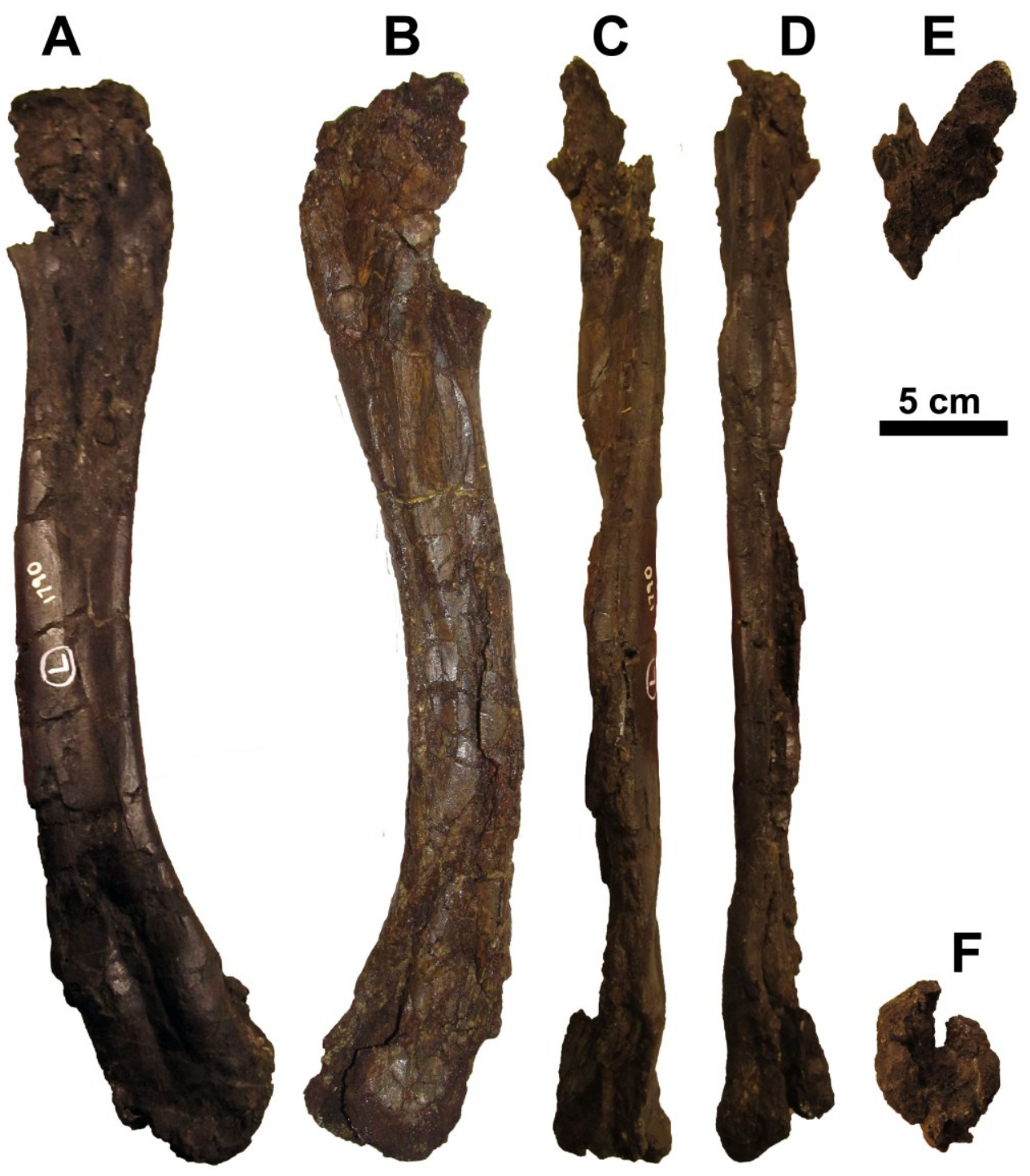


FIGURE 2.14. Left tibiotarsus and fibula of ROM 1790 in A) lateral, B) medial, C) anterior, D) posterior, E) proximal, and F) distal views. Abbreviations: as, astragalus; cc, cnemial crest; fi, fibula.

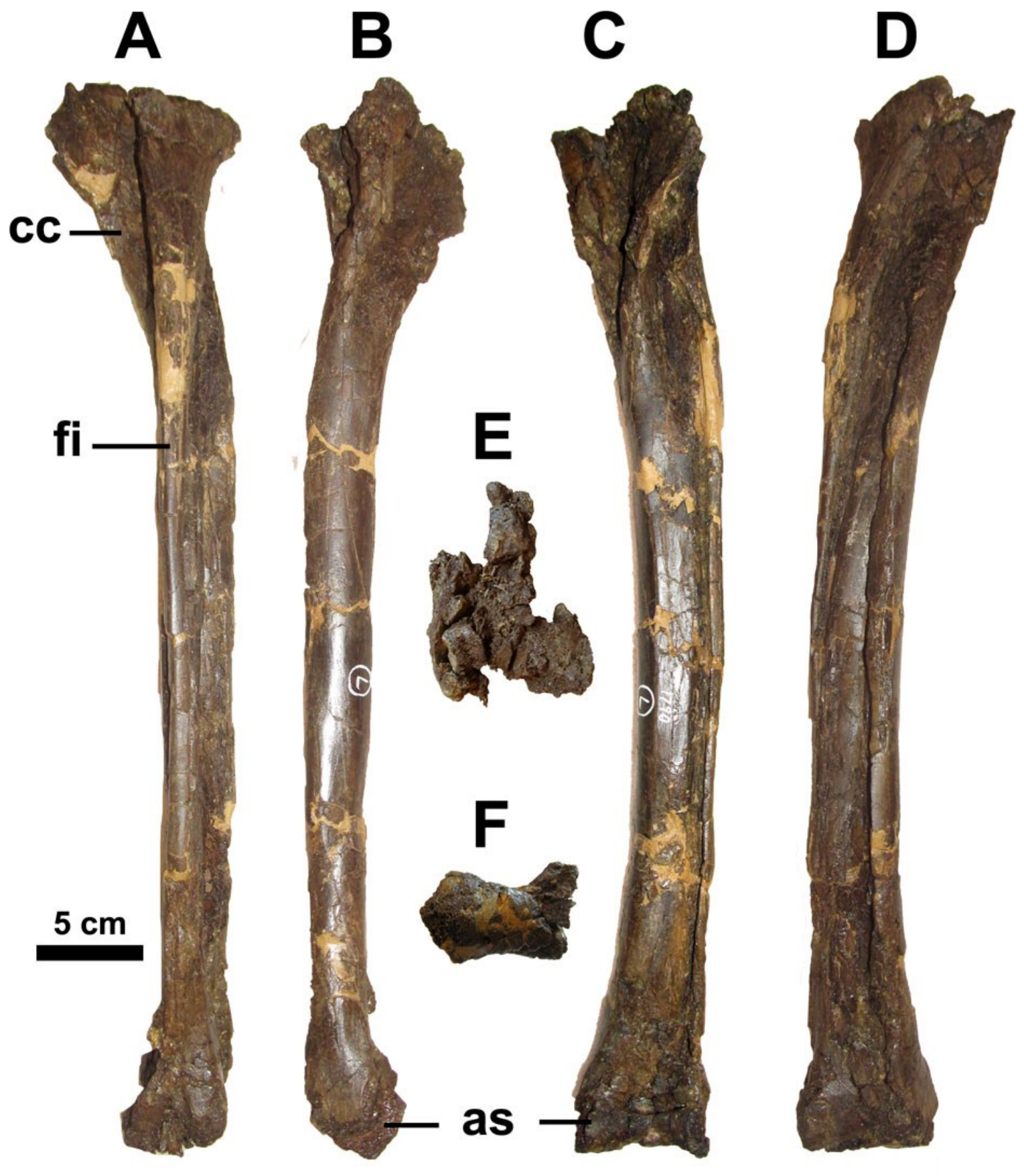


outline of the left tibia is distorted, with the medial condyle displaced anteriomedially so that it projects almost perpendicular to the cnemial crest, rather than approximately parallel as expected in ornithomimids. Despite this distortion, the medial condyle may still be distinctive in being noticeably larger than the lateral condyle, and more developed than in other ornithomimids including Archaeornithomimus (AMNH 6576), Sinornithomimus (Kobayashi and Lü 2003, fig. 22e), Gallimimus (Osmólska et al. 1972, fig. 15b), Qiupalong (Xu et al. 2011, fig. 4), Ornithomimus (AMNH 5201, ROM 851), and Struthiomimus (AMNH 5385). The cnemial crest is well developed, but its precise shape is obscured by poor preservation. The fibular crest is positioned high on the tibia and forms a long blade, as in Ornithomimus (AMNH 5201, ROM 851), Struthiomimus (AMNH 5385, UCMZ 1980.1), Qiupalong (Xu et al. 2011, fig. 4), and Gallimimus (ROM 21704, cast), rather than a short peak as in Archaeornithomimus (AMNH 6576) and "Ornithomimus" antiquus (AMNH 11039, cast). The nutrient foramen on the tibia described by Osmólska et al. (1972: 130) for Gallimimus was not observed. The complete tibia is weakly bowed out laterally, which could be attributed to distortion, but such bowing is observed in some other ornithomimid tibiae (AMNH 5385, AMNH 6576). The distal end of the tibia is expanded medially, as in other ornithomimids, but lacks the pronounced rounded flange observed in some ornithomimosaur taxa, including Harpymimus (Kobayashi and Barsbold 2005b, fig. 9e) and the basal ornithomimid Archaeornithomimus (AMNH 6576).

The fibulae are fragmentary and are preserved attached to their respective tibiae. Little of the right fibula remains, but the more complete left fibula can be seen 
to be similar to that of other ornithomimids. The fibula is expanded proximally with a maximum width of $55 \mathrm{~mm}$. The proximal expansion is asymmetrical, with the posterior corner being more expanded. The slender fibular shaft has a diameter of $9.5 \mathrm{~mm}$ and contacts the anterolateral side of the tibia. Its contact with the tarsus is not preserved.

The proximal tarsals are poorly preserved. The anteroventral corner of the right calcaneum is visible, but only fragments of the left calcanear region remain. The ascending process is only fragmentarily preserved on either astragalus. The contact between the astragalus and the distal tibia is clearly visible in medial view, but surprisingly not in posterior view on either leg (Fig. 2.15). The suture between the tibia and astragalus is often conspicuous in posterior view in specimens of Ornithomimus (ROM 851, ROM 852, TMP 1995.110.1) and Struthiomimus (AMNH 5257, AMNH 5385, UCMZ 1980.1), as well as in other ornithomimosaurs (Osmólska et al. 1972, Smith and Galton 1990, Kobayashi and Barsbold 2005a), but it is indistinct in the Ornithomimus brevitertius holotype ROM 797 and the Struthiomimus altus holotype CMN 930. Parks (1933: 11) described the astragalus of ROM 851 as "firmly fused to the tibia as in most dinosaurs," but, although the individual bones cannot be separated in that specimen, they retain an open suture. Complete closure of the posterior tibia-astragalus suture is rare in non-avian coelurosaurs, and has not been previously reported in Ornithomimidae, but also occurs in the alvarezsaurid Albinykus (Nesbitt et al. 2011).

Both metatarsi are preserved in articulation with attached distal tarsals, but the latter are very poorly preserved and no anatomical details can be distinguished. 
FIGURE 2.15. Distal end of right tibiotarsus of ROM 1790 in A) posteromedial and B) posterolateral views, showing fusion of the astragalus to the tibia. C) right tibia and astragalus of UCMZ 1980.1 (Struthiomimus altus) in posteromedial view, showing a distinct suture between these elements. Abbreviations: as, astragalus; ti, tibia.
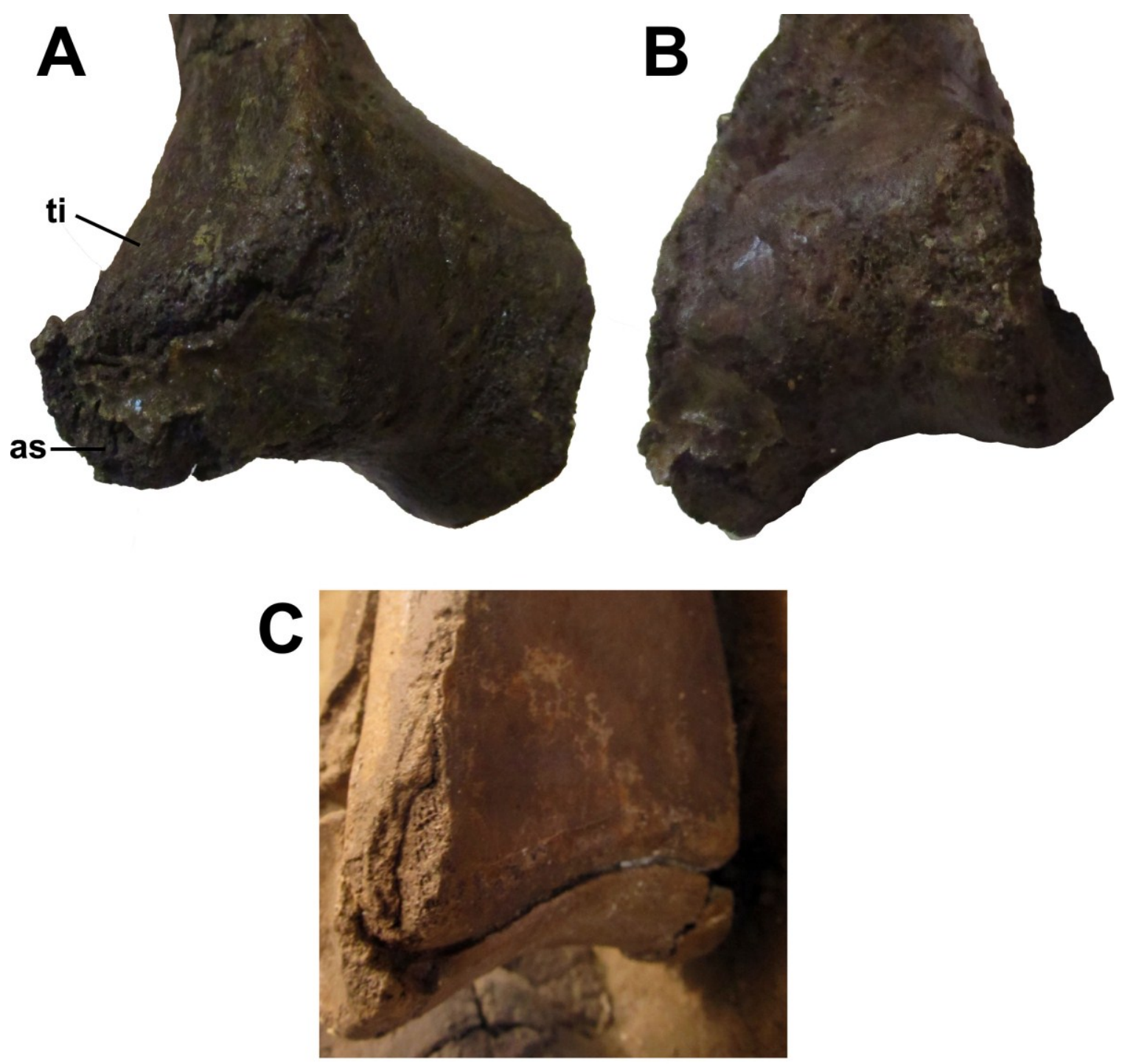
The poorly preserved right metatarsus is distorted proximally and is missing its distal end, while the left metatarsus is nearly complete (Fig. 2.16). As in other ornithomimids, the pes is fully arctometatarsalian and the first digit is absent. The second metatarsal is the shortest of the three metatarsals that bear phalanges, with its distal condyles entirely proximal to the distal condyle of the third metatarsal. The third metatarsal is the longest of the pes, but it is not completely preserved proximally on either side. The distal portion of the third metatarsal has a relatively straight medial border in anterior view, similar to Ornithomimus (CMN 8632, CMN 12228, ROM 797, ROM 851, TMP 1995.110.1), and differing from the strongly concave and sinuous medial border of the third metatarsal in Struthiomimus (AMNH 5339, AMNH 5385, UCMZ 1980.1). The small lateral process of the third metatarsal medial to the end of the fourth metatarsal is weakly distinguished. The shape of the third metatarsal in distal view is unique among ornithomimids in that it is deepest along its lateral edge and shallowest along its medial edge, with a straight posterior edge. There is no concavity on the posterior surface of the condyle. This differs from the distal outline of the third metatarsal in both Ornithomimus (AMNH 5201, CMN 8632, ROM 797, ROM 852), which has a deep, but narrow, medial condyle separated from a broader, flatter lateral condyle, and Struthiomimus (AMNH 5385, CMN 930), which is also deepest medially, but has subequal lateral and medial condyles separated by a concavity. The fourth metatarsal has a flared lateral condyle and a shallow collateral ligament fossa, as in other ornithomimids. The rudimentary fifth metatarsal is straight proximally and bends towards the fourth metatarsal at midlength. 
FIGURE 2.16. Left metatarsus of ROM 1790 in A) anterior (extensor), B) posterior (flexor), C) lateral, D) medial, E) proximal, and F) distal views. Abbreviations: dt, distal tarsal, MtII-V, metatarsals II to V.

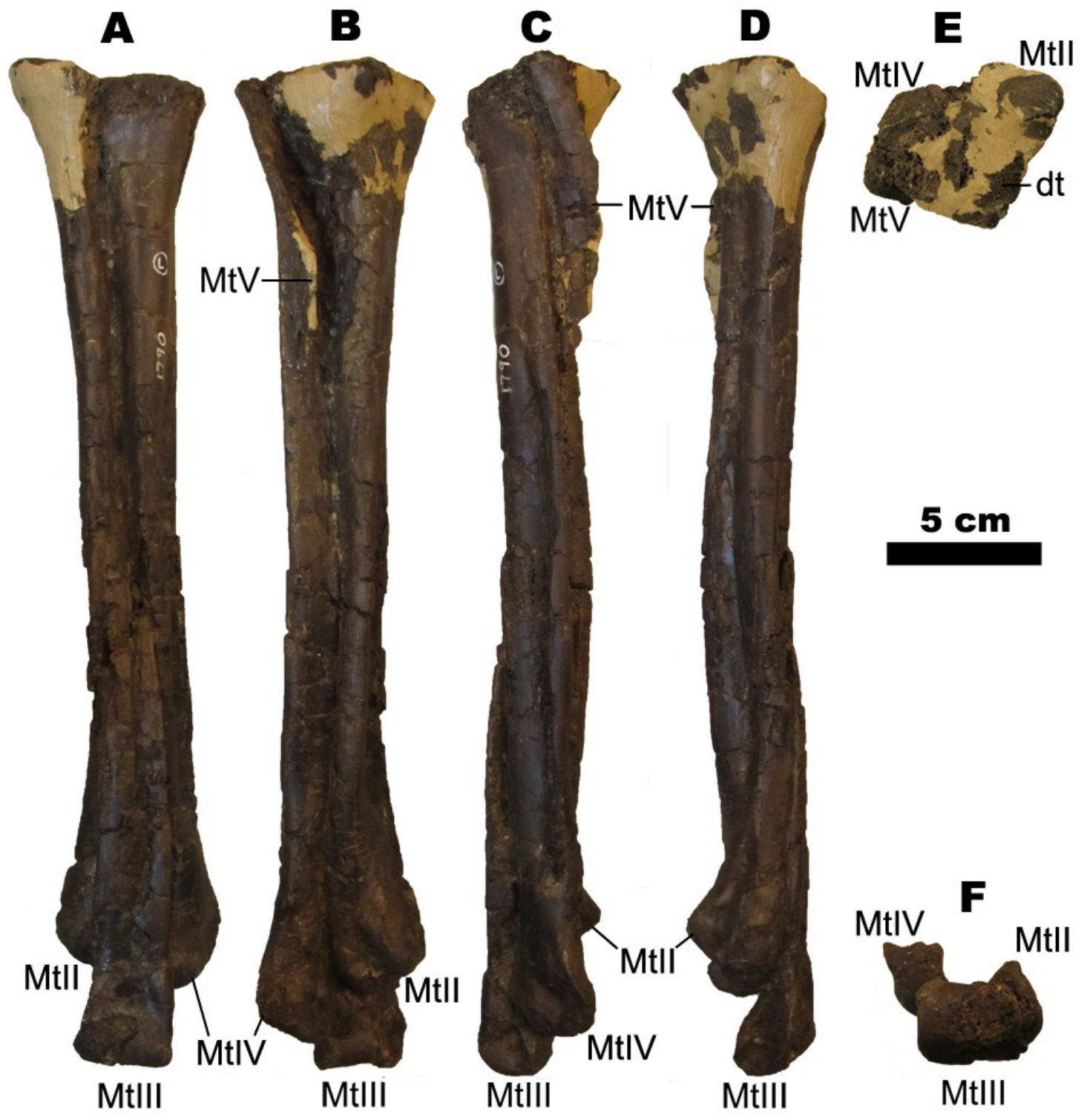


As preserved, the distal end of the left fourth metatarsal fits closely against the third metatarsal in anterolateral view, differing from the condition of a distally divergent fourth metatarsal described by Parks (1933) for some specimens of Ornithomimus (ROM 851, ROM 852), but this divergence is absent in others (CMN 8632, ROM 797). In posterior view, the left second and fourth metatarsals are preserved in contact distally to the end of the second metatarsal, which differs from the shorter contact length observed in other ornithomimids, including Ornithomimus (ROM 851, ROM 852) and Struthiomimus (AMNH 5339, CMN 930). However, the more extensive distal contact between the second and fourth metatarsals may be an artifact of the crushing. The presence or absence of a divergent fourth metatarsal may also be attributable to preservational, rather than biological, variation.

Only left pedal phalanges are preserved, but all of these elements are represented with the exception of phalanx II-1. The length of phalanx "II-1" was included in the principal component analysis by Cullen et al. (2013, table S3), but their measurement is anomalously short for an ornithomimid of this size, and may have been mistakenly taken from a different phalanx. Phalanx II-2 has a D-shaped proximal articular facet with a slightly more vertical medial edge, as in Struthiomimus (CMN 930), whereas this surface is more pear-shaped with a constricted dorsal portion in Ornithomimus (CMN 8632). A faint vertical ridge divides the proximal articular facet almost symmetrically. Collateral ligament pits are present medially and laterally. The distal articular facet is weakly ginglymoid, 
with a medial condyle that has a longer ventral surface than the lateral condyle (Fig. 2.17).

All non-ungual phalanges of the left digit III are essentially complete, but phalanx III-1 has a crushed and poorly preserved proximal articular facet, and a small amount of restoration on the shaft. Phalanx III-1 is deep proximally, with a pair of well-developed ventral ridges at the lateral and medial corners that converge at the middle of the shaft, defining a triangular depression on the proximal half of the ventral surface. The hyperextensor pit is a smaller depression that occurs in the distal half of the dorsal surface, proximal to the non-ginglymoid distal articular facet. Collateral ligament pits are strongly developed on all non-ungual phalanges of digit III. The distal articular facet is broader than the shaft of the phalanx at midlength, giving it an hourglass shape in dorsal/ventral view. Phalanx III-2 has similar characteristics to phalanx III-1, but is proportionately less elongate, and the ventral keels are much fainter. The shape of the proximal articular facet is subrectangular for its ventral half, with a weakly concave ventral edge and nearly vertical medial and lateral edges, and approximately semicircular for its dorsal half, thus having distinct dorsomedial and dorsolateral inflection points. A similar condition is observed in Ornithomimus (CMN 8632) and another specimen that Russell (1972) referred to Struthiomimus (CMN 8902), whereas in other specimens of Struthiomimus (AMNH 5355, CMN 930) the proximal articular facet of phalanx III-2 has more uniformly sloping sides without distinct inflection points. The distal articular facet is weakly indented between the condyles. Phalanx III-3 has a Dshaped proximal articular facet with rounded corners. The distal articular facet is 
FIGURE 2.17. Left pedal phalanges of ROM 1790.

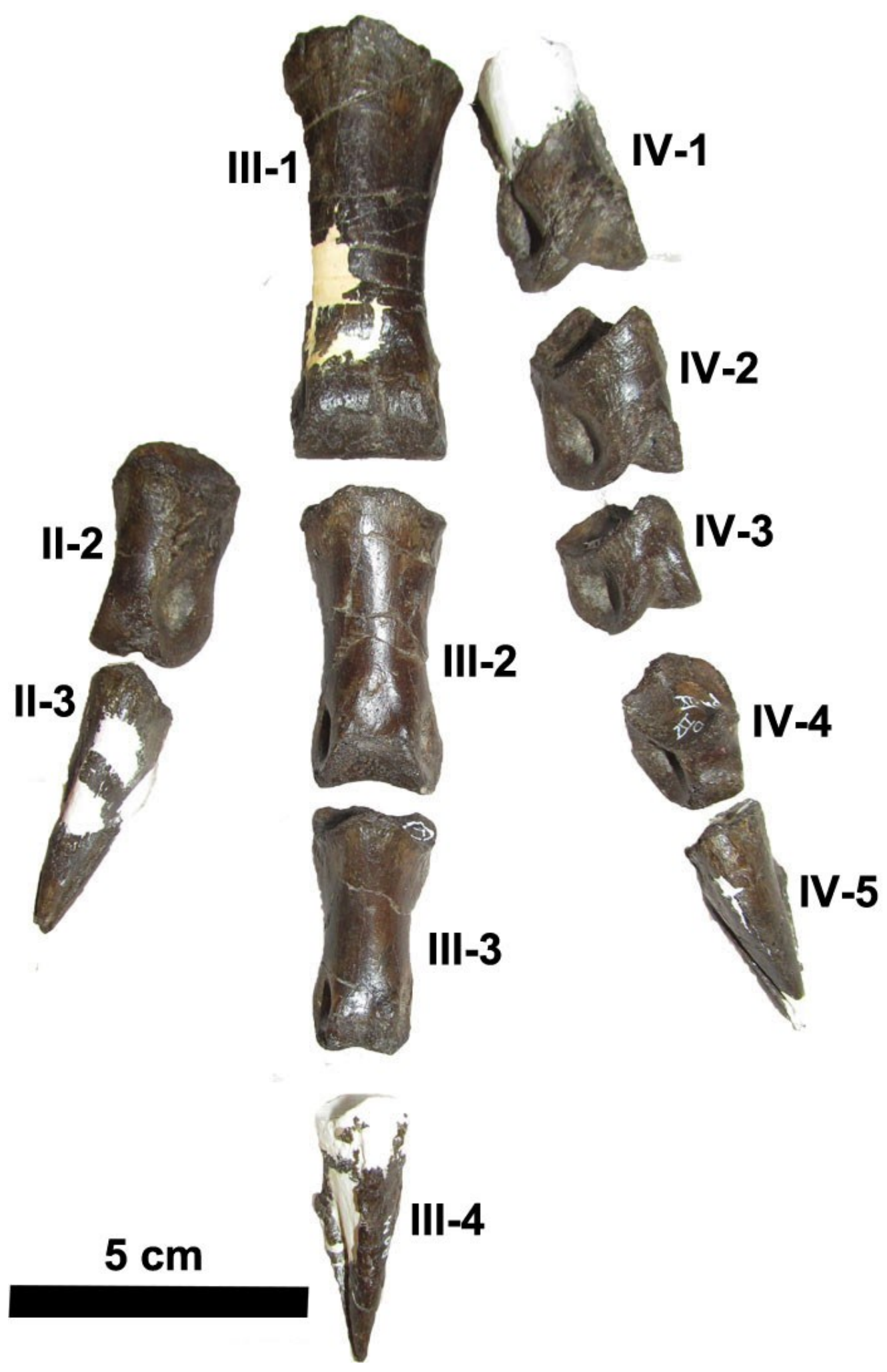


weakly ginglymoid, and the same width as the phalanx at mid-shaft. Unlike the more proximal phalanges of digit III, there is no hyperextensor pit.

The non-ungual phalanges of the left digit IV are essentially complete with the exception of phalanx IV-1, which is partially crushed and is missing its proximal articular facet. The proximal articular facets of phalanges IV-2, IV-3, and IV-4 are Dshaped with rounded corners, and have vertical ridges dividing the concave articular surfaces. The distal articular facets of the non-ungual phalanges of digit IV are strongly asymmetrical, with a medial condyle that is deeper and more slanted than the lateral condyle. Phalanges IV-1, IV-2, and IV-3 are strongly ginglymoid with an angular junction between the dorsal ridges of the condyles, but the groove between the condyle is poorly developed in phalanx IV-4, in which the distal end is curved dorsally. The ventral surfaces of the condyles are pronounced. The phalanges are successively abbreviated distally, with the extreme condition attained in phalanges IV-3 and IV-4 of the collateral ligament pits covering essentially the entire length of the phalanx. This condition is also seen in the holotype of S. altus (CMN 930), but is not as extreme in other specimens of that species (AMNH 5339, UCMZ 1980.1). The collateral ligament pits on all of the non-ungual phalanges of digit IV are shallower on the lateral side than on the medial side.

All of the left pedal unguals (phalanges II-3, III-4, and IV-5) are preserved, but parts of their surfaces have been restored (Fig. 2.18). The proximal articular facet is preserved on ungual II and partially preserved on ungual IV. On ungual II, the proximal articular facet is tall and subpentagonal, resembling Struthiomimus (CMN 930), and differing from the somewhat more rounded facet with a concave 
FIGURE 2.18. Pedal unguals of ROM 1790. Pedal ungual II-3 in A) lateral, B) proximal, and C) ventral view. Pedal ungual III-4 in D) lateral, E) proximal (completely restored) and F) ventral view. Pedal ungual IV-5 in G) lateral, H) proximal, and I) ventral view.
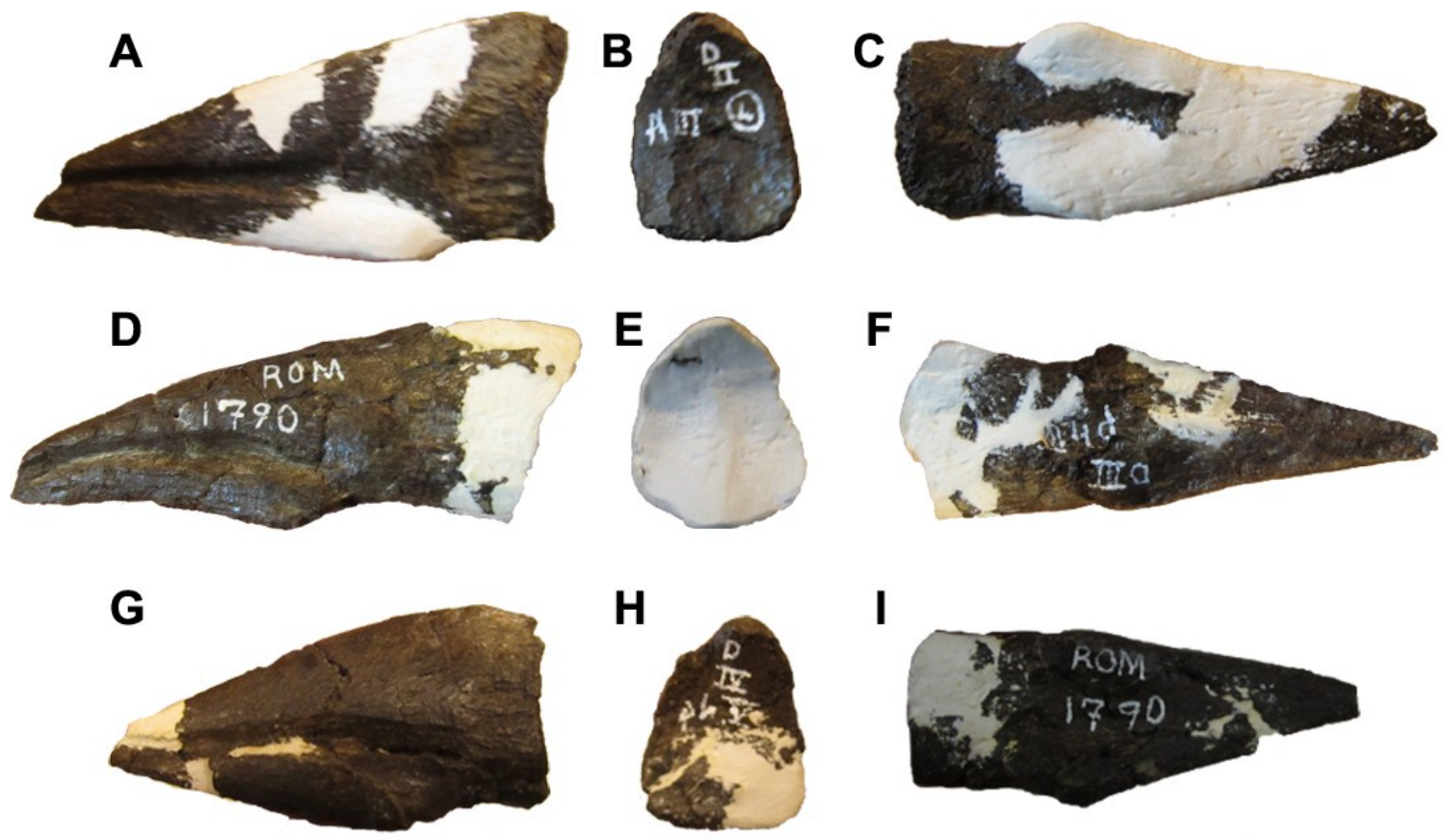

$2 \mathrm{~cm}$ 
dorsomedial inflection in Ornithomimus (CMN 8632). The facet is weakly asymmetrical, with a slightly higher convex inflection point from subvertical to steeply sloping on the medial side, whereas this inflection point is slightly higher on the lateral side in CMN 930. The incomplete proximal articular facet of ungual IV appears to have been similar in shape, but the entire facet is twisted medially with respect to the long axis of the ungual. The asymmetry of the proximal articular facet of ungual IV appears greater in CMN 8632 than ROM 1790, but this may be affected by the partial preservation and restoration in ROM 1790. Each ungual has an approximately horizontal proximodorsal shelf. The proximodorsal process on unguals II and IV (unpreserved on ungual III) does not hang over the proximal articular facet as prominently as in Struthiomimus (CMN 930), in which the facets appear more strongly arched in side view, but rather more closely resembles the reduced proximodorsal process of Ornithomimus (TMP 1995.110.1). The unguals are relatively straight, also as in Ornithomimus (TMP 1995.110.1). Ungual III is proportionately the most elongate, and ungual IV is least elongate. All of the unguals have prominent collateral grooves, as in other ornithomimids. The ungual spurs (sensu Osmólska et al. 1972: 134) are positioned proportionately more distally on ungual III. The ventro-lateral edges of the unguals are relatively sharp, in contrast to the more rounded ventro-lateral edges exemplified by CMN 930 (Longrich 2008, but see also Cullen et al. 2013). Ventrally, the portion of the ungual proximal to the spurs on unguals II and IV (unpreserved on ungual III) is approximately parallelsided, as in Struthiomimus (CMN 930), rather than markedly widest proximally as in Ornithomimus (CMN 8632, ROM 797). However, the distribution of these character 
states is reversed in the isolated unguals assigned to Ornithomimus sp. and S. altus by Longrich (2008, fig. 12). The ventral surface is concave on unguals III and IV, and shows less evidence of concavity on ungual II, but the ventral surface of ungual II is poorly preserved. Ungual II lacks the slight medial curvature that is present in Ornithomimus (ROM 797) and Struthiomimus (CMN 930). There is no trace on any of the unguals of a flexor tubercle, nor of the foramina or sulci that commonly occur in the ventral concavity in Ornithomimus and Struthiomimus, but this may be a preservational artifact. The width of the unguals in ventral view is proportionately similar to Struthiomimus (CMN 930), and distinct from a Horseshoe Canyon Formation specimen of Ornithomimus (ROM 797), in which the pedal unguals are similar in length to those of ROM 1790 but much narrower. However, it is unknown whether the pedal unguals were similarly narrow in the Dinosaur Park Formation Ornithomimus, because the only diagnostic specimen of Ornithomimus from that formation with associated pedal unguals (TMP 1995.110.1) does not expose them in a view that would allow this to be determined.

\section{DISCUSSION}

The taxonomy of Struthiomimus altus in the Belly River Group has not been a major source of disagreement since Russell (1972) published the first modern diagnosis of this taxon. However, this study finds that material included in Struthiomimus altus by Russell (1972) and subsequent authors is not taxonomically homogeneous. Some specimens previously referred to $S$. altus, including the relatively complete skeletons AMNH 5339 and UCMZ 1980.1, can be predicted to 
form a monophyletic group based on a suite of autapomorphies. In addition to the enlarged manus and manual unguals cited by previous authors (Makovicky et al. 2004, Currie 2005), potential autapomorphies distinguishing this group from Ornithomimus and ROM 1790 include the pelvis with a pubic boot that lies ahead of rather than mostly under the antilium (Fig. 2.19), and the more sinuous outline of metatarsal III compared to other ornithomimids (Fig. 2.20, also observed in AMNH 5385). However, some previously undescribed variation was noted among these specimens. The distal end of metacarpal I has a large, convex articular surface with reduced condyles in most derived ornithomimids (Kobayashi \& Lü 2003: character 30.1), including Anserimimus, Gallimimus, Ornithomimus, and possibly UCMZ 1980.1 (pers. obs. from photographs), though Nicholls and Russell (1985: 654) described the presence of an intercondylar groove restricted to the dorsal surface. In AMNH 5339, both first metacarpals have strongly ginglymoid distal articulations with fully distinct condyles, as in more basal ornithomimosaurs (Fig. 2.21). UCMZ 1980.1 may also differ from AMNH 5339 and most other ornithomimids in having a curved, rather than squared off postacetabular process of the ilium (Jin et al. 2012: character 45.1), but this can only be confidently stated if the edges of the ilia in both specimens are not restored (Fig. 2.19 A-B).

Unfortunately, none of the characters used to diagnose the "core" S. altus group can be confirmed in the fragmentary type specimen, CMN 930 (Fig. 2.22). Russell (1972: 382-383) acknowledged that CMN 930 is "virtually undeterminable," 
Figure 2.19. Pelvis of A) Struthiomimus altus AMNH 5339, B) Struthiomimus altus UCMZ 1980.1, C) ROM 1790, D) Ornithomimus sp. TMP 1995.110.1, E) Ornithomimus "currellii" (edmontonicus) ROM 851 (from Parks 1933), F) Ornithomimus "ingens" ROM 852 (from Parks 1933). The red line shows the anterior extent of the antilium and its varying relationship to the position of the pubic boot.

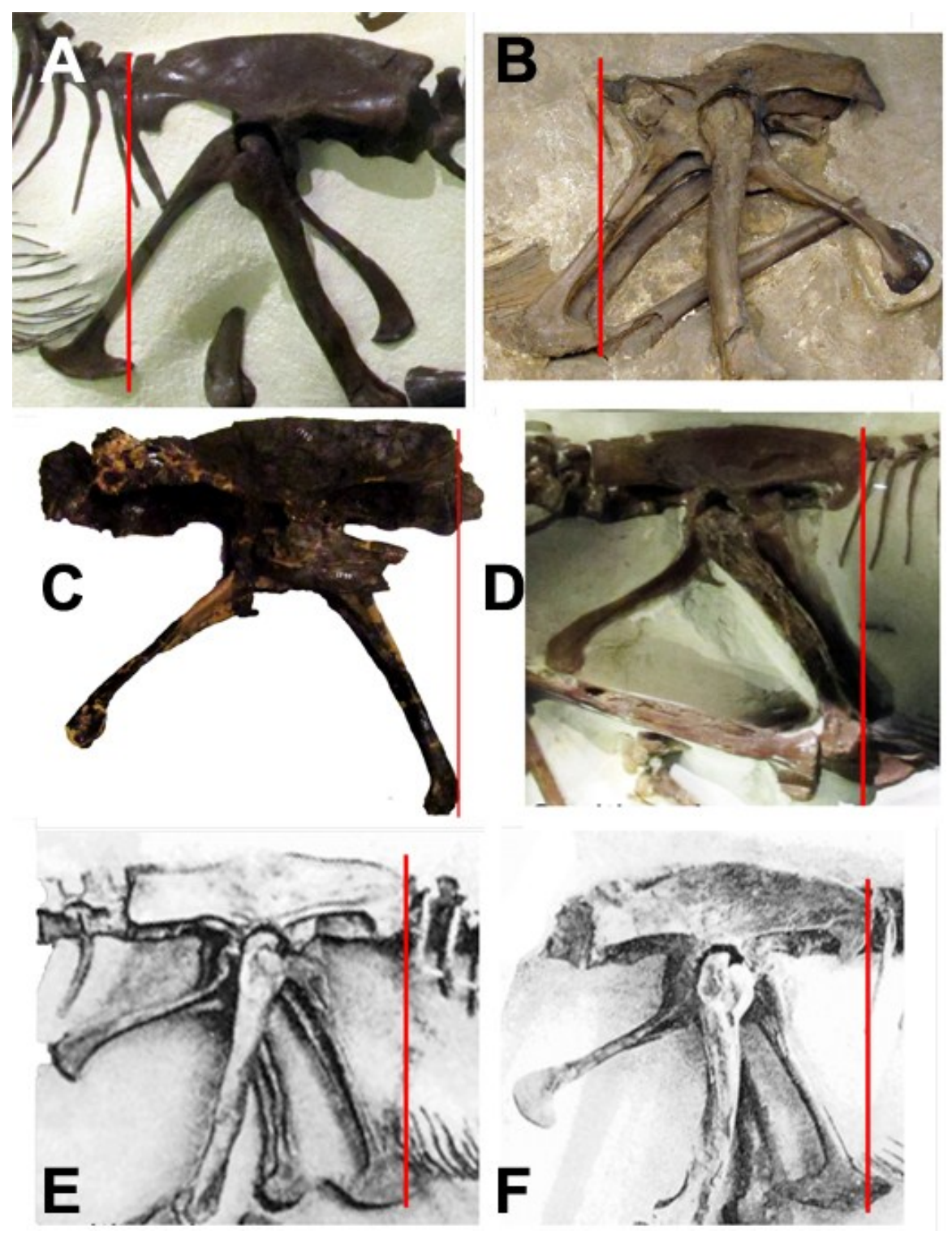


FIGURE 2.20. Distal metatarsals of A) Struthiomimus altus AMNH 5339 (after Osborn 1917), left pes; B) Struthiomimus altus AMNH 5385, left pes; C)

Struthiomimus altus UCMZ 1980.1, right pes; D) Ornithomimus edmontonicus CMN 8632, right pes; E) ROM 1790, left pes. Arrows indicate the pronounced concave medial edge of metatarsal III in specimens referred to Struthiomimus altus.
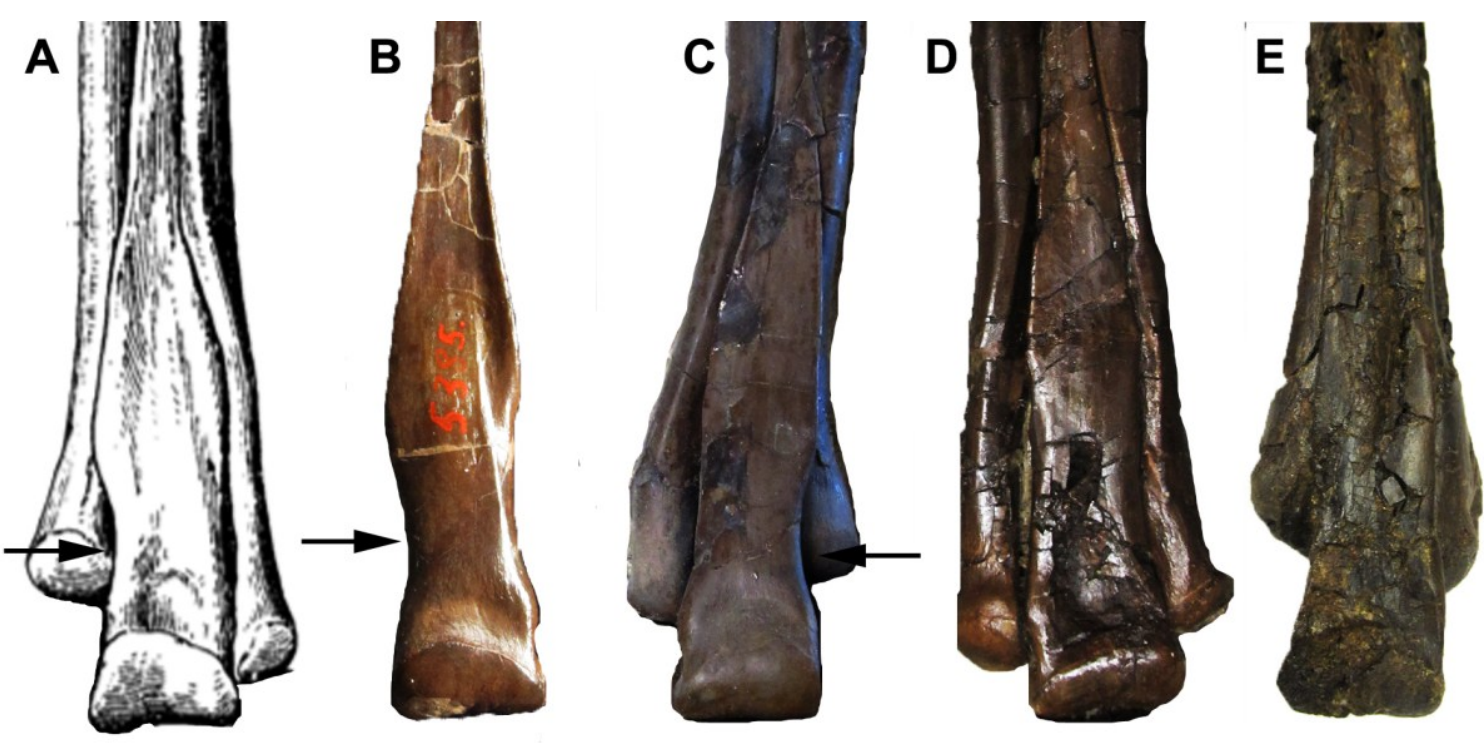
FIGURE 2.21. Variation in the distal end of metacarpal I in Struthiomimus altus. A) Left and right metacarpi of AMNH 5339, showing ginglymoid articulation. B) Left metacarpus of UCMZ 1980.1, showing non-ginglymoid articulation.

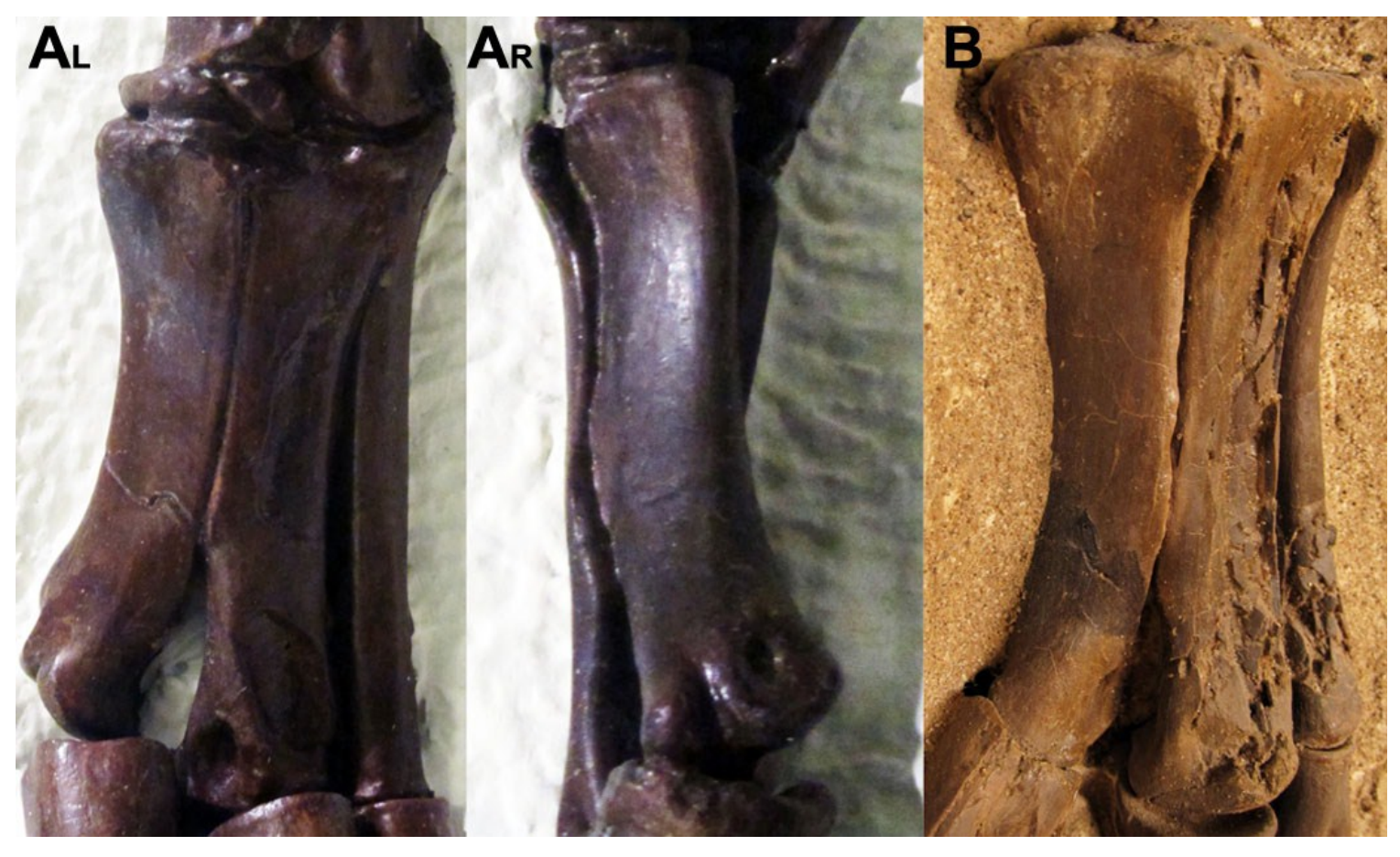


FIGURE 2.22. A) CMN 930, holotype of Struthiomimus altus. Scale bar $=10 \mathrm{~cm}$. B) AMNH 5339, unofficial "proxy holotype" and potential neotype of Struthiomimus altus.

A

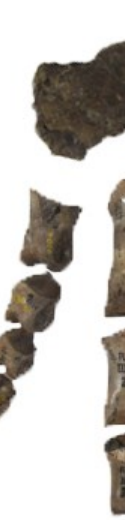

.....
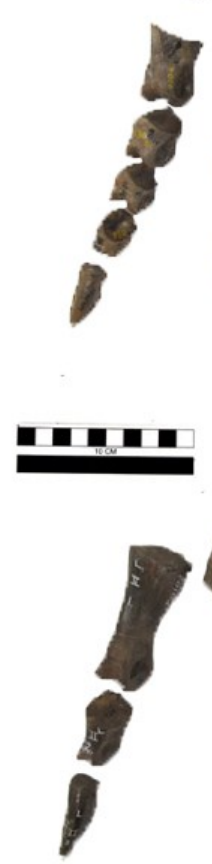

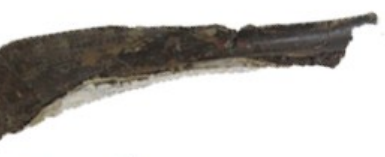

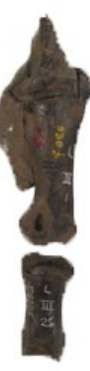
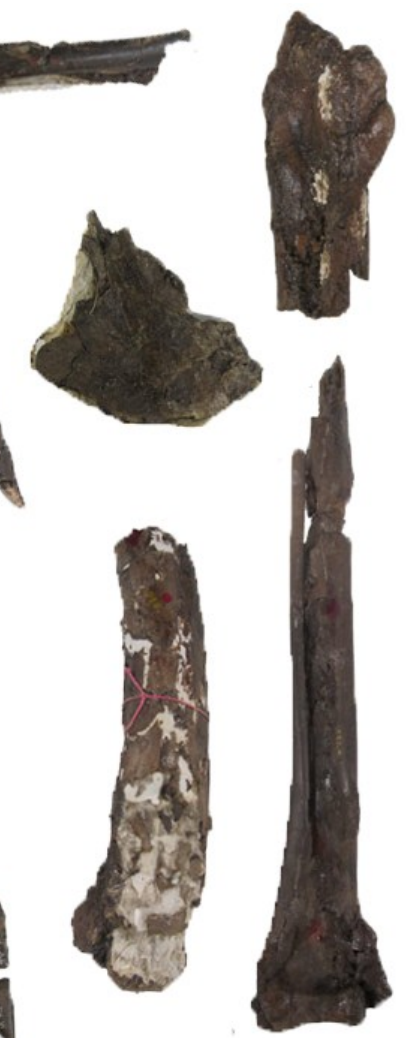
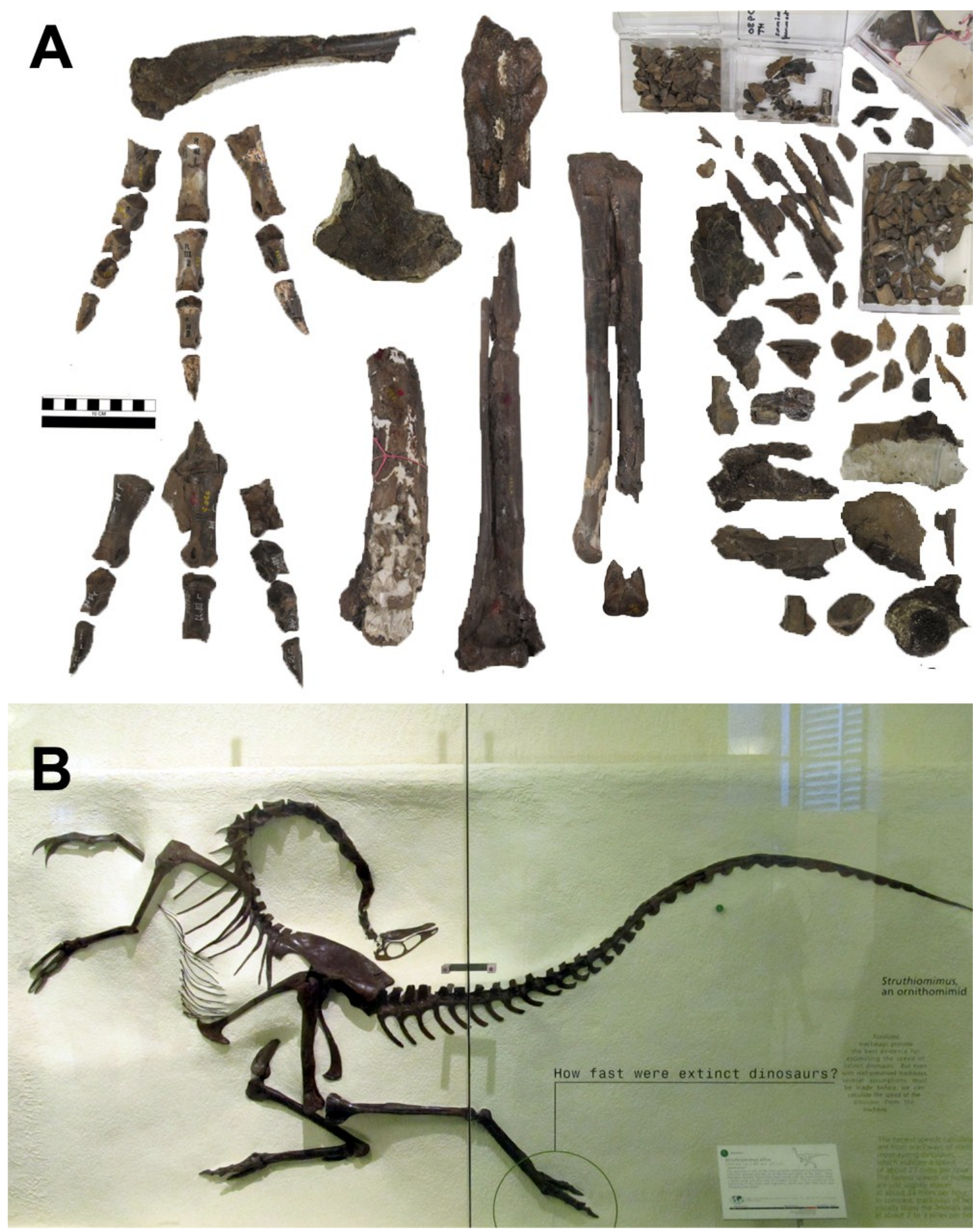
but considered it to be most likely conspecific with "the AMNH 5339 species" based on two points: the relatively great proximal depth of phalanx II-2 relative to its length, and the possibly incorrect belief that "the AMNH 5339 species" was the most abundant ornithomimid species present in the Dinosaur Provincial Park area. The former point was not supported by quantitative data, and could not be replicated. Overlain photographs of pedal phalanx II-2 scaled to the same length suggest that AMNH 5339 is proportionately more similar to the holotypes of O. edmontonicus (CMN 8632) and ROM 1790 for this element, and that the high proximodorsal process in CMN 930 may be uniquely derived in being slightly closer to the midlength of the phalanx (measured ventrally) (Fig. 2.23). Another potential derived character of CMN 930 is the shape of the proximal surface of pedal phalanx III-2, which has sloping sides (like pedal phalanx III-3) rather than vertical, subparallel sides as in CMN 8632, CMN 8902, ROM 1790, and the examined material from the Oldman Formation (Fig. 2.24). This character appears to be shared with the incomplete pedal phalanx III-2 of the S. altus referred specimen AMNH 5355, but can be difficult to confirm in mounted, articulated specimens. The shape of the proximal surface of pedal phalanx II-2 in CMN 930 resembles Ornithomimus and ROM 1790, whereas in AMNH 5385 pedal phalanx II-2 has a distinctly enlarged ventromedial lobe as in Qiupalong (Xu et al. 2011) (Fig. 2.25). AMNH 5385 is a probable member of "the AMNH 5339 species" based on metatarsal III shape (incompletely preserved in CMN 930), but a greater sample size is needed to determine whether is variation in pedal phalanx II-2 shape is of any taxonomic value. 
FIGURE 2.23. Proportions of pedal phalanx II-2 in A) Struthiomimus altus holotype CMN 930; B) Struthiomimus altus AMNH 5339; C) Ornithomimus edmontonicus holotype CMN 8632; D) ROM 1790. Phalanges are resized to uniform length.

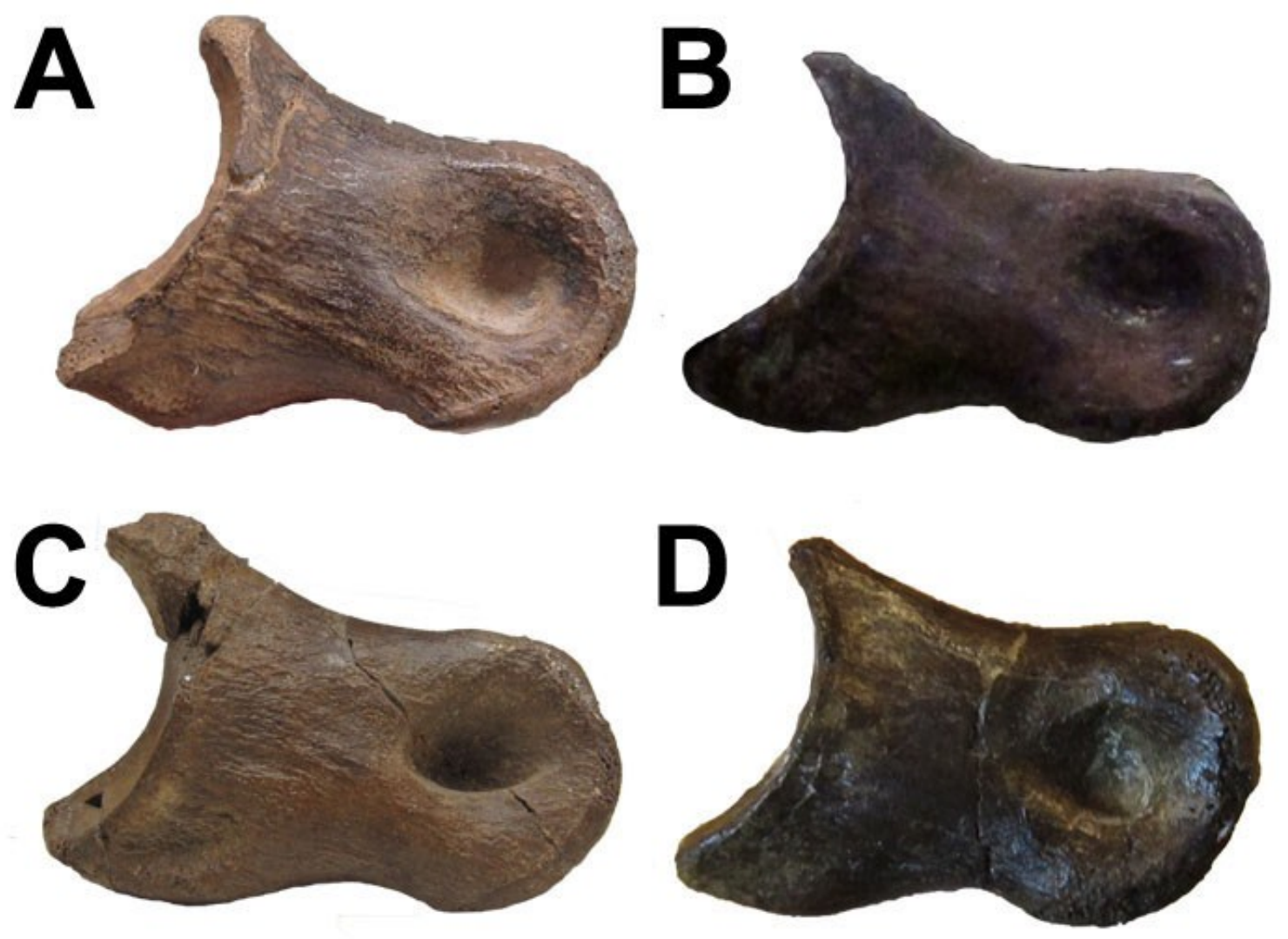


FIGURE 2.24. Proximal view of pedal phalanx III-2 in A) Struthiomimus altus CMN 930; B) Struthiomimus altus AMNH 5355; C) Ornithomimus edmontonicus CMN 8632; D) ROM 1790; E) CMN 8902; F) TMP 2005.012.0271; G) TMP 2008.075.0019; H) TMP 2009.033.0013. Phalanges are resized to approximately uniform width.
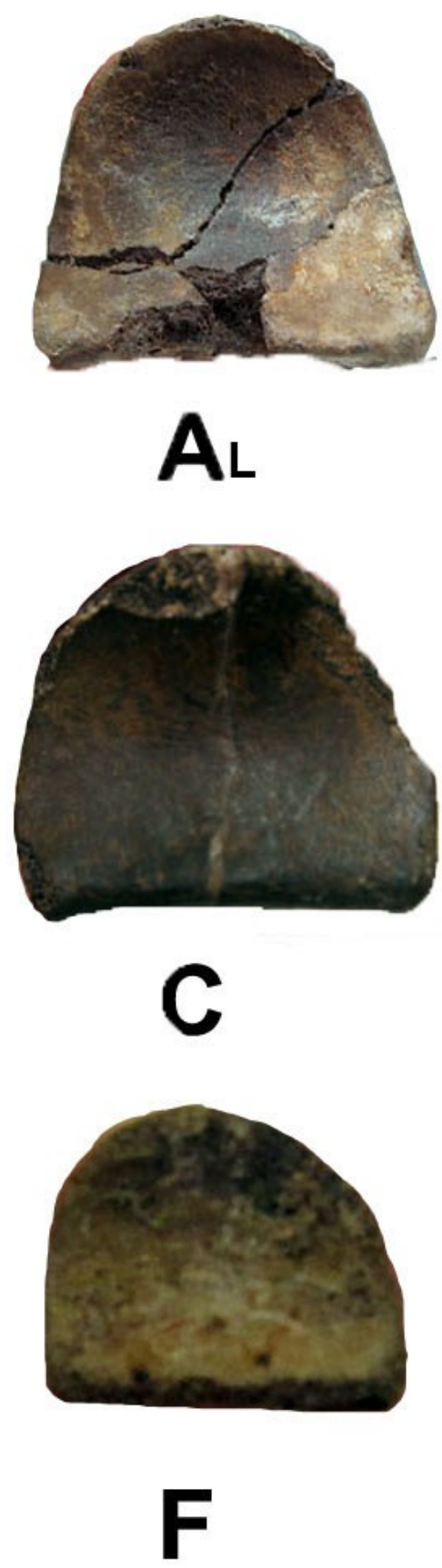
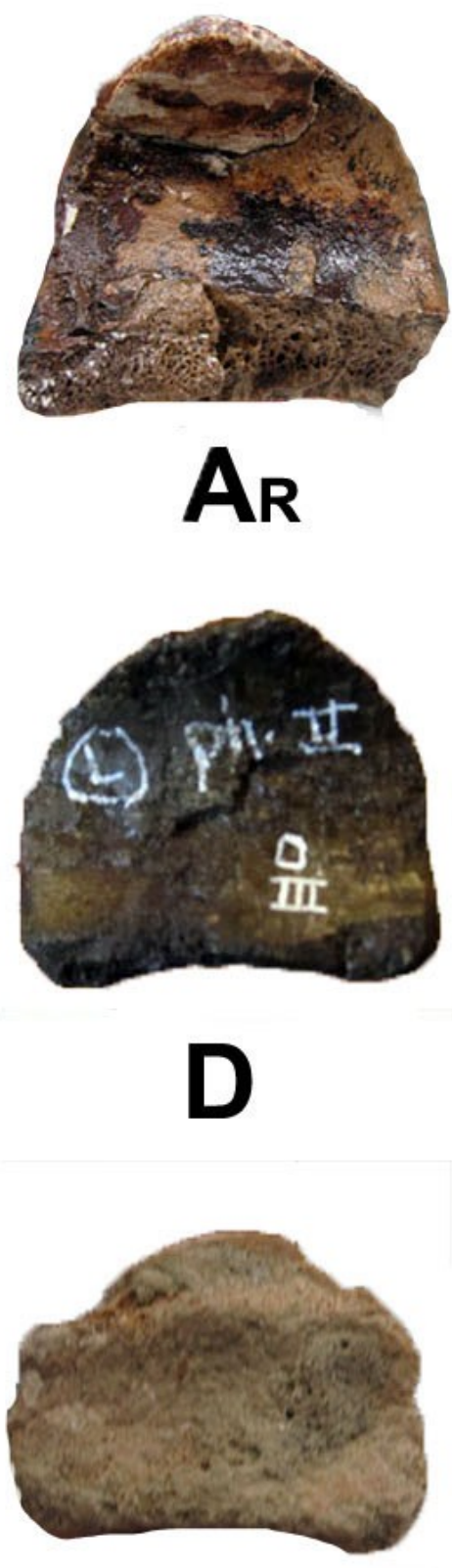

5

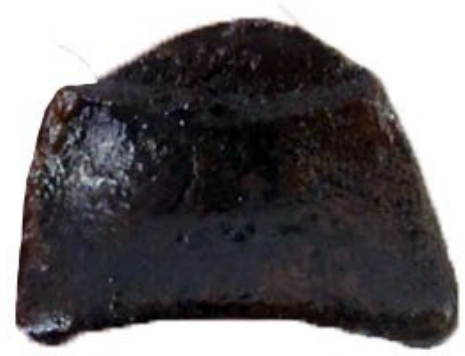

B

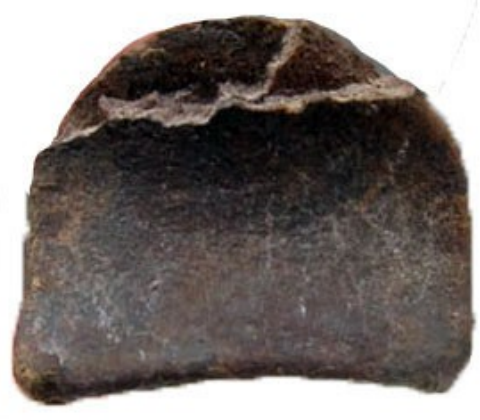

$\mathbf{E}$

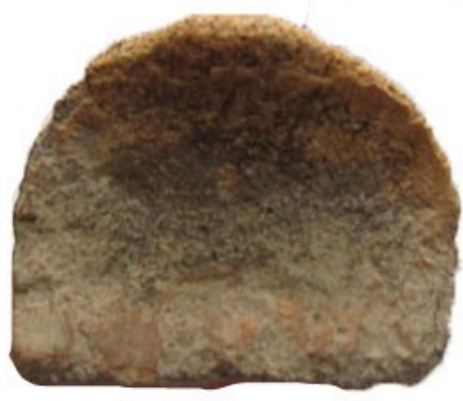

H 
FIGURE 2.25. Proximal view of pedal phalanx II-2 in A) Struthiomimus altus CMN 930; B) Struthiomimus altus AMNH 5385; C) Ornithomimus velox CMN 12242 (cast of YPM 542); D) Ornithomimus edmontonicus CMN 8632; E) ROM 1790; F) Qiupalong henanensis (after Xu et al. 2011); G) TMP 2002.068.0303; H) TMP 2011.053.0006; I) TMP 2011.053.0060. Elements in colour are known, greyscale images are mirrors to aid in comparisons. Phalanges are resized to approximately uniform width.

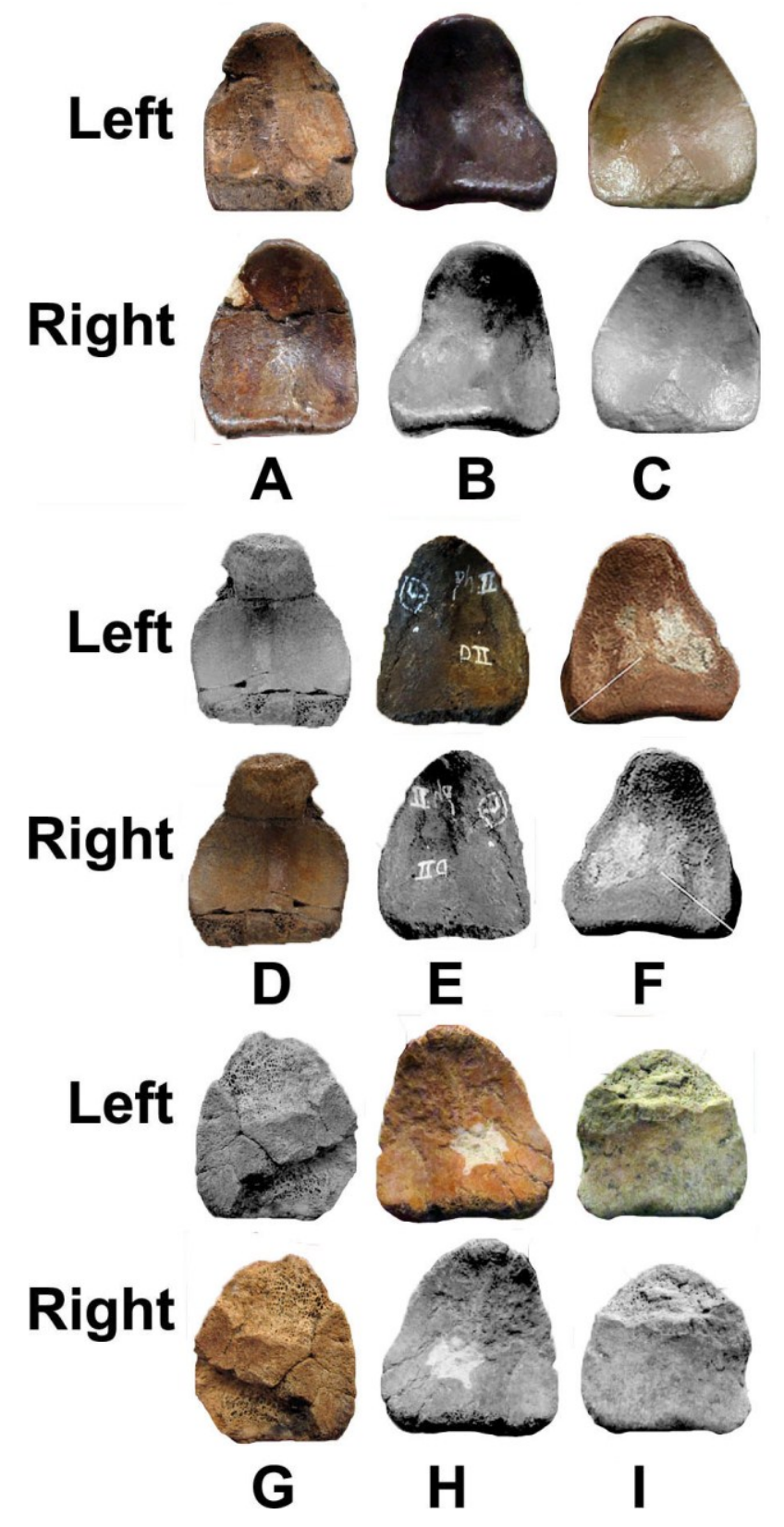


The inconclusive relationship of CMN 930 to most specimens commonly cited as "S. altus" raises the question of what action should be taken to stabilize the content and usage of this taxon. Formal petitions have been written to change the type specimens of other widely-used names that have been perceived to have been founded on inadequate material, including the theropods Coelophysis bauri (Colbert et al. 1992), Archaeopteryx lithographica (Bock \& Bühler 2007), Majungasaurus crenatissimus (Carrano et al. 2009), and Allosaurus fragilis (Paul \& Carpenter 2010). The most obvious choice for a neotype of S. altus would be AMNH 5339, the most complete individual assigned to this species that is from the same general locality (Dinosaur Provincial Park, probably Dinosaur Park Formation). CMN 930 was originally considered to represent a new species of Ornithomimus (Lambe 1902), until Osborn (1917) made "O." altus the type species of the genus Struthiomimus in his paper describing AMNH 5339. Strangely, Osborn twice referred to AMNH 5339 as the "genotype" specimen (Osborn 1917: 739, 741), while still recognizing CMN 930 as the "type," but this practice of a genus having a "genotype" specimen that differs from the holotype of the type species is not valid in modern taxonomy. Osborn's referral of AMNH 5339 to S. altus has been universally accepted by subsequent authors, even though it was made when only a single ornithomimid species was recognized in the Belly River Group, and no particularly strong character-based argument has been used to justify it. Parks (1928) justified the naming of a second ornithomimid species from the Belly River Group, "S." samueli (now O. samueli), based entirely on its differences from AMNH 5339, which he accepted to be representative of S. altus based on the authority of H. F. Osborn and 
B. Brown (Parks 1928: 5). Unfortunately there are no overlapping elements between the holotypes of S. altus (CMN 930) and O. samueli (ROM 840), making the use of reliable referred material essential to objectively distinguishing these species. The rediagnosis of S. altus by D. A. Russell (1972) also rests heavily on the acceptance that AMNH 5339 is a member of this species, and is based on characters that are unpreserved in CMN 930. Nicholls and A. P. Russell (1981:519) referred their specimen UCMZ 1980.1 to S. altus based on its similarity to AMNH 5339, and did not compare it to CMN 930, despite all elements of CMN 930 being represented in UCMZ 1980.1. Nicholls and Russell (1981: 526) concluded that " fragmentary material that lacks remains of the manus can only be tentatively assigned to a genus at present," apparently not realizing the implications of this statement for the validity of $S$. altus. More recent attempts to characterize $S$. altus have also relied on characters that are unpreserved in CMN 930 (Makovicky et al. 2004, Currie 2005, Kobayashi et al. 2006, Longrich 2008: 983). An argument could be made that AMNH 5339 should be nominated as a neotype, because it has already been serving as the "proxy holotype" (sensu Parker 2013) of S. altus for most of the history of research on Belly River Group ornithomimid taxonomy.

On the other hand, several facts could be used to argue in favour of retaining CMN 930 as the holotype of S. altus. Although he figured multiple specimens as "O." altus, Lambe (1902: 50) clearly intended for the partial skeleton CMN 930 to be the holotype, with all other material described as only "probably belonging to the same species." CMN 930 is still easily accessible to researchers, and the individual disarticulated elements can be freely manipulated and observed in all views. AMNH 
5339 is a less accessible specimen for many scientific purposes, being an articulated panel mount that can now only be viewed at a distance through an unmovable pane of glass. Although some observations requiring closer access can be taken from a cast (TMP 1985.008.0003), it is still impossible to observe certain elements in certain views, and a cast does not permit preservational or restorational artifacts to be adequately reevaluated. Furthermore, CMN 930 has been recently cited as a reference specimen for S. altus in the descriptive literature (Cullen et al. 2013). My own observations suggest that some characters in the pedal phalanges of CMN 930 may eventually prove to be taxonomically informative. A complete and definitive comparison of CMN 930 and AMNH 5339 is not presented at this time because the two specimens (or casts thereof) could not be examined side by side at the same institution. Therefore, although the taxonomy of S. altus is problematic, I would consider the proposal of a neotype to be premature. However, both specimens are demonstrably different from ROM 1790 in various parts of the skeleton. In the following discussion I tentatively retain S. altus in the "traditional" sense (cf. Osborn 1917, Nicholls \& Russell 1981), minus some material dubiously referred by Russell (1972).

\section{Taxonomic Status of ROM 1790}

Common characters of Ornithomimosauria and Ornithomimidae are readily apparent in ROM 1790, including a long, low edentulous snout with the maxilla excluded from the external naris, and an elongate, fully arctometatarsalian pes lacking digit I (Barsbold and Osmólska 1990, Makovicky et al. 2004). However, the 
absence of such highly informative regions as the posterior elements of the skull, the pectoral girdles and forelimbs, and the pubic boot makes the classification of this specimen within Ornithomimidae more challenging. The species-level classification of ROM 1790 was not discussed in print until decades after it was collected, though Sternberg (1950) and Dodson (1971) both indicated that it was identified as Struthiomimus. Russell (1972: 383) formally referred ROM 1790 to Struthiomimus altus, which has been widely followed (Holtz 1995, Gatesy and Middleton 1997, Witmer 1997, Currie 2005, Currie and Russell 2005, Kobayashi and Barsbold 2005a), but the rationale for this referral was never explicitly stated. The diagnosis of Struthiomimus (and thereby S. altus, by monotypy) provided by Russell (1972: 382) included the following characters:

"Length of presacral vertebral column more than combined lengths of femur, tibia-astragalus and third metatarsal." This character is indeterminate in ROM 1790, which preserves only a single, fragmentary presacral vertebra.

"Posterior width of anteriormost 15 caudal centra greater than half of central length, transition point between proximal and distal segments of tail occurs between caudals 15 and 16." Although the anterior caudal vertebrae are preserved in ROM 1790, they are crushed mediolaterally, so the posterior width of the centra cannot be observed to be greater than half of the central length. The numerical position of the transition point cannot be established with certainty, because the preserved caudal series is only partially articulated. The most distal caudal vertebra with a transverse process in ROM 1790 must be at least the 13th, which places the transition point at least one vertebra more distally than in the Ornithomimus 
specimen CMN 12228 from the Horseshoe Canyon Formation (Russell 1972). However, in the Ornithomimus specimen TMP 1995.110.1 from the Dinosaur Park Formation, the transition point is between the 14th and 15th caudal vertebrae. A transition point between the 15th and 16th caudal vertebrae is not unique to Struthiomimus among ornithomimids, as it also occurs in Gallimimus (Osmólska et al. 1972: 122).

"Humerus shorter than scapula. Antebrachium about half as long as femur, powerfully constructed. First metacarpal shorter than metacarpals 2 and 3, manus digits unequal in length, manus unguals unequal in length, heavily recurved and powerfully constructed. Ungual of third digit of manus longer than penultimate phalanx of third digit." None of these characters can be determined in ROM 1790, which does not preserve any forelimb material.

"Antilium, tibia, metatarsus, and digit 3 of pes shorter relative to femur than in Dromiceiomimus." Russell (1972, table 7) did not compare the length of the antilium to the femur in ROM 1790, but it is appears to have been proportionately as long or longer, rather than shorter, than the antilium in specimens that Russell (1972) referred to "Dromiceiomimus." The use of relative proportions to diagnose ornithomimid taxa was criticized by Nicholls and Russell (1981), and, if all of the named "Dromiceiomimus" and Ornithomimus species from Alberta are synonymous as suggested by Makovicky et al. (2004), the hindlimb proportions of Struthiomimus fall within the range of intraspecific variation for Ornithomimus. To date, the derived hindlimb proportions that characterize "Dromiceiomimus" (sensu Russell 1972) have only been observed in ornithomimids from the Horseshoe Canyon Formation. 
The Ornithomimus specimen TMP 1995.110.1 from the Dinosaur Park Formation has hindlimb proportions that are within the range of variation for Struthiomimus altus (sensu Russell 1972; see Macdonald 2013 for measurements of TMP 1995.110.1), so this character does not appear to be useful for classifying ornithomimids in that formation.

The diagnosis of Struthiomimus provided by Russell (1972) is therefore inadequate to justify his referral of ROM 1790 to that taxon. Subsequent diagnoses of Struthiomimus by Barsbold and Osmólska (1990), Makovicky et al. (2004), Kobayashi et al. (2006), and Longrich (2008) are similarly reliant on characters that are unfortunately not determinable in ROM 1790. ROM 1790 exhibits a number of unusual characters that are absent in all other examined ornithomimid material for which the character state can be determined, and are here considered autapomorphies of a new ornithomimid taxon. Each proposed autapomorphy can be used to distinguish the new taxon from both Ornithomimus and Struthiomimus, the only two named North American ornithomimid genera currently considered valid (Makovicky et al. 2004, Longrich 2008). These autapomorphies include the following:

1. The relatively short contact surface on the jugal process of the maxilla (Fig. 2.26) differs from the long groove present in the holotypes of Ornithomimus currellii (ROM 851), a specimen referred to Struthiomimus altus (AMNH 5339), and was formerly visible in the holotype of 0 . samueli (ROM 840), assuming the original description (Parks 1928: 8-9) is accurate. 
FIGURE 2.26. Maxilla-jugal contact (indicated by arrows) in Ornithomimosauria:

Short contact in A) ROM 1790; long contact in B) Garudimimus brevipes (after

Kobayashi and Barsbold 2005a), C) Struthiomimus altus (AMNH 5339, drawing after

Osborn 1917), D) Ornithomimus samueli (ROM 840, after Parks 1928), E)

Ornithomimus sp. (TMP 1995.110.1, with jugal in articulation), F) Ornithomimus

edmontonicus (ROM 851).
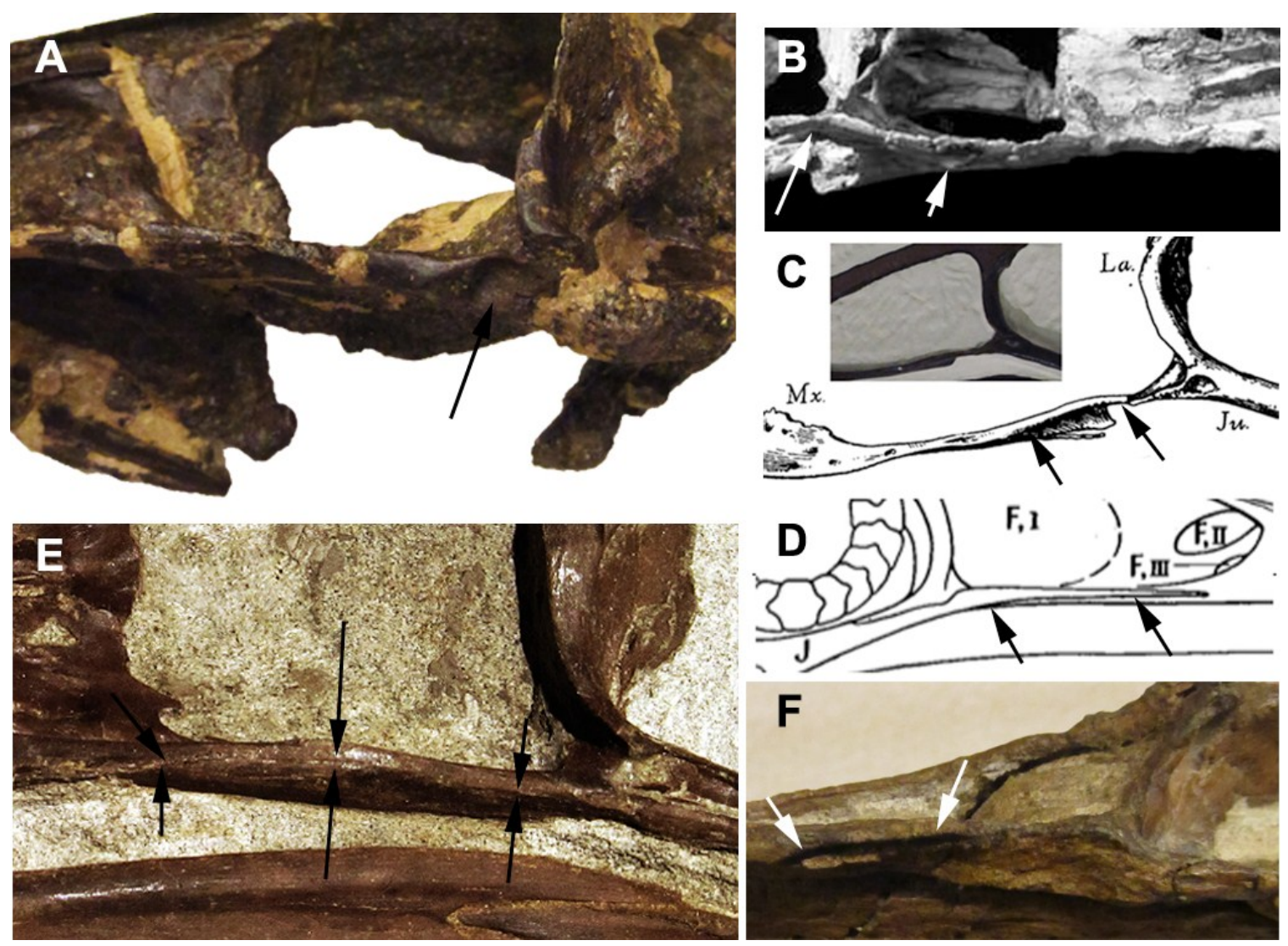
2. The reduction of the mid-caudal neural spines in the region of the transition point (Fig. 2.27) differs from the unreduced, rectangular neural spines in referred specimens of S. altus (AMNH 5339), O. ("Dromiceiomimus") brevitertius (CMN 12228), and Ornithomimus sp. (TMP 1995.110.1).

3. The convex, fused condition of the proximodorsal contact of the ischial shafts (Fig. 2.28) differs from the cleft condition in the holotypes of S. altus (CMN 930), $O$. brevitertius (ROM 797), O. currellii (ROM 851), and O. ingens (ROM 852). Although it may be argued that this fusion could be an ontogenetic character, ROM 797 displays no sign of it despite advanced fusion of the acetabulum and tibiotarsus.

4. The medial condyle of the tibia being larger than the lateral condyle in proximal view (Fig. 2.29) differs from specimens of Struthiomimus (AMNH 5385) and Ornithomimus (AMNH 5201, ROM 851), among other ornithomimids. However, this region is poorly preserved in ROM 1790 , and the validity of this character needs to be confirmed in another specimen with a better preserved proximal tibia.

5. The distal end of the third metatarsal, which is deepest laterally and lacks a fossa between the lateral and medial condyles (Fig. 2.30), differs from the conditions in the holotypes of O. velox (CMN 12242, cast), S. altus (CMN 930), O. brevitertius (ROM 797), O. edmontonicus (CMN 8632), O. currellii (ROM 851), and O. ingens (ROM 852).

Additional characters can be used to distinguish ROM 1790 from 
FIGURE 2.27. Most distal section of preserved caudal vertebrae in ROM 1790, in A) right lateral and B) dorsal view. Closeup of middle vertebra showing the reduced form of the neural spine in C) posterolateral and D) anterolateral view. Transitional caudal regions of E) Struthiomimus altus AMNH 5339, F) O. brevitertius CMN 12228, and G) Ornithomimus sp. TMP 1995.110.1 in lateral views. Arrows indicate the last vertebra with a preserved transverse process.

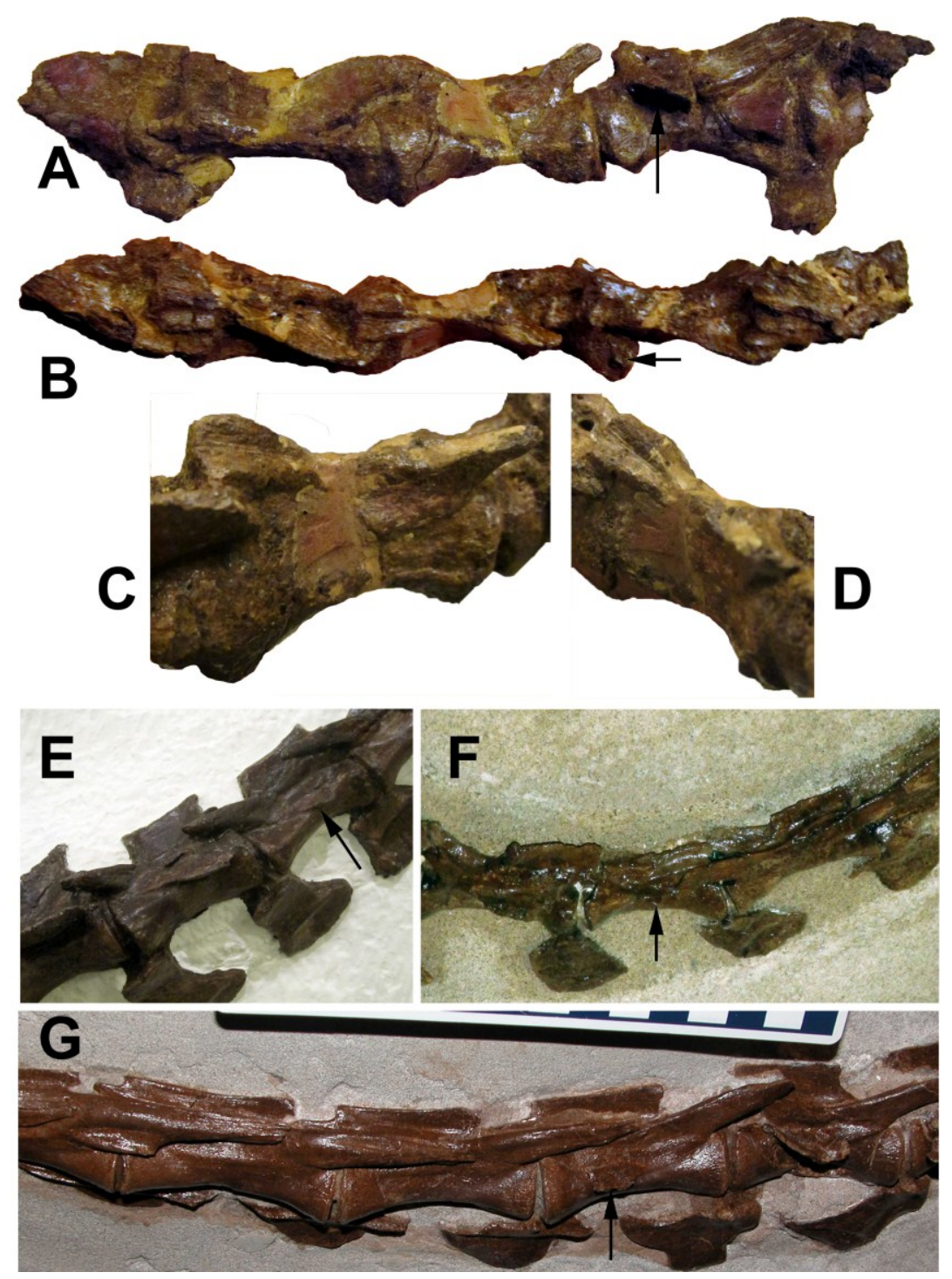


FIGURE 2.28. Posterior view of ischia of A) ROM 1790 (with closeup of fused area);

B) Struthiomimus altus CMN 930; C) Struthiomimus altus UCMZ 1980.1; D)

Ornithomimus brevitertius ROM 797; E) Ornithomimus "currellii" (edmontonicus)

ROM 851; F) Ornithomimus "ingens" ROM 852.

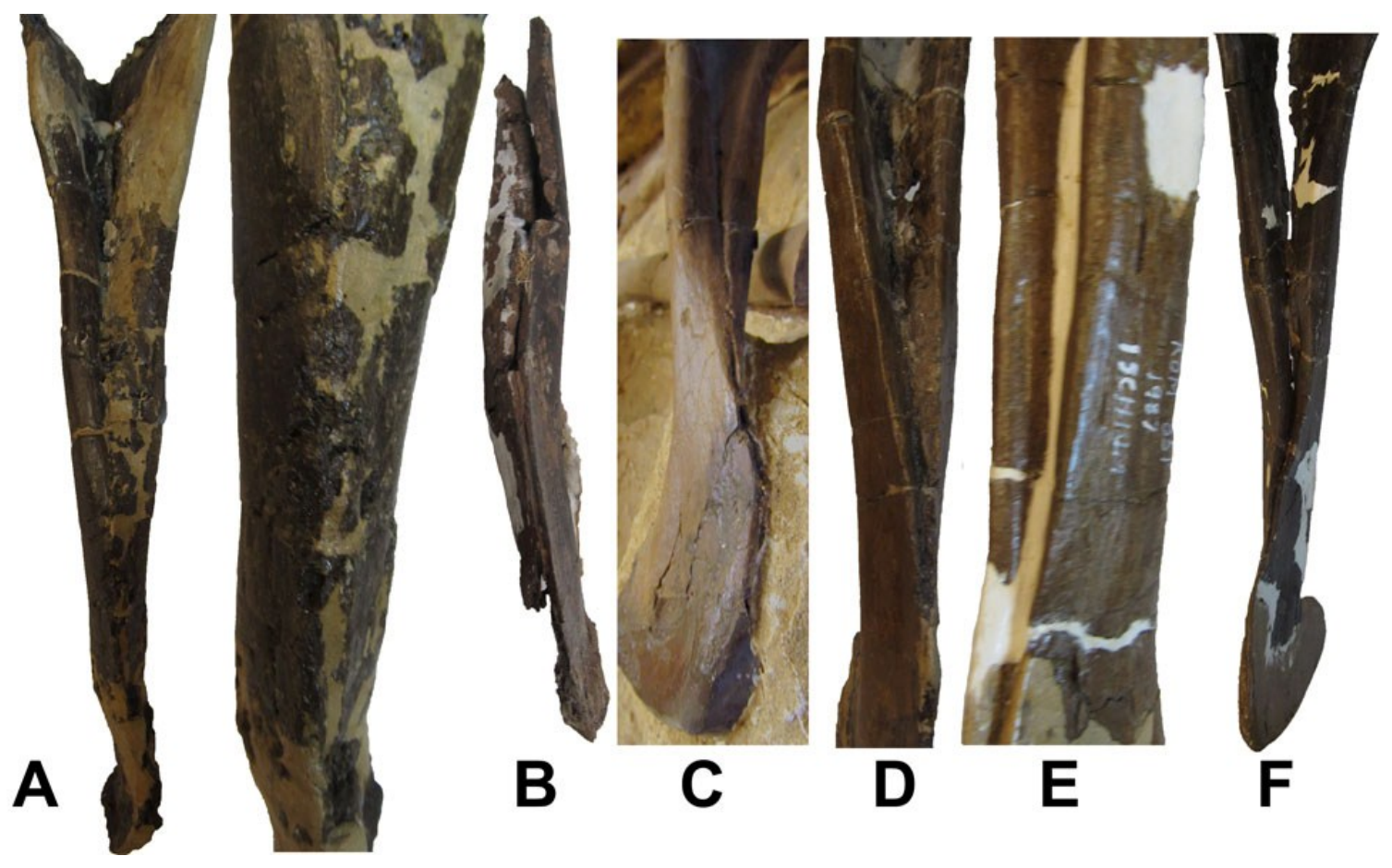


FIGURE 2.29 Proximal view of left tibiae of A) ROM 1790; B) Gallimimus bullatus (modified from Osmólska et al. 1972); C) Qiupalong henanensis (after Xu et al. 2011); D) Struthiomimus altus AMNH 5385; E) Ornithomimus "currellii" (edmontonicus) ROM 851. Abbreviations: cc, cnemial crest; lc, lateral condyle; mc, medial condyle.
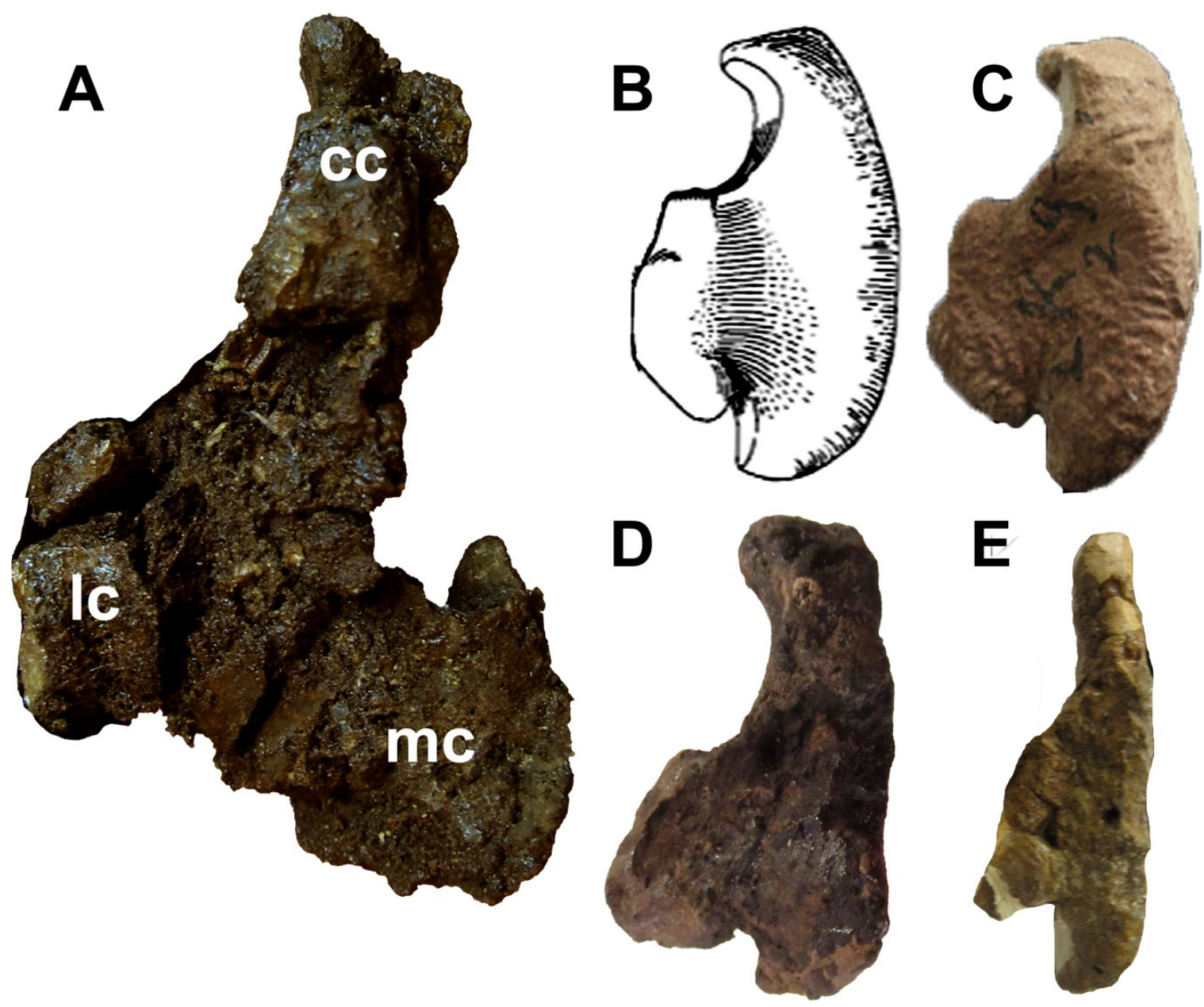
FIGURE 2.30. Metatarsal III in distal view, flexor side facing up: A) ROM 1790, left pes; B) Struthiomimus altus AMNH 5385, left pes; C) Struthiomimus altus CMN 930, right pes; D) Ornithomimus edmontonicus CMN 8632, left pes; E) Ornithomimus brevitertius ROM 797, right pes. F) Left metatarsal III of ROM 47421 and ROM 1790 compared, showing the conditons of the present versus absent distal concavity on the flexor side.

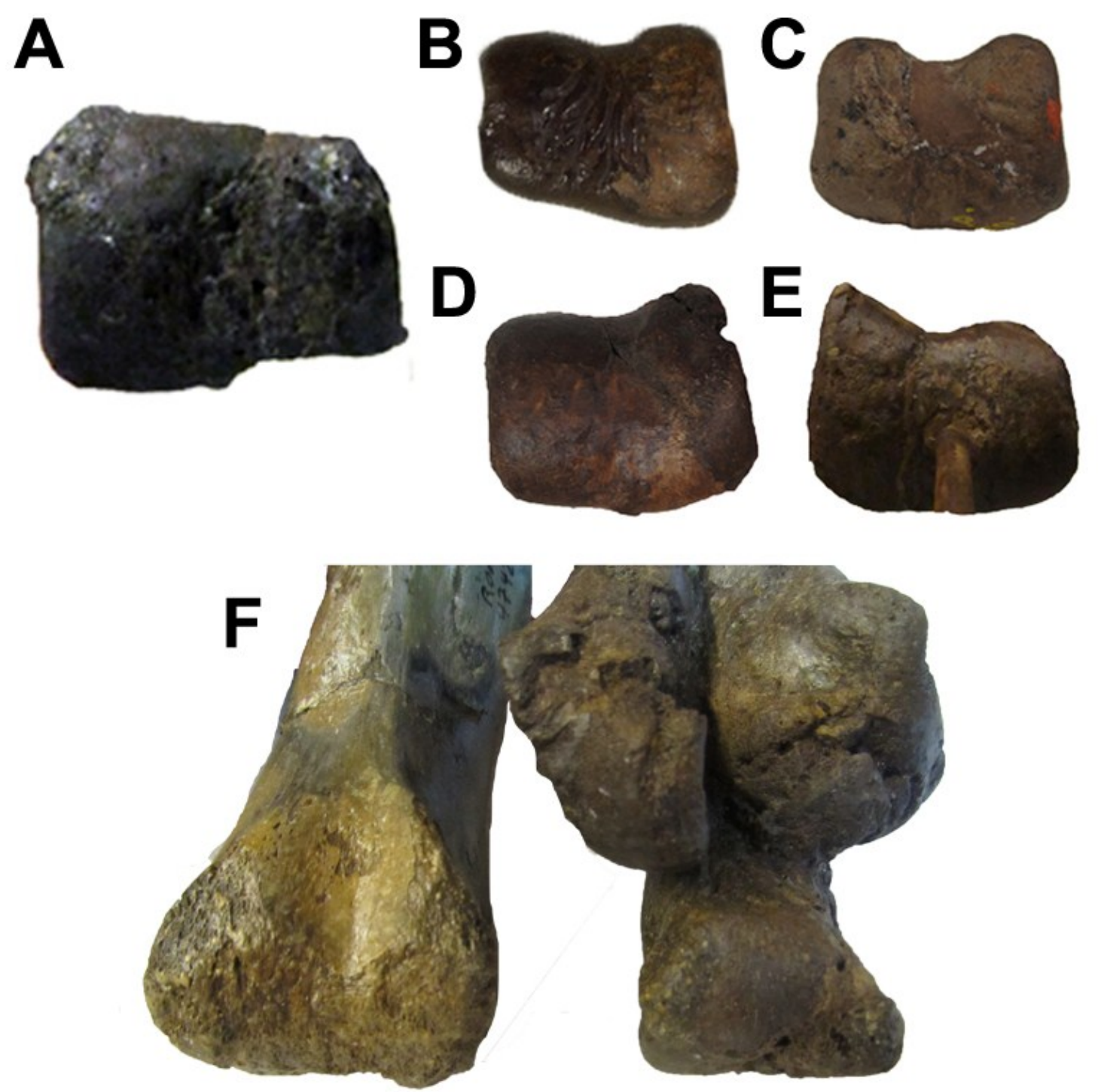


Struthiomimus altus, but these are symplesiomorphies shared with Ornithomimus. In S. altus (AMNH 5339, UCMZ 1980.1) the shaft of the pubis projects cranially well beyond the anterior margin of the ilium, so that the ilium does not directly overlie the pubic boot, whereas in Ornithomimus (CMN 12068, CMN 12228, ROM 851, ROM 852, TMP 1995.110.1), Qiupalong (Xu et al. 2011, fig. 3), Gallimimus (Osmólska et al. 1972, pl. XLV), Deinocheirus (Lee et al. 2014, fig. 3j), and Shenzhousaurus (Ji et al. 2003, fig. 10), the anterior margin of the ilium and the end of the pubic shaft (excluding the boot) project approximately equally far cranially, so that the pubic boot partially underlies the ilium. Although the complete pubic boot is not preserved in ROM 1790, the articulation of the pubis with the ilium and the distal expansion of its shaft indicate that the plesiomorphic ornithomimosaur condition was present. The third metatarsal of S. altus (AMNH 5339, AMNH 5385, UCMZ 1980.1) has a complex and distinctive shape in anterior view, with a strongly sinuous medial edge (Osborn 1917, fig. 3a). The distarticulated third metatarsal of AMNH 5385 is significant in being extremely similar in shape anteriorly to the articulated third metatarsals of AMNH 5339 and UCMZ 1980.1, while distally it resembles the distal fragment of the third metatarsal of the S. altus holotype (CMN 930) more closely than it resembles ROM 1790 or most specimens of Ornithomimus. The medial edge of the third metatarsal is straight or mildly concave in ROM 1790, Ornithomimus (CMN 8632, CMN 12228, ROM 797, ROM 851, TMP 1995.110.1), the Hell Creek ornithomimid (LACM 47520), Qiupalong (Xu et al. 2011, fig. 6), Anserimimus (Barsbold 1988, fig. 1), Gallimimus (Osmólska et al. 1972, pl. XLIX; 
LACM 154765, cast), Archaeornithomimus (AMNH 6565), and more basal ornithomimosaurs.

Available data also suggest that ROM 1790 does not represent a known species of Ornithomimus. The holotype of Ornithomimus samueli (ROM 840) was collected approximately 2 km east of ROM 1790 (Sternberg 1950), and along with TMP 1995.110.1 is one of the few specimens of Ornithomimus (sensu Makovicky et al. 2004) reported from the Dinosaur Park Formation. Additional differences separating ROM 1790 from these Ornithomimus specimens are cranial characters that are unpreserved in any specimen assigned to S. altus from the Dinosaur Park Formation. Although Russell (1972) and Sereno (2001) referred some material from the Horseshoe Canyon Formation to S. altus, including an articulated skeleton with a complete skull (TMP 1990.26.1), Longrich (2008: 983) considered the Horseshoe Canyon Formation material to represent a distinct, unnamed species of Struthiomimus. The prominent lateral foramen at the base of the narial process of the premaxilla was noted by Kobayashi and Barsbold (2005a: 1506) for Garudimimus, and was said to be present in other ornithomimosaurs. It is present in ROM 840 and TMP 1995.110.1 (Currie 2005, fig. 8), but is absent on the right premaxilla of ROM 1790 (Fig. 2.31). Unfortunately, the status of this character on the left premaxilla is ambiguous due to breakage, and the full distribution of this character could not be determined because many ornithomimid skulls are too damaged or were inaccessible for this study. The maxilla and the antorbital fenestra are proportionately long and shallow in ROM 840 and TMP 1995.110 .1 compared to 
FIGURE 2.31. Position of the foramen at the base of the narial process of the premaxilla (indicated by arrow) in A) the basal ornithomimosaur Garudimimus brevipes (after Kobayashi \& Barsbold 2005a) and B) the ornithomimid Ornithomimus samueli (ROM 840). This foramen may be absent in C) ROM 1790.
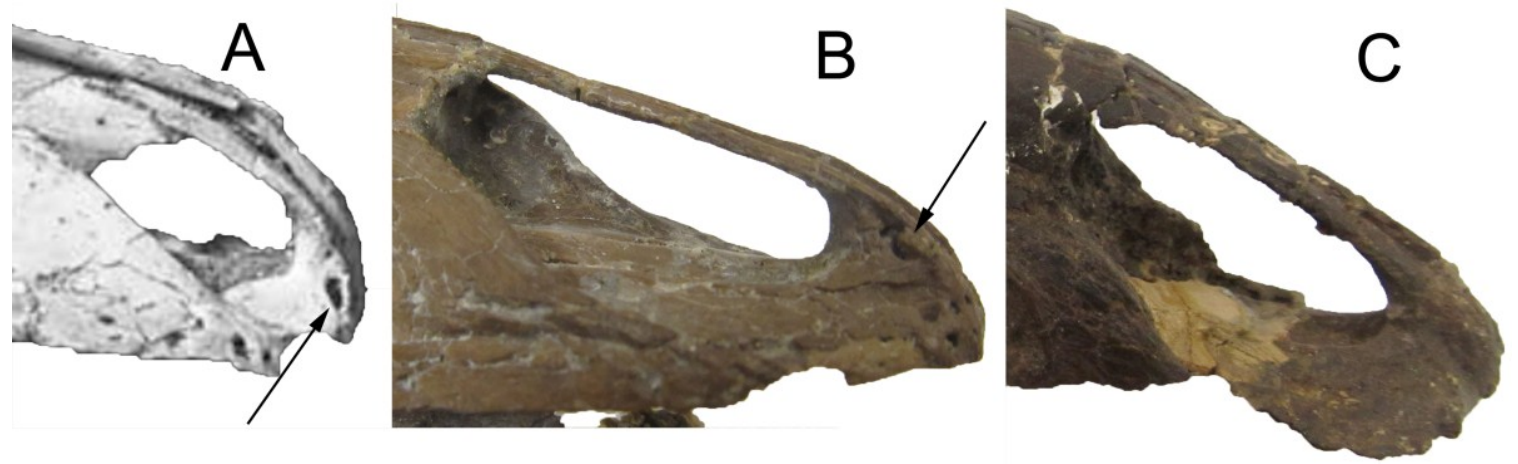
ROM 1790. ROM 1790 also differs from ROM 840 in the heavily pitted texture of the maxillae, which are smooth in the latter taxon. However, pitted maxillae are known in TMP 1995.110.1. In the well-studied theropod Tyrannosaurus rex, the maxillae may be pitted (LACM 150167) or unpitted (LACM 23844), suggesting that this variation could be interspecific (possibly ontogenetic) rather than taxonomically significant in ornithomimids as well (fig. 2.32).

\section{Ontogenetic Stage of ROM 1790}

Histological work on the femur of ROM 1790 (with Cullen and Evans, in prep.) suggests that ROM 1790 was a relatively mature individual, despite its small size when compared to most specimens of S. altus (hindlimb measurements are approximately $80 \%$ of those of AMNH 5339 and UCMZ 1980.1), agreeing with the advanced state of skeletal fusion in the pelvis and tibiotarsi. However, comparable histological sections so far only exist for specimens of Ornithomimus (Zelenitsky et al. 2012, Cullen et al. 2014), and no specimens of Struthiomimus.

\section{CONCLUSION}

A partial skeleton of an ornithomimid theropod, ROM 1790, from the lower Dinosaur Park Formation (Campanian) of Alberta is described, yielding new information on ornithomimid cranial and postcranial anatomy. Although this specimen was previously referred to Struthiomimus altus, it displays a mixture of characters resembling Ornithomimus and Struthiomimus, and possesses several unique characters that are considered autapomorphies of a new taxon. These 
FIGURE 2.32. Variation in maxilla texture of ornithomimid and tyrannosaurid theropods. A) ROM 1790, pitted maxilla. B) Ornithomimus samueli, ROM 840, smooth maxilla. C) Tyrannosaurus rex LACM 150157, pitted maxilla. D) Tyrannosaurus rex LACM 23844, smooth maxilla.
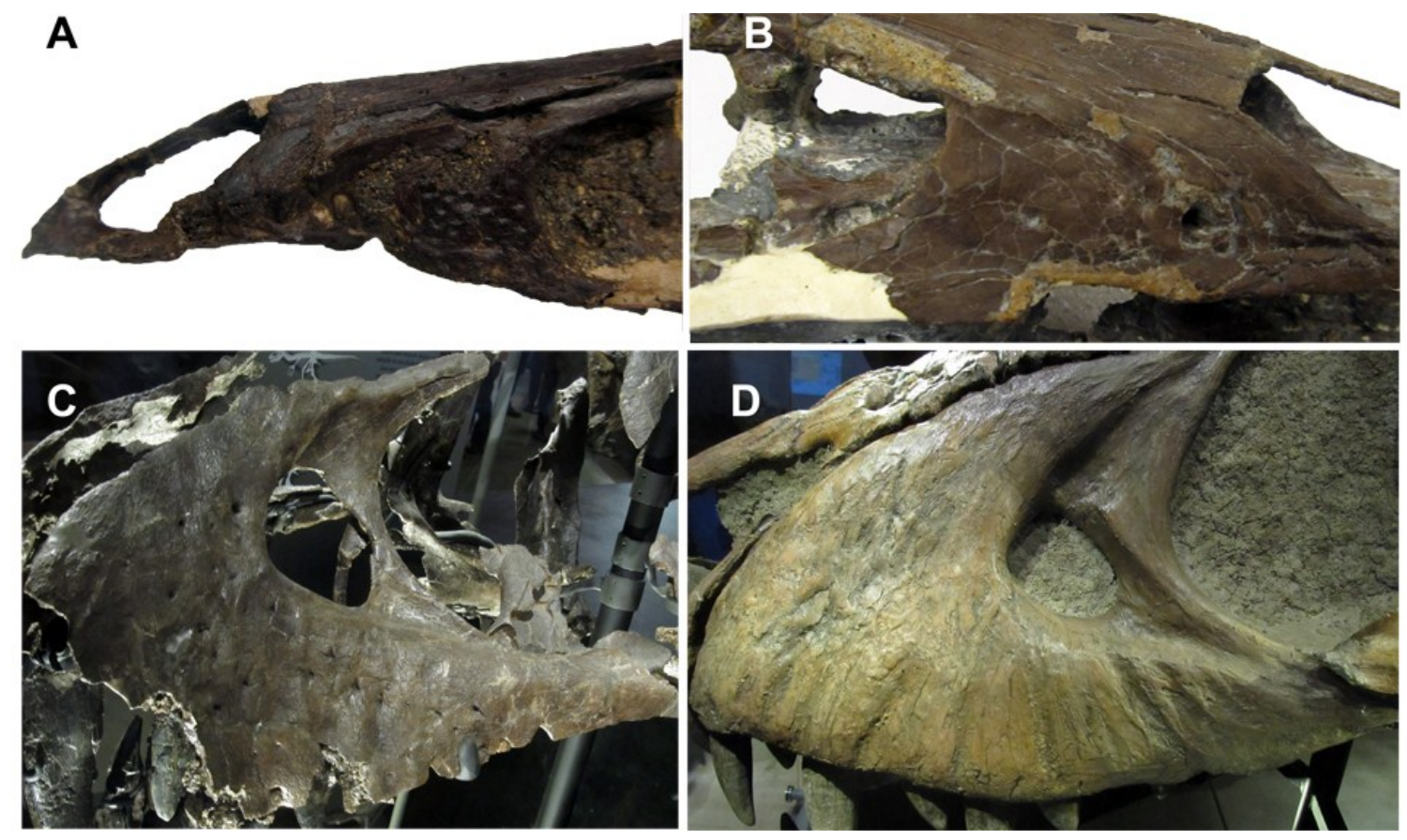
include 1) the shape of the maxilla-jugal contact, 2) the reduction of the mid-caudal neural spines, 3) the convex fusion of the left and right ischia, 4) the medial condyle of the tibia larger than the lateral condyle, and 5) the form of the distal end of the third metatarsal. Further characters differentiate the new taxon from each other ornithomimid taxon found in the Dinosaur Park Formation. The recognition of this new taxon increases the number of ornithomimid taxa known from the Dinosaur Park Formation to at least four. Fusion of the proximal tarsals to the tibia in some ornithomimid specimens was observed to be more complete than previously recognized, increasing the known resemblance of these non-avian coelurosaurs to birds.

\section{SYSTEMATIC PALAEONTOLOGY}

Theropoda Marsh, 1881

Ornithomimosauria Barsbold, 1976

Ornithomimidae Marsh, 1890

Rativates, new genus

Etymology: Latin ratis meaning raft, in reference to the ratite birds; and Latin vates meaning seer or foreteller. The name alludes to the paradox of an "ostrich mimic" that existed before ostriches. 
Diagnosis: As for the type species, R. evadens.

\section{R. evadens, new species}

Etymology: Latin evadere meaning to evade, in reference to this swift-footed dinosaur's ability to evade predators in the Late Cretaceous, as well as recognition as a new species in the 80 years following the discovery of the holotype.

Holotype: ROM 1790, incomplete skull and postcranial skeleton.

Type locality: Quarry no. Q028 (Currie and Koppelhus 2005) in the lower Dinosaur Park Formation (upper Campanian) near Dinosaur Provincial Park, Alberta, Canada.

Diagnosis: Rativates evadens is diagnosed by the following autapomorphies: 1) Maxilla with the contact for the jugal short and blunt rather than long and tapered, 2) mid-caudal neural spines reduced over the transition point of the tail, 3) ischial posterior contact convex and completely fused, 4) medial condyle of tibia larger than lateral condyle, and 5) the third metatarsal possessing a unique shape in distal view that has a straight posterior edge and is deeper laterally than medially. Among the approximately contemporaneous ornithomimid taxa in the Dinosaur Park Formation, it is further distinguished from Struthiomimus altus by a) the long antilium reaching approximately as far cranially as the end of the pubic shaft (excluding the boot), and b) the comparatively straight medial edge of the third metatarsal in anterior view; from Ornithomimus samueli by a) the absence of a foramen at the base of the nasal process of the premaxilla, and b) a proportionately shorter, deeper antorbital fossa (these characters unknown in the Dinosaur Park 
Formation material of S. altus); and from the unnamed large ornithomimid (Longrich 2008) by a) a relatively small adult body size, and b) straight pedal unguals that lack the strongly angled articular facet, large proximodorsal process, and prominent flexor tubercle of that taxon. 


\section{CHAPTER 3}

\section{EVALUATION OF IDENTIFIED OCURRENCES OF ORNITHOMIMIDAE IN THE UPPER CRETACEOUS (SANTONIAN-CAMPANIAN) OF ALBERTA}

\section{INTRODUCTION}

The paleobiogeographic history of ornithomimosaurs in the Late Cretaceous of Laramidia is poorly understood, with a long gap between the records of poorly known possible ornithomimosaurs in the Early Cretaceous of North America (Gilmore 1920, Ostrom 1970) and the well known Campanian-Maastrichtian taxa (Russell 1972). In Alberta, no articulated ornithomimosaur skeletons have been collected to date from the lower part (regressive phase) of the Campanian Belly River Group (Foremost and Oldman formations), or the older terrestrial dinosaurbearing sediments of the Santonian Milk River Formation. Occurrences of Ornithomimidae in these units are based on identification of isolated bones and are largely unsubstantiated records in faunal lists (Ryan \& Russell 2001, Weishampel et al. 2004). Phylogenetic analyses indicate that the Albertan ornithomimids Struthiomimus altus and Ornithomimus edmontonicus are deeply nested within a clade of Asian ornithomimosaurs (Kobayashi \& Lü 2003, Xu et al. 2011, Lee et al. 2014), suggesting that the ancestors of these taxa migrated into Laramidia from eastern Asia. The poor fossil record of ornithomimosaurs in North America prior to the late Campanian makes it unclear when this migration occurred. Zanno et al. (2013: 509) noted that ornithomimids are abundant in the late Campanian 
Kaiparowits Formation of Utah, but absent so far in the older Iron Springs, Dakota, Straight Cliffs, and Wahweap formations. Although they attributed this to taphonomic bias, a similar pattern is seen in Alberta with ornithomimids becoming suddenly abundant in the late Campanian Dinosaur Park Formation, and only questionably present based on limited material in older formations. A faunal interchange event in the Campanian involving the arrival of Ornithomimidae in Laramidia may have coincided with the arrival of Troodontidae, another family of coelurosaurs with Asian affinities that is reasonably abundant in the Dinosaur Park Formation yet absent in the Milk River Formation based on intensively studied tooth assemblages (Larson \& Currie 2013).

A search of museum collections and databases was conducted for material from the Milk River, Foremost, and Oldman formations previously identified as belonging to Ornithomimidae (Tables 3.1 and 3.2). Comparisons were made to associated ornithomimid skeletons including the holotypes of Struthiomimus altus (CMN 930), Ornithomimus edmontonicus (CMN 8632), and here newly described Rativates evadens (ROM 1790), as well as other Late Cretaceous coelurosaurs including tyrannosaurids, deinonychosaurs, and oviraptorosaurs. It is assumed that Late Cretaceous ornithomimid morphology was generally conservative, and that isolated elements not closely resembling their counterparts in more complete ornithomimid skeletons are probably not ornithomimid. Isolated elements that fall within the range of variation for that element in Ornithomimidae are considered probably ornithomimid, but if the element does not contain any diagnostic ornithomimid characters it is possible that the similarity is merely convergent or 
TABLE 3.1. List of material from the Milk River, Foremost, and Oldman formations previously catalogued as Ornithomimidae, and revised identifications.

\begin{tabular}{|c|c|c|c|c|}
\hline Formation & Specimen & Locality & Element(s) & Identification \\
\hline \multirow[t]{11}{*}{$\begin{array}{l}\text { Oldman } \\
\text { (upper) }\end{array}$} & $\begin{array}{l}\text { TMP } \\
1995.092 .0006\end{array}$ & Devil's Coulee & $\begin{array}{l}\text { caudal } \\
\text { vertebra }\end{array}$ & not seen \\
\hline & $\begin{array}{l}\text { TMP } \\
2001.036 .0003\end{array}$ & Manyberries & ulna & not seen \\
\hline & $\begin{array}{l}\text { TMP } \\
2007.035 .0026 \\
\end{array}$ & Murray Ranch & $\begin{array}{l}\text { caudal } \\
\text { vertebra }\end{array}$ & $\begin{array}{l}\text { ornithomimid, cf. } \\
\text { Ornithomimus }\end{array}$ \\
\hline & $\begin{array}{l}\text { TMP } \\
2009.033 .0011\end{array}$ & $\begin{array}{l}\text { South } \\
\text { Saskatchewan } \\
\text { River }\end{array}$ & $\begin{array}{l}\text { manual } \\
\text { ungual } \\
\text { fragment }\end{array}$ & ornithomimid \\
\hline & $\begin{array}{l}\text { TMP } \\
2009.033 .0012\end{array}$ & $\begin{array}{l}\text { South } \\
\text { Saskatchewan } \\
\text { River }\end{array}$ & pedal ungual & ornithomimid \\
\hline & $\begin{array}{l}\text { TMP } \\
2009.033 .0013\end{array}$ & $\begin{array}{l}\text { South } \\
\text { Saskatchewan } \\
\text { River }\end{array}$ & $\begin{array}{l}\text { pedal phalanx } \\
\text { III-2, other } \\
\text { fragments }\end{array}$ & ornithomimid \\
\hline & $\begin{array}{l}\text { TMP } \\
2009.033 .0014\end{array}$ & $\begin{array}{l}\text { South } \\
\text { Saskatchewan } \\
\text { River }\end{array}$ & $\begin{array}{l}\text { pedal phalanx } \\
\text { III-1 }\end{array}$ & ornithomimid \\
\hline & $\begin{array}{l}\text { TMP } \\
2009.039 .0190\end{array}$ & $\begin{array}{l}\text { McPheeters } \\
\text { bonebed }\end{array}$ & ungual & $\begin{array}{l}\text { turtle?, not } \\
\text { ornithomimid }\end{array}$ \\
\hline & $\begin{array}{l}\text { TMP } \\
2009.066 .0001\end{array}$ & $\begin{array}{l}\text { South } \\
\text { Saskatchewan } \\
\text { River }\end{array}$ & $\begin{array}{l}\text { phalanx } \\
\text { fragment }\end{array}$ & indeterminate \\
\hline & $\begin{array}{l}\text { TMP } \\
2010.076 .0007\end{array}$ & Murray Ranch & metatarsal & not seen \\
\hline & $\begin{array}{l}\text { TMP } \\
2012.037 .0118 \\
\end{array}$ & $\begin{array}{l}\text { McPheeters } \\
\text { bonebed }\end{array}$ & $\begin{array}{l}\text { caudal } \\
\text { vertebra }\end{array}$ & not seen \\
\hline \multirow[t]{4}{*}{$\begin{array}{l}\text { Oldman } \\
\text { (middle) }\end{array}$} & $\begin{array}{l}\text { TMP } \\
1996.012 .0140\end{array}$ & $\begin{array}{l}\text { Dinosaur } \\
\text { Provincial } \\
\text { Park }\end{array}$ & Metatarsal & not seen \\
\hline & $\begin{array}{l}\text { TMP } \\
2002.068 .0303\end{array}$ & $\begin{array}{l}\text { Dinosaur } \\
\text { Provincial } \\
\text { Park }\end{array}$ & $\begin{array}{l}\text { pedal phalanx } \\
\text { II-2 }\end{array}$ & ornithomimid \\
\hline & $\begin{array}{l}\text { TMP } \\
2005.012 .0271\end{array}$ & $\begin{array}{l}\text { Dinosaur } \\
\text { Provincial } \\
\text { Park }\end{array}$ & $\begin{array}{l}\text { pedal phalanx } \\
\text { III-2 }\end{array}$ & ornithomimid \\
\hline & $\begin{array}{l}\text { TMP } \\
2005.049 .0088\end{array}$ & $\begin{array}{l}\text { Dinosaur } \\
\text { Provincial } \\
\text { Park }\end{array}$ & $\begin{array}{l}\text { pedal phalanx } \\
\text { III-3 }\end{array}$ & $\begin{array}{l}\text { ornithomimid or } \\
\text { tyrannosaurid? }\end{array}$ \\
\hline
\end{tabular}


TABLE 3.1, Continued.

\begin{tabular}{|c|c|c|c|c|}
\hline & $\begin{array}{l}\text { TMP } \\
2008.045 .0017\end{array}$ & $\begin{array}{l}\text { Pinhorn } \\
\text { Ranch }\end{array}$ & metatarsal & not seen \\
\hline & $\begin{array}{l}\text { TMP } \\
2009.033 .0010\end{array}$ & $\begin{array}{l}\text { South } \\
\text { Saskatchewan } \\
\text { River }\end{array}$ & $\begin{array}{l}\text { proximal } \\
\text { femur }\end{array}$ & indeterminate \\
\hline & $\begin{array}{l}\text { TMP } \\
2011.052 .0008\end{array}$ & $\begin{array}{l}\text { Milk Ridge } \\
\text { Reservoir }\end{array}$ & $\begin{array}{l}\text { femur } \\
\text { fragments }\end{array}$ & indeterminate \\
\hline & UALVP 49009 & $\begin{array}{l}\text { Dinosaur } \\
\text { Provincial } \\
\text { Park }\end{array}$ & $\begin{array}{l}\text { astragalus } \\
\text { and } \\
\text { calcaneum }\end{array}$ & troodontid? \\
\hline & UALVP $53660 ?$ & $\begin{array}{l}\text { Dinosaur } \\
\text { Provincial } \\
\text { Park }\end{array}$ & pedal ungual & ornithomimid \\
\hline \multirow[t]{6}{*}{$\begin{array}{l}\text { Oldman } \\
\text { (lower) }\end{array}$} & $\begin{array}{l}\text { TMP } \\
2009.150 .0003\end{array}$ & Redcliff & $\begin{array}{l}\text { manual } \\
\text { ungual }\end{array}$ & ornithomimid? \\
\hline & $\begin{array}{l}\text { TMP } \\
2009.150 .0004\end{array}$ & Redcliff & $\begin{array}{l}\text { ungual } \\
\text { fragment }\end{array}$ & indeterminate \\
\hline & $\begin{array}{l}\text { TMP } \\
2011.053 .0006\end{array}$ & $\begin{array}{l}\text { South Side } \\
\text { Ceratopsian }\end{array}$ & $\begin{array}{l}\text { pedal phalanx } \\
\text { II-2 }\end{array}$ & ornithomimid \\
\hline & $\begin{array}{l}\text { TMP } \\
2011.053 .0007\end{array}$ & $\begin{array}{l}\text { South Side } \\
\text { Ceratopsian }\end{array}$ & metatarsal I & oviraptorosaur? \\
\hline & $\begin{array}{l}\text { TMP } \\
2011.053 .0020\end{array}$ & $\begin{array}{l}\text { South Side } \\
\text { Ceratopsian }\end{array}$ & $\begin{array}{l}\text { pedal phalanx } \\
\text { II-1 }\end{array}$ & ornithomimid? \\
\hline & $\begin{array}{l}\text { TMP } \\
2011.053 .0030\end{array}$ & $\begin{array}{l}\text { South Side } \\
\text { Ceratopsian }\end{array}$ & $\begin{array}{l}\text { pedal phalanx } \\
\text { III-1 }\end{array}$ & ornithomimid \\
\hline \multirow{5}{*}{$\begin{array}{l}\text { Oldman } \\
\text { (level not } \\
\text { known) }\end{array}$} & $\begin{array}{l}\text { TMP } \\
2008.075 .0019\end{array}$ & $\begin{array}{l}\text { Milk River } \\
\text { Natural Area }\end{array}$ & $\begin{array}{l}\text { pedal phalanx } \\
\text { III-2 }\end{array}$ & ornithomimid \\
\hline & $\begin{array}{l}\text { TMP } \\
2008.075 .0029\end{array}$ & $\begin{array}{l}\text { Milk River } \\
\text { Natural Area }\end{array}$ & $\begin{array}{l}\text { pedal phalanx } \\
\text { fragment }\end{array}$ & ornithomimid? \\
\hline & $\begin{array}{l}\text { TMP } \\
2011.053 .0060\end{array}$ & $\begin{array}{l}\text { Pinhorn } \\
\text { Ranch, North } \\
\text { Site }\end{array}$ & $\begin{array}{l}\text { pedal phalanx } \\
\text { II-2, pedal } \\
\text { ungual IV-5, } \\
\text { other bone } \\
\text { fragments }\end{array}$ & ornithomimid \\
\hline & $\begin{array}{l}\text { TMP } \\
2011.065 .0039\end{array}$ & $\begin{array}{l}\text { Cecil Nesmo's } \\
\text { site \# } 1\end{array}$ & $\begin{array}{l}\text { manual } \\
\text { ungual frag. }\end{array}$ & $\begin{array}{l}\text { indeterminate } \\
\text { coelurosaur }\end{array}$ \\
\hline & $\begin{array}{l}\text { TMP } \\
2011.071 .0012\end{array}$ & $\begin{array}{l}\text { Big Muddy } \\
\text { Channel }\end{array}$ & pedal phalanx & dromaeosaurid? \\
\hline \multirow[t]{2}{*}{ Foremost } & $\begin{array}{l}\text { TMP } \\
1988.086 .0020\end{array}$ & $\begin{array}{l}\text { Pinhorn } \\
\text { Ranch }\end{array}$ & $\begin{array}{l}\text { pedal phalanx } \\
\text { IV-4 }\end{array}$ & ornithomimid? \\
\hline & $\begin{array}{l}\text { TMP } \\
2009.037 .0065\end{array}$ & $\begin{array}{l}\text { Becker's } \\
\text { Coulee }\end{array}$ & $\begin{array}{l}\text { pedal phalanx } \\
\text { III-3 }\end{array}$ & ornithomimid? \\
\hline
\end{tabular}


TABLE 3.1, Continued.

\begin{tabular}{|c|c|c|c|c|}
\hline \multirow[t]{7}{*}{ Milk River } & CMN 8728 & $\begin{array}{l}\text { No. } 5 \text { (Russell } \\
\text { 1935) }\end{array}$ & pedal phalanx & cf. Elmisaurus? \\
\hline & $\begin{array}{l}\text { TMP } \\
1990.105 .0011 ?\end{array}$ & $\begin{array}{l}\text { Gilchrist } \\
\text { Ranch }\end{array}$ & $\begin{array}{l}\text { two phalanx } \\
\text { fragments }\end{array}$ & indeterminate \\
\hline & $\begin{array}{l}\text { TMP } \\
1991.105 .0006\end{array}$ & $\begin{array}{l}\text { Gilchrist } \\
\text { Ranch }\end{array}$ & $\begin{array}{l}\text { caudal } \\
\text { vertebra }\end{array}$ & dromaeosaurid? \\
\hline & $\begin{array}{l}\text { TMP } \\
1991.006 .0011\end{array}$ & $\begin{array}{l}\text { Verdigris } \\
\text { Coulee }\end{array}$ & $\begin{array}{l}\text { two phalanx } \\
\text { fragments }\end{array}$ & indeterminate \\
\hline & $\begin{array}{l}\text { TMP } \\
1994.337 .0013\end{array}$ & $\begin{array}{l}\text { Writing-On- } \\
\text { Stone } \\
\text { Provincial } \\
\text { Park }\end{array}$ & pedal phalanx & coelurosaur indet. \\
\hline & $\begin{array}{l}\text { TMP } \\
1994.337 .0018\end{array}$ & $\begin{array}{l}\text { Writing-On- } \\
\text { Stone } \\
\text { Provincial } \\
\text { Park }\end{array}$ & $\begin{array}{l}\text { manual } \\
\text { phalanx }\end{array}$ & tyrannosaurid? \\
\hline & $\begin{array}{l}\text { TMP } \\
2008.045 .0021\end{array}$ & Audet Ranch & Metatarsal & not seen \\
\hline
\end{tabular}


TABLE 3.2. Measurements of selected elements in mm. Height and width of phalanges are from the proximal end, unless unpreserved. Incomplete elements are indicated by an asterisk.

\begin{tabular}{|l|l|l|l|}
\hline Element & $\begin{array}{l}\text { Length } \\
\text { (mm) }\end{array}$ & $\begin{array}{l}\text { Height } \\
\text { (mm) }\end{array}$ & $\begin{array}{l}\text { Width } \\
\text { (mm) }\end{array}$ \\
\hline CMN 8728, phalanx & 22 & 10 & 10.5 \\
\hline ROM 58293, pedal ungual & 38 & 16 & 16 \\
\hline ROM 58701, pedal ungual & 39 & 16 & 15 \\
\hline TMP 1988.086.0020, phalanx & 9.1 & 8.0 & 7.7 \\
\hline TMP 1991.105.0006, caudal centrum & 54.9 & $\sim 13$ & 12.1 \\
\hline TMP 1994.377.0013, phalanx & 19.7 & 10.1 & 11.6 \\
\hline TMP 1994.377.0018, phalanx & $74.2^{*}$ & 19.1 (distal) & 24.2 (distal) \\
\hline TMP 2002.068.0303, phalanx & 38.6 & 25.4 & 21.8 \\
\hline TMP 2005.012.0271, phalanx & 22.5 & 8.4 & 10.2 \\
\hline TMP 2005.049.0088, phalanx & 44.9 & 21.8 & 25.7 \\
\hline TMP 2007.035.0026, caudal centrum & 37 & 7 & 12 \\
\hline TMP 2008.075.0019, phalanx & 57.7 & 21.7 & 28.3 \\
\hline TMP 2009.033.0012, pedal ungual & 37.9 & 17.9 & 15.2 \\
\hline TMP 2009.033.0013, phalanx & 51.2 & 20.5 & 25.4 \\
\hline TMP 2009.033.0014, phalanx & 37.8 & 15.9 & 18.4 \\
\hline TMP 2009.037.0065, phalanx & $29^{*}$ & $19 *$ & 17 \\
\hline TMP 2009.039.0190, phalanx & 22 & & 9 \\
\hline TMP 2011.053.0006, phalanx & 42 & 25 & 24 \\
\hline TMP 2011.053.0007, metatarsal & $54^{*}$ & & $\sim 21$ (distal) \\
\hline TMP 2011.053.0020, phalanx & 67 & 29 & 20 \\
\hline TMP 2011.053.0030, phalanx & 70 & 31 & 36 \\
\hline TMP 2011.053.0060, phalanx II-2 & 41 & $*$ & 22 \\
\hline TMP 2011.053.0060, pedal ungual & 38 & 17 & 15 \\
\hline TMP 2011.071.0012, phalanx & 26.9 & 12.5 & 11.2 \\
\hline UALVP 49009, astragalus & $98.5^{*}$ & & 68 \\
\hline UALVP 53660?, pedal ungual & 43 & 18.5 & 15.6 \\
\hline & & & \\
\hline
\end{tabular}


symplesiormorphic with another coelurosaurian clade. For example, phalanges from pedal digit III of smaller, more gracile tyrannosaurid specimens can be quite similar to those of ornithomimids (UALVP collections, pers. obs.). Additionally, teeth of Richardoestesia are reported from the formations in this study, but the phylogenetic position and postcranial anatomy of this enigmatic coelurosaur are unknown, making it uncertain whether or not isolated elements could potentially be confused with those of ornithomimids.

\section{MILK RIVER FORMATION}

The Milk River Formation is the oldest dinosaur-bearing formation exposed in southern Alberta. All known vertebrate fossils from the Milk River Formation were collected from its upper subunit, the Deadhorse Coulee Member (Larson et al. 2014). Although previously considered lowermost Campanian (Ryan \& Russell 2001, Weishampel et al. 2004), recent studies have shown that the vertebrate fossils from the Deadhorse Coulee Member are from the upper Santonian, with an age of approximately 84 Ma (Evans et al. 2013, Larson et al. 2014). The dinosaur record of the Milk River Formation includes the pachycephalosaurid Acrotholus (Evans et al. 2013), the leptoceratopsid Gryphoceratops (Ryan et al. 2012a), and a nonlambeosaurine hadrosaurid possibly related to Lophorhothon (Larson et al. 2014). Teeth have been referred to indeterminate ankylosaurids, ceratopsids, tyrannosaurids, and the small theropods Saurornitholestes, Richardoestesia, and Paronychodon (Ryan \& Russell 2001). Larson and Currie (2013) disputed the occurrence of Saurornitholestes, but recognized a saurornitholestine, a 
dromaeosaurine, and cf. Zapsalis from the dromaeosaurid teeth in this formation. L. S. Russell (1935) and Ryan and A. P. Russell (2001) referred isolated phalanges from the Milk River Formation to Ornithomimidae, and Weishampel et al. (2004) also listed this clade as occurring in this formation.

TMP 1991.105.0006 is a fragmentary distal caudal vertebra from Peng's Site at the Gilchrist Ranch (fig. 3.1). The prezygapophyses are not preserved. The centrum is extremely elongate and rod-like, but differs from diagnostic ornithomimid distal centra in that it is not dorsoventrally compressed, and lacks a ventral groove. It is more likely that this vertebra belongs to another coelurosaur group with elongate caudal vertebrae, such as Dromaeosauridae.

TMP 2008.045.0021, catalogued as an ornithomimid metatarsal from the Audet Ranch, was not observed because it was being temporarily stored at the CMNH.

CMN 8728, a small pedal phalanx (fig 3.2), is the only specimen from the Milk River Formation that has been previously described and figured as ornithomimid, by L. S. Russell (1935: 124) . D. A. Russell (1972: 376) considered ornithomimids unknown from the Milk River Formation, and suggested that CMN 8728 "probably belongs to an immature deinonychosaur." However, neither author listed any characters supporting his identification. Reexamination of CMN 8728 confirms D. A. Russell's conclusion that CMN 8728 is non-ornithomimid. In lateral view it superficially resembles an ornithomimid pedal phalanx III-2, but the distal condyles differ in being strongly ginglymoid and asymmetrical in size and orientation. This is consistent with a deinonychosaurian (dromaeosaurid) identity. However, in 
FIGURE 3.1. Caudal vertebra TMP 1991.105.0006 in A) dorsal, B) proximal, C) left lateral, and D) distal view.

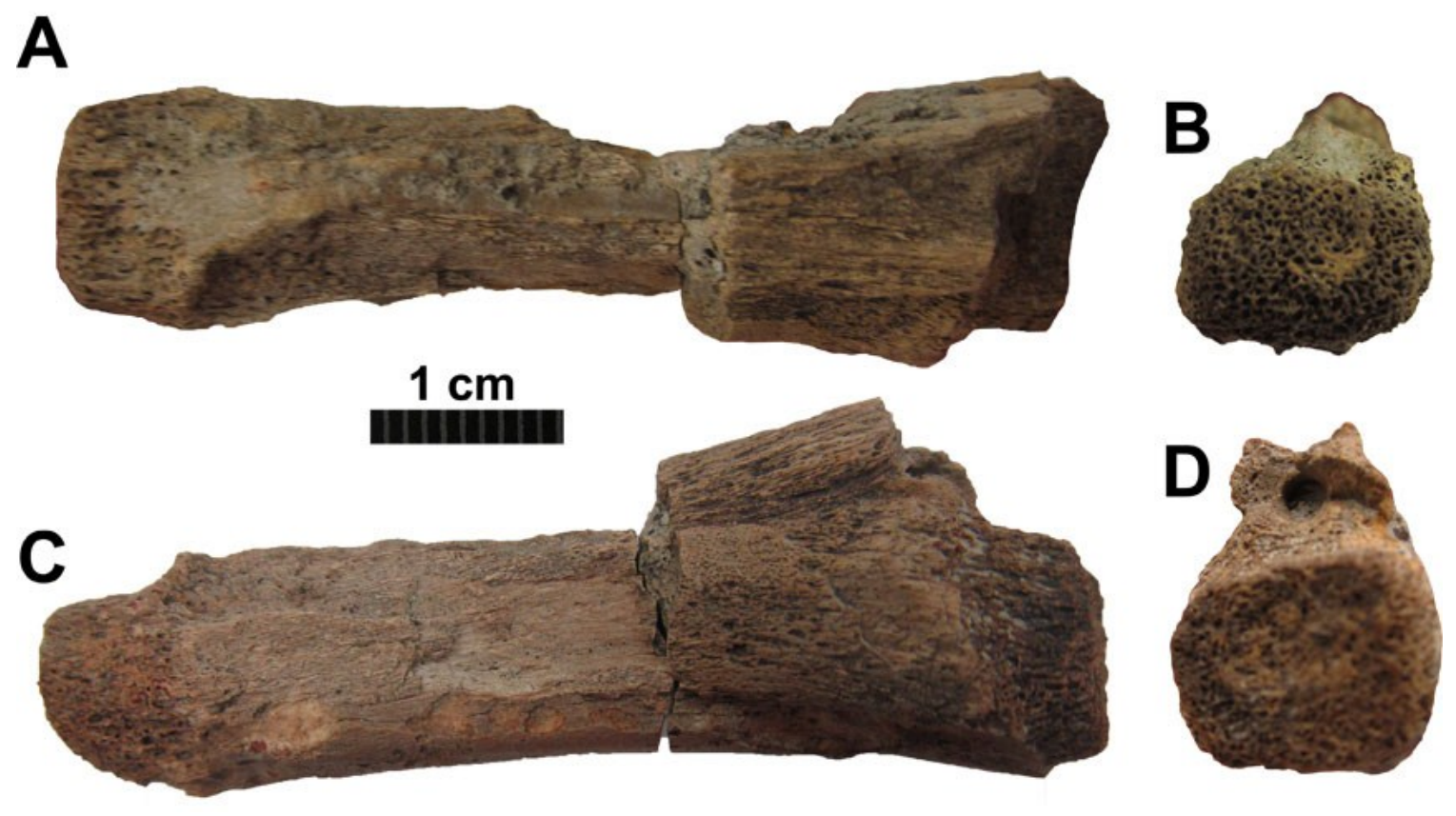


FIGURE 3.2. Pedal phalanx CMN 8728 in A-B) lateral/medial, C) dorsal, D) ventral,

E) proximal, and F) distal views. G) Elmisaurus MOR 752 after Varricchio (2001), not to the same scale.
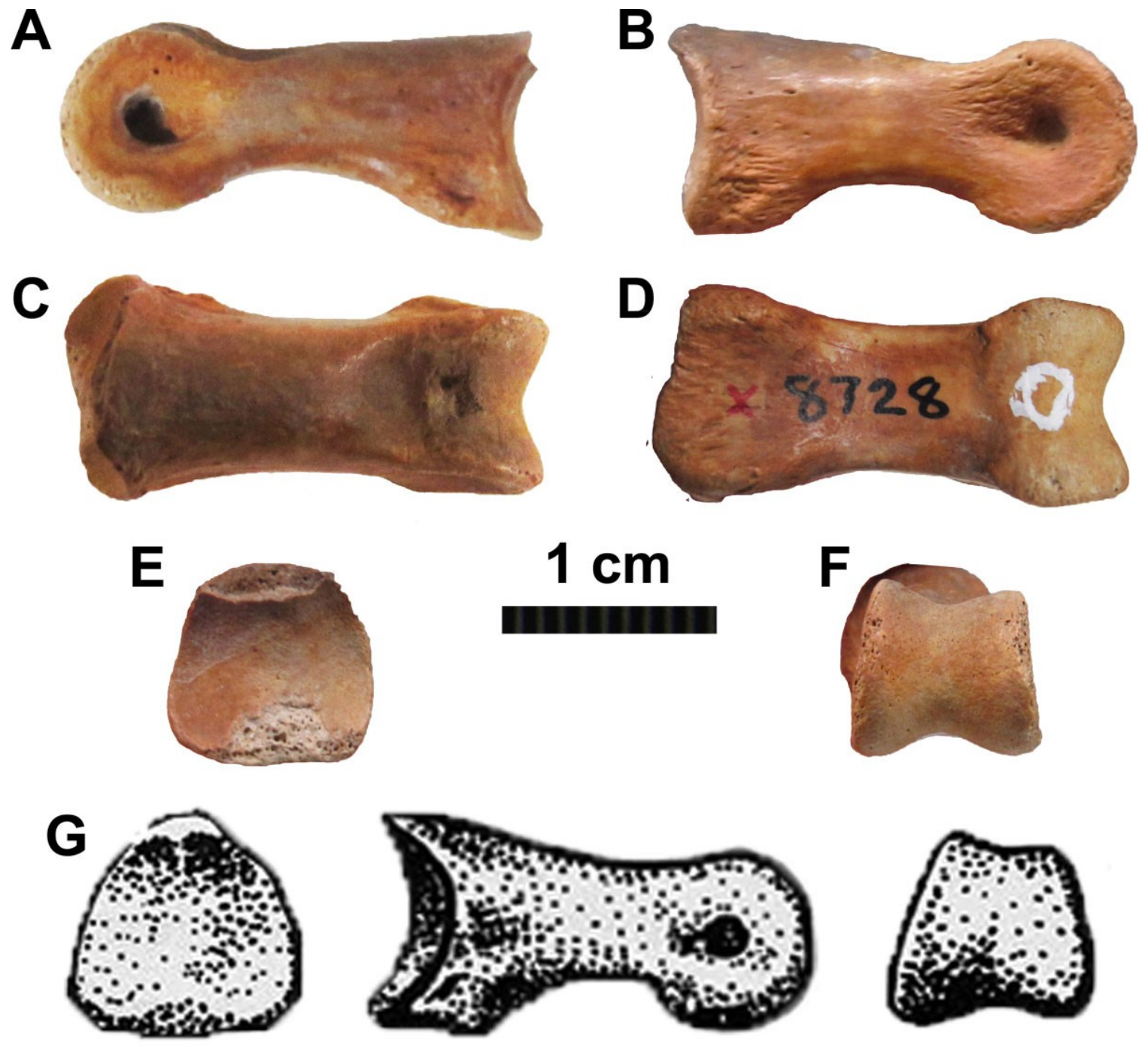
dromaeosaurids the shafts of the phalanges are often even more sharply constricted proximal to the distal condyles, and the ligament pits are often more elongate or dorsally displaced on the condyle. No phalanges of the dromaeosaurid Deinonychus antirrhopus (Ostrom 1969: fig. 75) are identical in all details to CMN 8728, but comparisons to a wider range of deinonychosaurs may reveal more similar taxa. CMN 8728 closely resembles the ginglymoid phalanx III-2 of MOR 752, a small theropod foot from the Hell Creek Formation of Montana referred to Elmisaurus elegans by Varricchio (2001: fig. 3b). In addition to being similar in overall shape, both have nearly circular distal condyles with a distinctly small, circular, and centrally positioned ligament pit. If CMN 8728 is related to MOR 752 and other elmisaurines, it would be notable as the first evidence of an oviraptorosaur in the Santonian of North America, and the oldest occurrence of this group in Canada.

TMP 1994.377.0013 is catalogued as an ornithomimid ungual from Writingon-Stone Provincial Park. This specimen actually consists of a non-ungual pedal phalanx and an indeterminate small conical element that bears little resemblance to an ungual or any other element of the ornithomimid skeleton (fig. 3.3). The nonungual phalanx is moderately elongate with an enlarged proximodorsal process, and the strong asymmetry of the ginglymoid condyles in dorsal and distal view suggests that it belongs to a left pedal digit IV. It does not resemble any ornithomimid phalanx, but could belong to the same taxon as CMN 8728 .

TMP 1994.377.0018, also from Writing-on-Stone Provincial Park, is a broken larger phalanx (fig. 3.4). It is elongate with a very broad distal intercondylar groove and prominent narrow margins of the large distal condyles. The proximal articular 
FIGURE 3.3. Pedal phalanx TMP 1994.377.0013 in A) lateral or medial, B) dorsal, C) distal, D) proximal, and E) ventral views. F-G) Indeterminate conical element in two views.

A
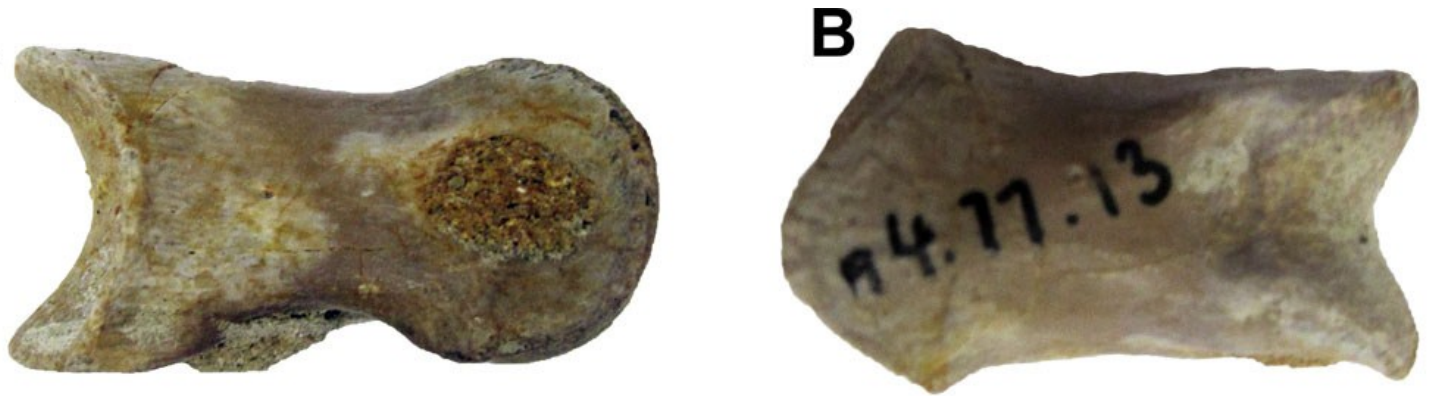

C
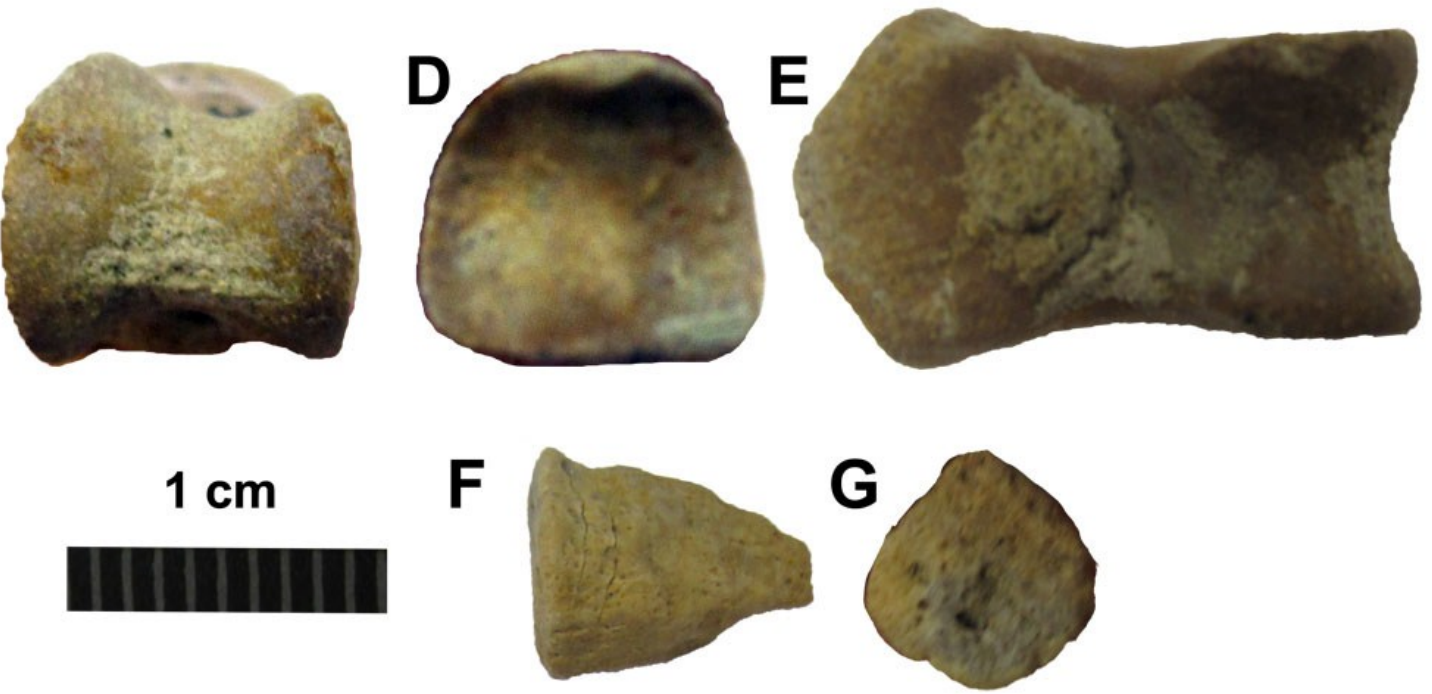
FIGURE 3.4. Manual phalanx TMP 1994.377.0018 in A-B) lateral/medial, C) dorsal,

D) ventral, E) distal, and F) proximal views.
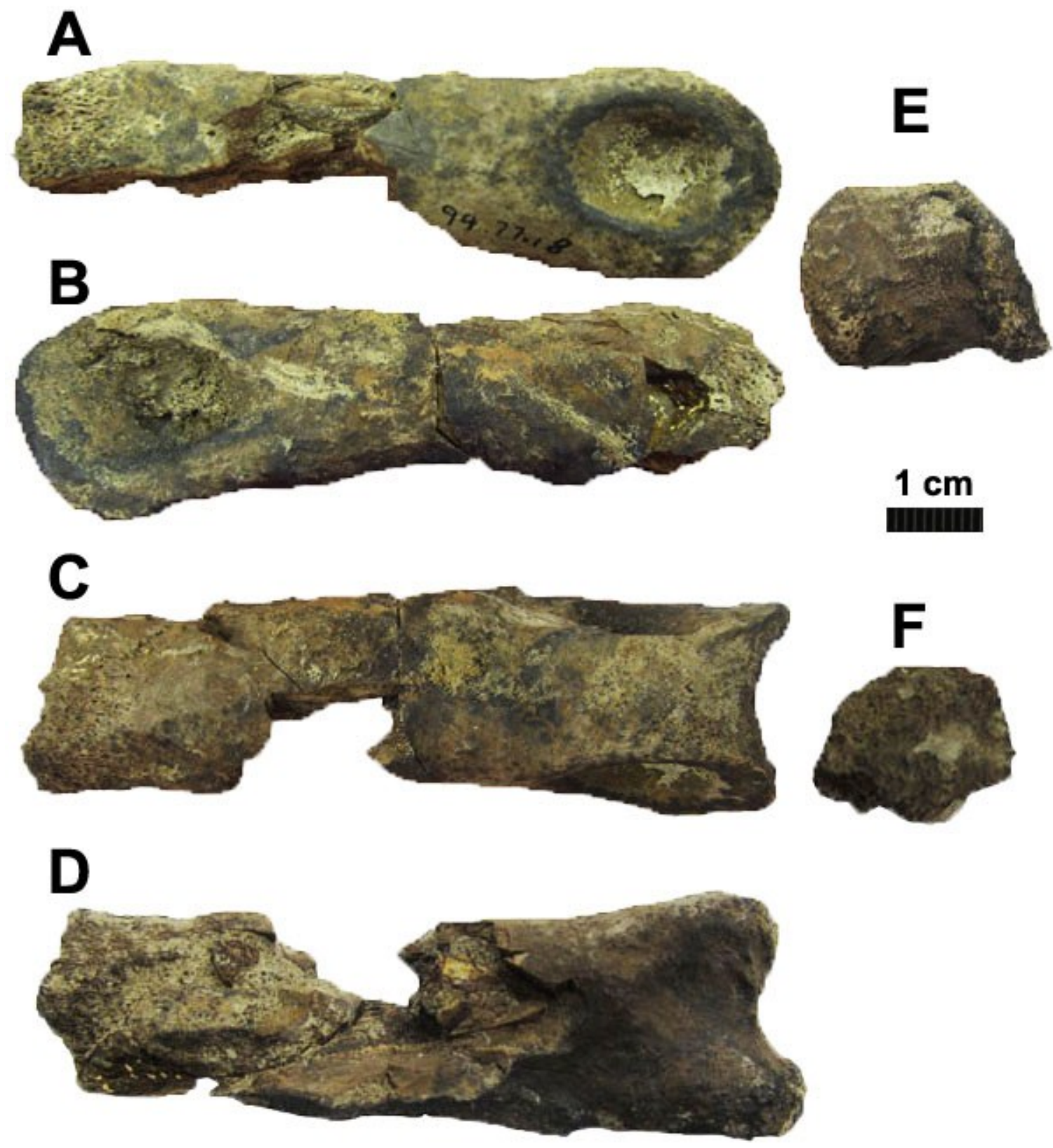
surface is not preserved. It does not resemble any element of the ornithomimid pes, and is probably a theropod penultimate manual phalanx, because the shaft is slender and the distal condyles are not as strongly distinguished from it. Assuming that this element is nearly complete, its size (over $74.2 \mathrm{~mm}$ long, distal width of 24.2 $\mathrm{mm}$ ) and proportions suggest that it is a manual phalanx I- 1 of a tyrannosaurid (Lambe 1917). In ornithomimids, the penultimate manual phalanges are narrower relative to their width, and in at least Struthiomimus (AMNH 5339) and Gallimimus (Osmólska et al. 1972: fig. 14) the area of the distal condyles is greater anteroventrally than dorsally to the ligament pits, rather than equal as in TMP 1994.377.0018.

Other phalangeal material from the Milk River Formation catalogued as ornithomimid consist only of fragments of distal condyles, and are likely indeterminate. TMP 1991.105.0011 is listed in the online catalogue (https://hermis.alberta.ca/rtmp/) as an Ornithomimus phalanx from the Gilchrist Ranch at Black Coulee. This specimen number was not found in the TMP collections, but two indeterminate distal phalanx fragments were catalogued as Ornithomimus from Peng's Site at the Gilchrist Ranch under the number TMP 1990.105.0011 (this number belongs to a specimen of the amphibian Scapherpeton, according to the online catalogue). TMP 1991.106.0011 is catalogued as an Ornithomimus phalanx from the P2 locality at Verdigris Coulee, but also consists of two indeterminate distal phalanx fragments.

\section{FOREMOST FORMATION}


The Foremost Formation is the oldest formation in the Campanian Belly River Group. It is separated from the Milk River Formation by the marine Pakowki Formation, and its base is approximately 4.2 Ma younger than the Deadhorse Coulee Member (Larson 2008). The Foremost Formation is a paralic unit that is mostly marine, but grades into near-shore nonmarine deposits towards the top (Ryan et al. 2012b). The dinosaur record of the Foremost Formation includes the pachycephalosaurid Colepiocephale (Sullivan 2003), the centrosaurine ceratopsid Xenoceratops (Ryan et al. 2012b), and a possible lambeosaurine hadrosaurid (Frankie Bedek, pers. comm. March 2015). Teeth have been referred to indeterminate ankylosaurids, nodosaurids, ?hypsilophodontids, tyrannosaurids, and the small theropods Dromaeosaurus, Saurornitholestes, Richardoestesia, and Paronychodon (Ryan \& Russell 2001). No published reports of Ornithomimidae from this formation were found, but two specimens were catalogued in the TMP.

TMP 1988.086.0020 is a very short phalanx from the Pinhorn Ranch locality, closely resembling an ornithomimid pedal phalanx IV-4 (fig. 3.5). The relatively symmetrical distal condyles and weak intercondylar groove distinguish it from pedal phalanx IV-3, which can have a similar overall shape. The shape of the proximal articulation indicates that it represents a right foot. At $9.1 \mathrm{~mm}$ long, it is approximately half the size of a typical ornithomimid pedal phalanx IV-4 from Alberta, but could represent a juvenile individual. The ventral edge of TMP 1988.086.0020 is relatively straight to very slightly concave for part of its length. It has a slightly less pronounced upturned distal end and convex ventral edge than in some ornithomimid individuals, including the holotypes of Struthiomimus altus 
FIGURE 3.5. Pedal phalanx TMP 1988.086.0020 in A) lateral, B) medial, C) distal, D) dorsal, E) ventral, and F) proximal view.

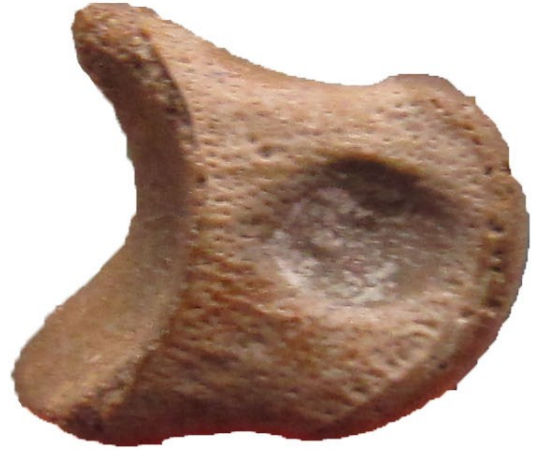

A

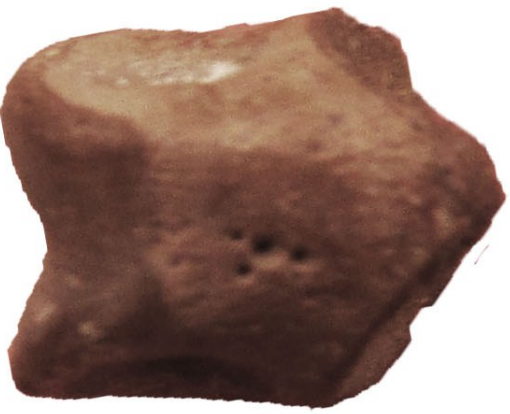

D

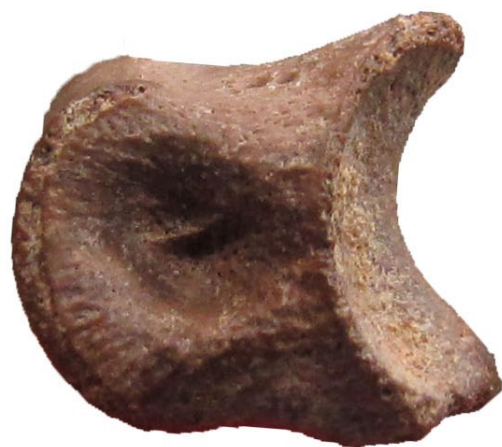

B

$1 \mathrm{~cm}$

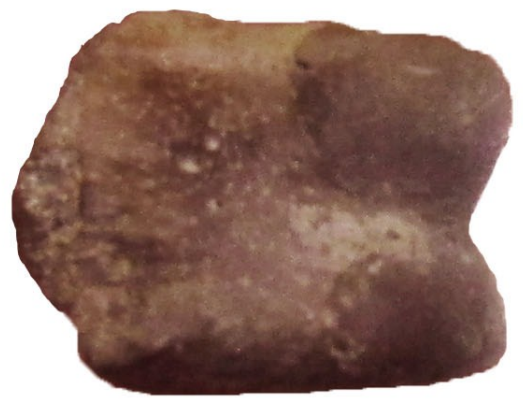

$\mathbf{E}$

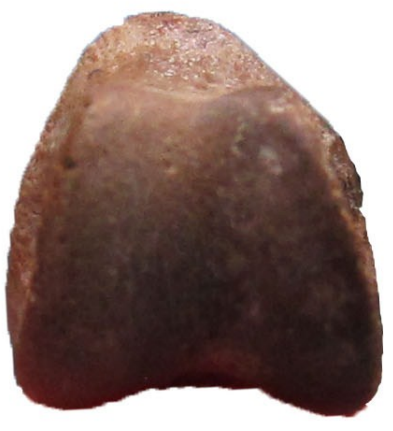

C

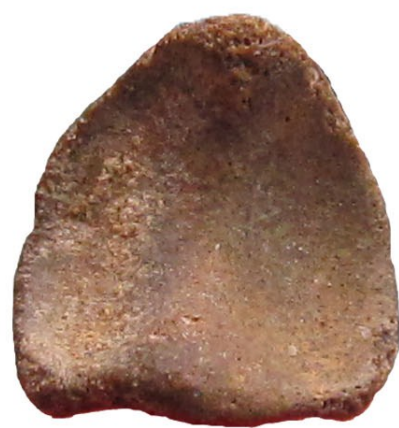

$\mathbf{F}$ 
(CMN 930), Ornithomimus edmontonicus (CMN 8632), or Rativates evadens (ROM 1790), but it compares well with the holotype of Ornithomimus brevitertius (ROM 797). Previous diagnoses and phylogenetic analyses of Ornithomimosauria or Ornithomimidae have not identified any characters of the fourth pedal digit as diagnostic of these clades. However, pedal phalanx IV-4 is much less abbreviated and has a stronger ventral concavity between the proximal articulation and the distal condyles in Dromaeosauridae (Ostrom 1969, Norell \& Makovicky 1999), Troodontidae (Zanno et al. 2011), and Caenagnathidae (Varricchio 2001; CMN 8538, pers. obs.), so TMP 1988.086.0020 can be excluded from those groups. Avimimus, another small coelurosaur possibly present in the Campanian of Alberta (Ryan \& Russell 2001), appears to have a relatively short pedal phalanx IV-4 also comparable in approximate size and shape to TMP 1988.086.0020 (Vickers-Rich et al. 2002: fig. 19). Avimimus portentosus reportedly possesses an autapomorphic ridge on the ventral surfaces of its digit IV phalanges (Vickers-Rich et al. 2002: 67), unlike the flat ventral surface of TMP 1988.086.0020, but this structure is not distinguishable in any published photographs, and could be variable among different avimimid species. Therefore, while an ornithomimid identification for TMP 1988.086.0020 is quite plausible, it may not be confirmed.

TMP 2009.037.0065, a partial phalanx from Becker's Coulee, most closely resembles pedal phalanx III-3 in ornithomimids (fig. 3.6). The proximal articular surface is missing, but enough is preserved to indicate that it resembled an ornithomimid phalanx III-3 in the general shape in proximal view, and in being more expanded in ventral view than the distal end. However, in ornithomimids 
FIGURE 3.6. Pedal phalanx TMP 2009.037.0065 in A-B) lateral/medial, C) dorsal, D) ventral, E) distal, and F) proximal views.

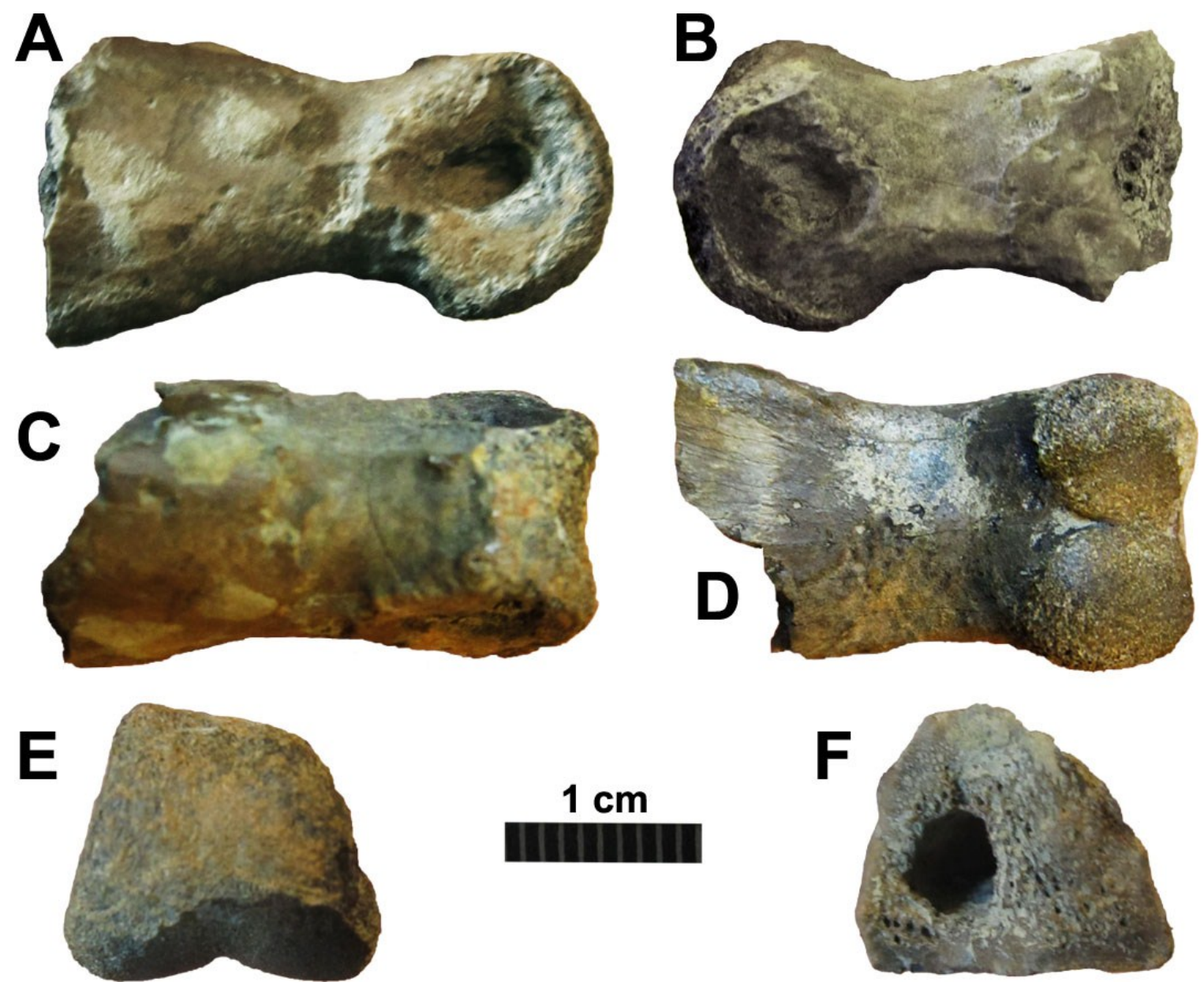


(CMN 930, ROM 1790), the dorsal edges of the distal condyles are approximately level across from each other in distal view, with a shallow concavity between them. In TMP 2009.037.0065 the shape of the distal end is more asymmetrical with the top of one condyle markedly higher than the other, and there is no dorsal concavity in distal view. This is a subtle difference between phalanges that are overall similar, so an ornithomimid identity for TMP 2009.037.0065 is regarded as possible, but uncertain.

\section{OLDMAN FORMATION}

The nonmarine Oldman Formation is the middle formation of the Belly River Group. The dinosaur record of the Oldman Formation includes the centrosaurine ceratopsids Albertaceratops, Centrosaurus, Coronosaurus, and the unnamed "South Side Ceratopsian" (Ryan et al. 2010, 2012b), the thescelosaurid Albertadromeus (Brown et al. 2013b), the hadrosaurids Brachylophosaurus and Hypacrosaurus, and the tyrannosaurid Daspletosaurus (Ryan \& Russell 2001). Teeth have been referred to indeterminate ankylosaurids, nodosaurids, pachycephalosaurids, and the small theropods Troodon (or Troodontidae indet., Larson \& Currie 2013), Dromaeosaurus, Saurornitholestes, Richardoestesia, and Paronychodon (Ryan \& Russell 2001). Ornithomimidae was included in the list of dinosaurs from the Oldman Formation by Weishampel et al. (2004), but not by Ryan and A. P. Russell (2001).

Earlier usages of the name "Oldman Formation" included what is now called the Dinosaur Park Formation, which was not recognized as separate formation until the early 1990s (Eberth \& Hamblin 1993). For example, the numerous 
ornithomimid specimens that D. A. Russell (1972) listed from the "Oldman Formation" are now either considered to be from the Dinosaur Park Formation (e.g. ROM 840, ROM 1790; Currie \& Russell 2005), or cannot be referred to either formation with certainty, because both formations crop out in the Dinosaur Provincial Park area where most of this material was collected (Eberth 2005). Longrich (2008) considered all ornithomimid material of unknown stratigraphic origin from Dinosaur Provincial Park to be more likely from the Dinosaur Park Formation, which has greater exposure and a more intensive history of collecting. To ensure that all material discussed in this section was actually collected in the Oldman Formation (sensu Eberth \& Hamblin 1993), only isolated material collected and identified after 1993 is considered.

The discussion of material from the Oldman Formation is also complicated by its diachronous contact with the Dinosaur Park Formation. Differing sediment sources and directions of sediment flow for the two formations resulted in the Dinosaur Park Formation succeeding the Oldman Formation earlier in more northern localities. The lower Dinosaur Park Formation in the Dinosaur Provincial Park area becomes time equivalent to the upper Oldman Formation in the Milk River area (Eberth 2005, Brown et al. 2013b). Consequently, the geographic locality must be taken into consideration to conclude that any material from the Oldman Formation represents the oldest definitive occurrence of Ornithomimidae in Alberta. However, material from the younger, more southern localities in the Oldman Formation is also worth reviewing, because Ryan et al. (2010) considered the upper Oldman Formation in southern Alberta to represent a relatively more 
xeric environment than the time-equivalent lower Dinosaur Park Formation farther north. Several authors (Barsbold \& Osmólska 1990, Norell et al. 2001a, Makovicky et al. 2004) have noted that ornithomimids are more commonly known from increasingly mesic paleoenvironments, such as the Dinosaur Park and Nemegt formations, and are surprisingly rare in drier paleoenvironments such as the Djadokhta Formation that are otherwise rich in theropod remains. The Oldman Formation material is assigned to the three informal subunits in Table 3.1.

\section{Lower Unit of Oldman Formation}

A fragmentary manual ungual is represented by TMP 2009.150.0003 from Redcliff (fig. 3.7 A). This fragment has a relatively straight ventral edge in lateral view, as in unguals of Ornithomimus (CMN 8632, ROM 851) and the middle section of the lateral unguals of Struthiomimus (AMNH 5339). The ventral surface is flat across in cross-section, as in Ornithomimus and Anserimimus (Bronowicz 2011: character 40.1). However, the ungual of TMP 2009.150.0003 is very narrow and does not have incipient alae.

TMP 2011.053.0007 is a distal end of a small theropod metatarsal from the South Side Ceratopsian locality. It is characterized by an extremely compressed, teardrop-shaped shaft, wide flanges above the distal condyles, and a prominent intercondylar groove, and is identified as left metatarsal I (compare to Chirostenotes; Currie \& Russell 1988: fig. 10g-i). The absence of metatarsal I is widely considered a synapomorphy of Ornithomimidae (Makovicky et al. 2004: 148), with the exception 
FIGURE 3.7. Fragmentary ornithomimid manual unguals from the Oldman

Formation: A) TMP 2009.150.0003. B) TMP 2009.033.0011.

A
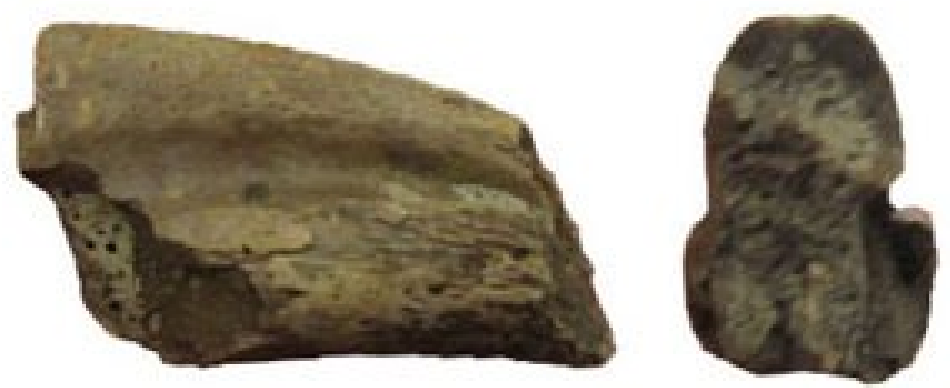

$1 \mathrm{~cm}$
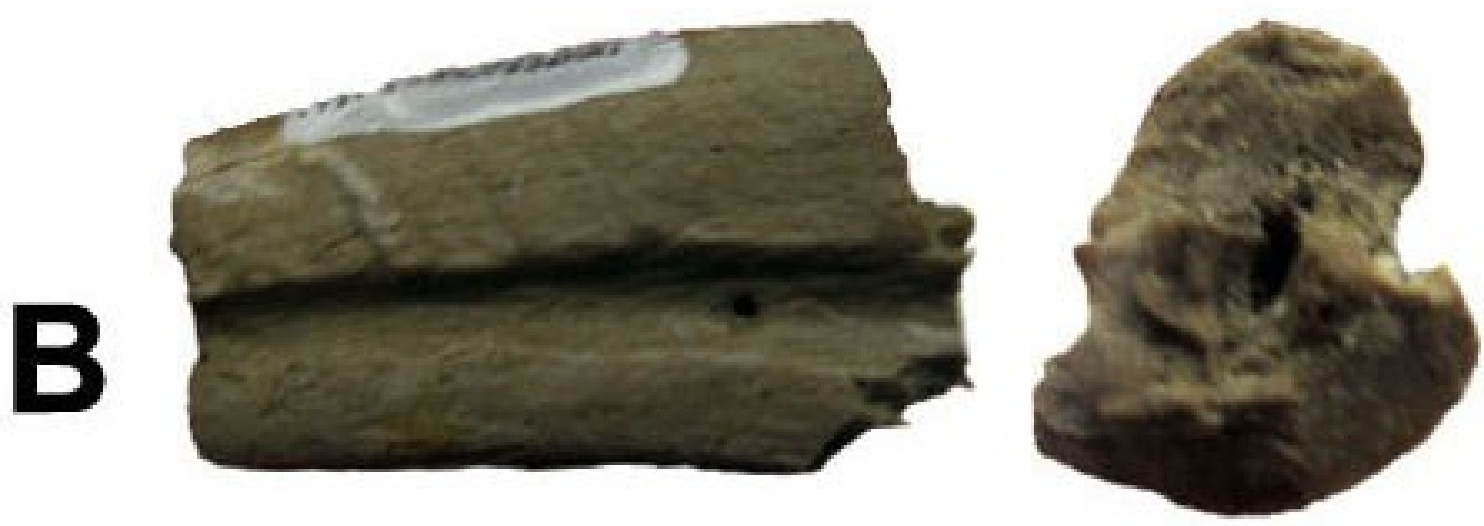
FIGURE 3.8. Metatarsal I in A) TMP 2011.053.0007 and B) Chirostenotes pergracilis (modified from Currie \& Russell 1988).

\section{A}
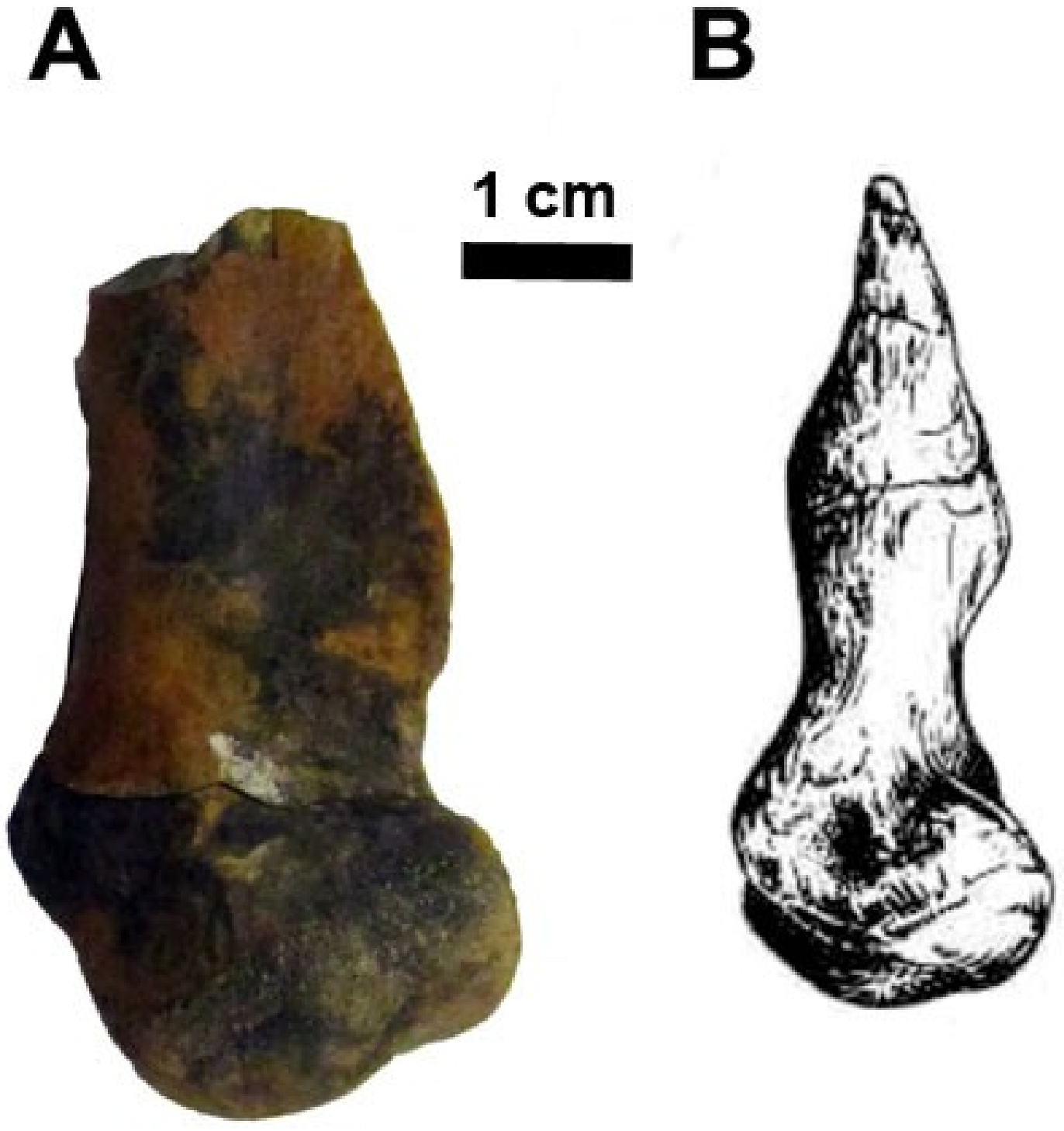
of an unnamed basal ornithomimid from China (Lü et al. 2009: fig. 5a), so this element is probably not ornithomimid.

The proportions of the phalanges in pedal digit II constitute a synapomorphy of derived ornithomimosaurs (Kobayashi \& Lü 2003: character 38.1), so these elements are distinctive. Pedal phalanx II- 1 is represented by TMP 2011.053.0020 from the South Side Ceratopsian site (fig. 3.9 A). It differs from pedal phalanx III-1 in being narrower and less symmetrical. Comparisons to other ornithomimids suggest that it is from the left foot, because the medial distal condyle is more upturned with a shallow pit, and the lateral distal condyle is more pendant with a deep pit. The distal condyles appear slightly reduced in comparison to other ornithomimids. The phalanx is very elongate and gracile, more closely resembling Ornithomimus edmontonicus (CMN 8632) than the relatively robust pedal phalanx II-1 in 0 . velox (CMN 12242, cast of YPM 542) and Struthiomimus altus (CMN 930).

A left pedal phalanx II-2 is represented by TMP 2011.053.0006 from the South Side Ceratopsian site (fig 3.9 B). The proximal surface is much wider ventrally than dorsally, and the ventromedial corner is expanded into a distinct lobe, resulting in a partly concave medial outline of the proximal surface (fig. 2.25). This condition is also present in Qiupalong henanensis (Xu et al. 2011: fig. 7e) and AMNH 5385, a partial skeleton from Dinosaur Provincial Park referred to Struthiomimus altus (Osborn 1917, Russell 1972), but not the type specimen (CMN 930).

Pedal phalanx III-1 is represented by TMP 2011.0053.0030 from the South Side Ceratopsian site (fig 3.9 C). Slight ridges are present along the proximoventral edges, but these are much weaker than in Rativates evadens (ROM 1790). This 
FIGURE 3.9. Ornithomimid pedal phalanges from the lower unit of the Oldman Formation: A) TMP 2011.053.0020, B) TMP 2011.053.0006, C) TMP 2011.0053.0030.
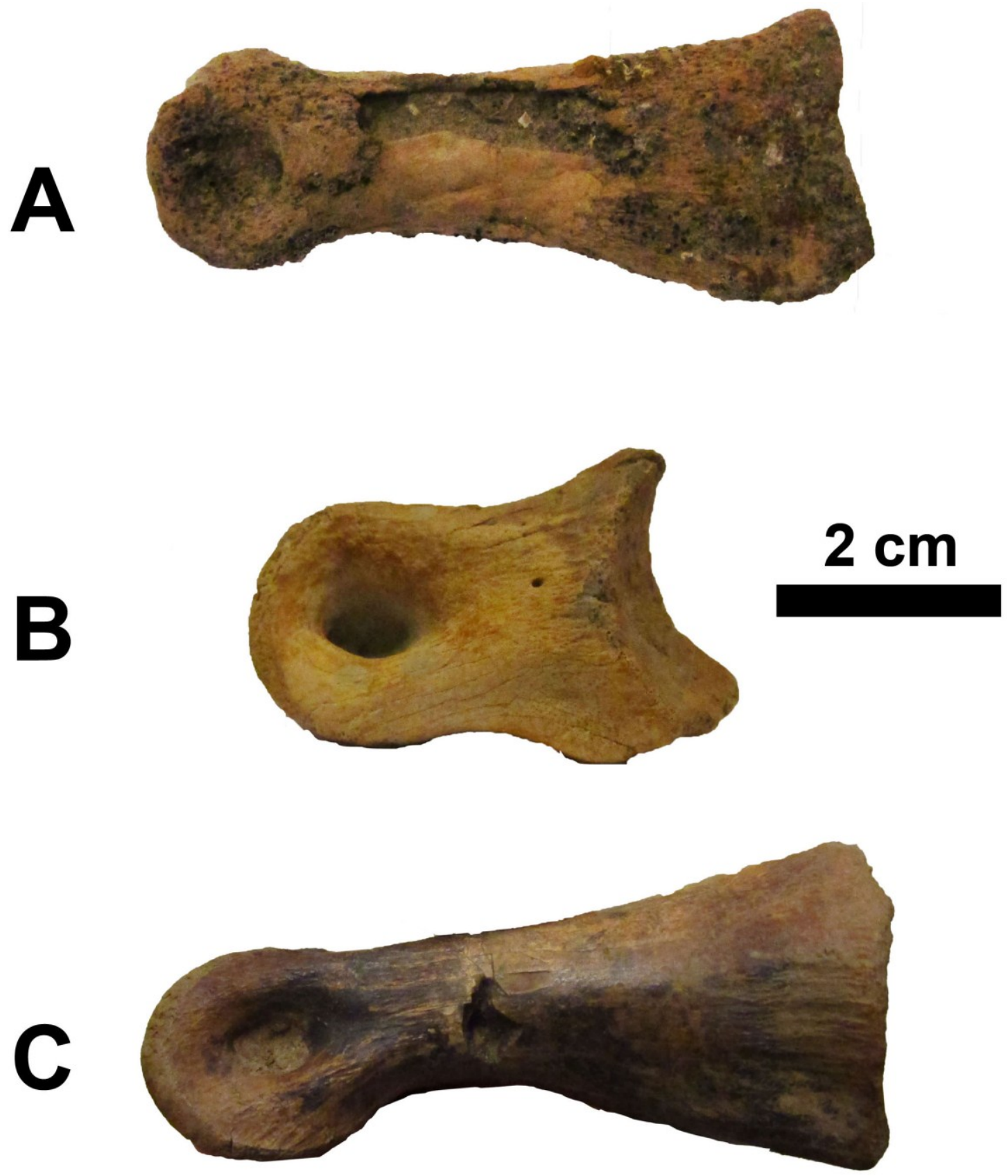
region is damaged or inaccessible in the holotypes of Struthiomimus altus and Ornithomimus edmontonicus.

An additional ungual fragment collected from the Redcliff locality, TMP 2009.150.0004, superficially resembles an ornithomimid pedal ungual, but differs in the absence of prominent grooves above the lateral and medial ridges, the absence of proximal "spurs," and the ridges positioned at mid-height on the ungual rather than along the ventral edge.

\section{Middle Unit of Oldman Formation (Comrey Sandstone)}

TMP 2009.033.0010 from the South Saskatchewan River area may represent a proximal fragment of an ornithomimid right femur (fig. 3.10). It has two large foramina medial to the proximal end of the lesser trochanter, which are definitely absent in at least one well-preserved specimen of Ornithomimus (ROM 852), but may have been present in others (AMNH 5201, ROM 851). Somewhat similarly positioned large foramina may also be visible in a published photograph of a Gallimimus femur (Osmólska et al. 1972: pl. 47), but are absent on a cast (ROM 21704). TMP 2011.052.0008, from the Milk Ridge Reservoir locality, consists of two fragments of uncertain association. The larger fragment also appears to have had two large foramina medial to the lesser trochanter, but the lesser trochanter is broken off. The greater trochanter and femoral head are similar in size and shape to other ornithomimids, and also indicate a right femur. The slightly smaller fragment may represent the distorted distal end of a left femur, but the shape is unusual and would lack the deeper intercondylar fossa characteristic of ornithomimid femora. 
FIGURE 3.10. Possible ornithomimid femora from the Oldman Formation, A) TMP 2009.033.0010 and B) TMP 2011.052.0008, compared to C) Ornithomimus "ingens" (ROM 852) from the Horseshoe Canyon Formation. Arrows indicate foramina.

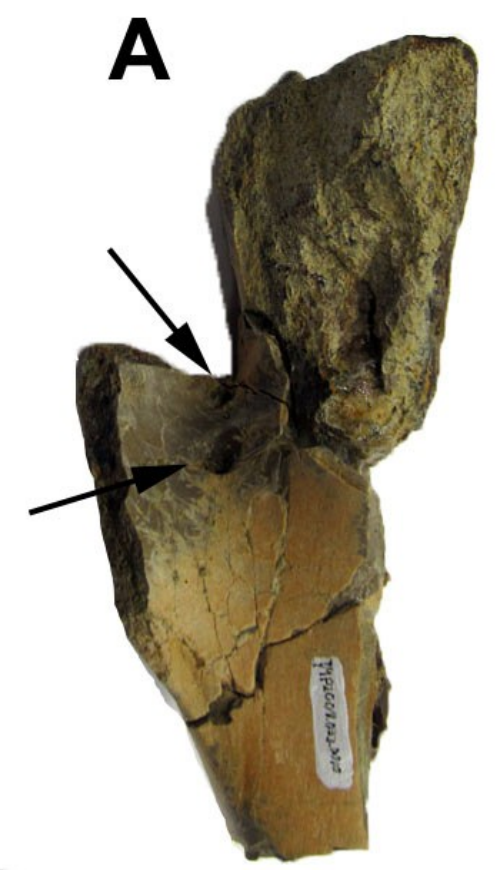

$3 \mathrm{~cm}$

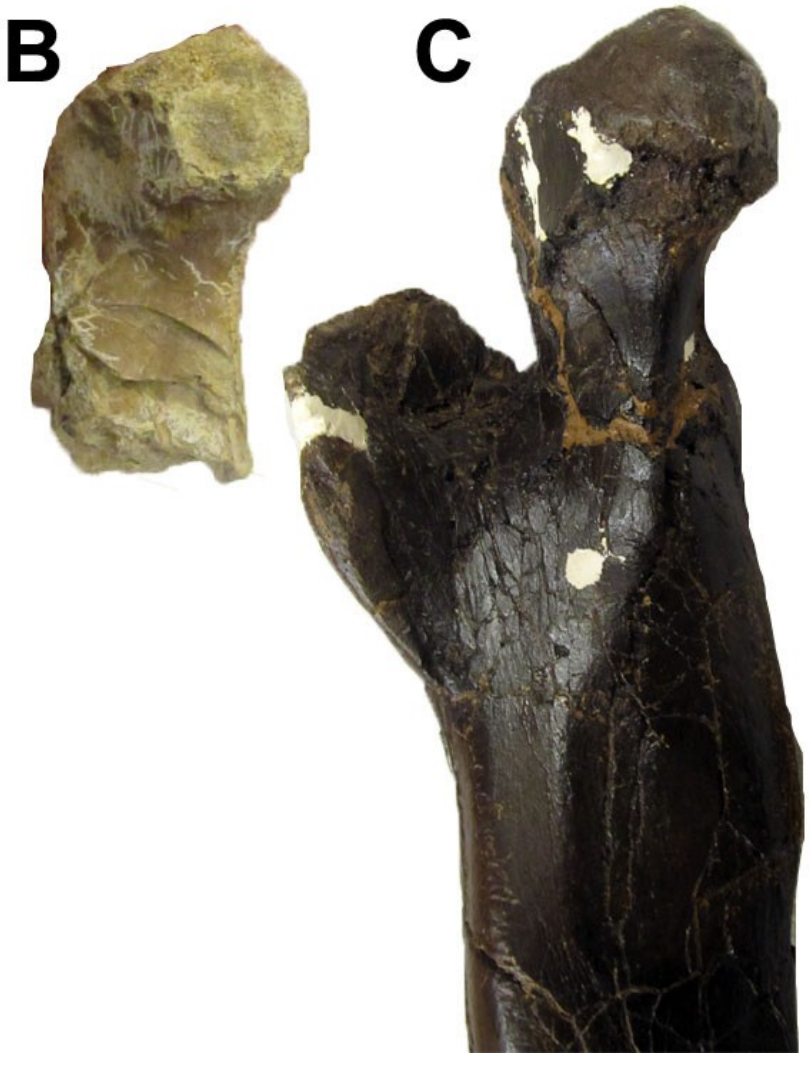


UALVP 49009 is a small theropod astragalus and fused calcaneum from the Oldman Formation of Dinosaur Provincial Park (fig. 3.11). Although catalogued as ornithomimid, it differs from other astragali of that family in having a proportionately narrower anterior ascending process that is centered over the lateral half of the astragalus. The medial edge of the ascending process is sinuous with a flared base above the medial condyle in anterior view, as in some troodontids (Zanno et al. 2011: fig. 9b), whereas it is relatively straight in ornithomimids and most other coelurosaurs.

TMP 1996.012.0140 is catalogued as an ornithomimid metatarsal and a phalanx from the Oldman Formation of Dinosaur Provincial Park, but I was unable to find it in the TMP collections. TMP 2008.045.0017, a metatarsal from the Pinhorn Ranch, was not observed because it is being temporarily stored at the CMNH.

A right pedal phalanx II-2 is represented by TMP 2002.068.0303, surfacecollected from the Coronosaurus bonebed BB138 in Dinosaur Provincial Park (fig. 3.12). The lateral edge of the proximal articular facet is approximately vertical in TMP 2002.053.0006, versus more inclined in TMP 2011.053.0006 from the lower unit.

Pedal phalanx III-2 is represented by TMP 2005.012.0271 from BB107 in Dinosaur Provincial Park (fig. 3.13). This specimen is very small for an ornithomimid pedal phalanx III-2 (22.5 mm long), and is proportionately very long and shallow in lateral view. The proximal articular surface has approximately parallel and vertical sides in proximal view, as in Ornithomimus edmontonicus (CMN 8632), Rativates evadens (ROM 1790), and the ?Struthiomimus altus referred 
FIGURE 3.11. Left astragalus and calcaneum of A) UALVP 49009 (Troodontidae?), compared to B) TMP 1985.036.0072, a typical ornithomimid left astragalus.
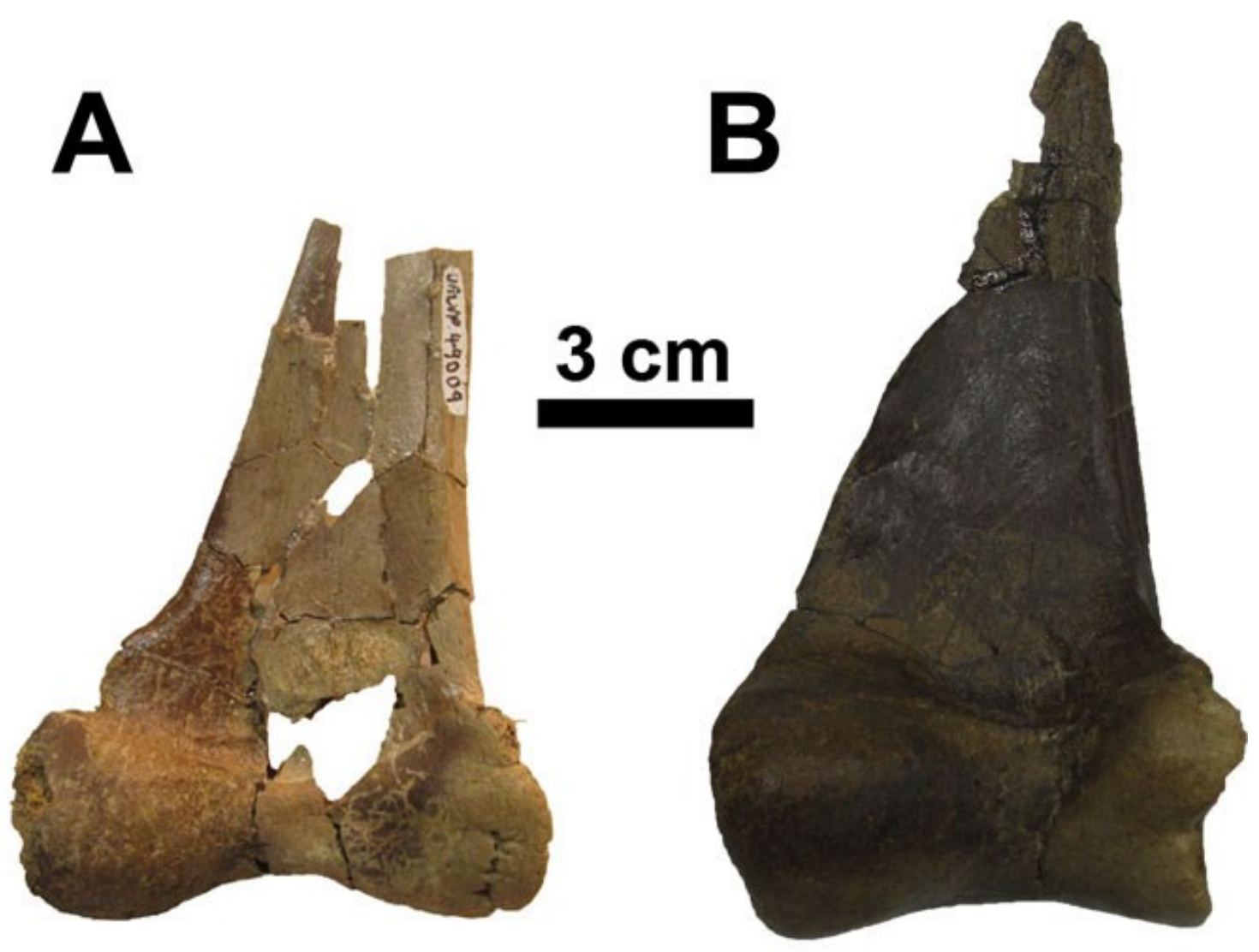
FIGURE 3.12. Ornithomimid pedal phalanx II-2, TMP 2002.068.0303 in A) medial, B) proximal, C) distal, and D) dorsal views.
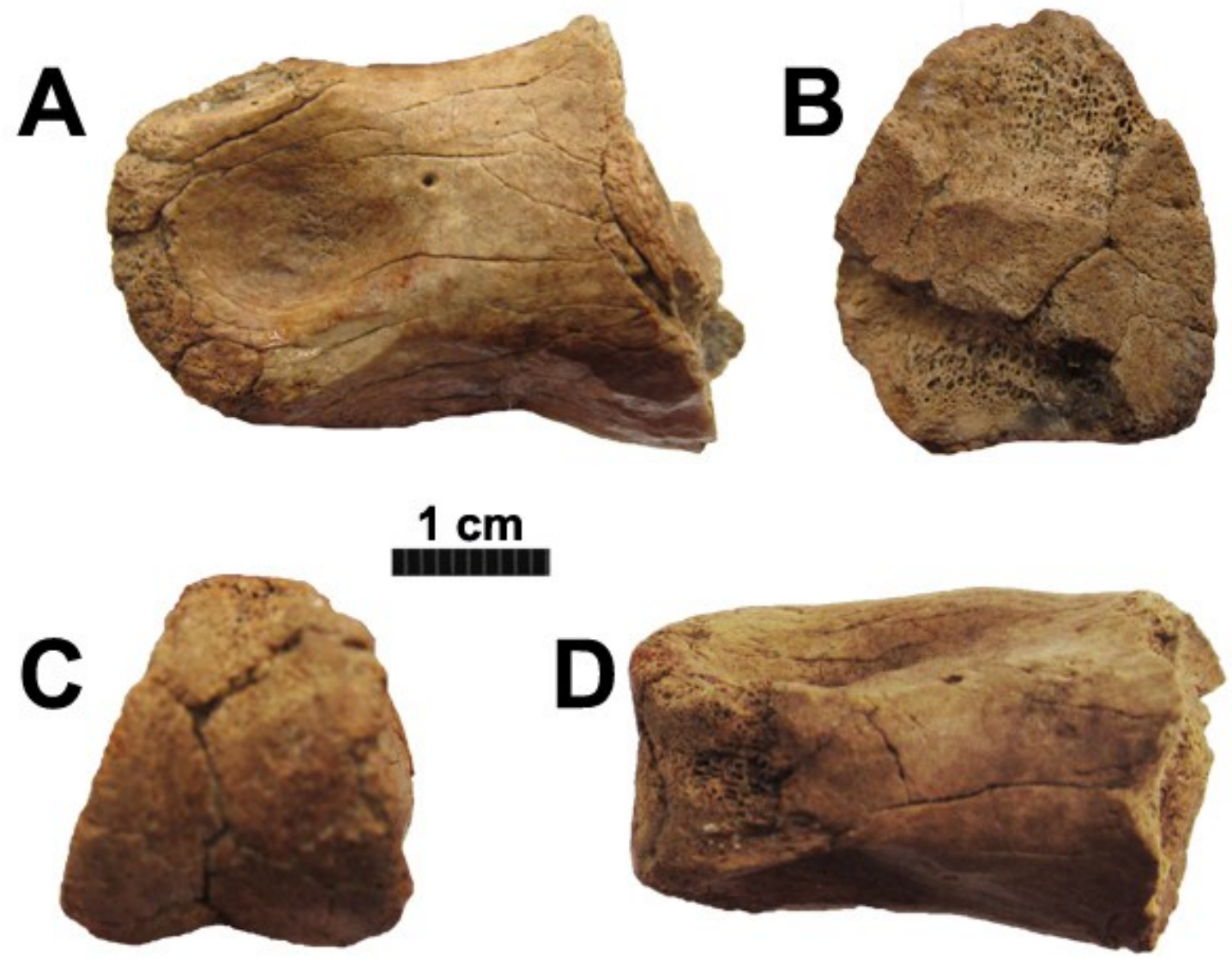
FIGURE 3.13. Ornithomimid pedal phalanx III-2, TMP 2005.012.0271 in A) lateral or medial, B) distal, C) proximal, and D) dorsal views.
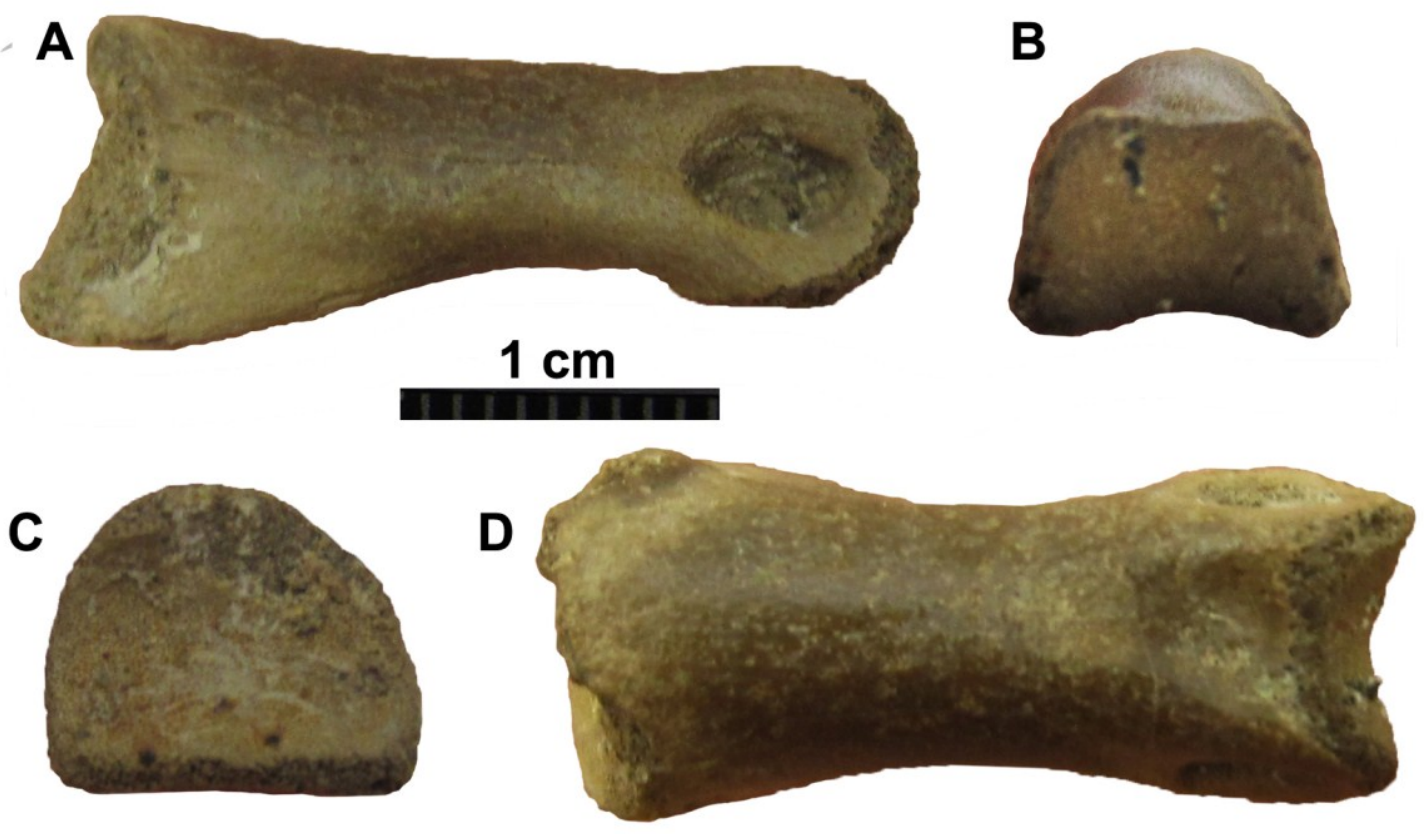
specimen CMN 8902 (described in Chapter 4). In other specimens of Struthiomimus altus (AMNH 5355, CMN 930), the sides of the proximal articular surface slope away from each other ventrally, as in a typical ornithomimid pedal phalanx III-3 (fig 2.24).

Pedal phalanx III-3 may be represented by TMP 2005.049.0088 from Dinosaur Provincial Park. This element is relatively large and robust, and is unusual in being nearly as wide distally $(22.9 \mathrm{~mm})$ as proximally $(25.7 \mathrm{~mm})$. Among known Albertan ornithomimids, its proportions are most nearly approached by Struthiomimus altus (CMN 930), but TMP 2005.049.0088 differs slightly from that specimen in having a more rugose texture around the collateral pits, sharper proximoventral corners of the distal condyles, and more defined edges around the bottoms of the distal condyles in ventral view. Although the size of TMP 2005.049.0088 is consistent with a relatively large ornithomimid such as Struthiomimus, it is also possible that this specimen represents a gracile, probably juvenile tyrannosaurid (compare to Lambe 1917: fig. 6-7).

Pedal unguals are among the most distinctive isolated elements referable to Ornithomimidae (fig. 3.14), usually characterized by their straight, triangular shape with flat ventral surfaces bordered by lateral and medial ridges that end in small "spurs" proximally (Osmólska et al. 1972). An ornithomimid pedal ungual was observed in the UALVP collection associated with a catalogue card that originally had the specimen number written as "UALVP 535648" and the source as the Dinosaur Park Formation; but this information has been crossed out, with the new specimen number written as UALVP 53660 and the source as Bonebed 60 in the 
FIGURE 3.14. Ornithomimid pedal unguals from the Oldman Formation. A-D) TMP 2009.033.0012. E-H) TMP 2011.053.0060.
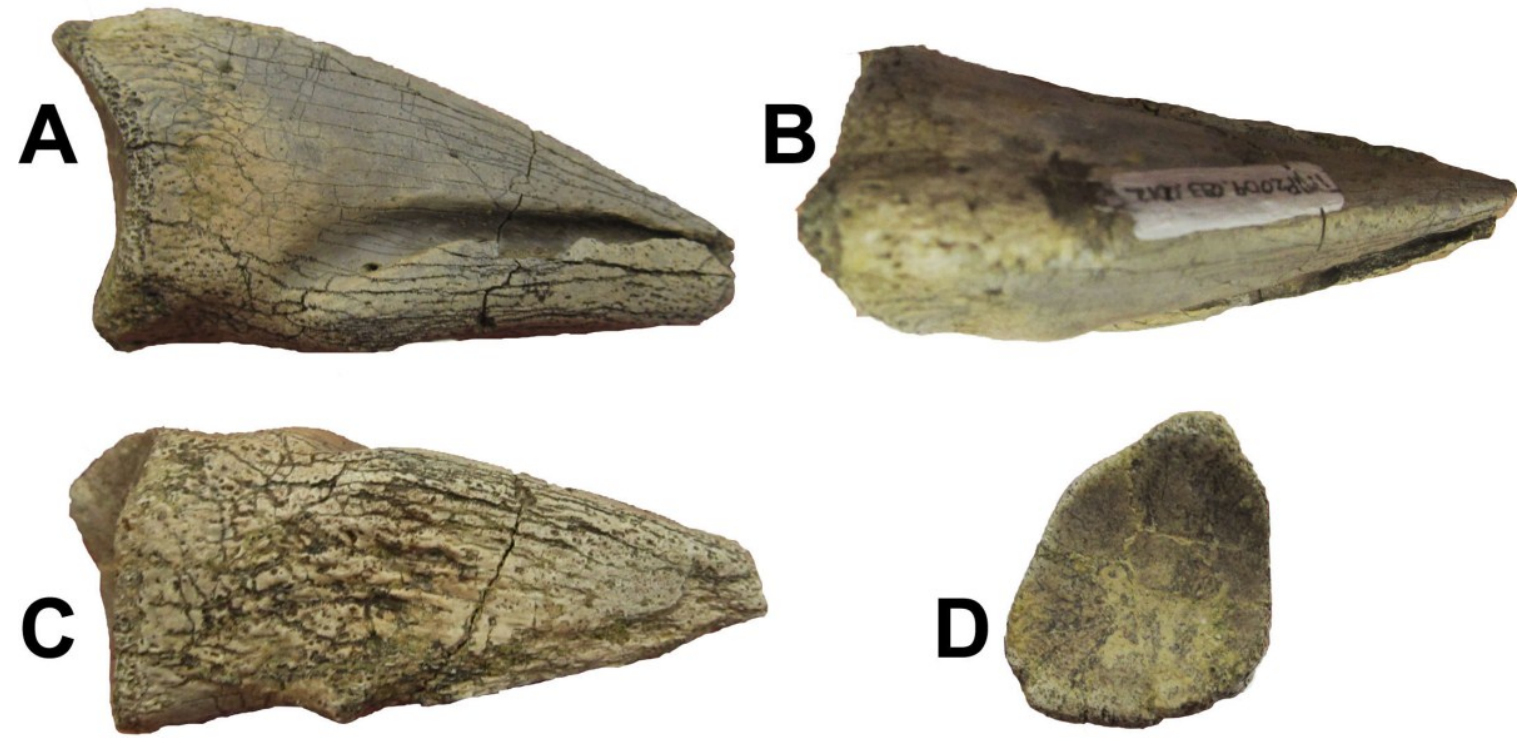

$1 \mathrm{~cm}$
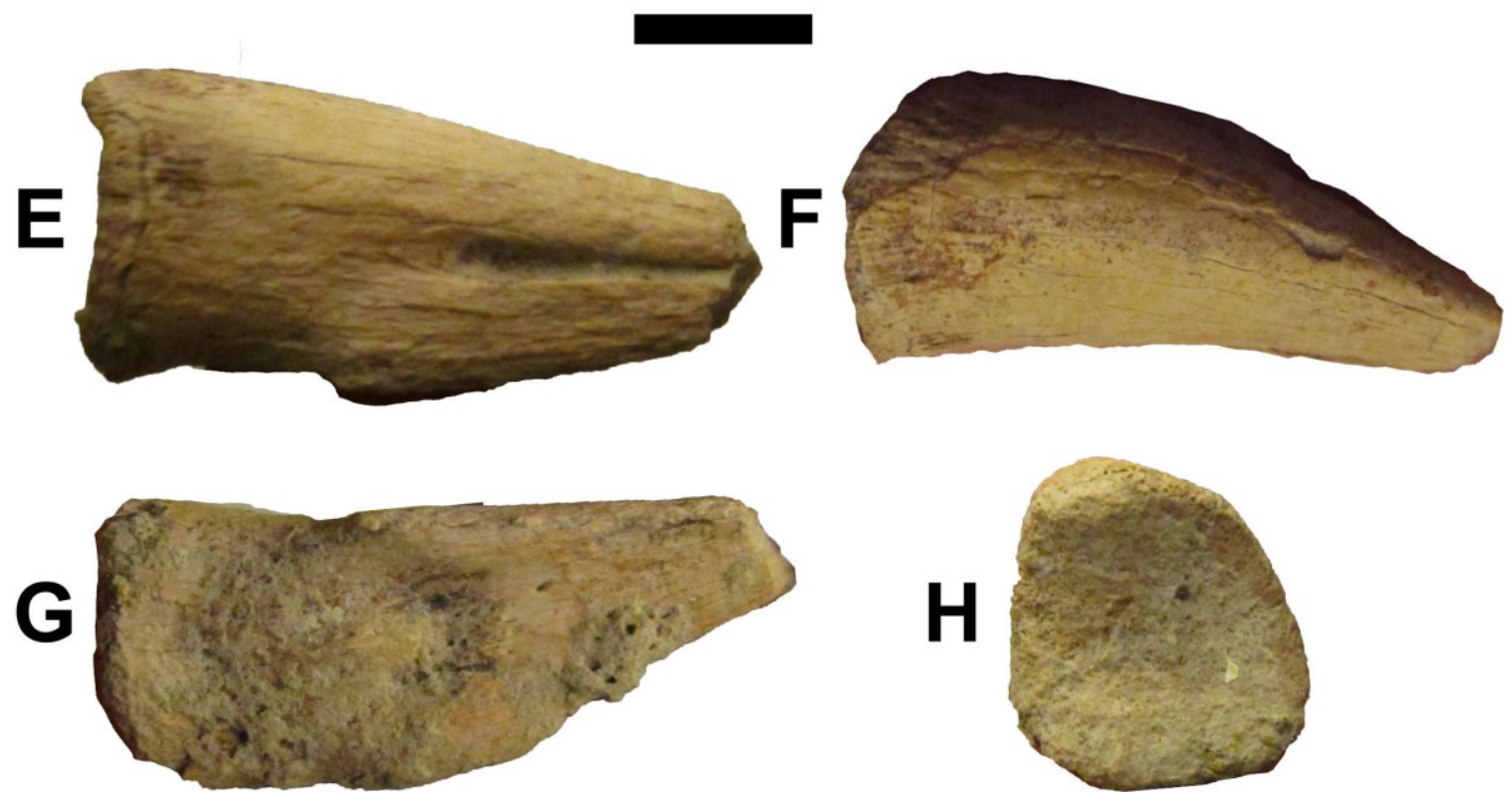
Oldman Formation of Dinosaur Provincial Park. However, according to the museum's online catalogue (http://vertebratepaleontology.museums.ualberta.ca), UALVP 53660 is " 1 large bone fragment ; 4 small bone fragments" from the Happy Jack \#2 locality. UALVP 53687 is listed in the online catalogue as "2 small theropod phalanges, 1 partial ornithomimid ungual" from Bonebed 60 , so it is possible that the ungual observed was actually part of that specimen (which was not otherwise seen).

\section{Upper Unit of Oldman Formation (time-equivalent to Dinosaur Park Formation)}

TMP 2007.035.0026 is a small, nearly complete distal caudal vertebra from the Murray Ranch locality (fig. 3.15). It is of typical ornithomimid form with an elongate, dorsoventrally compressed centrum and very elongate, flattened prezygapophyses. The centrum has a grooved ventral surface and a flat anterior articular surface. The neural spine is a low ridge that overhangs the spinoprezygapophyseal fossa anteriorly. It lacks a flanking trough posteriorly, agreeing with the description by Longrich (2008) for Ornithomimus and differing from Struthiomimus (including AMNH 5355, pers. obs.) and the unnamed large Dinosaur Park Formation ornithomimid (Longrich 2008: 969). TMP 2007.035.0026 lacks the distinctive grooves on the ventral surfaces of the prezygapophyses and on the lateral surfaces of the posterior neural arch that Zanno et al. (2011: fig. 6) figured for the holotype of Ornithomimus brevitertius (ROM 797). However, the occurrence of ventral grooves on the prezygapophyses begins more posteriorly in 
FIGURE 3.15. Ornithomimid distal caudal vertebra TMP 2007.035.0026 in A) right lateral, B) dorsal, C) ventral, and D) anterior view.

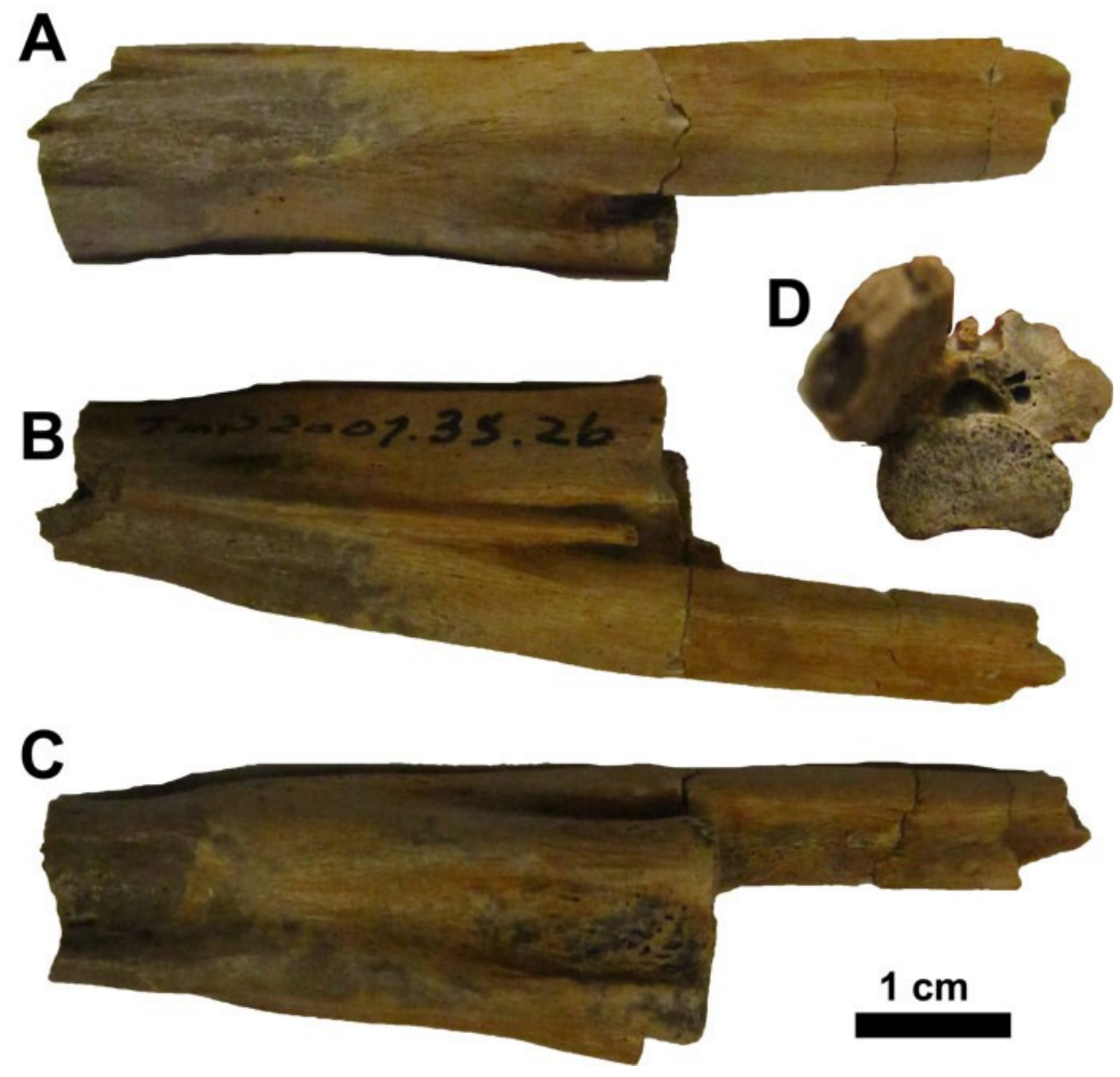


the caudal series of ROM 797 than the elongation of the prezygapophyses and acquisition of the overall "distal caudal" morphology, so the absence of this feature in a single, isolated caudal vertebra may not be taxonomically informative. TMP 1995.092.0006, catalogued as an ornithomimid caudal vertebra from Little Diablo's Hill at Devil's Coulee, could not be located in the TMP collections. TMP 2012.037.0118, catalogued as an ornithomimid caudal vertebra from the McPheeters Centrosaurus bonebed, was not observed because it was being temporarily stored at the CMNH.

TMP 2001.036.0003 is catalogued as an ornithomimid ulna from the Oldman Formation near the Milk River at Manyberries. This specimen was under study by Francois Therrien and was not accessible during my visit to the TMP collections (July 2013).

A fragmentary manual ungual is represented by TMP 2009.033.0011 from the South Saskatchewan River area (also including a proximal fragment of a nonungual phalanx, probably a left pedal phalanx II-1). As with TMP 2009.150.0003, this ungual is identified as ornithomimid based on the relatively straight ventral edge in lateral view (fig 3.7 B). The ventral surface is convex in cross-section, a plesiomorphic condition (Bronowicz 2011: character 40.0).

TMP 2010.076.0007, a metatarsal from the Murray Ranch, was not observed because it is being temporarily stored at the $\mathrm{CMNH}$.

Pedal phalanx III-1 is represented by TMP 2009.033.0014 from the South Saskatchewan River area. This specimen is small for an ornithomimid pedal phalanx III-1 (37.8 mm long), and has a particularly large and deep pit on the lateral distal 
condyle. As in TMP 2011.053.0030, the proximoventral ridges are present, but slight.

Pedal phalanx III-2 is represented by TMP 2009.033.0013 (also including other fragmentary elements, but no ungual, contrary to the catalogue label) from the South Saskatchewan River area. TMP 2009.033.0013 has slightly less elongate proportions than TMP 2005.012.0271, but agrees with it in having approximately parallel and vertical sides of the proximal articular surface. TMP 2009.066.0001 from the South Saskatchewan River area is a single side of a distal condyle of a phalanx, without any recognized informative features.

TMP 2009.033.0012 from the South Saskatchewan River area is an ornithomimid pedal ungual (fig 3.14 A-D). The skewed shape of the proximal articular suggests that it is a left pedal phalanx IV-5. Another catalogued ungual, TMP 2009.039.0190 from the McPheeters Centrosaurus bonebed in the Milk River area, differs from Ornithomimidae in that the entire ungual is dorsoventrally compressed, the lateral and medial ventral ridges contribute to the outline of the proximal surface rather than ending in small "spurs" distal to it, and the middle of the proximal articular surface bears two large pits divided by a thin vertical lamina.

\section{Undetermined Unit of Oldman Formation}

A distal fragment of a possible manual ungual is represented by TMP 2011.065.0039 from Cecil Nesmo's site \#1. This ungual is curved in lateral view, with a rounded ventral surface. Although curved unguals are within the range of 
variation for Ornithomimidae (Osmólska et al. 1972: fig. 14), fragments of curved unguals are not easily distinguished from those of non-ornithomimid coelurosaurs.

A left pedal phalanx II-2 is represented TMP 2011.053.0060 (also including an ornithomimid pedal ungual and various fragments) from the North Site at Pinhorn Ranch. In TMP 2011.053.0060 the ventromedial corner of the incomplete proximal surface was not distinctly enlarged, unlike TMP 2011.053.0006, possibly giving the medial edge a more convex outline as in the holotype of Struthiomimus altus (CMN 930), Ornithomimus spp. (CMN 8632, CMN 12069, CMN 12242), and Rativates evadens (ROM 1790).

Pedal phalanx III-2 is represented by TMP 2008.075.0019 from the Milk River Natural Area. TMP 2008.075.0019 is proportionately very long and shallow, like TMP 2005.012.0271, and has approximately parallel and vertical sides of the proximal articular surface

TMP 2008.075.0029 from the Milk River Natural Area is a distal fragment of a phalanx too incomplete to precisely identify. It has a broad, non-ginglymoid distal end consistent with an ornithomimid pedal phalanx III-1 or III-2. TMP 2011.071.0012 from the Big Muddy Channel locality is catalogued as an ornithomimid phalanx, but is definitively not referable to this clade. The enlarged proximodorsal process projects proximally well past the proximoventral end of the phalanx, and the circular, ginglymoid distal condyles project dorsally well above the shaft, and are approximately as wide across as the proximal surface. These features are more commonly seen in the pedal phalanges of dromaeosaurids (Ostrom 1969, Norell \& Makovicky 1999: fig. 16). 
An ornithomimid pedal ungual is included in TMP 2011.053.0060 from the North Site at Pinhorn Ranch in the Milk River area (fig. 3.14 E-H). ROM 58293 and ROM 58701 are ornithomimid unguals from the Milk River area with their source catalogued as "Oldman Fm.?". These two unguals were collected in 1968 (David Evans and Kevin Seymour, pers. comm. March 2015), but are included in the following discussion because they are probably from the Oldman Formation, and provide useful information on ornithomimid pedal ungual diversity. The rounded, approximately symmetrical proximal articular surface with a larger concavity on the left side suggests that ROM 58293 is a left phalanx III-4, while the more skewed shape of the proximal articular surfaces suggest that ROM 58701 represents a left phalanx IV-5, and TMP 2011.053.0060 a right phalanx IV-5.

The ungual included in TMP 2011.053.0060 is the most unusual pedal ungual in this sample, exhibiting an extreme lateral curvature. Although pedal ungual IV can be slightly curved laterally in Struthiomimus altus (CMN 930) and Ornithomimus edmontonicus (CMN 8632), the curve in TMP 2011.053.0060 is greater than in other ornithomimids. The posterodorsal process is very weak and not arched. The dorsal surface of the ungual is rounded in transverse section and very straight in lateral view, with a shallower slope than the other specimens. The lateral groove is straight and is separated from the proximal end of the ungual by a distance roughly equal to the height of the proximal articular facet, whereas in other examined ornithomimids the lateral groove on ungual IV often turns down proximally to reach the ventral edge, and is separated from the proximal end by approximately half of the proximal articular facet height. Some of these characters may be taxonomically distinctive, 
supporting multiple ornithomimid taxa in the Oldman Formation, but examination of a larger sample is needed to test this hypothesis.

In ROM 58701 the posterodorsal process is slightly more strongly developed, and unlike the other Oldman specimens there is a distinct step between the end of the posterodorsal process and the main dorsal edge. The dorsal surface of ornithomimid unguals in transverse section ranges from rounded in CMN 930 to sharply keeled in ROM 797. The dorsal keel is strongly pronounced in ROM 58701 among the possible Oldman Formation ornithomimid unguals, demonstrating that this variable is independent of the extreme narrowness of the ROM 797 unguals.

\section{DISCUSSION}

The presence of Ornithomimidae in the Milk River and Foremost formations could not be confirmed, though the ornithomimid identity of the Foremost Formation material is plausible. A few diagnostic ornithomimid elements are identified in the lowest informal unit of the Oldman Formation, and constitute the oldest definitive record of this group in Laramidia. Dissociated ornithomimid material from the Comrey Sandstone is also older than the oldest articulated and associated ornithomimid skeletons from Alberta, which occur in the lower Dinosaur Park Formation (Chapter 1). Some of the dissociated material from Alberta previously identified as ornithomimid may instead represent the oldest known Canadian oviraptorosaurs (CMN 8728, TMP 2011.053.0007).

The identification of valid taxonomic characters in ornithomimid pedal unguals is contentious. Longrich (2008) claimed to be able to distinguish between 
Ornithomimus and Struthiomimus based on characters of isolated pedal unguals, but Cullen et al. (2013) disputed this, noting that characters attributed to both taxa are variably present among the unguals of a single ornithomimid individual from the Horseshoe Canyon Formation. Longrich's comparison of ornithomimid unguals did not consider digit identity, nor use outgroup comparisons to establish plesiomorphic versus autapomorphic characters, and his figured exemplars of Ornithomimus sp. and Struthiomimus altus pedal unguals (Longrich 2008: fig. 12a-b) were collected as isolated unguals, not associated with diagnostic skeletons of these taxa. Longrich (2008) also ignored pedal ungual characters that conflict with his identifications, such as the lateral and medial sides of the proximal end being approximately parallel versus strongly converging distally (giving the ungual a constricted "waist") in ventral view: in Longrich's isolated exemplars, the former condition occurs in Ornithomimus sp. and the latter in Struthiomimus altus, but the opposite is observed in pedal unguals of CMN 930 (holotype of Struthiomimus altus) and ROM 797 (holotype of Ornithomimus brevitertius). The significance of the considerable morphological variation in ornithomimid pedal unguals is thus poorly understood. The examined ornithomimid pedal unguals from the Oldman Formation are generally similar in having straight ventral edges, relatively sharp ventrolateral edges, a weak flexor tubercle, and a weakly developed posterodorsal process, fitting in Longrich's concept of Ornithomimus (Longrich 2008: 990). 


\section{CHAPTER 4}

\section{PHYLOGENETIC RELATIONSHIPS OF ORNITHOMIMIDS FROM ALBERTA}

\section{INTRODUCTION}

Although numerous partial to nearly complete skeletons of ornithomimids have been described from the Upper Cretaceous Dinosaur Park and Horseshoe Canyon formations of Alberta, including six holotypes (Lambe 1902, Parks 1926, Parks 1928, Sternberg 1933, Parks 1933), the phylogenetic relationships of these specimens has rarely been explored in detail. Some widely accepted taxonomic referrals and synonymies are based on questionable logic and have never been tested using modern phylogenetic methods, yet phylogenetic analyses routinely use operational taxonomic units (OTUs) based on multiple specimens or even species of a genus. Even the basic question of whether or not Laramidian ornithomimids form an exclusive clade within Ornithomimidae is uncertain according to different analyses published in the past decade. The purpose of this chapter is to compile the existing knowledge on the phylogenetic relationships of Albertan ornithomimids, and create an improved data set to test their relationships at a finer scale, including determining a hypothesis for the phylogenetic relationship of ROM 1790.

Barsbold and Osmólska (1990: fig. 10) presented the first cladistic hypothesis of ornithomimid relationships, though no reference to a data matrix was provided and their cladogram may have been conjectural rather than the result of a quantitative phylogenetic analysis (Fig. 4.1). Barsbold and Osmólska considered Ornithomimus to be the most basal of the three Laramidian ornithomimid genera, 
FIGURE 4.1. Early cladistic hypotheses of ornithomimosaur relationships, after A) Barsbold and Osmólska (1990), B) consensus tree of Yacobucci (1990; as explained by Margaret Yacobucci, pers. comm. January 2015), and C) Osmólska (1997).

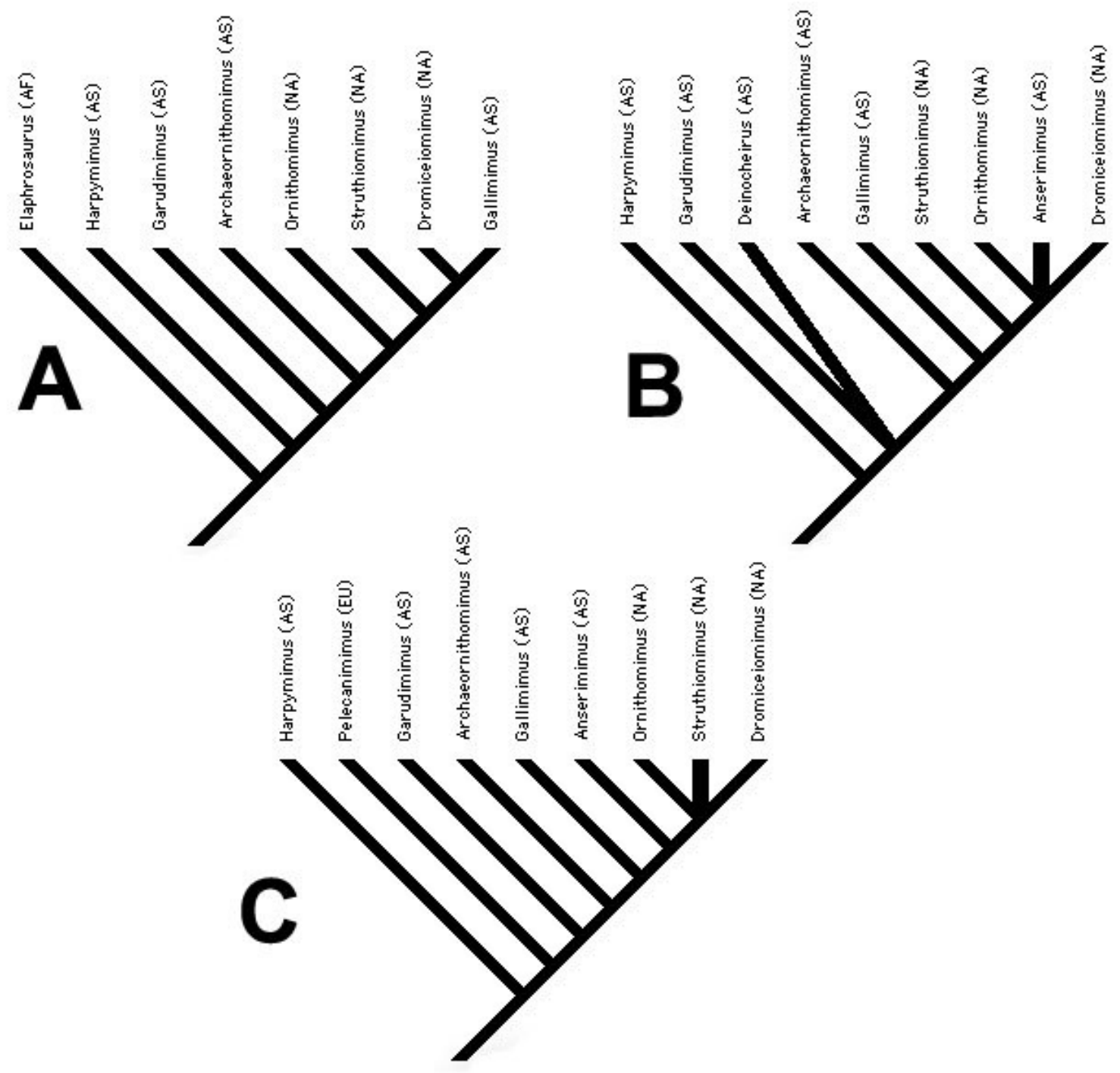


with Struthiomimus as the sister taxon of a "Dromiceiomimus" + Gallimimus clade. Regarding the latter Barsbold and Osmólska (1990: 242) considered both to be the "most derived" ornithomimids, based on the elongated hindlimb of "D." brevitertius and secondarily shortened manus of Gallimimus, but did not name any shared characters that would unite them. The first quantitative, but unpublished, analysis of ornithomimid relationships was discussed the same year in an abstract by Yacobucci (1990). Her consensus tree differed in recovering the Mongolian genus Gallimimus basal to the clade containing all Laramidian ornithomimids, in which Struthiomimus was basal to a polytomy consisting of Ornithomimus, "Dromiceiomimus," and the Mongolian Anserimimus (Margaret Yacobucci, pers. comm. January 2015). Another apparently conjectural and unexplained cladogram of ornithomimid relationships appeared in a later article by Osmólska (1997: fig. 5), depicting an unresolved Ornithomimus + Struthiomimus + "Dromiceiomimus" grouping as the sister taxon of Anserimimus.

The first quantitative analysis of ornithomimid phylogeny with a published tree and data matrix was included in the description of Sinornithomimus by Kobayashi and Lü (2003), and includes characters explained in more detail in an unpublished PhD dissertation by Kobayashi (2004). Kobayashi and Lü (2003) recovered a monophyletic Laramidian ornithomimid clade in which Struthiomimus was the sister taxon of Ornithomimus + "Dromiceiomimus". However, Table 6 of Kobayashi and Lü (2003: 256) reveals that each Laramidian ornithomimid OTU is a composite based on material from multiple formations, and that their "Struthiomimus" OTU includes data from ROM 1790. Kobayashi and Barsbold 
(2004), Xu et al. (2011), Bronowicz (2011), Jin et al. (2012), and Cullen et al. (2013) all employed modified versions of the Kobayashi and Lü (2003) matrix to test the phylogenetic position of newly described ornithomimosaur material. These authors consistently recovered a monophyletic Laramidian ornithomimid clade (Fig. 4.2), with the exception of Bronowicz (2011) who was unable to resolve the relationships of derived ornithomimids. Xu et al. (2011) and Cullen et al. (2013) merged Ornithomimus and "Dromiceiomimus" into a single OTU, following the formal synonymization of these genera by Makovicky et al. (2004).

The first decade of the 21st century also saw the initiation of a major phylogenetic analysis of Coelurosauria by the AMNH-based Theropod Working Group (Norell et al. 2001b), which was adopted as a standard template for a coelurosaurian phylogenetic matrix by many subsequent authors (see citations in Senter 2007). However, because most of these analyses were published in descriptions of non-ornithomimosaur theropods, the variations in the ornithomimid topology were not explicitly noted in the discussion sections, despite some novel and varied results being recovered (Fig. 4.3). Makovicky et al. (2004: 148) speculated that Ornithomimus, Anserimimus, and Archaeornithomimus may form a clade, but their analysis resolved no unambiguous clades within Ornithomimidae. Kirkland et al. (2005) were the first to fully resolve the topology within Ornithomimidae using a version of the Theropod Working Group matrix, and found Struthiomimus as the sister taxon of Gallimimus, Ornithomimus as the sister taxon of Anserimimus, and Archaeornithomimus as basal to the other four genera. Norell et al. (2006) published the first analysis to not recover the five traditional ornithomimid 
FIGURE 4.2. Consensus trees of phylogenetic analyses based on variations of the dataset used by Kobayashi and Lü (2003), after A) Kobayashi and Lü (2003), B) Bronowicz (2011), C) Xu et al. (2011), and D) Jin et al. (2012).
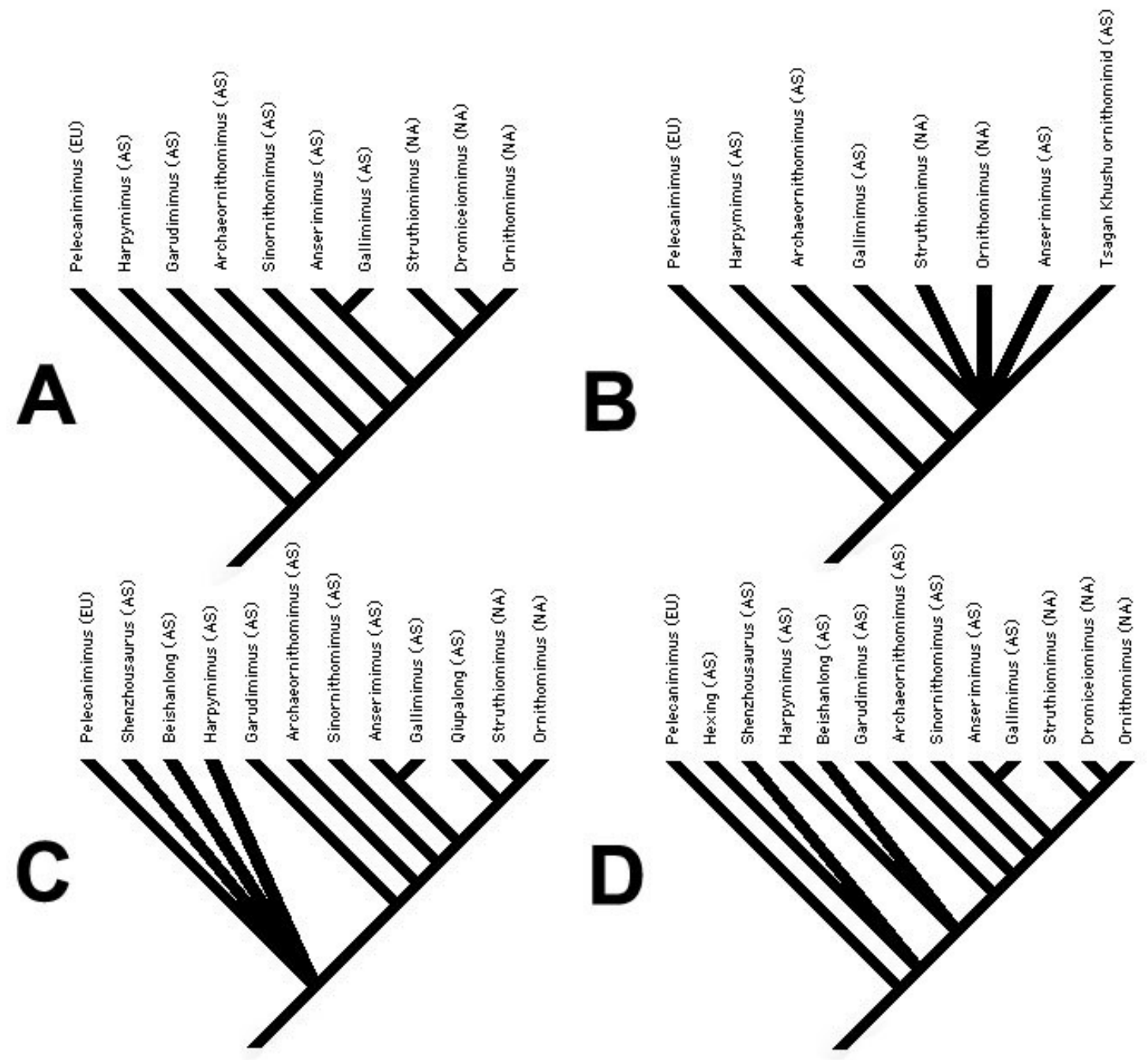
FIGURE 4.3. Consensus trees of phylogenetic analyses based on variations of the dataset used by the Theropod Working Group (Norell et al. 2001b), after A) Makovicky et al. (2004), B) Kirkland et al. (2005), C) Norell et al. (2006), D) Turner et al. (2012), E) Senter et al. (2012), and F) Lee et al. (2014).

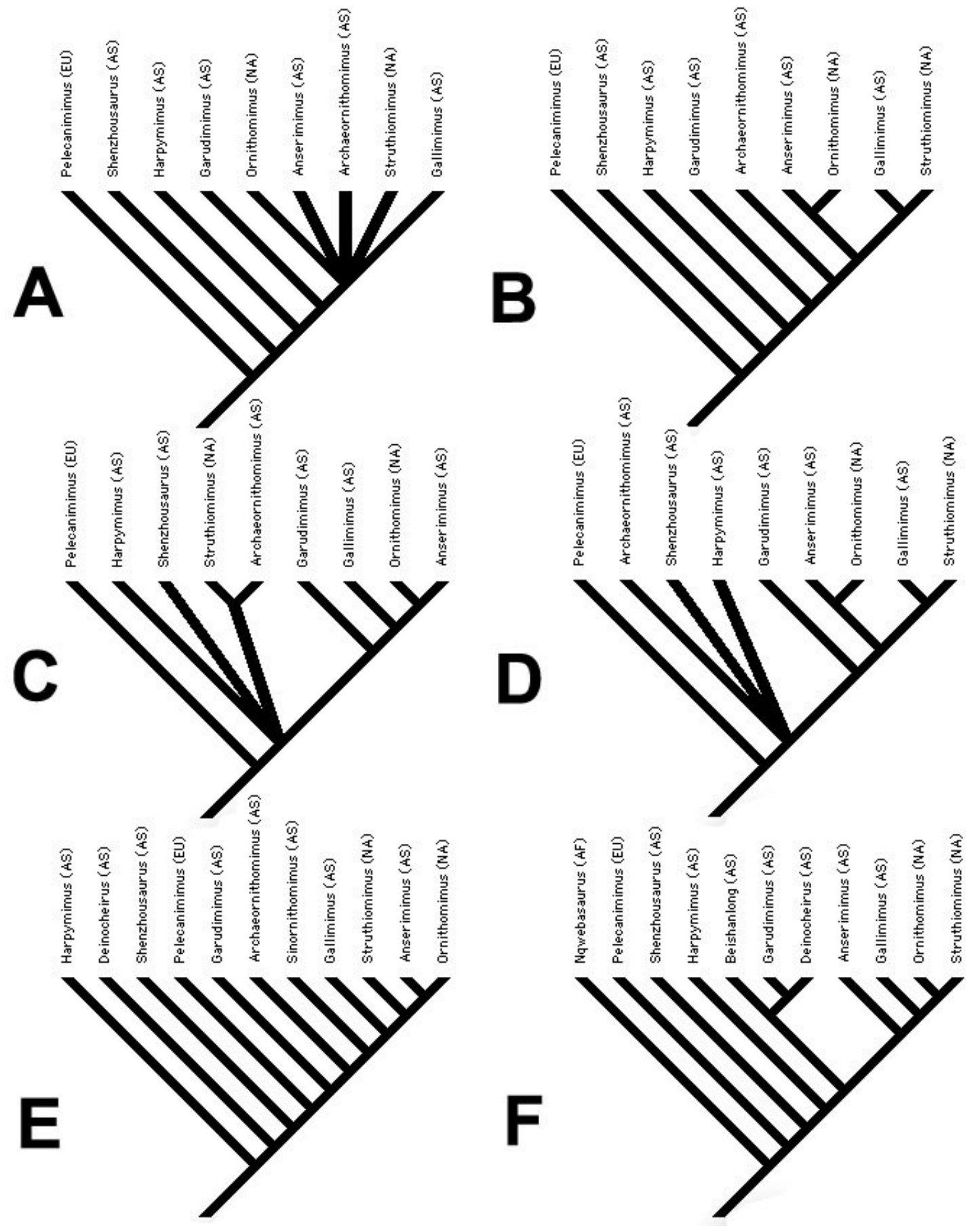


genera (Archaeornithomimus, Anserimimus, Gallimimus, Struthiomimus, and Ornithomimus) as monophyletic. Instead, Archaeornithomimus and Struthiomimus were recovered as basal ornithomimosaur sister taxa outside of a clade containing Garudimimus and the remaining ornithomimids, in which Ornithomimus was the sister taxon of Anserimimus. Turner et al. (2007a, 2007b, 2012) also recovered Archaeornithomimus in a more basal position outside of the Garudimimus + Ornithomimidae clade, but returned Struthiomimus to its traditional position as an ornithomimid. Turner et al. (2012) also resolved a Struthiomimus + Gallimimus clade as the sister taxon of an Ornithomimus + Anserimimus clade. Senter (2007) published a major revision of the Theropod Working Group analysis that found a monophyletic Ornithomimidae and placed all ornithomimosaur taxa on a combshaped tree, with Archaeornithomimus, Gallimimus, Struthiomimus, and Anserimimus as successively closer relatives of Ornithomimus.

Beginning with Choinere et al. (2012), some recent revisions of the Theropod Working Group data set have excluded Archaeornithomimus and recovered a novel topology in Ornithomimidae with Anserimimus as the most basal member of this clade, followed by Gallimimus and Struthiomimus as successively closer relatives of Ornithomimus (Choiniere et al. 2014, Lee et al. 2014). These are the only versions of the Theropod Working Group analysis so far to recover the monophyletic Laramidian ornithomimid clade originally found by Kobayashi and Lü (2003). Unfortunately, many of the characters scored by Choiniere et al. (2012, online supplementary information) as differing between Ornithomimus and Struthiomimus did not have citations to the descriptive literature and could not be confirmed by my 
own observations, and many of their other scorings could not be verified due to lack of access to Asian ornithomimosaur collections. Therefore, I did not attempt to integrate this dataset into my analysis.

\section{METHODS}

A character-taxon matrix was constructed using characters from previously published ornithomimosaur analyses. Characters 1-48 were taken from Cullen et al. (2013) who derived their characters from those of Xu et al. (2011). Characters 3943 and 45 of Jin et al. (2012) are included here as characters 49-54. Characters 44, 46, and 47 taken from Jin et al. (2012) are synonymous with characters 39, 48, and 47 of Xu et al. (2011), respectively. Characters 55-66 are new characters based, in part, on the diagnoses of Albertan ornithomimid taxa in Russell (1972), Makovicky et al. (2004), and Longrich (2008). Modified and rescored characters from previous analyses are discussed in Appendix 1.

Initially 13 individual ornithomimid specimens from the Dinosaur Park and Horseshoe Canyon Formations of Alberta were scored in the analysis, including all of the holotypes. To improve the resolution of the tree, individuals from the same formation that are widely considered the same taxon were combined into a single OTU. "Dinosaur Park Formation Struthiomimus" is based on personal observations of AMNH 5339, AMNH 5355, CMN 930 (holotype of Struthiomimus altus), and UCMZ 1980.1, but excludes ROM 1790, which was reidentified as representing a new taxon in Chapter 2. "Horseshoe Canyon Formation Struthiomimus" is based on observations taken from photographs of TMP 1990.26.1. "Horseshoe Canyon 
Formation Ornithomimus" is based on personal observations of CMN 8632 (holotype of Ornithomimus edmontonicus), CMN 12228, ROM 797 (holotype of Ornithomimus brevitertius), ROM 851 (holotype of Ornithomimus currellii), and ROM 852 (holotype of Ornithomimus ingens). Although this assemblage has been considered nonmonophyletic in older classifications (Russell 1972, Barsbold \& Osmólska 1990), most recent authors have recognized only a single species for the Horseshoe Canyon Formation Ornithomimus material (Makovicky et al. 2004, Longrich 2008, Eberth et al. 2013, Cullen et al. 2014), and there is little variation among these specimens for the characters in this analysis. The conspecificity of the Dinosaur Park Formation Ornithomimus individuals (ROM 840, TMP 1995.110.1) is less certain (Currie 2005b, Longrich 2008, Brown et al. 2013a), so these were retained as separate OTUs. The type species Ornithomimus velox (Marsh 1890) from the Denver Formation of Colorado is excluded from this analysis because it is currently being redescribed, and the existing literature and casts are not reliable enough to derive character states from (Mark Loewen, pers. comm. November 2014).

The cladistic analysis was performed using the software program TNT v. 1.0 [18]. Allosaurus fragilis was designated the outgroup, and characters were run equally weighted, except character 26 , which was run ordered. The analysis included a 10000 replicate random addition traditional search with tbr branch swapping holding 1000 trees at each replicate, followed by an additional round of tbr branch-swapping. In order to assess the robusticity of the topological results. Bremer Decay values were calculated using the option in TNT. 


\section{RESULTS AND DISCUSSION}

The phylogenetic analysis resulted in 309 most parsimonious trees. Each tree had a tree length of 114 steps $(\mathrm{CI}=0.596$, and $\mathrm{RI}=0.726)$, with the Strict Consensus Tree showing a polytomy of most ornithomimid taxa including Sinornithomimus, Gallimimus, Anserimimus, Qiupalong, Rativates, Ornithomimus, and Struthiomimus (Fig. 4.4). Bremer decay values were 0 for each branch reflecting the large amount of missing data within the analyzed data set.

When Rativates is excluded from the analysis, the strict consensus tree closely resembles the topology recovered by Kobayashi and Lü (2003) and Xu et al. (2011), except that Ornithomimus and Struthiomimus are not united to the exclusion of Qiupalong. The 50\% Majority Rule tree recovers ROM 1790 in a polytomy with Qiupalong and other Albertan specimens. Within this clade, the two Struthiomimus OTUs are recovered as sister taxa, supporting the exclusion of ROM 1790 from Struthiomimus. The monophyly of Ornithomimus (sensu Makovicky et al. 2004) including all material previously referred to "Dromiceiomimus" is not supported or rejected by this analysis. The evidence supporting Beishanlong as a very basal ornithomimosaur was previously discussed by Choiniere et al. (2012). Lee et al. (2014) recovered Beishanlong in a much more derived position related to Garudimimus and Deinocheirus, but this hypothesis is untested in the present analysis because data from Deinocheirus were not included. 
FIGURE 4.4. Results of the phylogenetic analysis. A) Strict Consensus tree, B) 50\% Majority Rule tree, C) Strict Consensus tree excluding ROM 1790.
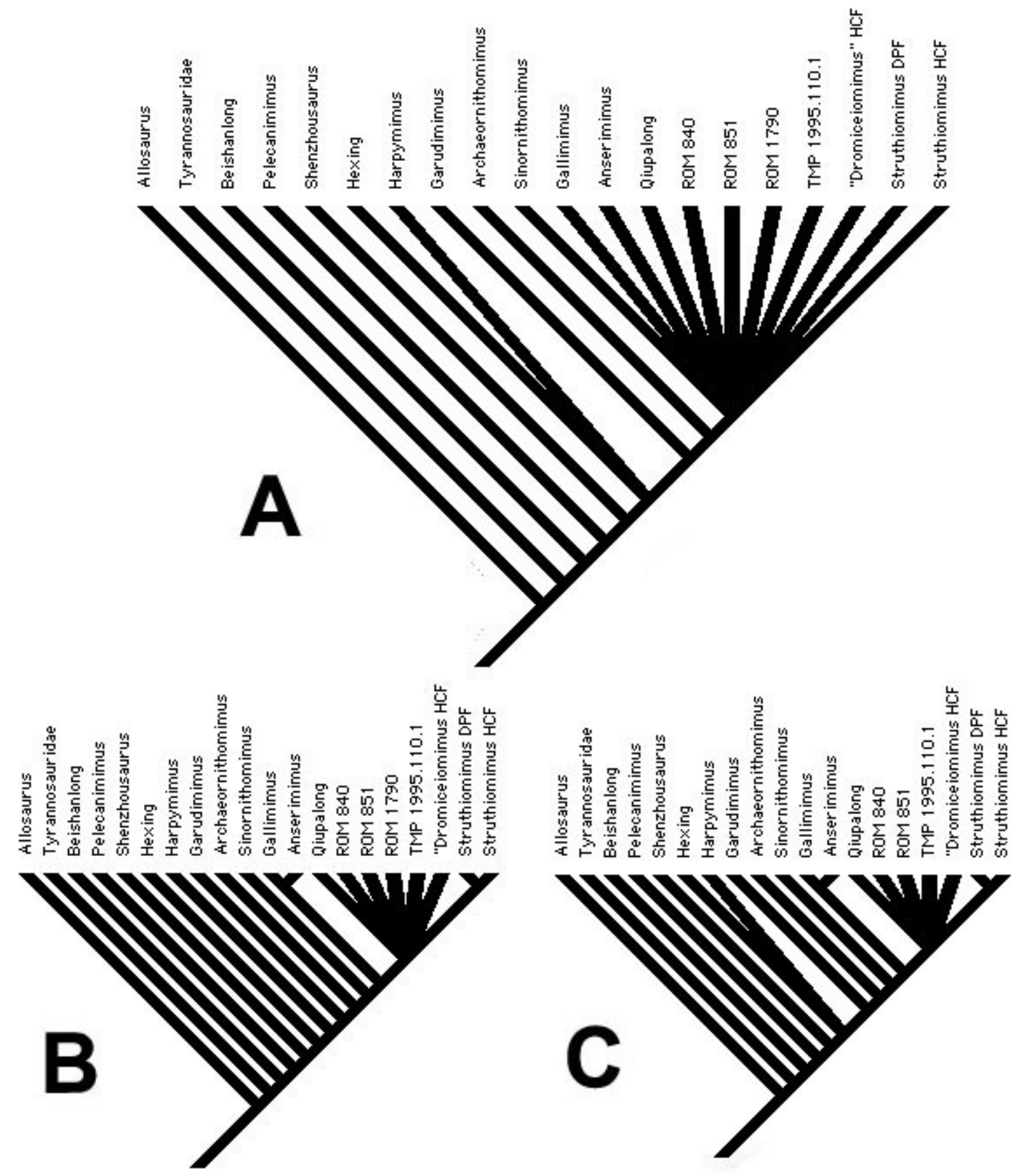


\section{Phylogenetic Position of Rativates evadens}

The phylogenetic analysis suggests that Rativates evadens is closely related to both Ornithomimus and Struthiomimus, but it could not be determined if it was more closely related to either one of these taxa. ROM 1790 lacks preservation of most regions that have previously been used to diagnose or differentiate ornithomimid species in the Belly River Group, such as the posterior half of the skull and mandibles, forelimbs, and distal caudal vertebrae (Nicholls \& Russell 1981, Makovicky et al. 2004, Kobayashi et al. 2006, Longrich 2008, Zelenitsky et al. 2012). Instead, autapomorphic characters of ROM 1790 occur mainly in regions that appear relatively conservative between Ornithomimus and Struthiomimus. The flexor edge of metatarsal III in distal view is partially flat in at least some of the Horseshoe Canyon Formation specimens of Ornithomimus (AMNH 5201, CMN 8632, ROM 797, ROM 852), but the distal end of these metatarsals is still deeper medially than laterally, and there is a concavity between the condyles on the distal flexor surface. Since no unambiguous synapomorphies were found to unite ROM 1790 with Ornithomimus, Struthiomimus, or any other named ornithomimid taxon, the new genus Rativates was proposed for the new species R. evadens.

Of the elements known to be diagnostic for Rativates, the third metatarsal is the most commonly encountered in collections of isolated ornithomimid elements from the Belly River Group. Examination of isolated third metatarsals catalogued as ornithomimid (including CMN 176, CMN 771, CMN 2543, CMN 2544, CMN 2545, CMN 12227, ROM 31665, ROM 47421, UALVP 87, and UALVP 48695) did not 
identify any additional specimens referable to this taxon. Dodson (1971: 68) suggested that certain rare dinosaur taxa collected in the Belly River Group around Dinosaur Provincial Park might represent "fortuitous appearances of animals that habitually inhabited other environments in other areas." The apparent rarity of Rativates material could also be explained if this genus happened to become extinct more quickly than Struthiomimus and Ornithomimus, which are both known to continue into the Horseshoe Canyon Formation (Russell 1972, Eberth et al. 2013).

\section{Relationship of Qiupalong to Albertan Ornithomimids}

Xu et al. (2011) described a partial ornithomimid skeleton from the Upper Cretaceous Qiupa Formation of central China as belonging to a new genus and species, Qiupalong henanensis. Their phylogenetic analysis recovered Qiupalong as the sister taxon of a Laramidian ornithomimid clade including Struthiomimus altus and Ornithomimus edmontonicus, a result supported in the present study. According to the text, the two synapomorphies supporting this clade are "straight pubic shaft and large acute angle between pubic shaft and boot" (Xu et al. 2011: 213, 221). However, the character of a nearly straight pubic shaft (Xu et al. 2011: character 34.0) is scored as occurring symplesiomorphically in all ornithomimids except Archaeornithomimus. The similarly worded, newly added character of a straight distal end of the pubic shaft (Xu et al. 2011: character 44.1) is scored as present in Gallimimus as well as Ornithomimus and Qiupalong, and is thus optimized as a synapomorphy of a more inclusive ornithomimid clade. The actual distribution of this character may be more complex, because the distal end of the pubic shaft is 
recurved in ornithomimid material from the Kaiparowits and Hell Creek formations of the western USA (DeCourten \& Russell 1985: 1097; LACM 47520, pers. obs.: Fig. 4.5). The two derived character states scored as uniquely shared by Qiupalong and Laramidian ornithomimids are a large acute angle between the pubic shaft and boot (Xu et al. 2011: character 45.1) and the tip of the anterior extension of the pubic boot extended more anteriorly than the anterior border of the pubic shaft (Xu et al. 2011: character 46.1). Both of these characters were scored by Xu et al. (2011) only for Qiupalong henanensis and Ornithomimus edmontonicus in this clade, and were considered unknown in Struthiomimus altus. The short anterior extension of the pubic boot (Xu et al. 2011: character 43.0) and curved pedal unguals (Xu et al. 2011: character 47.0) of Qiupalong henanensis were considered reversals (Xu et al. 2011: 221). Xu et al. (2011: 214) proposed the following diagnosis for Qiupalong henanensis: "An ornithomimid theropod dinosaur with unique features (a notch on the lateral surface of the medial posterior process of the proximal end of tibia and a small pit is present at the contact between astragalus and calcaneum) as well as a combination of primitive (short anterior extension of pubic boot) and derived features (arctometatarsal condition, straight pubic shaft, and wide angle between pubic shaft and boot)."

The partial ornithomimid skeleton CMN 8902 preserves the first known example of a "Qiupalong-like" pubis in a Laramidian ornithomimid, combining a straight distal shaft with a short anterior extension of the pubic boot (Fig. 4.6). CMN 8902 was collected from the upper Belly River Group of the Dinosaur Provincial Park area by C. M. Sternberg in 1921. Although the quarry has not yet been 
FIGURE 4.5. Mounted pelvis of the undescribed Hell Creek ornithomimid, LACM 47520.

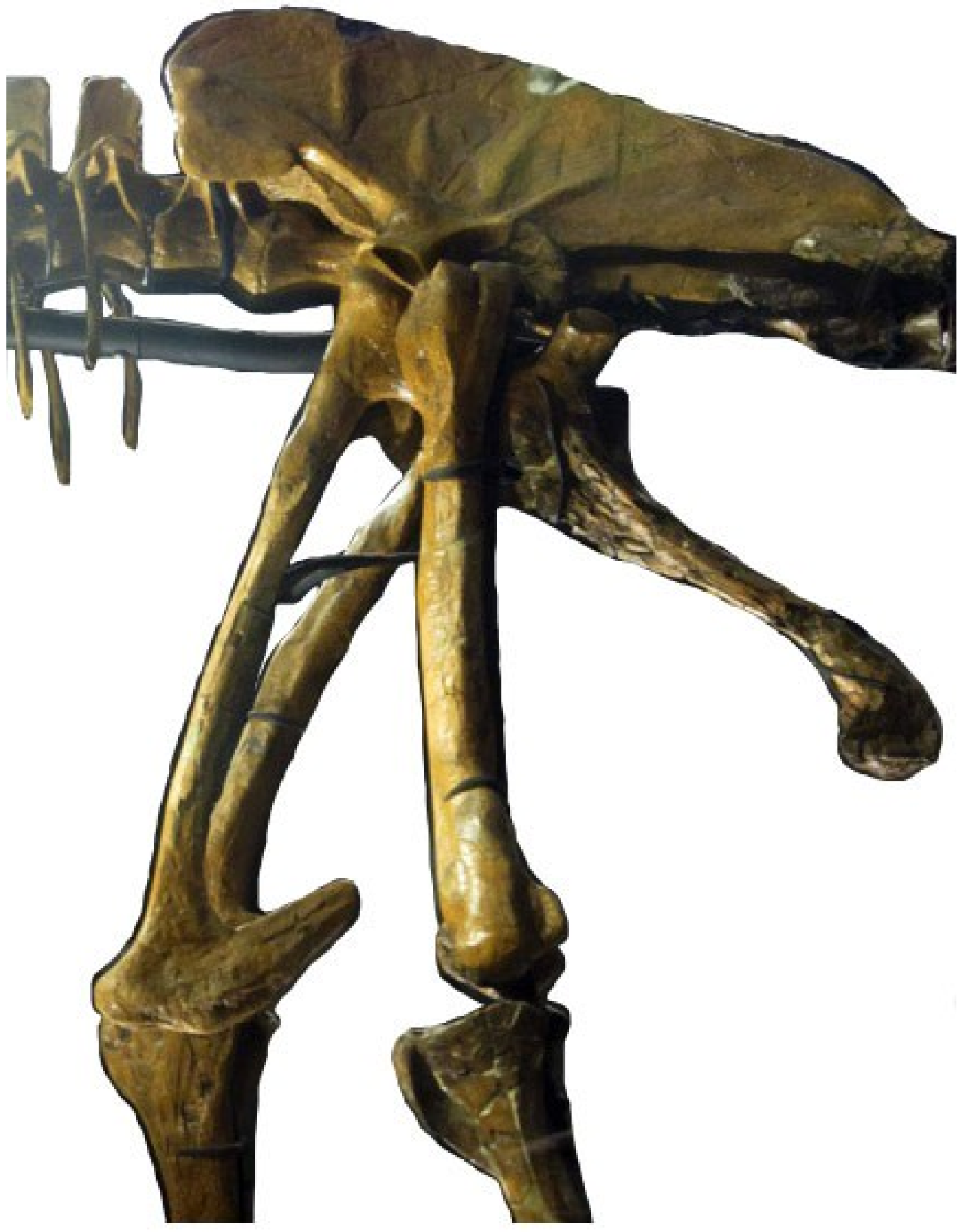


FIGURE 4.6. Distal pubes of CMN 8902 in A) right lateral and B) anterior view. Scale bar $=5 \mathrm{~cm}$. C) Comparison of ornithomimid pubic boots, from left to right:

Qiupalong henanensis (after Xu et al. 2011), CMN 8902, and Struthiomimus altus AMNH 5339. Scaled to the same approximate pubic shaft width.

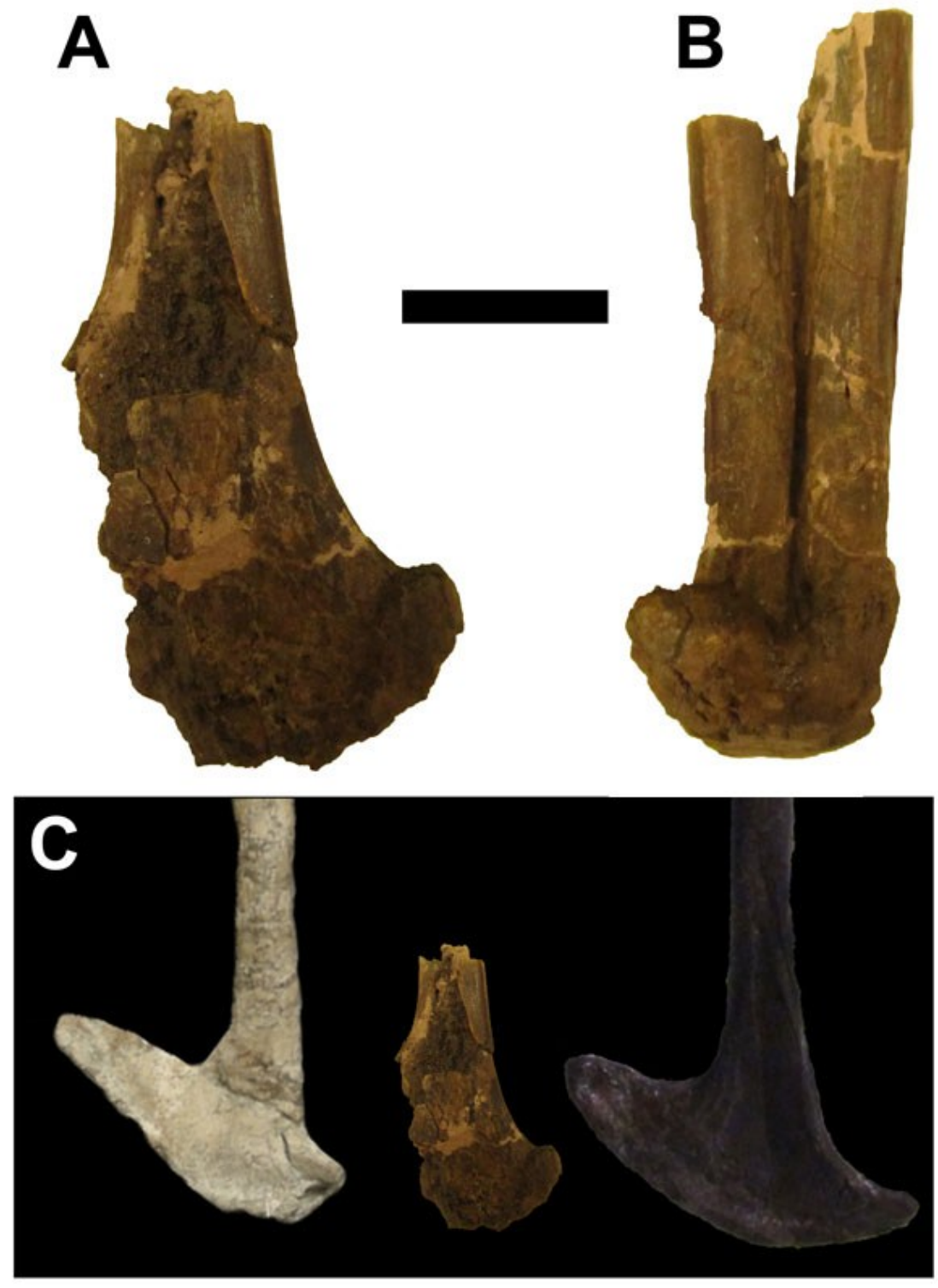


relocated to establish its precise stratigraphic position, Sternberg's handwritten label for this specimen gives the locality as "11/2 miles [2.4 km] east of mouth of Little Sandhill Creek, middle of the beds," and it is probably in the Dinosaur Park Formation. The complete preservation of the anterior extension of the right pubic boot is supported by comparison to AMNH 5201, a partial skeleton from the Horseshoe Canyon Formation most recently referred to Ornithomimus (Cullen et al. 2013) with unusually good three-dimensional preservation of the pubic boot. In both specimens, the very anterior tips of the pubes are slightly upturned, and laterally divergent from each other. D. A. Russell (1972: 383) referred CMN 8902 to Struthiomimus altus, but the anterior extension of the pubic boot is longer and more comparable to Ornithomimus edmontonicus in the more complete Struthiomimus altus referred specimen AMNH 5339. The fragmentary pubis of the Struthiomimus altus holotype (CMN 930) unfortunately does not preserve the anterior extension, but the relatively deep and convex ventral edge of the boot (Xu et al. 2011: character 35.1) distinguishes it from Qiupalong henanensis (this character is not determinable in CMN 8902). CMN 8902 may differ from CMN 930 in the shape of the proximal end of pedal phalanx III-2, but the association of pedal phalanges with CMN 8902 is not certain because they were not mentioned by Russell (1972: 383). CMN 8902 is distinguishable from Ornithomimus by its distal caudal vertebrae, which plesiomorphically lack ventral grooves on the prezygapophyses (Kobayashi et al. 2006, Zanno et al. 2013: fig. 6) and lateral grooves on the neural arch for the succeeding prezygapophyses (Zanno et al. 2013: fig. 6). This derived state for these characters are observed in the Belly River Group ornithomimid CMN 12441 (pers. 
obs.), referred to Ornithomimus edmontonicus by Russell (1972: 381). CMN 8902 is not easily distinguished from Qiupalong henanensis or Rativates evadens, due to the incomplete and fragmentary nature of the available materials, though the latter two are distinguishable from each other.

The isolated "Qiupalong-like" right ankle UALVP 53595, consisting of the calcaneum attached to part of the astragalus, was collected from the Dinosaur Park Formation at the Happy Jack's locality in Dinosaur Provincial Park (Fig. 4.7). A distinct notch or pit is present on the anterodorsal corner at the contact between the astragalus and the calcaneum, identical to the condition considered autapomorphic for Qiupalong henanensis by Xu et al. (2011: fig. 5). This character has not been previously noted in Laramidian ornithomimids, but in many specimens this region is not preserved well enough for it to be unambiguously determinable. It may be notable that the calcaneum and astragalus of UALVP 53595, though inseperable from each other, were collected detached from the tibia, whereas in most partial and complete skeletons of Albertan ornithomimids the astragalus and calcaneum are partially fused to the tibia and are not detachable (Parks 1933). In most Albertan ornithomimid skeletons the suture between the tibia and astragalus is still clearly visible, but in some cases (ROM 797, ROM 1790, pers. obs.) this suture is nearly obliterated by fusion. If the degree of ankle fusion in ornithomimids is an ontogenetic variable, it could be that the pit between the astragalus and calcaneum also shrank or closed with age, though the ontogenetic stage of the Qiupalong henanensis holotype is unknown and it is difficult to confirm the absence of this character in most examined Belly River Group specimens. Xu et al. (2011: 215) 
FIGURE 4.7. Right astragalocalcaneum fragment of UALVP 53595 in A) anterior, B) posterolateral, and C) oblique anterodorsal view, compared to D) left astragalocalcaneum of Qiupalong henanensis (after Xu et al. 2011). Arrows indicate the potentially autapomorphic pit between the calcaneum and astragalus.
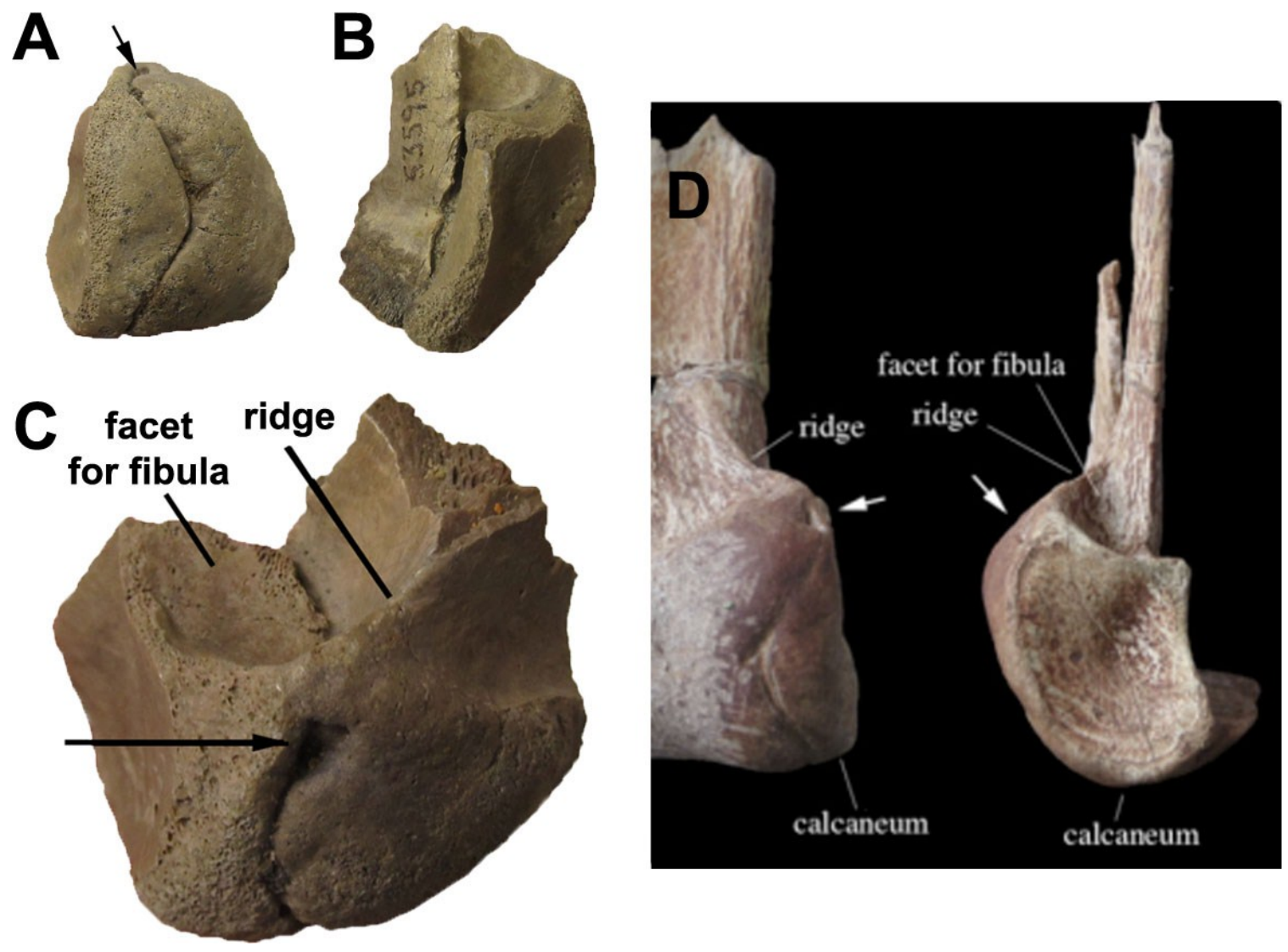
suggested that the distal end of the fibula in Qiupalong henanensis articulated only with the astragalus, but no fibula of this taxon is known, and the figures (Xu et al. 2011: fig. 5) do not reveal any major differences from UALVP 53595, which does have a facet for the fibula on the calcaneum as in other ornithomimids.

Curved pedal unguals are also present in large ornithomimid material from the Dinosaur Provincial Park area described by Longrich (2008), though these unguals are distinct from the known pedal ungual of Qiupalong henanensis (Xu et al. 2011: fig. 7) in having an enlarged proximodorsal process, a very deep flexor depression, and a prominent, ridge-like flexor tubercle (Longrich 2008: fig. 10-11). The notch on the "lateral surface of the medial posterior process of the proximal end of tibia" cited in the diagnostis of Qiupalong henanensis is indicated by arrows to actually be on the lateral (fibular) condyle (Xu et al. 2011: fig. 4c,e). The proximal tibiae of many Laramidian ornithomimids are damaged or poorly preserved, or inaccessibly mounted in articulation with the other elements of the leg, making it difficult to confirm how common the presence or absence of this character was in these taxa. However, the notch appears to have probably been present in Ornithomimus edmontonicus (both tibiae of ROM 851, pers. obs.), and was possibly widespread in this clade (Fig. 4.8).

One taxonomic solution would be to refer CMN 8902 and UALVP 53595 to Qiupalong. The presence in the Dinosaur Park Formation of a theropod genus originally described from Asia would not be an unprecedented hypothesis, because it has previously been suggested for Elmisaurus, Avimimus, and Erlikosaurus, although none of those referrals are definitive (Ryan \& Russell 2001, Currie 2005b). 
FIGURE 4.8. Comparison of A) left tibia of Qiupalong henanensis (after Xu et al.

2011), and B) both tibiae and fibulae of Ornithomimus edmontonicus (ROM 851) in proximal view. Arrows indicate a notch in the lateral condyle that Xu et al. (2011) described as autapomorphic of $Q$. henanensis.

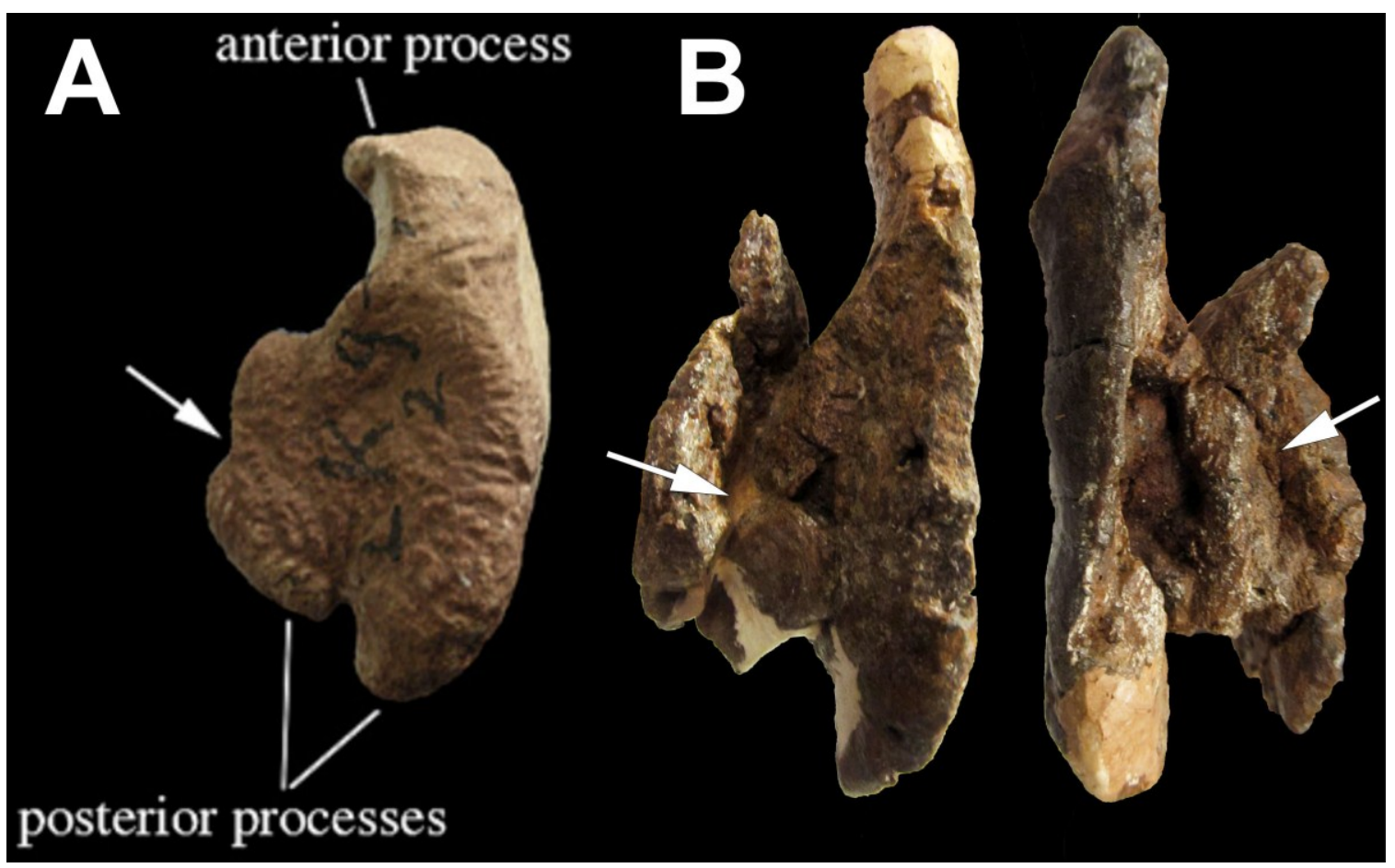


However, because these regions are poorly preserved or unpreserved in many other ornithomimid specimens from the Belly River Group, it may not be possible to state definitively that these "Qiupalong-like "characters do not have a broader distribution within Ornithomimidae than originally supposed. Either way, the recognition of characters that have been considered diagnostic of Qiupalong henanensis in some ornithomimid specimens from the Dinosaur Park Formation supports the phylogenetic result that this taxon is closely related to Albertan ornithomimids. Xu et al. (2011: 214) were only able to assign the age of $Q$. henanensis as "late Late Cretaceous," and described the Qiupa Formation as disconformably underlying the Paleocene Gaoyugou Formation. A later paper by Jiang et al. (2011) determined that the contact between the Qiupa and Gaoyugou formations is conformable, and corresponds to the K/Pg boundary. While the chronological duration of the Qiupa Formation was not estimated, at least some of it is uppermost Maastrichtian, and therefore much younger than the upper Campanian Dinosaur Park Formation. If the oldest occurrence of Qiupalong-like ornithomimid material is in Alberta, rather than China, it is possible that the Qiupalong lineage evolved in Laramidia during the Campanian and later migrated back into Asia.

\section{APPENDIX 1. LIST OF CHARACTERS.}

1. Premaxillary teeth: present (0) or absent (1) (Holtz 1994, Kobayashi \& Lü 2003: character 1). 
2. Posterior end of maxillary process of premaxilla terminates anterior to anterior border of antorbital fossa (0) or extends more posteriorly (1) (Kobayashi \& Lü 2003: character 2).

3. Maxillary teeth: present (0) or absent (1) (Holtz 1994, Kobayashi \& Lü 2003: character 3).

4. Maxilla participates in external narial opening (0) or separated from opening by maxilla-nasal contact (1) (Xu et al. 2002, Kobayashi \& Lü 2003: character 4).

5. Series of foramina along ventral edge of lateral surface of maxilla: present (0) or absent (1) (Kobayashi \& Lü 2003: character 5). Kobayashi and Lü (2003) scored Garudimimus as possessing the derived state of no foramina in this position, but the redescription of this taxon by Kobayashi and Barsbold (2005b: 1506) found that these foramina were present.

6. Prominence on lateral surface of lacrimal: present (0) or absent (1) (Xu et al. 2002, Kobayashi \& Lü 2003: character 6).

7. Area of exposed prefrontal in dorsal view: less than that of lacrimal (0) or approximately the same (1) (Xu et al. 2002, Kobayashi \& Lü 2003: character 7). 
8. Parasphenoid bulla: absent (0) or present (1) (Osmólska et al. 1972, Kobayashi \& Lü 2003: character 8).

9. Ventral edge of dentary: straight (0), or rostral portion reflected ventrally (1) (Kobayashi \& Lü 2003: character 9). This character was modified from its original wording by Jin et al. (2012).

10. Dentary teeth: present (0) or absent (1) (Holtz 1994, Kobayashi \& Lü 2003: character 10).

11. Dentary subtriangular in lateral view (0) or with sub parallel dorsal and ventral borders (1) (Currie 1995, Kobayashi \& Lü 2003: character 11).

12. Dorsal border of dentary in transverse cross-section: rounded and lacks "cutting edge" (0) or sharp with "cutting edge" (1) (Kobayashi \& Lü 2003: character 12).

13. Accessory mandibular condyle, lateral to lateral condyle of quadrate: absent (0) or present (1) (Kobayashi \& Lü 2003: character 13).

14. Foramen on dorsal edge of surangular dorsal to mandibular fenestra: present (0) or absent (1) (Hurum 2001, Kobayashi \& Lü 2003: character 14). Kobayashi and Lü (2003) scored Garudimimus as possessing the derived state of no foramen in this position. Kobayashi and Barsbold (2005b: fig. 2e) indicated the presence of this 
foramen on their interpretive drawing of the right surangular, though they did not discuss it in their description.

15. Posterior surangular foramen: absent (0) or present (1) (Sereno 1999, Kobayashi \& Lü 2003: character 15). Kobayashi and Lü (2003) scored this character as (0) in Allosaurus, Tyrannosauridae, Gallimimus, Struthiomimus, "Dromiceiomimus," and Sinornithomimus; and (1) in Harpymimus, Garudimimus, and Ornithomimus. In most of the former taxa, the foramen is actually present (Madsen 1976, Sereno 2001, Currie 2003, Makovicky et al. 2004, pers. obs. of AMNH 5339 and ROM 840), and in the latter taxa it is absent (Kobayashi \& Barsbold 2005a, Kobayashi \& Barsbold 2005b, pers. obs. of TMP 1995.110.1). The only correctly scored taxon is Sinornithomimus, which was described as lacking this foramen (Kobayashi \& Lü 2003: 244). This character could be modified by switching the character descriptions assigned to each state, and rescoring Sinornithomimus.

16. Number of accessory antorbital fenestra: one (0) or two (1) (Kobayashi \& Lü 2003: character 16).

17. Mandibular fenestra: heart-shaped with a short and wide process of dentary at anterior part of external mandibular fenestra (0) or oval-shaped without the process (1) (Kobayashi \& Lü 2003: character 17). 
18. Neck length: less (0) or more (1) than twice skull length (Pérez-Moreno et al. 1994, Kobayashi \& Lü 2003: character 18).

19. Anteroposterior lengths of cervical neural spines: more (0) or less (1) than one third of neural arch lengths (Makovicky 1995, Kobayashi \& Lü 2003: character 19).

20. Posterior process of coracoid: short (0) or long (1) (Pérez-Moreno et al. 1994, Kobayashi \& Lü 2003: character 20).

21. Biceps tubercle of coracoid: positioned close to base of posterior process (0) or more anteriorly (1) (Kobayashi \& Lü 2003: character 21).

22. Depression on dorsal surface of supraglenoid buttress of scapula: present (0) or weak/absent (1) (Nicholls and Russell 1985, Kobayashi \& Lü 2003: character 22).

23. Infraglenoid buttress of coracoid: aligned with posterior process (0) or is offset laterally from line of posterior process (1) (Kobayashi \& Lü 2003: character 23).

24. Robustness of humerus, ratio of width of proximal end to total length: greater (0) or less than 0.2 (1) (Kobayashi \& Lü 2003: character 24).

25. Deltopectoral crest of humerus: strong (0) or weak (1) (Kobayashi \& Lü 2003: character 25). 
26. Radial condyle of humerus: larger than ulnar condyle (0), approximately equal (1), or smaller (2) (Kobayashi \& Lü 2003: character 26).

27. Entepicondyle of humerus: weak (0) or strong (1) (Kobayashi \& Lü 2003: character 27).

28. Length of metacarpal I: approximately half or less than metacarpal II (0), slightly shorter (1) or longer (2) (Russell 1972, Kobayashi \& Lü 2003: character 28). Russell (1972) originally used the second derived state to support the monophyly of Ornithomimus velox and Ornithomimus edmontonicus. Kobayashi and Lü (2003) scored the second derived state as present in two ornithomimid genera, Anserimimus and Ornithomimus. However, Barsbold (1988: 125) originally described and illustrated the only known specimen of Anserimimus planinychus as having a first metacarpal slightly shorter than the second and third, with reported metacarpal lengths of $72 \mathrm{~mm}, 75 \mathrm{~mm}$, and $74 \mathrm{~mm}$, respectively. Kobayashi (2004) remeasured these elements as $73.5 \mathrm{~mm}, 73.0 \mathrm{~mm}$, and $73.6 \mathrm{~mm}$, respectively, but did not mention or explain the conflict with the proportions in the original description. The photograph of the metacarpus (Kobayashi \& Barsbold 2006: fig. 4b) appears to support the new interpretation, but without access to the specimen it cannot be confirmed that this is not caused by a slight difference in perspective between the drawing (Barsbold 1988: fig. 1c) and the photograph. Therefore, the state of this character in Anserimimus has provisionally been rescored as unknown, 
because the literature is conflicting and there is insufficient published information to determine which source is correct (and the actual measurement discrepancy between the two states is very small). The second derived state is confirmed in both Dinosaur Park Formation (TMP 1995.110.1) and Horseshoe Canyon Formation (CMN 8632, ROM 851) specimens of Ornithomimus.

29. Distal end of metacarpal I: medially (0) or laterally (1) rotated (Pérez-Moreno and Sanz 1995, Kobayashi \& Lü 2003: character 29).

30. Distal end of metacarpal I forms ginglymoid articulation with distinct condyles (0) or relatively large convex phalangeal articulation with reduced condyles (1) (Pérez-Moreno and Sanz 1995, Kobayashi \& Lü 2003: character 30).

31. Metacarpal II: longer [modified from "shorter"] (0) or shorter [modified from "longer"] (1) than metacarpal III (Kobayashi \& Lü 2003: character 31). Kobayashi and Lü (2003) considered the plesiomorphic state to be the second metacarpal shorter than the third, which they scored as the condition in Allosaurus. The condition in tyrannosaurids was scored as unknown. However, published figures and measurements of Allosaurus (Gilmore 1920, Madsen 1976) and Tyrannosaurus (Lipkin \& Carpenter 2008) indicate that the second metacarpal was actually longer than the third in these taxa. The second metacarpal is also longer than the third in a variety of early or basal coelurosaurs and maniraptoriforms including Compsognathidae (Currie \& Chen 2001, Gishlick \& Gauthier 2007), Tanycolagreus 
(Carpenter et al. 2005), Haplocheirus (Choiniere et al. 2010), Falcarius (Zanno 2006), and the possible basalmost ornithomimosaur Nqwebasaurus (de Klerk et al. 2000, Choiniere et al. 2012), strongly suggesting that a longer second metacarpal is the actual plesiomorphic state. The longer third metacarpal of Harpymimus (approximately $110 \%$ as long as the second metacarpal; Kobayashi \& Barsbold 2005a) is rescored as a derived character that appears to be an autapomorphy of that taxon. The ambiguity concerning the lengths of the metacarpals in Anserimimus is discussed above. Some other ornithomimosaurs have second and third metacarpals similar enough in length that this character is uncertain. Pérez-Moreno et al. (1994) described the length of the third metacarpal as $98 \%$ of that of the second metacarpal, but in the accompanying photograph (Pérez-Moreno et al. 1994: fig. $2 \mathrm{~b}$ ) it is the third metacarpal that looks slightly longer. According to measurements by Russell (1972) and Nicholls and Russell (1981), the Struthiomimus altus specimens AMNH 5339 and UCMZ 1980.1 both have second and third metacarpals that are essentially identical in length, making them technically impossible to score for this character as presently worded. However, when measured by Osborn (1917) and Kobayashi (2004), respectively, these specimens had second metacarpals that were slightly longer than their third metacarpals. The measurement differences involved to cause these discrepancies are so small that the functional and phylogenetic importance of the character is doubtful.

32. First phalanx of manual digit I: shorter (0) or longer (1) than metacarpal II (Pérez-Moreno et al. 1994, Kobayashi \& Lü 2003: character 32). 
33. Flexor tubercles of manual unguals: positioned at proximal end (0) or distally placed (1) (Nicholls and Russell 1985, Kobayashi \& Lü 2003: character 33).

34. Pubic shaft: nearly straight (0) or curved (1) (Norell et al. 2002, Kobayashi \& Lü 2003: character 34). The derived state of this character, as scored by Kobayashi and Lü (2003), is autapomorphic of Archaeornithomimus.

35. Ventral border of pubic boot: nearly straight or slightly convex (0) or strongly convex with ventral expansion (1) (Kobayashi \& Lü 2003: character 35).

36. First pedal digit: present (0) or absent (1) (Kobayashi \& Lü 2003: character 36).

37. Proximal end of metatarsal III exposed in anterior view (0) or covered by metatarsals II and IV anteriorly (1) (Norell et al. 2002, Kobayashi \& Lü 2003: character 37).

38. Length of pedal phalanx II-2: more than $60 \%$ of pedal phalanx II-1 (0) or less (1) (Kobayashi \& Lü 2003: character 38).

39. Ischium straight (0) or ventrally curved anteriorly (1) (Ji et al. 2003, Xu et al. 2011: character 39). 
40. Angular exposed almost to end of mandible in lateral view reaches or almost reaches articular (0) or excluded from posterior end angular suture turns ventrally and meets ventral border of mandible rostral to glenoid (1) (Ji et al. 2003, Xu et al. 2011: character 40).

41. Brevis fossa poorly developed adjacent to ischia peduncle and without lateral overhang medial edge of brevis fossa visible in lateral view (0), or fossa well developed along full length of postacetabular blade, lateral overhang extend along full length of fossa medial edge completely covered in lateral view (1) (Ji et al. 2003, Xu et al. 2011: character 41).

42. Midcaudal vertebrae short prezygapophyses extend less than one half centrum length (0) or moderate prezygapophyses extend more than one half but less than one centrum length (1) (Kobayashi and Barsbold 2005a, Xu et al. 2011: character 42).

43. Anterior extension of the pubic boot; nearly absent (0) or present (1) (Xu et al. 2011: character 43).

44. Distal end of pubic shaft is curved (0) or straight (1) (Xu et al. 2011: character 44). 
45. Acute angle between pubic shaft and boot is small (0) or large (1) (Xu et al. 2011: character 45). Xu et al. (2011) introduced this character as a synapomorphy uniting Qiupalong and Ornithomimus (it was scored as unknown in Struthiomimus). Unfortunately, this character was never quantified, and no boundary between "small" and "large" angles was suggested. In the accompanying figure (Xu et al. 2011: fig. 8) this angle does not look substantially greater in Qiupalong than in other ornithomimosaurs such as Archaeornithomimus or Gallimimus. The Ornithomimus specimen ROM 851 actually appears to have a distinctly smaller acute angle than any other ornithomimid figured by Xu et al. (2011). However, the pubic boot of this specimen is damaged, and the possibly conspecific ROM 797 has a large angle. This character is provisionally retained in the present analysis, but it needs to be better explained to be scored in all of the included specimens.

46. Tip of anterior extension of the pubic boot is at the level of anterior border of pubic shaft (0) or is more extended anteriorly (1) (Xu et al. 2011: character 46).

47. Pedal unguals curved in lateral view (0) or straight (1) (Makovicky et al. 2010, Xu et al. 2011: character 47).

48. Shaft of MT III with straight medial border in dorsal view (0) or with a medial expansion forming a convexity or bulge along the distal part of the shaft (1) (Kobayashi and Barsbold 2005b, Makovicky et al. 2010, Xu et al. 2011: character 48). 
49. Dorsal edge of dentary: straight (0), or rostral portion concave resulting in a gap between upper and lower jaws when jaws are closed (1) (Jin et al. 2012: character 38).

50. Retroarticular process of mandible: deflected ventrally (0), or curved caudodorsally (1) (Makovicky et al. 2004, Jin et al. 2012: character 40).

51. Surangular flange: absent (0) or present (1) (Makovicky et al. 2004, Jin et al. 2012: character 41).

52. Proximal and distal ends of humerus: in the same plane (0), or twisted (1) (Kobayashi \& Barsbold 2005a, Jin et al. 2012: character 42).

53. Radius and ulna: well separated distally (0), or closely appressed distally (1) (Nicholls \& Russell 1985, Makovicky et al. 2004, Jin et al. 2012: character 43). Jin et al. (2012) scored Beishanlong as possessing the derived state, but the published photograph (Makovicky et al. 2010: fig. 1n) shows these elements to be not appressed for most of the distal region.

54. Postacetabular process of ilium: gently curved (0), or truncated (1) (Ji et al. 2003, Jin et al. 2012: character 45). 
55. Ventral edge of maxilla: straight (0) or convex (1) (Longrich, 2008).

56. Antorbital fenestra: more than half of antorbital fossa (0), or slightly less than half as long as antorbital fossa (1). (Kobayashi \& Barsbold 2005b).

57. Orbital rim of frontal, in dorsal view: relatively straight (0), or strongly concave (1). (Longrich, 2008)

58. Frontal with a notch to receive accessory ramus of the postorbital: absent $(0)$ or present (1) (Kobayashi et al., 2006; Longrich, 2008).

59. Quadratojugal with a bifid dorsal ramus for reception of the descending ramus of the squamosal: absent (0), or present (1) (Makovicky et al., 2004).

60. Quadratojugal with a well-defined incision in the caudal border for the quadrate foramen: absent (0), or present (1) (Makovicky et al., 2004).

61. Humerus: shorter (0) or longer (1) than scapula (Russell, 1972).

62. Manus: shorter (0) or longer (1) than humerus (Makovicky et al., 2004).

63. Manual phalanx III-3 shorter (0) or longer (1) than manual ungual III-4 (Russell, 1972). 
64. Manual ungual I strongly curved (0) or relatively straight (1) (Russell 1972).

65. Manual unguals II and III strongly curved (0) or relatively straight (1).

66. Length of tibiotarsus relative to femur less than (0) or greater than (1) 1.15 (Russell 1972).

\author{
APPENDIX 2. DATA MATRIX. \\ Allosaurus $\quad 0000000000000000000000000000000000000001$ \\ 00010100000000000000000000 \\ Tyrannosauridae $0001000000000000000000000[12][01] 00000000$ \\ 010[01]1 01[01]1 000[01]0 $0000010000000 ? 0 ? 0$ \\ Pelecanimimus 0?0?? 0?100 10??? 0?1?1 ????1 ??110 011?? ????0 \\ ????? ???00 101?0 ????? ??111? \\ Hexing 1011 ? $10 ? 00$ 101?? ?1?01 ?1001 10??0 ??1?? 000?? \\ ????? ?0?10 101?? 100?? 01?00 1 \\ Shenzhousaurus 1011? 1??00 101?? 0???? ????? ????? ??100 ???0? \\ 0?000 0??10 1??00 000?? ??111 ? \\ Harpymimus $\quad 1011110 ? 10101011110 ? 01001100001010 ? ? 00 ? 0$ \\ $10 ? 0 ? ? 0010101101000001111 ?$ \\ Beishanlong ????? ????? ????? ????1 010011 1???? ??1?? ?0?1? ????? \\ ?00?? ?00?? ????? 0?011 0
}


Garudimimus

$11110111111110111 ? 0 ?$ ????? ????? ???00 $001 ? 0$

$1 ? 100001111 ? ? 10100 ? 0$ ????? 0

Archaeornithomimus ????? ????? ????? ???01 010012011001110 ?1?1?

$1 ? 100$ 011?? ??11? ????? ????? ?

Sinornithomimus

$1111111111111 ? 1$ ??111 0[01]001 201100110011111

101?? $0111111111100 ? ? 101 ? 10$

Anserimimus

????? ????? ????? ???11 $1010021 ? 11$ ?1100 1111?

111?? 0?1?? ?1??? ????? ?0?11 ?

Gallimimus

$11111111111110000110111[01] 12[01] 11101100$

$1111011110 ? 1111111110 ? 000100000$

Qiupalong

????? ????? ????? ????? ????? ????? ????0 11???

$1 ? 011$ 101?? ????? ????? 1???? ?

StruthiomimusDPF $1 ? 110$ ???11 $111 ? 0$ ?1111 01001 2011[01] ?1101 11111

11[01]1? 11111 ?11[01]1 ?1000110010

StruthiomimusHCF 11110 01?11 ??110 11??1 000?1 ?0111 ?01?1 ??1?0

1111? 111?1 1?111 $1100011 ? 010$

ROM1790

1111? 1111111 ??? ????? ????? ????? ???0? ?111?

1??1? ?11?? ???1? 1???? 1???? 0

TMP19951101 $111101111111111111 ? 1000 ? ?$ ?0211 ????1 11110

$1111 ? 111111 ? 110001111$ ???? 0

R0M840

1111011111111001 1?1? ??011 ?0??? ??1?? ????1

????? ???11 ?11?0 00?11 1??11 ? 
R0M851

1111? 11?11 111?? $011110 ? 011$ ?021101101 11111

$1 ? 1101111111 ? 1 ? 10 ? 11101110$

"Dromiceiomimus" ????? ???11 111?? ????? ????? ????? ???01 1111?

11111111111 ??1? ?011? 1???? 1 


\section{CHAPTER 5}

\section{CONCLUSIONS}

\section{DIVERSITY OF BELLY RIVER GROUP ORNITHOMIMIDAE}

The Belly River Group has produced the oldest definitive records of

Ornithomimidae in Alberta. Earlier reports of Ornithomimidae from the Santonian Milk River Formation were based on material that is indeterminate or referable to other theropod clades. The oldest formation in the Belly River Group, the Foremost Formation, has produced two isolated phalanges that strongly resemble phalanges of ornithomimids, but nonetheless slightly differ from all examined definitive ornithomimid specimens and exhibit no unambiguous synapomorphies of Ornithomimidae. Therefore, the presence of Ornithomimidae in the Foremost Formation is considered uncertain. In Alberta, definitive ornithomimid elements appear in the lower unit of the Oldman Formation, including a pedal phalanx II-2. Morphological variation was observed in ornithomimid phalanges and unguals from the Oldman Formation, but the known specimens are too few and too incomplete to make a convincing case for whether more than one taxon of Ornithomimidae is present in the Oldman Formation, whether any turnover of species occurs within the formation, or whether any ornithomimid species are shared by the Oldman and Dinosaur Park formations.

The taxonomy of Struthiomimus altus in the Belly River Group has not been a major source of disagreement since Russell (1972) published the first modern diagnosis of this taxon. However, this study finds that material included in S. altus by Russell (1972) and subsequent authors is not morphologically or taxonomically 
homogeneous. The holotype of S. altus (CMN 930) is less securely related to the most representative referred specimens than commonly assumed, but arguments can be made both for and against the designation of a neotype, and more work is needed to determine the appropriate nomenclatural action to take. Rativates evadens gen. et sp. nov. erected based on a specimen previously referred to $S$. altus (ROM 1790), and is supported by the following autapomorphic characters: 1.short and blunt contact for the jugal on the maxilla, 2. reduced mid-caudal neural spines over the transition point of the tail, 3. ischia with a convex and completely fused posterior contact, 4. larger medial condyle than lateral condyle of the proximal tibia, and, 5. third metatarsal possessing a unique shape in distal view that is deeper laterally than medially and lacks the groove on the flexor surface.

The characters of the ischia and third metatarsal can be confirmed to differ from the holotype of S. altus (CMN 930), and the remaining characters also differ in other referred S. altus material from the Belly River Group (e.g. AMNH 5339, AMNH 5385). Although the referral of ROM 1790 to $S$. altus has been widely accepted in the past, most characters previously used to diagnose S. altus (Russell 1972, Makovicky et al. 2004) are in regions that are not preserved or not determinable in this specimen. Limb element ratios do not reliably separate $S$. altus from other known ornithomimids (including Ornithomimus sp.) in the Dinosaur Park Formation. Rativates evadens will be the third ornithomimid to be named based on material from the Dinosaur Park Formation, after Struthiomimus altus (Lambe 1902) and Ornithomimus samueli (Parks 1928). 


\section{ORIGIN OF ORNITHOMIMIDAE IN LARAMIDIA}

The earliest reported possible ornithomimosaurs from North America, from the middle Lower Cretaceous of Utah, are not much younger than the oldest known ornithomimosaurs in Europe or Asia. However, all records of pre-Campanian ornithomimosaurs from North America are fragmentary or undescribed (and in some cases both), making it difficult to reconstruct the paleobiogeography of the clade. Zanno and Makovicky (2011), based on the morphology of unguals, included Ornithomimidae among several dinosaur clades of probable Asian origin now reported from the lower Albian Cloverly Formation in Montana, and argued for a pre-108 Ma initiation of the Early Cretaceous Laurasian interchange event. However, definitive members of Ornithomimidae are not known from the Lower Cretaceous in Asia. The present state of the literature does not permit a definite conclusion on whether the Lower Cretaceous North American theropod record includes basal ornithomimosaurs, true ornithomimids, or neither.

After their unconfirmed presence in the lower Cenomanian, the next oldest diagnostic ornithomimid material from North America does not occur until the Campanian. All Upper Cretaceous ornithomimosaur material from North America has been referred to the family Ornithomimidae, differing from the Upper Cretaceous of Mongolia where ornithomimid and deinocheirid ornithomimosaurs coexist in the Bayanshiree and Nemegt formations (Kobayashi and Barsbold 2006, Barsbold et al. 2007, Lee et al. 2014). The significance of the apparent North American ornithomimosaur hiatus is uncertain, considering that North American 
dinosaurs in general are poorly represented during this span. D'Emic and Foreman (2012) noted that the extripation of sauropods and allosauroids, the first North American appearance of hadrosauroids, and the opening of a persistent Western Interior Seaway all occurred around the same time during the Cenomanian. It is possible, though speculative, that a temporary extripation of North American ornithomimosaurs occurred as part of the same paleoecological transition. However, Zanno et al. (2013) noted that the toothlessness of Late Cretaceous ornithomimosaurs creates a bias against their collection and recognition in sites where small theropods are represented primarily by isolated elements, and they did not consider the lack of identified ornithomimosaur fossils from upper Cenomanian to lower Campanian deposits in the western United States to reflect a true absence.

The results of the present study reject previous claims that ornithomimids are known from the Santonian Milk River Formation of Alberta (L. S. Russell 1935, Ryan and A. P. Russell 2001, Weishampel et al. 2004), extending the pattern of a sudden appearance of Ornithomimidae in the Campanian to northern Laramidia. Since the records of possible ornithomimids in the Foremost Formation and definitive ornithomimids in the Oldman Formation also consist entirely of small, isolated elements, their apparent absence in the Milk River Formation is not easily explained as a taphonomic or collecting bias. In Mexico, ornithomimids are known from the late Campanian El Gallo and Cerro del Pueblo formations (Rivera-Sylva and Carpenter 2014), but have not been reported from any older localities, such as the unnamed formation that has produced Santonian hadrosauroid material (RamírezVelasco et al. 2012). Although the sample size is not large enough to draw definitive 
statistical conclusions, given the intensive sampling in the Milk River and Foremost formations, and a similar biostratigraphic distribution reported for southern Laramidia, it is suggested that the Late Cretaceous ornithomimid clade did not migrate into Laramidia until the Campanian. At least three genera are present near the bottom of the late Campanian Dinosaur Park Formation, suggesting that ornithomimids may have undergone a rapid burst of diversification shortly after their entry into Laramidia, if a single origin for Laramidian ornithomimids is supported.

\section{PHYLOGENY AND PALEOBIOGEOGRAPHY OF LARAMIDIAN ORNITHOMIMIDS}

The monophyly of the well-known Campanian-Maastrichtian Laramidian ornithomimids is another uncertainty affecting paleobiogeographic hypotheses. Kobayashi and Lü (2003) and subsequent authors using a modified version of their analysis (Xu et al. 2011, Cullen et al. 2013) found that Ornithomimus (including "Dromiceiomimus") and Struthiomimus are sister taxa nested within a series of Asian outgroups, and only a single migration from Asia is needed to account for their presence in Laramidia. However, other workers have suggested that Ornithomimus is more closely related to the Mongolian genus Anserimimus (Yacobucci 1990, Bronowicz 2011), requiring either separate migrations from Asia for the ancestors of Ornithomimus and Struthiomimus, or a migration of the ancestor of Anserimimus into Asia from Laramidia. King and Jones (1997) suggested that based on available evidence, North American ornithomimids first appeared in Appalachia, and from there spread to Laramidia during the mid-Campanian. However, this model is 
reliant on material that has not been shown as adequately diagnostic as ornithomimid, and none of the Appalachian ornithomimosaur material has been included in a published phylogenetic analysis.

Unfortunately, the phylogenetic relationships of Laramidian ornithomimids were not able to be resolved in the present analysis such that definitive statements about the number and direction of migration events can be made. The lack of the pectoral girdle, forelimb, and pubic boot for Rativates is probably responsible for this lack of resolution, because the regions are especially dense in characters adapted from the analyses of Kobayashi and Lü (2003) and Xu et al. (2011). Excluding Rativates restores the recovery of an exclusively Asian Gallimimus + Anserimimus clade and a North American and Asian Ornithomimus + Struthiomimus + Qiupalong clade, as previously found by Xu et al. (2011) and Cullen et al. (2013). Although the monophyly of Laramidian ornithomimids to the exclusion of all Asian forms was not demonstrated in this analysis, it was also not rejected. However, the original interpretation of Qiupalong as the exclusively Asian sister taxon of the Laramidian clade is complicated by the discovery that characters used to diagnose Qiupalong appear first in ornithomimids from Alberta. Further study of the Asian $Q$. henanensis material is needed to establish a revised diagnosis of this species.

Cladistic analyses of ornithomimid relationships have so far been biased in using primarily Albertan material to represent all of Laramidian ornithomimid diversity. Ornithomimids from the United States and Mexico are not known or described completely enough to include in the phylogenetic analysis, but may introduce additional complications to the standard phylogenetic hypothesis of a 
single Laramidian ornithomimid clade. LACM 47520 (Fig. 4.5) is a very large undescribed ornithomimid from the late Maastrichtian Hell Creek Formation of Montana that appears to preserve part of the pubis. If this element has not been misleadingly restored, the distal end displays a small anterior extension of the pubic boot (Xu et al. 2011: character 43.0), a distally recurved pubic shaft (DeCourten \& Russell 1985; Xu et al. 2011: character 44.0), a relatively small acute angle between the pubic shaft and boot (Xu et al. 2011: character 45.0), and the tip of the anterior extension level with the anterior border of the proximal shaft (Xu et al. 2011: character 46.0), all consistent with more basal Asian ornithomimids outside of the normally recognized "Laramidian clade." Although it is impossible to draw any conclusions from undescribed material that was not closely observed, this material suggests that there is much work to be done in the future to resolve the issue of Laramidian ornithomimid relationships.

No North American ornithomimid species is confirmed to have had a large geographic range, but this may be due to the current distribution of published material that is diagnostic to species: Campanian ornithomimids are poorly known from the United States, Maastrichtian ornithomimids are poorly known from Canada, and no diagnostic material has been reported from more disparate localities such as the Arctic or the Southeast. The presence of possible new taxa from the late Campanian in Utah and Mexico (Lavender et al. 2010, Anguillon-Martinez 2010) and from the Maastrichtian in Alberta (Eberth et al. 2013) suggests that ornithomimid species may have been latitudinally segregated in Laramidia, as has been postulated for other dinosaur groups. The recent revision of Appalachian theropods by 
Brusatte et al. (2012) supports the taxonomic distinction of Laramidian and Appalachian ornithomimids, contrary to earlier suggestions that the same ornithomimid genus (Horner and Baird 1979) or species (Sullivan 1997) occurred on both sides of the Western Interior Seaway.

Most dinosaur groups in the Late Cretaceous of Alberta had a relatively high rate of species turnover, with species not exceeding the duration of one geological formation in a region (Ryan and Evans 2005, Larson and Currie 2013). In contrast, published material assigned to Struthiomimus altus ranges from at least the lower part of the Dinosaur Park Formation (UCMZ 1980.1) to the Morrin Member of the Horseshoe Canyon Formation (AMNH 5257) in Alberta, and unpublished material anecdotally assigned to this species (the "Margie" specimen) may ultimately extend its range to the upper Maastrichtian Hell Creek Formation in Montana.

Ornithomimus edmontonicus (sensu Zanno et al. 2012, Eberth et al. 2013) occurs from the lower part of the Dinosaur Park Formation (TMP 1995.110.0001) to the Tolman Member of the Horseshoe Canyon Formation (AMNH 5201). However, Longrich (2008) did not consider either of the Dinosaur Park Formation Struthiomimus and Ornithomimus to be the same species as their congeners in the Horseshoe Canyon Formation. The present taxonomic revision, though limited to material from the Dinosaur Park Formation, suggests that ornithomimid diversity in the Late Cretaceous was higher than previously recognized, even among material that has long been referred to the single species $S$. altus. Closer review of the material from the Horseshoe Canyon Formation may reveal additional hidden diversity. 


\section{SUMMARY}

This new research into Ornithomimidae from Alberta has both enriched and complicated our understanding of the clade. The recent overview by Makovicky et al. (2004) reduced the diversity of Albertan ornithomimids to just two named species spanning from the Campanian to the Maastrichtian. This study recognizes material collected over 80 years ago as the holotype of a new taxon, Rativates evadens, that is so far endemic to the Dinosaur Park Formation. Additional previously unrecognized morphological diversity may hint at higher taxonomic diversity more consistent with the rapid turnover than the over six million years of stasis that has been proposed for ornithomimid species (Eberth et al. 2013). The apparently sudden appearance of definitive ornithomimids in Campanian localities across Laramidia suggests that their arrival from Asia may have occurred later than previously expected. The presence of Qiupalong-like ornithomimid material in Alberta strengthens the biogeographic link to Asia, and may also suggest that the exchange of ornithomimids between the continents was more complex than a single one-way migration. These conclusions make it clear that Ornithomimidae has been an often overlooked group that is in need of even more attention, but this newly complicated view of ornithomimid diversity and evolution is compatible with the highly dynamic state of knowledge surrounding even the most well-studied dinosaur clades. 


\section{REFERENCES}

Aguillón Martínez, M. C. 2010. Fossil vertebrates from the Cerro del Pueblo Formation, Coahuila, Mexico, and the distribution of late Campanian (Cretaceous) terrestrial vertebrate faunas. M.Sc. thesis, Southern Methodist University, Dallas.

Allain, R., Vullo, R., Leprince, A., Néraudeau, D., and Tournepiche, J.-F. 2011. An ornithomimosaur-dominated bonebed from the Early Cretaceous of southwestern France. Journal of Vertebrate Paleontology, Program and Abstracts, 2011, 61.

Allain, R., Vullo, R., Le Loeuff, J., and Tournepiche, J.-F. 2014. European ornithomimosaurs (Dinosauria, Theropoda): an undetected record. Geologica Acta 12: 127-135.

Averianov, A. 0. 2006. On an ornithomimid dinosaur (Saurischia, Ornithomimosauria) from the Cenomanian of Fergana. Paleontological Journal 40: 323-327.

Baird, D. 1986. Upper Cretaceous reptiles from the Severn Formation of Maryland. The Mosasaur 3: 63-85.

Baird, D. and Horner, J. R. 1979. Cretaceous dinosaurs of North Carolina. Brimleyana 2: $1-28$. 
Barrett, P. M. 2005. The diet of ostrich dinosaurs (Theropoda: Ornithomimosauria). Palaeontology 48: 347-358.

Barsbold, R. 1976. [On the evolution and systematics of the late Mesozoic dinosaurs]. Sovmestna Svetsko-Mongolska Paleontologiceska Ekspedici Trudy 3: 6875.

Barsbold, R. 1988. A new Late Cretaceous ornithomimid from the Mongolian People's Republic. Paleontological Journal 1988: 124-127.

Barsbold, R. and Osmólska, H. 1990. Ornithomimosauria. In The Dinosauria. Edited by D. B. Weishampel, P. Dodson, and H. Osmólska. University of California Press, Berkeley. pp. 225-244.

Barsbold, R. and Perle, A. 1984. The first record of a primitive ornithomimosaur from the Cretaceous of Mongolia. Paleontological Journal 1984: 118-120.

Béland, P. and Russell, D. A. 1978. Paleoecology of Dinosaur Provincial Park (Cretaceous), Alberta, interpreted from the distribution of articulated vertebrate remains. Canadian Journal of Earth Sciences 15: 1012-1024. 
Bock, W. J. and Bühler, P. Archaeopteryx lithographica von Meyer, 1861 (Aves):

proposed conservation of usage by designation of a neotype. Bulletin of Zoological Nomenclature 64: 182-184.

Bravo-Cuevas, V. M. and Rodríguez-de la Rosa, R. 2014. A summary of the Mesozoic vertebrate tracks of Mexico. pp. 181-192 in Rivera-Sylva, H. E., Carpenter, K., and Frey, E. (eds.). Dinosaurs and Other Reptiles from the Mesozoic of Mexico. Indiana University Press, Bloomington.

Britt, B. B., Stadtman, K. L, and Scheetz, R. D. 1996. The Early Cretaceous Dalton Wells dinosaur fauna and the earliest North American titanosaurid sauropod. Journal of Vertebrate Paleontology 16: 24A.

Britt, B. B., Eberth, D. A., Scheetz, R. D., Greenhalgh, B. W., and Stadtman, K. L. 2009. Taphonomy of debris-flow hosted dinosaur bonebeds at Dalton Wells, Utah (Lower Cretaceous, Cedar Mountain Formation, USA). Palaeogeography, Palaeoclimatology, Palaeoecology 280: 1-22.

Bronowicz, R. 2011. New material of a derived ornithomimosaur from the Upper Cretaceous Nemegt Formation of Mongolia. Acta Palaeontologica Polonica 56: 477488. 
Brown, C. M., Evans, D. C., Campione, N. E., O'Brien, L. J., and Eberth, D. A. 2013a. Evidence for taphonomic size bias in the Dinosaur Park Formation (Campanian, Alberta), a model Mesozoic terrestrial alluvial-paralic system. Palaeogeography, Palaeoclimatology, Palaeoecology 372: 108-122.

Brown, C. M., Evans, D. C., Ryan, M. J., and Russell, A. P. 2013b. New data on the diversity and abundance of small-bodied ornithopods (Dinosauria, Ornithischia) from the Belly River Group (Campanian) of Alberta. Journal of Vertebrate Paleontology 33: 495-520.

Brusatte, S. L., Choiniere, J. N., Benson, R. B., and Norell, M. A. 2012. Theropod dinosaurs from the Late Cretaceous of eastern North America: anatomy, systematics, biogeography and new information from historic specimens. Journal of Vertebrate Paleontology, Program and Abstracts, 2012, 70.

Buffetaut, E., Suteethorn, V., and Tong, H. 2009. An early 'ostrich dinosaur' (Theropoda: Ornithomimosauria) from the Early Cretaceous Sao Khua Formation of NE Thailand. The Geological Society, London, Special Publications 315: 229-243.

Campbell, J. A. 2014. A re-evaluation of the chasmosaurine ceratopsid Chasmosaurus (Dinosauria: Ornithischia) from the Upper Cretaceous (Campanian) Dinosaur Park Formation of western Canada. M.Sc. thesis, Carleton University. 
Carpenter, K. and Young, D. B. 2002. Late Cretaceous dinosaurs from the Denver Basin, Colorado. Rocky Mountain Geology 37: 237-254.

Carpenter, K., Miles, C., and Cloward. K. 2005. New small theropod from the Upper Jurassic Morrison Formation of Wyoming. In The Carnivorous Dinosaurs. Edited by K. Carpenter. Indiana University Press, Bloomington. pp. 23-48.

Carrano, M. T., Krause, D. W., O'Connor, P. M., and Sampson, S. D. 2009. Megalosaurus crenatissimus Depéret, 1896 (currently Majungasaurus crenatissimus; Dinosauria, Theropoda): proposed replacement of the holotype by a neotype. Bulletin of Zoological Nomenclature 66: 261-264.

Chatterjee, S. 1993. Shuvosaurus, a new theropod. National Geographic Research and Exploration 9: 274-285.

Choiniere, J. N., Xu, X., Clark, J. M., Forster, C. A., Guo, Y., and Han, F. 2010. A basal alvarezsauroid theropod from the early Late Jurassic of Xinjiang, China. Science 327: 571-574.

Choiniere, J. N., Forster, C. A., and de Klerk, W. J. 2012. New information on Nqwebasaurus thwazi, a coelurosaurian theropod from the Early Cretaceous Kirkwood Formation in South Africa. Journal of African Earth Sciences 71-72: 1-17. 
Choiniere, J., Clark, J. M., Forster, C. A., Norell, M. A., Eberth, D. A., Erickson, G. M., Chu, H., and Xu, X. 2014. A juvenile specimen of a new coelurosaur (Dinosauria: Theropoda) from the Middle-Late Jurassic Shishugou Formation of Xinjiang, People's Republic of China. Journal of Systematic Palaeontology 12: 177-215.

Claessens, L., Loewen, M., and Lavender, Z. 2011. A reevaluation of the genus Ornithomimus based on new preparation of the holotype of 0 . velox and new fossil discoveries. Journal of Vertebrate Paleontology, Program and Abstracts, 2011, 90.

Clark, J. M., Forster, C., Wang, Y., and Andres, B. 2002. New small dinosaurs from the Upper Jurassic Shishugou Formation at Wucaiwan, Xinjiang, China. Journal of Vertebrate Paleontology 22: 44A.

Colbert, E. H., Charig, A. J., Dodson, P., Gillette, D. D., Ostrom, J. H., and Weishampel, D. 1992. Coelurus bauri Cope, 1887 (currently Coelophysis bauri; Reptilia, Saurischia): proposed replacement of the lectotype by a neotype. Bulletin of Zoological Nomenclature 49: 276-279.

Cox, B., Savage, R. J. G., Gardiner, B., Harrison, C., and Palmer, D. 1999. The Simon \& Schuster Encyclopedia of Dinosaurs \& Prehistoric Creatures. Simon \& Schuster, New York. 
Cullen, T. M., Ryan, M. J., Schröder-Adams, C., Currie, P. J., and Kobayashi, Y. 2013. An ornithomimid (Dinosauria) bonebed from the Late Cretaceous of Alberta, with implications for the behavior, classification, and stratigraphy of North American ornithomimids. PLoS One 8: e58853, 1-9.

Cullen, T. M., Evans, D. C., Ryan, M. J., Currie, P. J., and Kobayashi, Y. 2014.

Osteohistological variation in growth marks and osteocyte lacunar density in a theropod dinosaur (Coelurosauria: Ornithomimidae). BMC Evolutionary Biology 14: $231,1-14$.

Currie, P. J. 2000. Possible evidence of gregarious behavior in tyrannosaurids. Gaia 15: 271-277.

Currie, P. J. 2003. Cranial anatomy of tyrannosaurids from the Late Cretaceous of Alberta. Acta Palaeontologica Polonica 48: 191-226.

Currie, P. J. 2005a. History of research. In Dinosaur Provincial Park: A Spectacular Ancient Ecosystem Revealed. Edited by P. J. Currie and E. B. Koppelhus. Indiana University Press, Bloomington. pp. 3-33.

Currie, P. J. 2005b. Theropods, including birds. In Dinosaur Provincial Park: A Spectacular Ancient Ecosystem Revealed. Edited by P. J. Currie and E. B. Koppelhus. Indiana University Press, Bloomington. pp. 367-397. 
Currie, P. J. and Chen, P.-J. 2001. Anatomy of Sinosauropteryx prima from Liaoning, northeastern China. Canadian Journal of Earth Sciences 38: 705-727.

Currie, P. J. and Koppelhus, E. B. (eds.) 2005. Dinosaur Provincial Park: A Spectacular Ancient Ecosystem Revealed. Indiana University Press, Bloomington.

Currie, P. J. and Russell, D. A. 1988. Osteology and relationships of Chirostenotes pergracilis (Saurischia, Theropoda) from the Judith River (Oldman) Formation of Alberta, Canada. Canadian Journal of Earth Sciences 25: 972-986.

Currie, P. J. and Russell, D. A. 2005. The geographic and stratigraphic distribution of articulated and associated dinosaur remains. In Dinosaur Provincial Park: A Spectacular Ancient Ecosystem Revealed. Edited by P. J. Currie and E. B. Koppelhus. Indiana University Press, Bloomington. pp. 537-569.

DeCourten, F. L. and Russell, D. A. 1985. A specimen of Ornithomimus velox (Theropoda, Ornithomimidae) from the terminal Cretaceous Kaiparowits Formation of southern Utah. Journal of Paleontology 59: 1091-1099.

de Klerk, W. J., Forster, C. A., Sampson, S. D., Chinsamy, A., and Ross, C. F., 2000. A new coelurosaurian dinosaur from the Early Cretaceous of South Africa. Journal of Vertebrate Paleontology 20: 324-332. 
D'Emic, M. D. and Foreman, B. Z. 2012. The beginning of the sauropod dinosaur hiatus in North America: insights from the Lower Cretaceous Cloverly Formation of Wyoming. Journal of Vertebrate Paleontology 32: 883-902.

Dodson, P. 1971. Sedimentology and taphonomy of the Oldman Formation (Campanian), Dinosaur Provincial Park, Alberta (Canada). Palaeogeography, Palaeoclimatology, Palaeoecology 10: 21-74.

Dyke, G., Wang, X., and Kaiser, G. 2011. Large fossil birds from a Late Cretaceous marine turbidite sequence on Hornby Island (British Columbia). Canadian Journal of Earth Sciences 48: 1489-1496.

Eberth, D. A. 2005. The geology. In Dinosaur Provincial Park: A Spectacular Ancient Ecosystem Revealed. Edited by P. J. Currie and E. B. Koppelhus. Indiana University Press, Bloomington. pp. 54-82.

Eberth, D. A. and Braman, D. R. 2012. A revised stratigraphy and depositional history for the Horseshoe Canyon Formation (Upper Cretaceous), southern Alberta plains. Canadian Journal of Earth Sciences 49:1053-1086. 
Eberth, D. A. and Currie, P. J. 2005. Vertebrate taphonomy and taphonomic modes. In Dinosaur Provincial Park: A Spectacular Ancient Ecosystem Revealed. Edited by P. J. Currie and E. B. Koppelhus. Indiana University Press, Bloomington. pp. 453-457.

Eberth, D. A. and Hamblin, A. P. 1993. Tectonic, stratigraphic, and sedimentologic significance of a regional discontinuity in the upper Judith River Group (Belly River wedge) of southern Alberta, Saskatchewan, and northern Montana. Canadian Journal of Earth Sciences 30: 174-200.

Eberth, D. A., Evans, D. C., Brinkman, D. B., Therrien, F., Tanke, D. H., and Russell, L. S. 2013. Dinosaur biostratigraphy of the Edmonton Group (Upper Cretaceous), Alberta, Canada: evidence for climate influence. Canadian Journal of Earth Sciences 50: 701-726.

Evans, D. C., Schott, R. K., Larson, D. W., Brown, C. M., and Ryan, M. J. 2013. The oldest North American pachycephalosaurid and the hidden diversity of small-bodied ornithischian dinosaurs. Nature Communications 4: 1828, 1-10.

Evans, D. C., McGarrity, C. T., and Ryan, M. J. 2014. A skull of Prosaurolophus maximus from southeastern Alberta and the spatiotemporal distribution of faunal zones in the Dinosaur Park Formation. In Hadrosaurs. Edited by D. A. Eberth and D. C. Evans. Indiana University Press, Bloomington. pp. 200-207. 
Farke, A.A., M.J. Ryan, M. J., Barrett, P. M., Tanke, D. H., Braman, D. R., Loewen, M. A. and Graham, M. R. 2011. A new centrosaurine from the Late Cretaceous of Alberta and the evolution of parietal ornamentation in horned dinosaurs. Acta Palaeontologia Polonica 56: 691-702.

Farlow, J. 0. 2013. On the makers of "metatarsal" tridactyl dinosaur footprints of the Paluxy River (Glen Rose Formation, Dinosaur Valley State Park, Somervell County, Texas). Geological Society of America Abstracts with Programs 45, no. 4: 22.

Fiorillo, A. R. 1991. Taphonomy and depositional setting of Careless Creek Quarry (Judith River Formation), Wheatland County, Montana, U.S.A. Palaeogeography, Palaeoclimatology, Palaeoecology 81: 281-311.

Fiorillo, A. R. and Tykoski, R. S. 2014. A diminutive new tyrannosaur from the top of the world. PLoS One 9 (e91287): 1-13.

Fiorillo, A. R., McCarthy, P. J., Flaig, P. P., Brandlen, E., Norton, D. W., Zippi, P., Jacobs, L., and Gangloff, R. A. 2011. Paleontology and paleoenvironmental interpretation of the Kikak-Tegoseak Quarry (Prince Creek Formation: Late Cretaceous), northern Alaska: a multi-disciplinary study of a high-latitude ceratopsian dinosaur bonebed. In New Perspectives on Horned Dinosaurs. Edited by M. J. Ryan, B. J. Chinnery-Allgier, and D. A. Eberth. Indiana University Press, Bloomington. pp. 456-477. 
Fix, M. F. and Darrough, G. E. 2004. Dinosauria and associated vertebrate fauna of the Late Cretaceous Chronister Site of southeast Missouri. Geological Society of America Abstracts with Programs 36, no. 3:14.

Gangloff, R. A., May, K. C., and Storer, J. E. 2004. An early Late Cretaceous dinosaur tracksite in central Yukon Territory, Canada. Ichnos 11: 299-309.

Gatesy, S. M. and Middleton, K. M. 1997. Bipedalism, flight, and the evolution of theropod locomotor diversity. Journal of Vertebrate Paleontology 17: 308-329.

Gauthier, J. A. 1986. Saurischian monophyly and the origin of birds. Memoirs of the California Academy of Sciences 8: 1-55.

Gilmore, C. W. 1920. Osteology of the carnivorous Dinosauria in the United States National Museum, with special reference to the genera Antrodemus (Allosaurus) and Ceratosaurus. Bulletin of the United States National Museum 110: 1-159.

Gilmore, C. W. 1933. On the dinosaurian fauna of the Iren Dabasu Formation. Bulletin of the American Museum of Natural History 67: 23-78.

Gishlick, A. D. and Gauthier, J. A. 2007. On the manual morphology of Compsognathus longipes and its bearing on the diagnosis of Compsognathidae. Zoological Journal of the Linnean Society 149: 569-581. 
Glut, D. F. 1997. Dinosaurs: The Encyclopedia. McFarland and Company, Jefferson.

Gross, R. 1998. Dinosaur Country: Unearthing the Alberta Badlands. Badlands Books, Edmonton.

Hasegawa, Y., Manabe, M., Kase, T., Nakajima, S. and Takakuwa, Y. 1999. An ornithomimid vertebra from the Early Cretaceous Sebayashi Formation, Sanchu Terrane, Gunma Prefecture, Japan. Bulletin of Gunma Museum of Natural History, 3: $1-6$.

Holtz, T. R. 1994. The phylogenetic position of the Tyrannosauridae: implications for theropod systematics". Journal of Paleontology 68: 1100-1117.

Holtz, T. R. 1995. The arctometatarsalian pes, an unusual structure of the metatarsus of Cretaceous Theropoda (Dinosauria: Saurischia). Journal of Vertebrate Paleontology 14: 480-519.

Holtz, T. R. 1996. Phylogenetic taxonomy of the Coelurosauria (Dinosauria: Theropoda). Journal of Paleontology 70: 536-538. 
Horner, J. R., Goodwin, M. B., and Myhrvold, N. 2011. Dinosaur census reveals abundant Tyrannosaurus and rare ontogenetic stages in the Upper Cretaceous Hell Creek Formation (Maastrichtian), Montana, USA. PLoS One 6, e16574: 1-9.

Hunt, R. K. 2003. An Early Cretaceous theropod foot from southwestern Arkansas. Proceedings Journal of the 2003 Arkansas Undergraduate Research Conference, 87103.

Hunt, R. K. and Lehman, T. M. 2008. Attributes of the ceratopsian dinosaur Torosaurus, and new material from the Javelina Formation (Maastrichtian) of Texas. Journal of Paleontology 82: 1127-1138.

Ji, Q., Norell, M. A., Makovicky, P. J., Gao, K.-Q., Ji, S., and Yuan, C. 2003. An early ostrich dinosaur and implications for ornithomimosaur phylogeny. American Museum Novitates 3420: 1-19.

Jiang, X. J., Liu, Y. Q., Ji, S. A., Zhang, X. L., Xu, L., Jia, S. H., Lü, J. C., Yuan, C. X., and Li, M. 2011. Dinosaur-bearing strata and K/T boundary in the Luanchuan-Tantou Basin of western Henan Province, China. Science China Earth Sciences 54: 1149-1155.

Jin, L., Jun, C., and Godefroit, P. 2012. A new basal ornithomimosaur (Dinosauria: Theropoda) from the Early Cretaceous Yixian Formation, northeast China. In 
Bernissart Dinosaurs and Early Cretaceous Ecosystems. Edited by P. Godefroit. Indiana University Press, Bloomington. pp. 466-487.

King, D. T. and Jones, E. D. 1997. Late Cretaceous dinosaurs of the southeastern United States. Gulf Coast Association of Geological Societies Transactions 47:263-269.

Kirkland, J. I., Lucas, S. G., and Estep, J. W. 1998a. Cretaceous dinosaurs of the Colorado Plateau. New Mexico Museum of Natural History and Science Bulletin, 14: 79-89.

Kirkland, J. I., Britt, B. B., Whittle, C. H., Madsen, S. K., and Burge, D. L. 1998b. A small coelurosaurian theropod from the Yellow Cat Member of the Cedar Mountain Formation (Lower Cretaceous, Barremian) of eastern Utah. New Mexico Museum of Natural History and Science Bulletin 14: 239-248.

Kirkland, J. I., Zanno, L. E., Sampson, S. D., Clark, J. M., and DeBileux, D. 2005. A primitive therizinosauroid dinosaur from the Early Cretaceous of Utah. Nature 435: 84-87.

Knutsen, E. M. 2007. Beak morphology in extant birds with implications on beak morphology in ornithomimids. M.Sc. thesis, University of Oslo. 
Kobayashi, Y. 2004. Asian ornithomimosaurs. Ph.D. thesis, Southern Methodist University.

Kobayashi, Y. and Barsbold, R. 2005a. Reexamination of a primitive ornithomimosaur, Garudimimus brevipes Barsbold, 1981 (Dinosauria: Theropoda), from the Late Cretaceous of Mongolia. Canadian Journal of Earth Sciences 42: 15011521.

Kobayashi and Barsbold, R. 2005b. Anatomy of Harpymimus okladnikovi Barsbold and Perle 1984 (Dinosauria; Theropoda) of Mongolia. In The Carnivorous Dinosaurs. Edited by K. Carpenter. Indiana University Press, Bloomington. pp. 97-126.

Kobayashi, Y. and Barsbold, R. 2006. Ornithomimids from the Nemegt Formation of Mongolia. Journal of the Paleontological Society of Korea 22: 195-207.

Kobayashi, Y. and Lü, J.-C. 2003. A new ornithomimid dinosaur with gregarious habits from the Late Cretaceous of China. Acta Palaeontologica Polonica 48: 235259.

Kobayashi, Y., Makovicky, P., and Currie, P. 2006. Ornithomimids (Theropoda: Dinosauria) from the Late Cretaceous of Alberta, Canada. Journal of Vertebrate Paleontology 26: 86A. 
Ksepka, D. T. and Norell, M. A. 2004. Ornithomimosaur cranial material from Ukhaa Tolgod (Omnogov, Mongolia). American Museum Novitates 3448: 1-4.

Lambe, L. M. 1902. New genera and species from the Belly River series (midCretaceous). Contributions to Canadian Palæontology 3: 23-81.

Lambe, L. M. 1917. The Cretaceous theropodous dinosaur Gorgosaurus. Memoirs of the Geological Survey of Canada 100: 1-84.

Lambert, D. 1983. A Field Guide to Dinosaurs. Avon Books, New York.

Langston, W. 1959. Alberta and fossil vertebrates. In Alberta Society of Petroleum Geologists 9th Annual Field Conference, Moose Mountain - Drumheller, Alberta. pp. 820.

Langston, W. 1974. Nonmammalian Comanchean tetrapods. Geoscience and Man 8: $77-102$.

Langston, W. 1975. The ceratopsian dinosaurs and associated lower vertebrates from the St. Mary River Formation (Maestrichtian) at Scabby Butte, southern Alberta. Canadian Journal of Earth Sciences 12: 1576-1608. 
Larson, D. W., 2008. Diversity and variation of theropod dinosaur teeth from the uppermost Santonian Milk River Formation (Upper Cretaceous), Alberta: a quantitative method supporting identification of the oldest dinosaur tooth assemblage in Canada. Canadian Journal of Earth Sciences 45: 1455-1468.

Larson, D. W. and Currie, P. J. 2013. Multivariate analyses of small theropod dinosaur teeth and implications for palaeoecological turnover through time. PLoS One 8: e54329, 1-14.

Larson, D. W., Campione, N. E., Brown, C. M., Evans, D. C., and Ryan, M .J. 2014. Hadrosauroid material from the Santonian Milk River Formation of southern Alberta, Canada. In Hadrosaurs. Edited by D.C. Evans and D.E. Eberth. Indiana University Press, Bloomington. pp. 136-152.

Lavender, Z., Drake, A., Loewen, M., Zanno, L., and Claessens, L. 2010. Threedimensional geometric morphometric analysis and univariant measurement analysis on an undescribed Ornithomimus manus. Journal of Vertebrate Paleontology, Program and Abstracts, 2010, 120A.

Lee, Y.-N., Barsbold, R., Currie, P. J., Kobayashi, Y., Lee, H.-J., Godefroit, P., Escuillié, F., and Chinzorig, T. 2014. Resolving the long-standing enigmas of a giant ornithomimosaur Deinocheirus mirificus. Nature 515: 257-260. 
Leidy, J. 1865. Memoir on the extinct reptiles of the Cretaceous formations of the United States. Smithsonian Contributions to Knowledge 14 (6): 1-135.

Lillegraven, J. A. and Eberle, J. J. 1999. Vertebrate faunal changes through Lancian and Puercan time in southern Wyoming. Journal of Paleontology 73: 691-710.

Lipkin, C. and Carpenter, K. 2008. Looking again at the forelimb of Tyrannosaurus rex. In Tyrannosaurus rex: the Tyrant King. Edited by P. Larson, \& K. Carpenter. Indiana University Press. Bloomington. pp.167-190.

Lockley, M. G., Nadon, G., and Currie, P. J. 2003. A diverse dinosaur-bird footprint assemblage from the Lance Formation, Upper Cretaceous, eastern Wyoming: Implications for ichnotaxonomy. Ichnos 11: 229-249.

Lockley, M., Cart, K., Martin, J., and Milner, A. R. C. 2011. New theropod tracksites from the Upper Cretaceous "Mesaverde" Group, western Colorado: Implications for ornithomimosaur track morphology. New Mexico Museum of Natural History and Science Bulletin 53:321-329.

Longrich, N. R. 2008. A new, large ornithomimid from the Cretaceous Dinosaur Park Formation of Alberta, Canada: implications for the study of dissociated dinosaur remains. Palaeontology 51: 983-997. 
Longrich, N. R. 2014. The horned dinosaurs Pentaceratops and Kosmoceratops from the upper Campanian of Alberta and implications for dinosaur biogeography. Cretaceous Research 51: 292-308.

Lü, J., Xu, L., Jiang, X., Jia, S., Li, M., Yuan, C., Zhang, X., and Ji, Q. 2009. A preliminary report on the new dinosaurian fauna from the Cretaceous of Ruyang Basin, Henan Province of central China. Journal of the Paleontological Society of Korea 25: 43-56.

Lucas, S. G., Mateer, N. J., Hunt, A. P., and O'Neill, F. M. 1987. Dinosaurs, the age of the Fruitland and Kirtland Formations, and the Cretaceous-Tertiary boundary in the San Juan Basin, New Mexico. Geological Society of America Special Paper 209: 35-50.

Lucas, S. G., Heckert, A. B., and Sullivan, R. M. 2000. Cretaceous dinosaurs in New Mexico. New Mexico Museum of Natural History and Science Bulletin 17: 83-90.

Lyson, T. R. and Longrich, N. R. 2011. Spatial niche partitioning in dinosaurs from the latest cretaceous (Maastrichtian) of North America. Proceedings of the Royal Society B 278: 1158-1164.

Macdonald, I. 2013. A description of a Dromiceiomimus (Dinosauria: Theropoda) with comments on the validity of the taxon. B.Sc. thesis, University of Alberta. 
Madsen, J. H. 1976. Allosaurus fragilis: a revised osteology. Utah Geological Survey Bulletin 109: 1-163.

Makovicky, P. J., Norell, M. A., Clark, J. M., and Rowe, T. 2003. Osteology and relationships of Byronosaurus jaffei (Theropoda: Troodontidae). American Museum Novitates 3402: 1-32.

Makovicky, P. J., Kobayashi, Y., and Currie, P. J. 2004. Ornithomimosauria. In The Dinosauria, Second Edition. Edited by D. B. Weishampel, P. Dodson, and H. Osmólska. University of California Press, Berkeley. pp. 137-150.

Mallon, J. C., Evans, D. C., Ryan, M. J., and Anderson, J. S. 2012. Megaherbivorous dinosaur turnover in the Dinosaur Park Formation (upper Campanian) of Alberta, Canada. Palaeogeography, Palaeoclimatology, Palaeoecology 350-352: 124-138.

Marsh, 0. C. 1881. Classification of the Dinosauria. American Journal of Science (ser. 3) 23: 81-86.

Marsh, O. C. 1890. Description of new dinosaurian reptiles. American Journal of Science (ser. 3) 39: 81-86.

Marsh, O. C. 1892. Notice of new reptiles from the Laramie Formation. American Journal of Science (ser. 3) 43: 449-453. 
Marsh, O. C. 1896. The Dinosaurs of North America. U.S. Geological Survey Annual Report for 1894-1895 16: 133-244.

Martill, D. M., Earland, S., and Naish, D. 2006. Dinosaurs in marine strata: evidence from the British Jurassic, including a review of the allochthonous vertebrate assemblage from the marine Kimmeridge Clay Formation (Upper Jurassic) of Great Britain. pp. 35-72 in Colectivo Arqueológico-Paleontológico Salense (ed.), Actas de las III Jornadas sobre Dinosaurios y su Entorno. 1-31. Salas de los Infantes, Burgos.

Mateus, O., Dyke, G. J., Motchurova-Dekova, N., Kamenov, G. D., and Ivanov, P. 2010. The first record of a dinosaur from Bulgaria. Lethaia 43: 88-94.

Matsukawa, M., Lockley, M. G., Hayashi, K., Korai, K., Chen P. and Zhang H. 2014. First report of the ichnogenus Magnoavipes from China: New discovery from the Lower Cretaceous inter-mountain basin of Shangzhou, Shaanxi Province, central China. Cretaceous Research 47: 131-139.

Matthew, W. D. and Brown, B. 1922. The family Deinodontidae, with notice of a new genus from the Cretaceous of Alberta. Bulletin of the American Museum of Natural History 46: 367-385. 
Neabore, S., Loewen, M., Zanno, L., Getty, M., and Claessens, L. 2007. Threedimensional scanning and analysis of the first diagnostic ornithomimid forelimb material from the Late Cretaceous Kaiparowits Formation. Journal of Vertebrate Paleontology 27:123A.

Nesbitt, S. J. and Norell, M. A. 2006. Extreme convergence in the body plans of an early suchian (Archosauria) and ornithomimid dinosaurs (Theropoda). Proc. R. Soc. B 273: 1045-1048.

Nesbitt, S. J., Clarke, J. A., Turner, A. H., and Norell, M. A. 2011. A small alvarezsaurid from the eastern Gobi Desert offers insight into evolutionary patterns in the Alvarezsauroidea. Journal of Vertebrate Paleontology 31: 144-153.

Nicholls, E. L. and Russell, A. P. 1981. A new specimen of Struthiomimus altus from Alberta, with comments on the classificatory characters of Upper Cretaceous ornithomimids. Canadian Journal of Earth Sciences 18: 518-526.

Nicholls, E. L. and Russell, A. P. 1985. Structure and function of the pectoral girdle and forelimb of Struthiomimus altus (Theropoda: Ornithomimidae). Palaeontology 28: 643-677. 
Norell, M. A. and Makovicky, P. J. 1999. Important features of the dromaeosaurid skeleton II: information from newly collected specimens of Velociraptor mongoliensis. American Museum Novitates 3282: 1-45.

Norell, M. A., Makovicky, P. J., and Currie, P. J. 2001a. The beaks of ostrich dinosaurs. Nature 412: 873-874.

Norell, M. A., Clark, J. M. and Makovicky, P. J. 2001b. Phylogenetic relationships among coelurosaurian dinosaurs. In New Perspectives on the Origin and Evolution of Birds. Edited by J. Gauthier and L. F. Gall. Yale University Press, New Haven. pp. 4967.

Norell, M. A., Clark, J. M., Turner, A. H., Makovicky, P. J., Barsbold, R., and Rowe, T. 2006. A new dromaeosaurid theropod from Ukhaa Tolgod (Ömnögov, Mongolia). American Museum Novitates 3545: 1-51.

Osborn, H. F. 1917. Skeletal adaptations of Ornitholestes, Struthiomimus, Tyrannosaurus. Bulletin of the American Museum of Natural History 35: 733-771.

Osmólska, H. 1997. Ornithomimosauria. In The Encyclopedia of Dinosaurs. Edited by P.J. Currie and K. Padian. pp. 499-503. 
Osmólska, H., Roniewicz, E., and Barsbold, R. 1972. A new dinosaur, Gallimimus bullatus n. gen., n. sp. (Ornithomimidae) from the Upper Cretaceous of Mongolia. Palaeontologia Polonica 27: 103-143.

Ostrom, J. H. 1969. Osteology of Deinonychus antirrhopus, an unusual theropod from the Lower Cretaceous of Montana. Peabody Museum of Natural History Bulletin 30: 1-165.

Ostrom, J. H. 1970. Stratigraphy and paleontology of the Cloverly Formation (Lower Cretaceous) of the Bighorn Basin area, Wyoming and Montana. Peabody Museum Bulletin 35: 1-234.

Parker, W. G. 2013. Redescription and taxonomic status of specimens of Episcoposaurus and Typothorax, the earliest known aetosaurs (Archosauria: Suchia) from the Upper Triassic of western North America, and the problem of proxy "holotypes." Earth and Environmental Science Transactions of the Royal Society of Edinburgh 103: 313-338.

Parks, W. A. 1926. Struthiomimus brevetertius - a new species of dinosaur from the Edmonton Formation of Alberta. Transactions of the Royal Society of Canada (Series 3) 20:65-70. 
Parks, W. A. 1928. Struthiomimus samueli, a new species of Ornithomimidae from the Belly River Formation of Alberta. University of Toronto Studies, Geological Series 26: $1-24$.

Parks, W. A. 1933. New species of dinosaurs and turtles from the Upper Cretaceous formations of Alberta. University of Toronto Studies, Geological Series 34: 1-33.

Paul, G. S. and Carpenter, K. Allosaurus Marsh, 1877 (Dinosauria, Theropoda): proposed conservation of usage by designation of a neotype for its type species Allosaurus fragilis Marsh, 1877. Bulletin of Zoological Nomenclature 67: 53-56.

Pereda-Suberbiola, X., Ruiz-Omeñaca, J. I., Canudo, J. I., Torcida, F., and Sanz, J.L. 2012. Dinosaur faunas from the Early Cretaceous of Spain. In Bernissart Dinosaurs and Early Cretaceous Terrestrial Ecosystems. Edited by P. Godefroit. Indiana University Press, Bloomington. pp. 378-407

Perez-Moreno, B. P., Sanz, J. L., Buscalioni, A. D., Moratalla, J. J., Ortega, F., and Rasskin-Gutman, D. 1994. A unique multi-toothed ornithomimosaur dinosaur from the Lower Cretaceous of Spain. Nature 370: 363-367.

Quinn, J. H. 1973. Arkansas dinosaur. Geological Society of America Abstracts with Programs 5 (3): 276-277. 
Rainforth, E. C. 2003. Revision and re-evaluation of the Early Jurassic dinosaurian ichnogenus Otozoum. Palaeontology 46: 803-838.

Rauhut, O. W. M. 2003. The interrelationships and evolution of basal theropod dinosaurs. Special Papers in Palaeontology 69: 1-213.

Reid, M. 1990. The Last Great Dinosaurs. Red Deer College Press, Red Deer.

Rivera-Sylva, H. E. and Carpenter, K. 2014. Mexican saurischian dinosaurs. In Dinosaurs and Other Reptiles from the Mesozoic of Mexico. Edited by H. E. RiveraSylva, K. Carpenter, and E. Frey. Indiana University Press, Bloomington. pp. 143-155.

Rivera-Sylva, H. E., Rodríguez-de la Rosa, R., and Oritz-Mendieta, J. A. 2006. A review of the dinosaurian record from Mexico. Topics in Geobiology 24: 233-248.

Ruben, J. A., Hillenius, W. J., Geist, N. R., Leitch, A., Jones, T. D., Currie, P. J., Horner, J. R., and Epse, G. 1996. The metabolic status of some Late Cretaceous dinosaurs. Science 273: 1204-1207.

Russell, D. A. 1972. Ostrich dinosaurs from the Late Cretaceous of western Canada. Canadian Journal of Earth Sciences 9: 375-402. 
Russell, D. A. 1977. A Vanished World: The Dinosaurs of Western Canada. National Museums of Canada, Ottawa.

Russell, D. A. 1984. A check list of the families and genera of North American dinosaurs. Syllogeus 53: 1-35.

Russell, D. A. and Manabe, M. 2002. Synopsis of the Hell Creek (uppermost Cretaceous) dinosaur assemblage. Geological Society of America Special Paper 361: 169-176.

Russell, L. S. 1930. Upper Cretaceous dinosaur faunas of North America. Proceedings of the American Philosophical Society 69: 133-159.

Russell, L. S. 1935. Fauna of the upper Milk River beds, southern Alberta. Transactions of the Royal Society of Canada, third series, section IV 29:115-128.

Ryan, M. J. and Evans, D. C. 2005. Ornithischian dinosaurs. In Dinosaur Provincial Park: A Spectacular Ancient Ecosystem Revealed. Edited by P. J. Currie and E. B. Koppelhus. Indiana University Press, Bloomington. pp. 312-348.

Ryan, M. J. and Russell, A. P. 2001. Dinosaurs of Alberta (exclusive of Aves). In Mesozoic Vertebrate Life. Edited by D. H. Tanke and K. Carpenter. Indiana University Press, Bloomington. pp. 279-297. 
Ryan, M., Evans, D., Brown, C., Scott, E., and Chiba, K. 2010. Paleobiogeographic range of Centrosaurus apertus (Ornithischia: Ceratopsidae), with implications for Late Cretaceous dinosaur provinciality and evolution. Journal of Vertebate Paleontology, Program and Abstracts, 2010, 154A-155A.

Ryan, M. J., Evans, D. C., Currie, P. J., Brown, C. M., and Brinkman, D. 2012a. New leptoceratopsids from the Upper Cretaceous of Alberta, Canada. Cretaceous Research 35: 69-80.

Ryan, M. J., Evans, D. C., and Shepherd, K. M. 2012b. A new ceratopsid from the Foremost Formation (middle Campanian) of Alberta. Canadian Journal of Earth Sciences 49: 1251-1262.

Sankey, J. T. 2010. Faunal composition and significance of high diversity, mixed bonebeds containing Agujaceratops mariscalensis and other dinosaurs, Aguja Formation (upper Cretaceous), Big Bend, Texas. In New Perspectives on Horned Dinosaurs. Edited by M. J. Ryan, B. J. Chinnery-Allgeier, and D. A. Eberth. Indiana University Press, Bloomington. pp. 520-537.

Sato, T., Eberth, D. A., Nicholls, E. L., and Manabe, M. 2005. Plesiosaurian remains from non-marine to paralic sediments. In Dinosaur Provincial Park: A Spectacular 
Ancient Ecosystem Revealed. Edited by P. J. Currie and E. B. Koppelhus. Indiana University Press, Bloomington. pp. 249-276.

Scheetz, A., Britt, B., Scheetz, R., Rauhut, O., and Chure, D. 2010. An ornithomimidlike basal coelurosaur from the Early Cretaceous (Aptian) Cedar Mountain Formation of Utah. Journal of Vertebrate Paleontology, Program and Abstracts, 2010, 158A.

Schwimmer, D. R., Williams, G. D., Dobie, J. L., and Siesser, W. G. 1993. Late Cretaceous dinosaurs from the Blufftown Formation in western Georgia and eastern Alabama. Journal of Paleontology 67:288-296.

Senter, P. 2007. A new look at the phylogeny of Coelurosauria (Dinosauria: Theropoda). Journal of Systematic Palaeontology 5: 429-463.

Senter, P., Kirkland, J. I., DeBlieux, D. D., Madsen, S., and Toth, N. 2012. New dromaeosauids (Dinosauria: Theropoda) from the Lower Cretaceous of Utah, and the evolution of the dromaeosaurid tail. PLoS One 7: e36790, 1-20.

Sereno, P. C. 1998. A rationale for phylogenetic definitions, with application to the higher-level taxonomy of Dinosauria. Neues Jahrbuch für Geologie und Paläontologie, Abhandlungen 210: 41-83. 
Sereno, P. C. 2001. Alvarezsaurids: birds or ornithomimosaurs? In New Perspectives on the Origin and Early Evolution of Birds. Edited by J. Gauthier and L. F. Gall. Yale University, Connecticut. pp. 69-98.

Smith, D. and Galton, P. 1990. Osteology of Archaeornithomimus asiaticus (Upper Cretaceous, Iren Dabasu Formation, People's Republic of China). Journal of Vertebrate Paleontology 10: 255-265.

Sternberg, C. M. 1924. Notes on the Lance Formation of southern Saskatchewan. The Canadian Field-Naturalist 38:66-70.

Sternberg, C. M. 1926. Dinosaur tracks from the Edmonton Formation of Alberta. Canadian Department of Mines, Geological Survey, Geological Series 46, Bulletin 44: 85-87.

Sternberg, C. M. 1932. Dinosaur tracks from Peace River, British Columbia. National Museum of Canada, Annual Report 1930: 59-85.

Sternberg, C. M. 1933. A new Ornithomimus with a complete abdominal cuirass. The Canadian Field-Naturalist 47: 79-83.

Sternberg, C. M. 1950. Steveville west of the Fourth Meridian, with notes on fossil localities. Geological Survey of Canada Map 969A. 
Sternberg, C. M. 1934. Notes on certain recently described dinosaurs. The Canadian Field-Naturalist 48:7-8.

Sullivan, R. M. 1997. A juvenile Ornithomimus antiquus (Dinosauria: Theropoda: Ornithomimosauria), from the Upper Cretaceous Kirtland Formation (De-Na-Zin Member), San Juan Basin, New Mexico. New Mexico Geological Society Guidebook, 48th Field Conference, Mesozoic Geology and Paleontology of the Four Corners Region, pp. 249-254.

Sullivan, R. M. 2003. Revision of the dinosaur Stegoceras Lambe (Ornithischia, Pachycephalosauridae). Journal Of Vertebrate Paleontology 23 (1): 181-207.

Sullivan, R. M., Tanke, D. H., and Rothschild, B. M. 2000. An impact fracture in an ornithomimid (Ornithomimosauria: Dinosauria) metatarsal from the Upper Cretaceous (late Campanian) of New Mexico. New Mexico Museum of Natural History and Science Bulletin 17:109-111.

Swisher, C. C., Wang, X., Zhou, Z., Wang, Y., Jin, F., Zhang, J., Xu, X., Zhang, F., and Wang, Y. 2002. Further support for a Cretaceous age for the feathered-dinosaur beds of Liaoning, China: new 40Ar/39Ar dating of the Yixian and Tuchengzi Formations. Chinese Science Bulletin 47:136-139. 
Tahara, R. and Larsson, H. C. E. 2011. Cranial pneumatic anatomy of Ornithomimus edmontonicus (Ornithomimidae: Theropoda). Journal of Vertebrate Paleontology 31: 127-143.

Tsuihiji, T., Barsbold, R., Watabe, M., Tsogtbaatar, K., Chinzorig, T., Fujiyama, Y., and Suzuki, S. 2014. An exquisitely preserved troodontid theropod with new information on the palatal structure from the Upper Cretaceous of Mongolia. Naturwissenschaften 101: 131-142.

Trexler, D. 2001. Two Medicine Formation, Montana: geology and fauna. In Mesozoic Vertebrate Life: New Research Inspired by the Paleontology of Philip J. Currie. Edited by D. Tanke and K. Carpenter. Indiana University Press, Bloomington. pp. 298-309.

Triebold, M. 1997. The Sandy Site: small dinosaurs from the Hell Creek Formation of South Dakota. In Dinofest International: Proceedings of a Symposium sponsored by Arizona State University. Edited by D. L. Wolberg, E. Sump, and G. D. Rosenberg. The Academy of Natural Sciences, Philadelphia. pp. 245-248.

Turner, A. H., Hwang, S. H., and Norell, M. A. 2007a. A small derived theropod from Öösh, Early Cretaceous, Baykhangor Mongolia. American Museum Novitates 3557: 127. 
Turner, A. H., Pol, D., Clarke, J. A., Erickson, G. M., and Norell, M. A. 2007 b. A basal dromaeosaurid and size evolution preceding avian flight. Science 317: 1378-1381.

Turner, A. H., Makovicky, P. J., and Norell, M. A. 2012. A review of dromaeosaurid systematics and paravian phylogeny. Bulletin of the American Museum of Natural History 371:1-206.

Varricchio, D. J. 1995. Taphonomy of Jack's Birthday Site, a diverse dinosaur bonebed from the Upper Cretaceous Two Medicine Formation of Montana. Palaeogeography, Palaeoclimatology, Palaeoecology 114:297-323.

Varricchio, D. J. 2001. Late Cretaceous oviraptorosaur (Theropoda) dinosaurs from Montana. In Mesozoic Vertebrate Life. Edited by D. H. Tanke and K. Carpenter. Indiana University Press, Bloomington. pp. 42-57.

Vickers-Rich, P. A., Chiappe, L. M., and Kurzanov, S. M. 2002. The enigmatic birdlike dinosaur Avimimus portentosus: comments and a pictorial atlas. In Mesozoic Birds: Above the Heads of Dinosaurs. Edited by L. M. Chiappe and L. M. Witmer. University of California Press, Berkeley. pp. 65-86.

Watanabe, A., Erickson, G. M., and Druckenmiller, P. S. 2013. An ornithomimosaurian from the Upper Cretaceous Prince Creek Formation of Alaska. Journal of Vertebrate Paleontology 33: 1169-1175. 
Weishampel, D. B. 1990. Dinosaur distribution. In The Dinosauria. Edited by D. B. Weishampel, P. Dodson, and H. Osmólska. University of California Press, Berkeley. pp. 63-140.

Weishampel, D. B., Barrett, P. M., Coria, R. O., Le Loeuff, J., Xu X., Zhao X., Sanhi, A., Gomani, E. M. P., and Noto, C. R. 2004. Dinosaur distributions. In The Dinosauria, Second Edition. Edited by D. B. Weishampel, P. Dodson, and H. Osmólska. University of California Press, Berkeley. pp. 517-606.

White, P. D., Fastovsky, D. E., and Sheehan, P. M. 1998. Taphonomy and suggested structure of the dinosaurian assemblage of the Hell Creek Formation (Maastrichtian), eastern Montana and western North Dakota. Palaios 13:41-51.

Witmer, L. M. 1997. The evolution of the antorbital cavity of archosaurs: A study in soft-tissue reconstruction in the fossil record with an analysis of the function of pneumaticity. Society of Vertebrate Paleontology Memoir 3: 1-76.

Xu, L., Kobayashi, Y., Lü, J., Lee, Y.-N., Liu, Y., Tanaka, K., Zhang, X., Jia, S., and Zhang, J. 2011. A new ornithomimid dinosaur with North American affinities from the Late Cretaceous Qiupa Formation in Henan Province of China. Cretaceous Research 32: 213-222. 
Xu, X., Ma, Q. Y., and Hu, D. Y. 2010. Pre-Archaeopteryx coelurosaurian dinosaurs and their implications for understanding avian origins. Chinese Science Bulletin 55: 39713977.

Yacobucci, M. M. 1990. Phylogeny and biogeography of Ornithomimosauria (Theropoda: Saurischia). Journal of Vertebrate Paleontology, Program and Abstracts, 1990, 51A.

Zanno, L. E. 2006. The pectoral girdle and forelimb of the primitive therizinosauroid Falcarius utahensis (Theropoda, Maniraptora): analyzing evolutionary trends within Therizinosauroidea. Journal of Vertebrate Paleontology 26: 636-650.

Zanno, L. E. and Makovicky, P. J. 2011. On the earliest record of Cretaceous tyrannosauroids in western North America: implications for an Early Cretaceous Laurasian interchange event. Historical Biology 23: 317-325.

Zanno, L. E., Varricchio, D. J., O'Connor, P. M., Titus, A. L., and Knell, M. J. 2011. A new troodontid theropod, Talos sampsoni gen. et sp. nov., from the Upper Cretaceous Western Interior Basin of North America. PLoS One 6: e24487, 1-20.

Zanno, L. E., Loewen, M. A., Farke, A. A., Kim, G.-S., Claessens, L. P. A. M., and McGarrity, C. T. 2013. Late Cretaceous theropod dinosaurs of southern Utah. In At 
The Top of the Grand Staircase: The Late Cretaceous of Southern Utah. Edited by A. L. Titus and M. A. Loewen. Indiana University Press, Bloomington. pp. 504-525.

Zelenitsky, D. K., Therrien, F., Erickson, G. M., DeBuhr, C. L., Kobayashi, Y., Eberth, D., and Hadfield, F. 2012. Feathered non-avian dinosaurs from North America provide insight into wing origins. Science 338: 510-514.

Zhou, Z. 2006. Evolutionary radiation of the Jehol Biota: chronological and ecological perspectives. Geological Journal 41:377-393. 